\title{
ROTEIRIZAÇÃO PARA VEÍCULOS DE COLETA DE RESÍDUOS SÓLIDOS DOMICILIARES UTILIZANDO UM SISTEMA DE INFORMAÇÃO GEOGRÁFICA-SIG
}

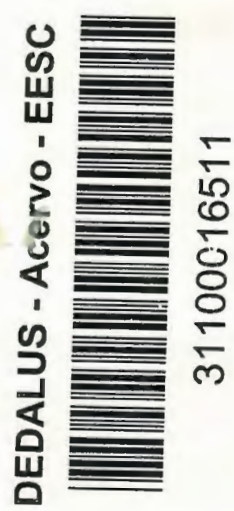

KELLY KLEYCIANE DELUQUT

Dissertação apresentada à Escola de Engenharia de São Carlos, da Universidade de São Paulo, como parte dos requisitos para obtenção do Título de Mestre em Engenharia Civil.

ORIENTADOR: Prof. Dr. Edson Martins de Aguiar 


\section{FOLHA DE APROVACÃO}

Candidata: Engenheira KELLY KLEYCIANE DELUQUI

Dissertação defendida e aprovada em 18.09.1998 pela Comissão Julgadora:

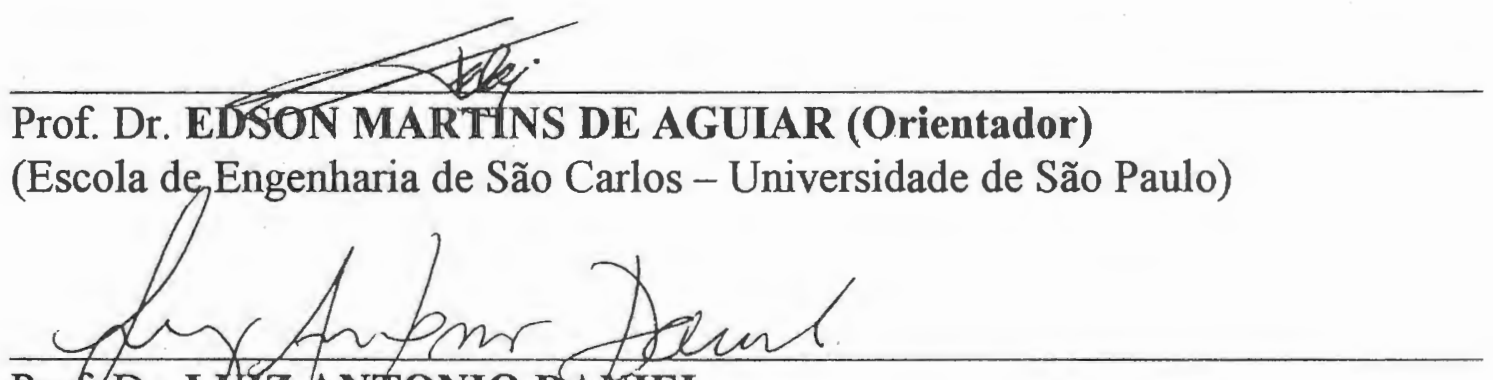
Prof.Dr. LUIZZ ANTONIO DANIEL (Escola de Engenharia de São Carlos - Universidade de São Paulo)

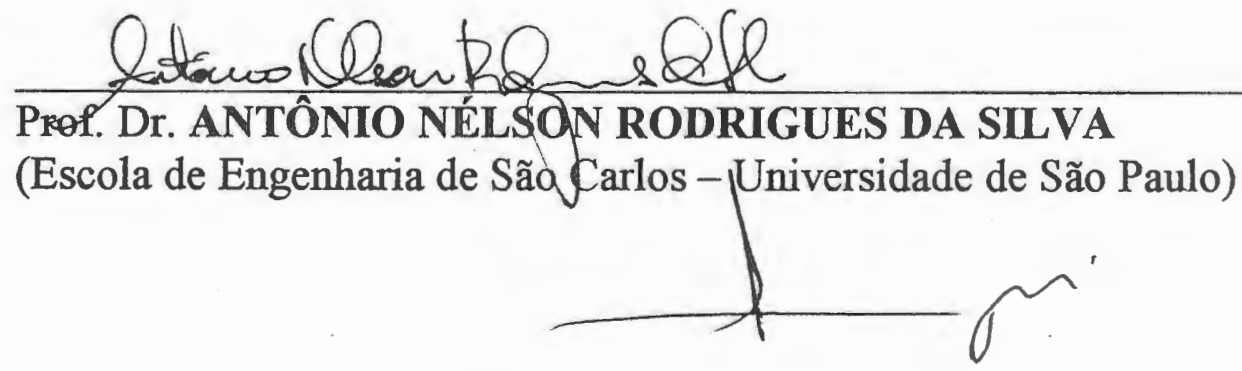

Prof. Titular FAZAL HUSSAIN CHAUDHRY Coordenador da Área de Hidráulica e Saneamento $\frac{1 \text { Sm Clutsy }}{\text { JOSÉ CAREOS A. CINTRA }}$

Presidente da Comissão de Pós-Graduação da EESC 
DEDICATÓRIA

Aos meus pais Aroldo e Ebe, meus irmãos Lysiane e Herlony e ao Geron, sempre incentivadores. 


\section{AGRADECIMENTOS}

À Deus, por seu infinito amor.

Ao Professor Dr. Edson Martins de Aguiar pela orientação.

Aos Professores Dr. Antônio Nélson Rodrigues da Silva e Dr. João Bosco Ladislau de Andrade pela colaboração no decorrer do presente trabalho.

À Professora Maria José Baião pela contribuição na conclusão deste trabalho, com críticas esclarecedoras.

Ao Sr. Erci Carlos Andreotti, gerente operacional da VEGA Sopave Engenharia Ambiental, na cidade de São Carlos-SP, pelo fornecimento de dados e informações.

Ao Sr. Paulo Pacheco Teixeira, gerente da Agência Central dos Correios, na cidade de São Carlos-SP, pela colaboração para o envio de questionários às prefeituras municipais.

Às Prefeituras Municipais, empresas públicas e particulares, que forneceram informações sobre os sistema de coleta de resíduos sólidos domiciliares.

À Coordenadoria de Aperfeiçoamento de Pessoal de Nível Superior - CAPES, pela bolsa concedida.

A todos os amigos e colegas que, direta e indiretamente contribuíram para a realização deste trabalho. 


\section{SUMÁRIO}

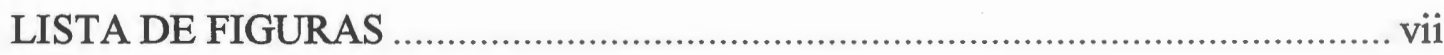

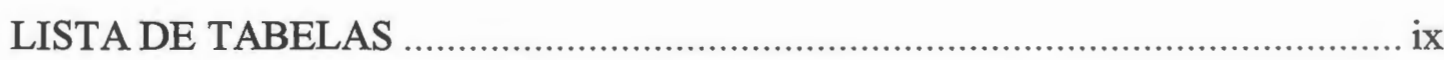

LISTA DE ABREVIATURAS E SIGLAS …........................................... xi

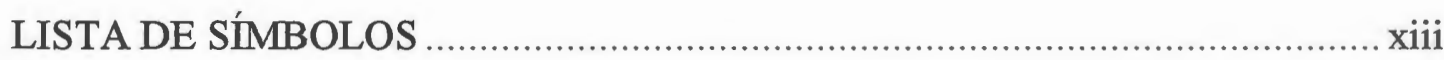

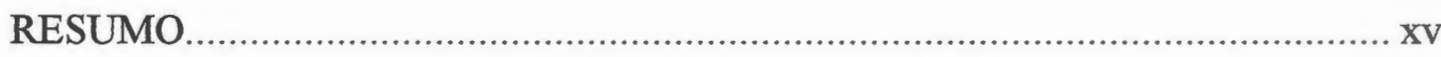

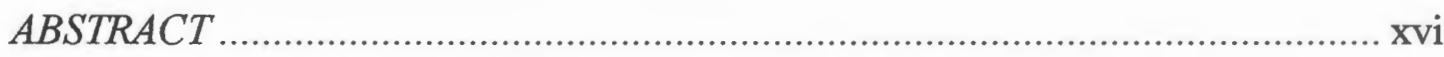

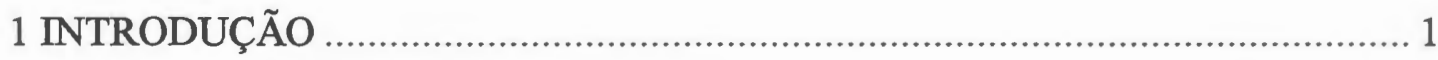

2 REVISÃO DE LITERATURA

2.1 Generalidades sobre resíduos sólidos urbanos ...........................................................

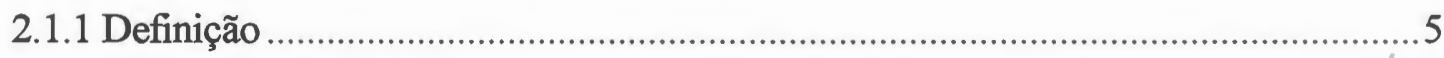

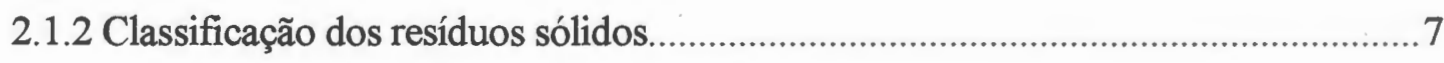

2.2 Composição e características dos resíduos sólidos ..................................................... 13

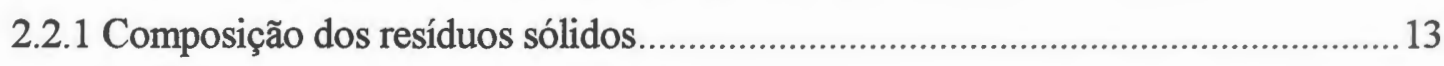

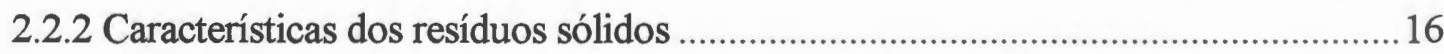

2.3 Atividades associadas ao gerenciamento dos resíduos sólidos urbanos ......................20

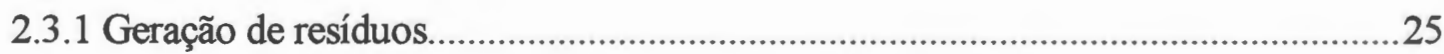

2.3.2 Separação, acondicionamento e processamento na fonte.....................................29

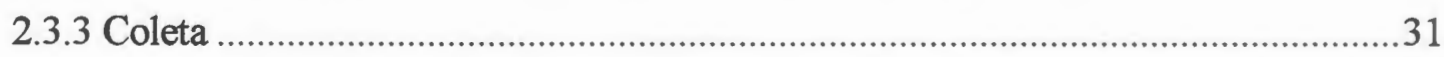

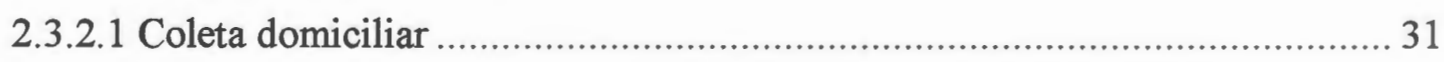

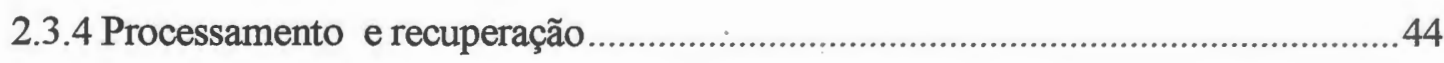

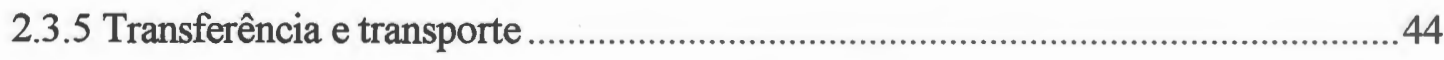

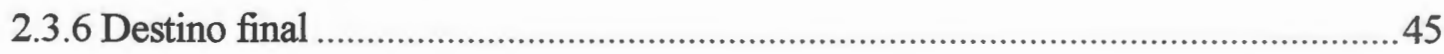

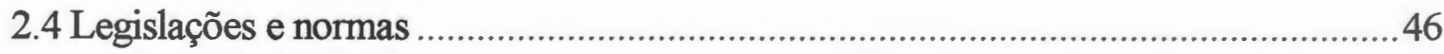

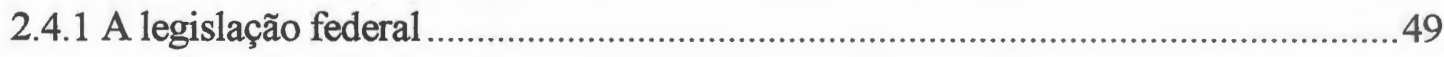


2.4.2 A legislação estadual (Estado de São Paulo).

2.4.3 Normas Técnicas Brasileiras (NBR) da Associação Brasileira de Normas Técnicas

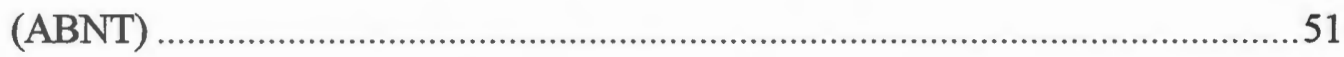

2.5 Os Sistemas de Informação Geográfica-SIG ..............................................................53

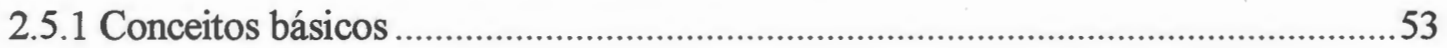

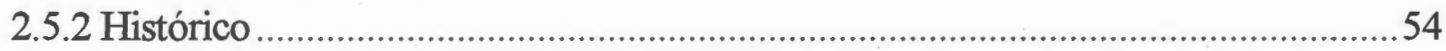

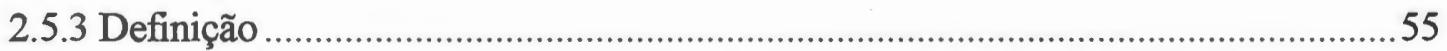

2.5.4 Fontes de dados e estruturas de representação ........................................................57

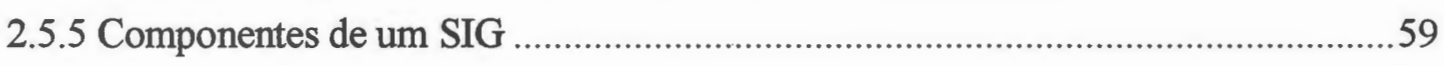

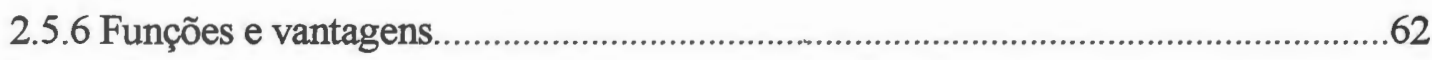

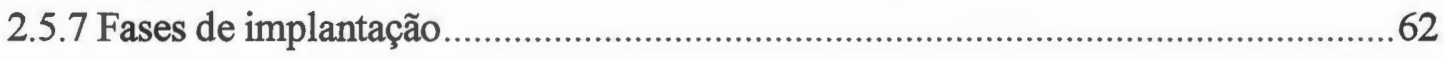

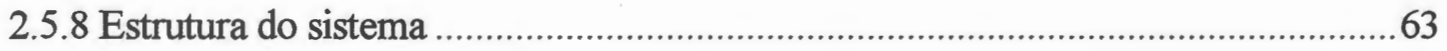

2.5.9 Aplicação dos Sistemas de Informações Geográfica no Gerenciamento Urbano...64

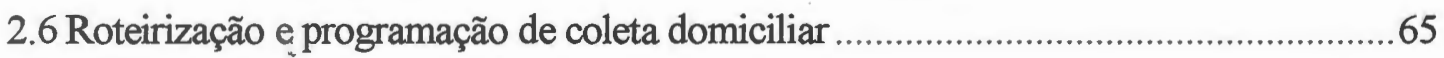

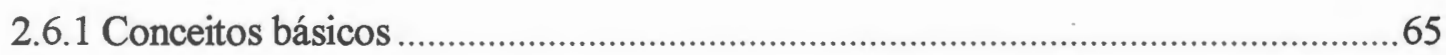

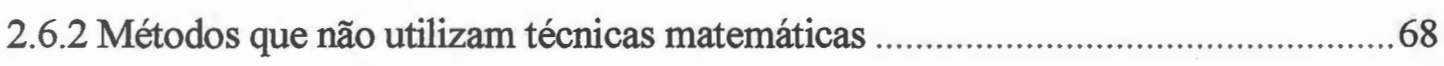

2.6.3 Métodos que utilizam técnicas matemáticas ...................................................... 70

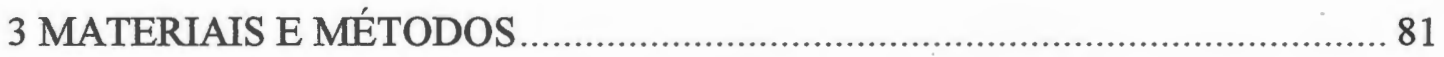

3.1 Elaboração e distribuição de questionário para municípios brasileiros .........................81

3.2 Equacionamento dos dados para aplicação do software ..............................................83

3.2.1 Descrição de software e hardware a serem utilizados ............................................84

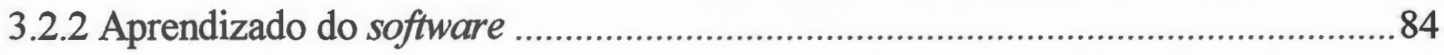

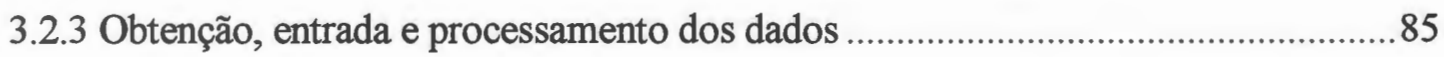

3.2.3.1 Rotina - roteamento em arco (Arc Routing) ........................................... 91

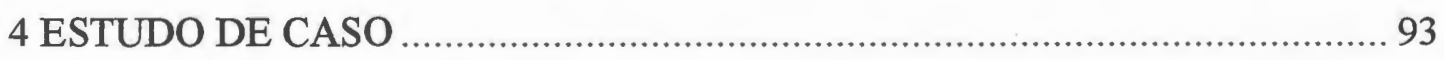

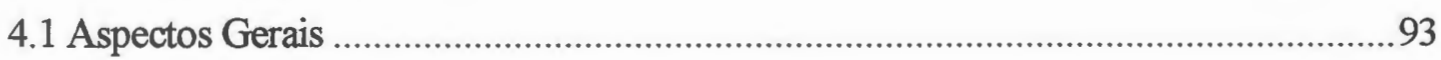

4.2 Considerações sobre o local de aplicação do software ................................................9.

4.3 Aplicação da rotina de roteamento em arco .............................................................. 101

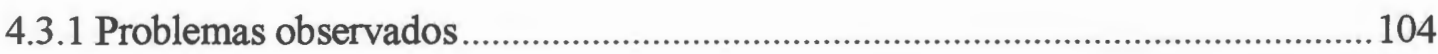

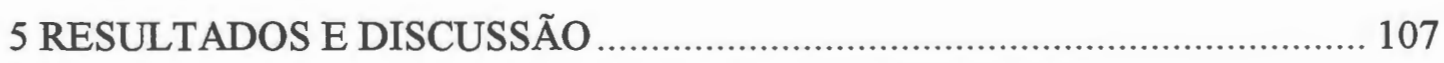

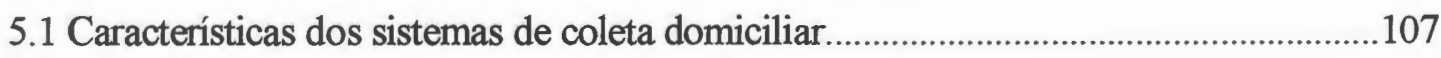

5.2 Resultados da rotina de roteamento em arco 
6 CONCLUSÕES E RECOMENDAÇÕES

6.1 Sistemas de coleta de resíduos sólidos domiciliares de municípios de médio porte... 135

6.2 A aplicação do Sistema de Informação Geográfica-SIG . 137

6.3 Propostas para trabalhos futuros 138

ANEXO A 139

ANEXO B 141

ANEXO C 151

ANEXO D. .165

REFERÊNCIA BIBLIOGRÁFICA 215 


\section{LISTA DE FIGURAS}

FIGURA 1 - Classificação dos resíduos sólidos....................................................... 11

FIGURA 2 - Operações efetuadas na área de resíduos sólidos domiciliares ............ 22

FIGURA 3 - Ações recomendáveis para o gerenciamento de resíduos sólidos ......... 23

FIGURA 4 - Inter-relação entre os elementos funcionais do gerenciamento dos

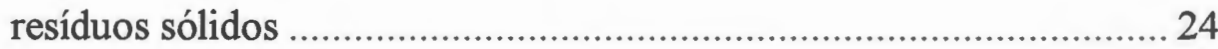

FIGURA 5 - Disposição final dos resíduos sólidos no Brasil .................................... 46

FIGURA 6 - Elementos de um Sistema de Informação Geográfica-SIG.................... 56

FIGURA 7 - Formas de representações dos dados ............................................... 58

FIGURA 8 - Equipamentos periféricos utilizados para entrada de dados .................. 60

FIGURA 9 - Equipamentos periféricos utilizados para armazenamento de dados ... 61

FIGURA 10 - Equipamentos periféricos utilizados para saída de dados.................... 61

FIGURA 11 - Representação de uma rede viária e seu grafo ..................................... 66

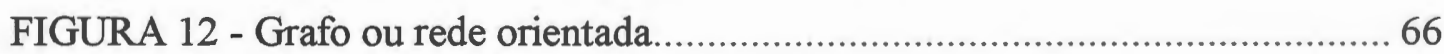

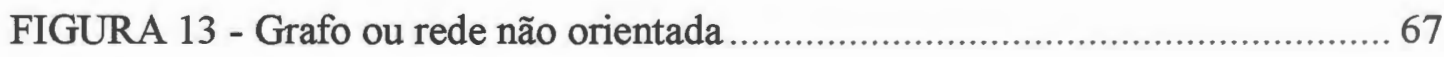

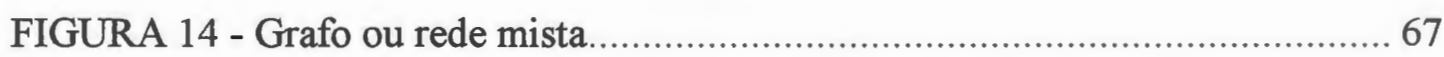

FIGURA 15 - O problema das setes pontes em Kalingrad ....................................... 71

FIGURA 16 - Descrição dos capítulos do tutorial para o software TransCAD 3.0.. 85

FIGURA 17 - Sistema viário da cidade de São Carlos ............................................. 86

FIGURA 18 - Representação do nome dos logradouros........................................... 87

FIGURA 19 - Base de dados da camada de linha .................................................. 90

FIGURA 20 - Direção de fluxo dos links.............................................................. 91

FIGURA 21 - Localização dos setores de coleta escolhidos para área de estudo .... 95

FIGURA 22 - Setor de Coleta 1......................................................................... 96

FIGURA 23 - Setor de Coleta 2.......................................................................... 97 


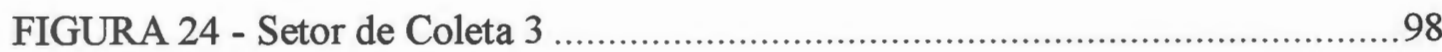

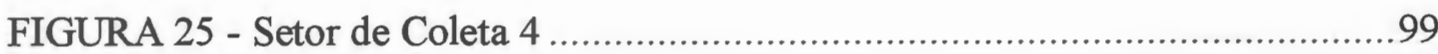

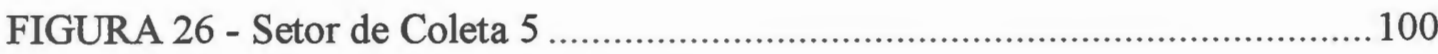

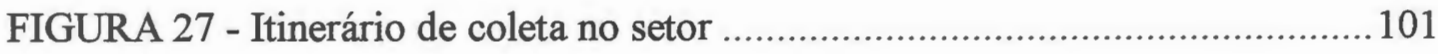

FIGURA 28 - Seleções na camada de pontos ...................................................... 102

FIGURA 29 - Sentido que o link deveria ser atravessado ................................... 105

FIGURA 30 - Percurso de Coleta Total no Setor 1 (PCT1)..................................125

FIGURA 31 - Percurso de Coleta Total no Setor 2 (PCT2)...................................125

FIGURA 32 - Percurso de Coleta Total no Setor 3 (РCT3)..................................125

FIGURA 33 - Percurso de Coleta Total no Setor 4 (PCT4) ................................. 126

FIGURA 34 - Percurso de Coleta Total no Setor 5 (PCT5) ................................126

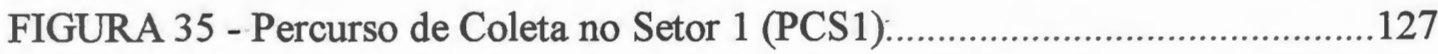

FIGURA 36 - Percurso de Coleta no Setor 2 (PCS2) ..............................................127

FIGURA 37 - Percurso de Coleta no Setor 3 (PCS3)...............................................127

FIGURA 38 - Percurso de Coleta no Setor 4 (PCS4)................................................128

FIGURA 39 - Percurso de Coleta no Setor 5 (PCS5) ...............................................128

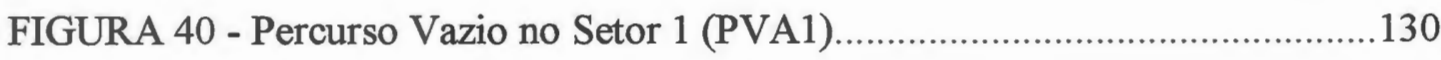

FIGURA 41 - Percurso Vazio no Setor 2 (PVA2) ...................................................130

FIGURA 42 - Percurso Vazio no Setor 3 (PVA3).....................................................130

FIGURA 43 - Percurso Vazio no Setor 4 (PVA4) ..................................................131

FIGURA 44 - Percurso Vazio no Setor 5 (PVA5) ......................................................131

FIGURA 45 - Percurso Cheio no Setor 1 (PCH1) ....................................................131

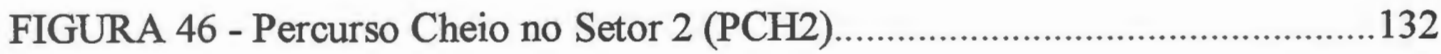

FIGURA 47 - Percurso Cheio no Setor 3 (PCH3) ................................................... 132

FIGURA 48 - Percurso Cheio no Setor 4 (PCH4) ....................................................132

FIGURA 49 - Percurso Cheio no Setor 5 (PCH5)...................................................... 133 


\section{LISTA DE TABELAS}

TABELA 1 - Classificação dos resíduos sólidos quanto à sua fonte geradora ........... 7

TABELA 2 - Critérios de classificação de resíduos sólidos e respectivas classes ... 10

TABELA 3 - Composição percentual média do resíduo sólido domiciliar em alguns países.

TABELA 4 - Composição percentual média do resíduo sólido domiciliar de algumas capitais brasileiras

TABELA 5 - Composição física dos resíduos sólidos urbanos da cidade de São

Carlos

TABELA 6 - Fatores e parâmetros intervenientes na caracterização dos resíduos sólidos 16

TABELA 7 - Massa específica média de algumas localidades 17

TABELA 8 - Ações obrigatórias para o gerenciamento integrado de resíduos sólidos . 21

TABELA 9 - Índices de geração de resíduos sólidos em alguns países. 25

TABELA 10 - Evolução do índice de geração de resíduos sólidos urbanos em algumas localidades (kg/hab.dia) ............................................. 26

TABELA 11 - Produção diária de resíduos sólidos no Brasil .............................. 26

TABELA 12 - Quantidade de resíduos sólidos (residenciais e comerciais) gerados em diferentes países 27

TABELA 13 - Formas de acondicionamento 29

TABELA 14 - Evolução dos equipamentos utilizados para coleta de resíduos sólidos 36

TABELA 15 - Grupos de normas da família ISO-14000 ................................... 52

TABELA 16 - Vantagens e desvantagens das estruturas raster e vetorial............... 58

TABELA 17 - Classificação dos municípios brasileiros...................................... 82

TABELA 18 - Distribuição da população nos municípios brasileiros em 1996 ....... 82

TABELA 19 - Distribuição da população dos municípios amostrados 83 
TABELA 20 - Campos a serem preenchidos na base de dados da camada de linhas.. 89 TABELA 21 - Campos a serem preenchidos na base de dados da camada de pontos. 89 TABELA 22 - Parâmetros operacionais 103

TABELA 23 - Porcentagem de questionários recebidos 107

TABELA 24 - Aspecto geral dos sistemas de coleta domiciliar nos municípios de médio porte......

TABELA 25 - Aspecto técnico dos sistemas de coleta domiciliar nos municípios de médio porte. .109

TABELA 26 - Aspecto social e sanitário dos sistemas de coleta domiciliar nos municípios de médio porte. 109

TABELA 27 - Parâmetros operacionais de coleta para o Setor 1, obtidos a partir de dados fornecidos pela VEGA Sopave

TABELA 28 - Parâmetros operacionais de coleta para o Setor 2, obtidos a partir de dados fornecidos pela VEGA Sopave.

TABELA 29 - Parâmetros operacionais de coleta para o Setor 3, obtidos a partir de dados fornecidos pela VEGA Sopave

TABELA 30 - Parâmetros operacionais de coleta para o Setor 4, obtidos a partir de dados fornecidos pela VEGA Sopave

TABELA 31 - Parâmetros operacionais de coleta para o Setor 5, obtidos a partir de dados fornecidos pela VEGA Sopave. 118.

TABELA 32 - Parâmetros operacionais de coleta para o-Setor 1, obtidos a partir da rotina de roteamento em arco (arc routing)

TABELA 33 - Parâmetros operacionais de coleta para o Setor 2, obtidos a partir da rotina de roteamento em arco (arc routing).

TABELA 34 - Parâmetros operacionais de coleta para o Setor 3, obtidos a partir da rotina de roteamento em arco (arc routing)

TABELA 35 - Parâmetros operacionais de coleta para o Setor 4, obtidos a partir da rotina de roteamento em arco (arc routing).

TABELA 36 - Parâmetros operacionais de coleta para o Setor 5, obtidos a partir da rotina de roteamento em arco (arc routing).

TABELA 37 - Extensão total dos links, quilometragem de porcentagem de repetições dos links em cada setor de coleta. 


\section{LISTA DE ABREVIATURAS E SIGLAS}

$\begin{array}{ll}\text { AANP } & \text { - Aspectos Ambientais das Normas e Produtos } \\ \text { ABNT } & \text { - Associação Brasileira de Normas Técnicas } \\ \text { ACV } & \text { - Avaliação do Ciclo de Vida } \\ \text { ADA } & \text { - Avaliação de Desempenho Ambiental } \\ \text { AM/FM } & \text { - Automated Mapping/Facility Management } \\ \text { CAD } & \text { - Computer Aided Design } \\ \text { CETESB } & \text { - Companhia de Tecnologia de Saneamento Ambiental } \\ \text { CNEN } & \text { - Comissão Nacional de Energia Nuclear } \\ \text { COMCAP } & \text { - Companhia de Melhoramentos da Capital } \\ \text { COMHUR } & \text { - Companhia Municipal da Habitação e Urbanismo de Resende } \\ \text { COMLURB } & \text { - Companhia Municipal de Limpeza Urbana } \\ \text { CONAMA } & \text { - Conselho Nacional do Meio Ambiente } \\ \text { CPP } & \text { - Chinese Postman Problem } \\ \text { DAEP } & \text { - Departamento de Água e Esgoto de Penápolis } \\ \text { DLU } & \text { - Departamento de Limpeza Urbana } \\ \text { EIA } & \text { - Estudo de Impacto Ambiental } \\ \text { ENDURB } & \text { - Empresa Municipal de Desenvolvimento Urbano e Rural de Bauru } \\ \text { ESURB } & \text { - Empresa Municipal de Serviços, Obras e Urbanização } \\ \text { EPI } & \text { - Equipamento de Proteção Individual } \\ \text { FAS } & \text { - Fundo de Apoio ao Desenvolvimento } \\ \text { FUNDUNESP } & \text { - Fundação para o Desenvolvimento da UNESP } \\ \text { GEIPOT } & \text { - Empresa Brasileira de Planejamento dos Transportes } \\ \text { GPS } & \text { - Sistema Global de Posicionamento (Global Positioning System) } \\ \text { IBGE } & \text { - Instituto Brasileiro de Geografia e Estatística } \\ & \end{array}$


ISO

- Organização Internacional de Normatização

ITAURB - Empresa de Desenvolvimento de Itabira Ltda.

$\mathrm{kg} \quad$ - Quilograma

$\mathrm{kg} /$ hab.ano - Quilo por habitante ano

$\mathrm{kg} /$ hab.dia - Quilo por habitante dia

$\mathrm{km}$ - Quilômetro

LIMPURB - Empresa de Limpeza Urbana

$\mathrm{m}^{3} \quad$ - Metro Cúbico

NBR - Norma Brasileira Registrada

PM - Prefeitura Municipal

PNSB - Pesquisa Nacional de Saneamento Básico

PNUD - Programa das Nações Unidas para o Desenvolvimento

PRODESAN - Progresso e Desenvolvimento de Santos S.A.

RIMA - Relatório de Impacto sobre o Meio Ambiente

SAE - Superintendência de Água e Esgoto de Ourinhos

SGA - Sistema de Gerenciamento Ambiental

SIG - Sistema de Informação Geográfica

SISNAMA - Sistema Nacional do Meio Ambiente

SLU

- Superintendência de Limpeza Urbana

$\mathrm{t}$

- Tonelada

t/ano

- Tonelada por ano

$\mathrm{t} /$ dia

- Tonelada por dia 


\section{LISTA DE SÍMBOLOS}

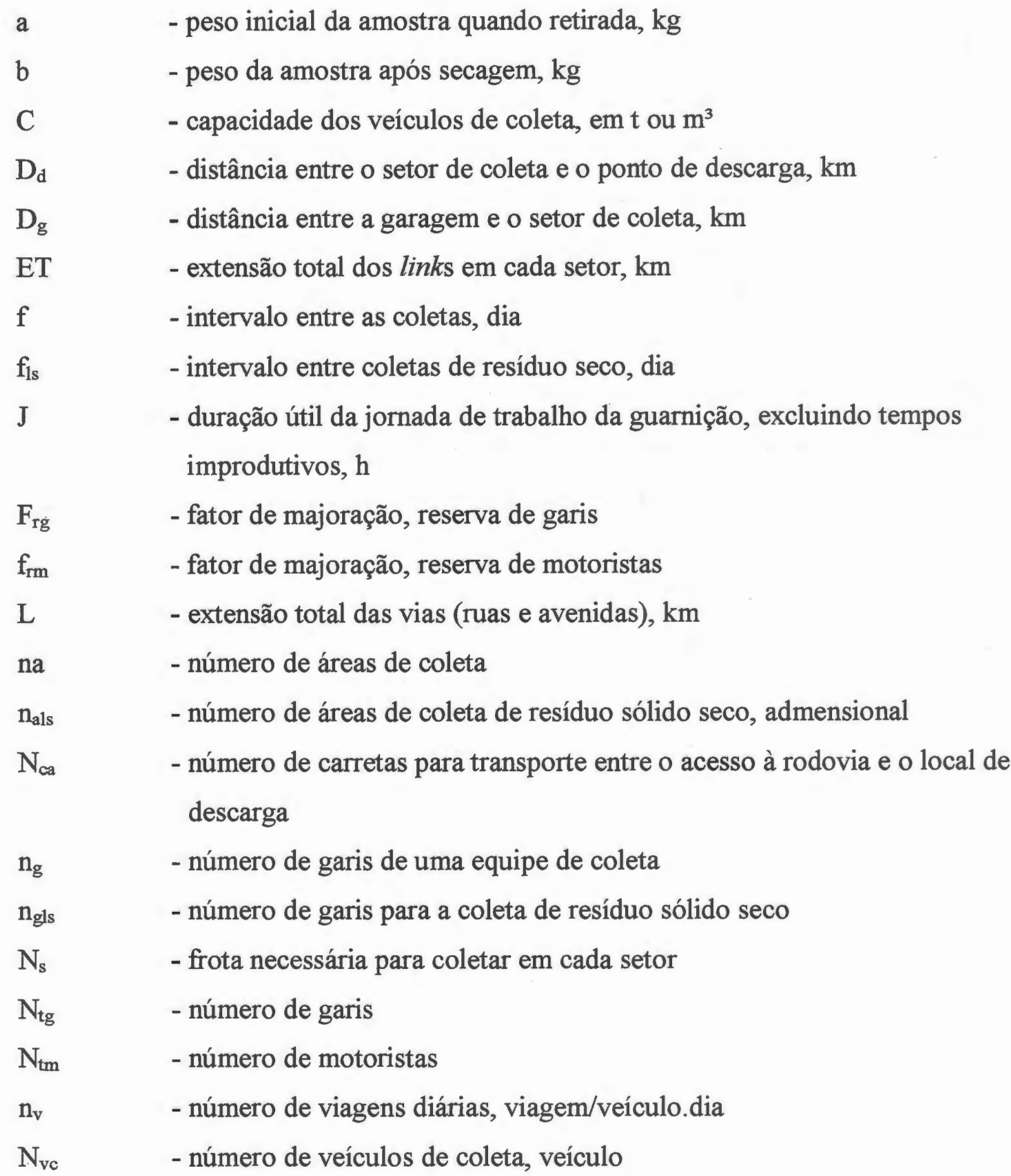




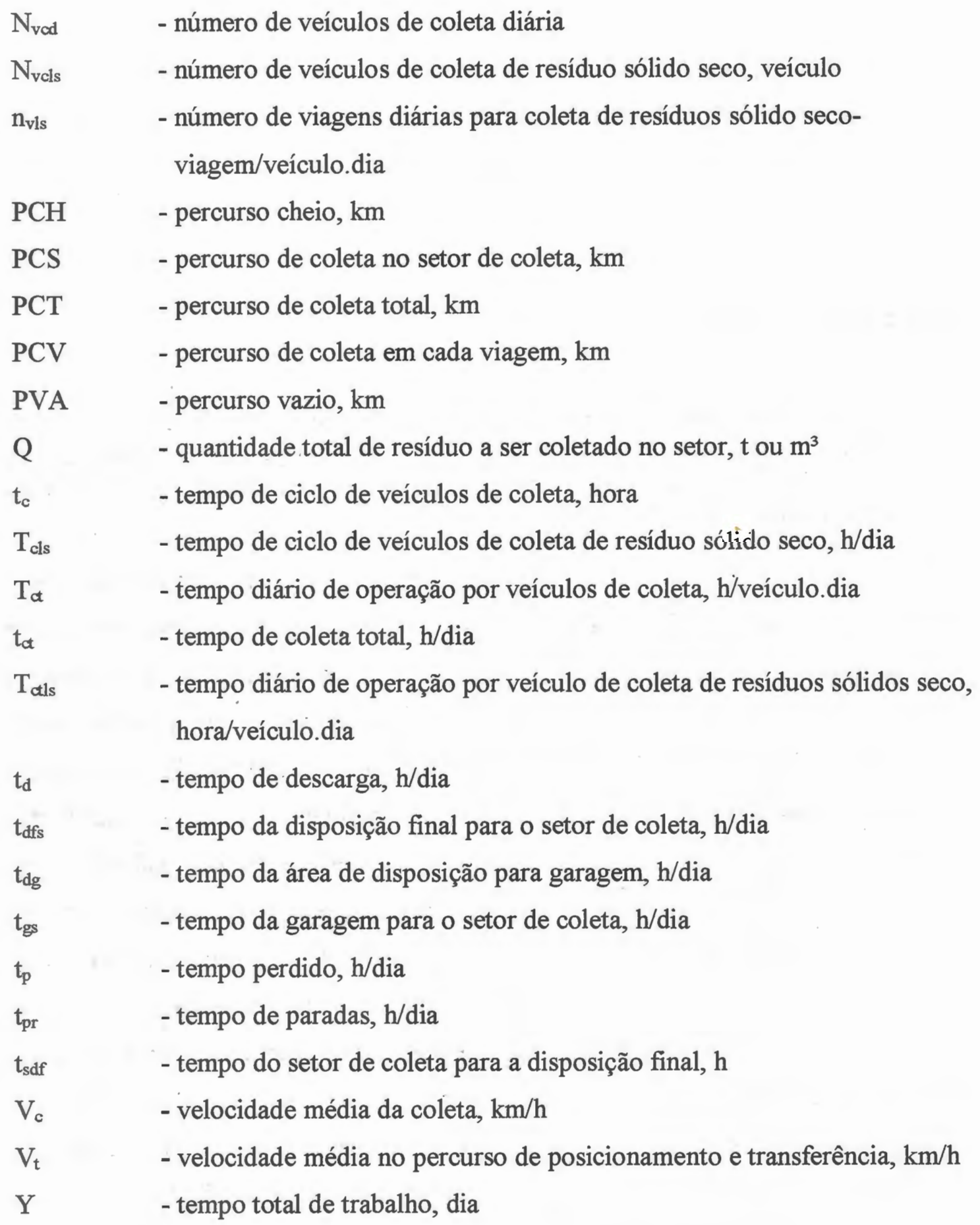




\section{RESUMO}

DELUQU, K.K. (1998). Roteirização para veículos de coletà de resíduos sólidos domiciliares utilizando um Sistema de Informação Geográfica-SIG. São Carlos, 1998. 222p. Dissertação (Mestrado) - Escola de Engenharia de São Carlos, Universidade de São Paulo.

O referencial básico deste trabalho foi levantamento sobre sistemas de coleta de resíduos sólidos domiciliares em municípios brasileiros, objetivando caracterizar o planejamento e execução de serviços em municípios brasileiros de médio porte. $\mathrm{O}$ Sistema de Informação Geográfica-SIG foi o determinante neste trabalho, sendo utilizado o software TransCAD como ferramenta para a roteirização dos veículos coletores. Considerando São Carlos-SP como município de médio porte e dentro dos padrões preestabelecidos para a realização do presente trabalho, realizou-se um estudo de caso, abrangendo cinco setores de coleta que compõe a área central. Os resultados obtidos pelo TransCAD e os dados fornecidos por empresa responsável pela execução dos serviços de coleta, foram processados no software Microsoft EXCEL, for Windows versão 97, para obtenção dos parâmetros operacionais tais como: Percurso de coleta total (PCT), Percurso de Coleta no Setor (PCS), Percurso Cheio (PCH), Percurso Vazio (PVA) e a extensão total dos links (ET) de cada setor de coleta. Os resultados indicaram que a quilometragem de repetição de passagem, em ruas já servidas, foi superior quando calculada a partir da aplicação do TransCAD. Com relação a características dos sistemas de coleta dos municípios brasileiros observou-se que o aspecto operacional relativo a definição dos roteiros não são priorizados dentro do sistema de gerenciamento da coleta.

Palavras-chave: resíduos sólidos; coleta domiciliar; roteirização de veículos; sistema de informação geográfica 


\section{ABSTRACT}

DELUQUI, K.K. (1998). Routing for vehicles of collection of residential solid waste using a Geographical Information System-GIS. São Carlos, 1998. 222p. Dissertação (Mestrado) - Escola de Engenharia de São Carlos, Universidade de São Paulo.

The basic referential of this study was a survey on collection systems of residential solid waste in Brazilian municipal districts, aiming to characterize the planning and execution of services in Brazilian medium sized municipal districts. The Geographical Information System-SIG was the determinant in this study and TransCAD software was used as a tool for the routing of the collecting vehicles. By considering São Carlos-SP a medium sized municipal and according to the patterns pre-established for the accomplishment of the present study, a case study, was carried out comprehending five collection sections which compose the central area. The results obtained by TransCAD and the data provided by the company responsible for the collection services were processed in Microsoft EXCEL, Windows version 97, for the obtaining of operational parameters such as: Course of Total Collection (CTC), Course of Collection in the Section (CCS), Full Course (FC), Empty Course (EC) and the total extension of the links (TE) of each collection section. The results indicated that the passage repetition in streets already served, was greater when calculated from the values obtained by the application of TransCAD. Regarding the characteristics of the collection systems in Brazilian municipal districts, it observed that the relative operational aspect which refers to the definition of the routes is not prioritized in the management system of collection.

Keywords: solid waste; residential collection; routing of vehicles; geographical information system 


\section{INTRODUÇÃO}

"O homem não se deve deixar usar pela tecnologia, e sim, usá-la para melhorar sua qualidade de vida e do ambiente em que vive."

T.Kawabe

A coleta de resíduos é uma das atividades mais importantes a serem desenvolvidas dentro de um sistema de gerenciamento de resíduos sólidos, sendo a sua importância decorrente de elevados custos operacionais (equipamentos e pessoal envolvido) bem como do aspecto estético a que está relacionada.

A otimização do processo de coleta deve buscar a máxima satisfação da população com a prestação de serviço através da adequada consideração dos aspectos de qualidade, custos, atendimento e proteção à saúde pública. Sendo assim, é fundamental que se estabeleça um controle operacional dos serviços prestados que permita a avaliação do mesmo.

A roteirização dos veículos de coleta, de uma maneira geral, é feita manualmente em mapas considerando os sentidos das vias e as características da área de coleta - freqüência e horário de coleta - e, muitas vezes, é definida aleatoriamente pelo motorista do caminhão coletor, resultando em serviços ineficientes e de baixa qualidade.

Muitos municípios brasileiros operam com sistemas de coleta de resíduos sólidos sub ou super-dimensionados. Diante dessas condições existe a necessidade de se buscar uma alternativa que associe dados operacionais à tecnologia disponível.

Justifica-se assim, o empenho em pesquisas visando o planejamento dos sistemas de manejo de resíduos sólidos, especificamente a coleta, em termos de qualidade dos serviços, racionalização da frota e pessoal, aumento da produtividade e redução de custos. 
De acordo com ROSSETTO \& CUNHA (1994) do ponto de vista de modelagem matemática, o problema de roteirização é considerado bastante complexo. O grande desafio enfrentado consiste na definição de modelos matemáticos e no desenvolvimento de algoritmos que possibilitem considerar as restrições encontradas nos problemas reais, onde o modelo deve se adaptar aos problemas a serem resolvidos e não o contrário. Muitas vezes, os problemas são simplificados de forma a se adaptar às restrições do modelo disponível.

A tecnologia disponível nos últimos anos tem facilitado’o manuseio de grande número de dados através de sistemas computacionais. Estes sistemas são denominados Sistemas de Informação Geográfica-SIG e oferecem ferramental operacional que auxilia e agiliza os procedimentos de planejamento, gerência e de tomadas de decisão.

A utilização de um SIG para transporte se mostra viável haja vista a estrutura dos programas adaptados para o problema de roteirização de veículos de coleta de resíduos sólidos, objeto deste trabalho. Estes fornecem acessibilidade à base de dados geográficos e de transporte, possibilitando que esses elementos sejam combinados de diferentes maneiras. A existência de uma representação da rede de trabalho de uma cidade através de um SIG, pode conferir representatividade e fidelidade às condições reais em que os deslocamentos do veículo coletor ocorrem, o que permite simular alternativas de roteirização de veículos de coleta de resíduos sólidos que resultem na visualização e avaliação integrada de aspectos técnicos, econômicos e ambientais.

Neste trabalho será utilizado um SIG aplicado aos transportes. O software é denominado comercialmente TransCAD, e permite desenvolver rotas utilizando-se de algoritmos que incluem um procedimento de roteirização em arco (Arc Routing), objetivando minimizar a extensão total a ser percorrida pelos veículos coletores.

O presente trabalho tem como objetivo geral:

- Caracterizar sistemas de coleta de resíduos sólidos domiciliares de municípios brasileiros de médio porte, do planejamento à execução dos serviços.

- Avaliar a aplicabilidade de um Sistema de Informação Geográfica na solução de problemas de roteirização de veículos de coleta domiciliar. 
E como objetivos específicos:

- Analisar procedimentos adotados para definir roteiro do caminhão coletor em municípios brasileiros de médio porte;

- Analisar as distâncias percorridas pelo caminhão coletor durante a operação de coleta;

- Verificar o nível de repetição de passagem sobre links que já foram servidos pelo serviço de coleta. 


\section{REVISÃO DE LITERATURA}

\subsection{Generalidades sobre resíduos sólidos urbanos}

\subsubsection{Definição}

Existem diversas definições e classificações para os resíduos sólidos gerados em aglomerados urbanos que diferem entre si, conforme os parâmetros que se adotem e os objetivos a que se destinem.

O termo resíduo sólido também é comumente denominado lixo. Segundo alguns filósofos, a palavra lixo deriva de lix, que em latim medieval já decadente, deriva do verbo lixare, cujo significado seria polir ou desbastar. Em qualquer dos casos, tanto a lixívia quanto o produto do desbaste podem ser entendidos como parte de um todo maior, o resto de uma ação sobre um objeto original.

ROCHA $^{1}$ apud SARTORI (1995) relata que, para muitos estudiosos, a palavra resíduos deriva de residuu, que em latim significa o que resta de qualquer substância.

FERREIRA (1988), em seu Dicionário Básico da Língua Portuguesa, define lixo: "Aquilo que se varre da casa, do jardim, da rua, e se joga fora, entulho. Tudo o que não presta e se joga fora. Sujidade, sujeira, imundície. Coisa ou coisas inúteis, velhas, sem valor". A autor define ainda resíduo: "Remanescente. Aquilo que resta de qualquer substância, resto. O resíduo do que sofreu alteração de qualquer agente exterior, por processos mecânicos, químicos, físicos."

\footnotetext{
${ }^{1}$ ROCHA, A.A. (1993). A história do lixo. In: Resíduos Sólidos e Meio Ambiente, Série seminários. São Paulo: Secretaria do Meio Ambiente, Coordenadoria de Educação Ambiental apud SARTORI, H.J.F. (1995) Discussão sobre a Caracterização Física de Resíduos Sólidos Domiciliares. Belo Horizonte. 102p. Dissertação (Mestrado) - Universidade Federal de Minas Gerais.
} 
Para SEWELL (1978) os resíduos sólidos são os materiais indesejados pelo homem, que não podem fluir diretamente para os rios ou se elevar imediatamente para o ar. São os resíduos não-líquido, não gasoso, da manufatura, construção, preparo de alimentos, recreação, agricultura e outras atividades que usam os materiais e então deles se descartam.

PHILIPI JUNIOR (1986) propõe as seguinte definições:

- São todos os materiais rejeitados que não possuem aproveitamento econômico imediato.

- São todos materiais resultantes das atividades humanas de produção e de consumo, com exceção de dejetos e outros materiais sólidos com um conteúdo líquido suficiente para fluir.

OLIVEIRA (1992) considera que os resíduos sólidos, para o seu produtor, não possuem mais um valor econômico suficiente para conservá-lo.

TCHOBANOGLOUS et al. (1993) definem que são todos os resíduos provenientes das atividades humanas e animais e normalmente são sólidos, sendo descartados quando desnecessários ou indesejáveis.

Para LEÃO (1997) resíduo é algo que fez parte de um processo produtivo ou não, e que eventualmente não está sendo aproveitado, mas que ainda apresenta uma utilização em potencial.

As definições apresentam algumas características comuns, sendo a sua maioria uma peculiaridade de cada autor. Buscando adotar uma definição usual para resíduos sólidos optou-se pela da Associação Brasileira de Normas Técnicas (ABNT), que através da Norma Brasileira Registrada - NBR 10004 define:

\subsection{Residuos Sólidos}

"Resíduos nos estados sólido e semi sólidos, que resultam de atividades da comunidade de origem: industrial, doméstica, hospitalar, comercial, agrícola, de serviços e de varrição. Ficam incluídos nesta definição os lodos provenientes de sistemas de tratamento de água, aqueles gerados em equipamentos e instalações de controle de poluição, bem como determinados líquidos cujas 
particularidades tornem inviável o seu lançamento na rede pública de esgotos ou corpos de água, ou exijam para isso soluções técnica e economicamente inviáveis em face à melhor tecnologia possivel". (ABNT, 1987, p.1)

\subsubsection{Classificação dos resíduos sólidos}

Os resíduos sólidos podem ser classificados de várias formas, considerando aspectos como o local de produção, a origem, a natureza física dos resíduos (seco ou molhado), a composição química (matéria orgânica e inorgânica) e o grau de biodegradabilidade (facilmente, moderadamente e não biodegradáveis).

OLIVEIRA (1992) classificou os resíduos sólidos segundo o local de produção. O resíduo sólido gerado em aglomerados humanos é denominado urbano, já o formado fora das cidades, ou melhor, no "campo" é classificado como resíduo sólido rural.

A tabela 1 apresenta a classificação dos resíduos sólidos quanto à sua fonte geradora proposta por TCHOBANOGLOUS et al. (1993). 
TABELA 1 - Clasśificação dos resíduos sólidos quanto à sua fonte geradora

\begin{tabular}{|c|c|c|}
\hline Fonte & $\begin{array}{l}\text { Unidade Típicas, Atividades ou } \\
\text { Localização onde os Resíduos } \\
\text { São Gerados }\end{array}$ & Tipos de Resíduos Sólidos \\
\hline Residência & $\begin{array}{l}\text { Família simples e várias famílias } \\
\text { em residências independentes, } \\
\text { apartamentos de baixo, médio e } \\
\text { alto padrão. }\end{array}$ & $\begin{array}{l}\text { Resíduos de alimentos, papel, papelão, } \\
\text { plásticos, tecidos, couros, resíduos de } \\
\text { jardinagem e poda, madeira, vidro, latas de } \\
\text { estanho, alumínio, outros metais, cinzas, } \\
\text { resíduo proveniente da varrição, resíduos } \\
\text { especiais (incluindo itens volumosos, artigos } \\
\text { eletrônicos, linha branca, resíduos de } \\
\text { jardinagem e poda coletados separadamente, } \\
\text { baterias, óleos e pneus), RSD perigosos. }\end{array}$ \\
\hline Comércio & $\begin{array}{l}\text { Lojas, restaurantes, mercados, } \\
\text { escritórios, hotéis, motéis, lojas } \\
\text { de impressão, estações de } \\
\text { serviços mecânicos, etc. }\end{array}$ & $\begin{array}{l}\text { Papel, papelão, plásticos, madeira, resíduo } \\
\text { de alimentos, vidro, metal, resíduos } \\
\text { especiais (veja acima), resíduos perigosos, } \\
\text { etc. }\end{array}$ \\
\hline Instituições & $\begin{array}{l}\text { Escolar, hospitalar, prisões, } \\
\text { centros governamentais. }\end{array}$ & $\begin{array}{l}\text { Papel, plásticos, madeira, resíduos de } \\
\text { alimentos, vidro, metal, resíduos especiais, } \\
\text { resíduos perigosos. }\end{array}$ \\
\hline $\begin{array}{l}\text { Construção e } \\
\text { Demolição }\end{array}$ & $\begin{array}{l}\text { Áreas de novas construções, } \\
\text { recuperação/renovação } r \text { de } \\
\text { estradas, entulhos de } \\
\text { pavimentação. }\end{array}$ & Madeira, aço, concreto, poeira, etc. \\
\hline $\begin{array}{c}\text { Serviços } \\
\text { Municipais } \\
\text { (Exceto unidades de } \\
\text { Tratamento) }\end{array}$ & $\begin{array}{l}\text { Varrição, limpeza de boca de } \\
\text { lobo, parques e praias, outras } \\
\text { áreas de recreação. }\end{array}$ & $\begin{array}{l}\text { Resíduos especiais, refugos, resíduos, } \\
\text { varrição, podas de árvore, resíduos de } \\
\text { parques em geral, praias e áreas de } \\
\text { recreação. }\end{array}$ \\
\hline $\begin{array}{l}\text { Unidades de } \\
\text { Tratamento; } \\
\text { Incineradores } \\
\text { Municipais }\end{array}$ & $\begin{array}{l}\text { Processos de tratamento de água, } \\
\text { efluentes e resíduos industriais. }\end{array}$ & $\begin{array}{l}\text { Resíduos das unidades de tratamento, } \\
\text { principalmente compostos por lodos } \\
\text { residuais. }\end{array}$ \\
\hline Município & Todos citados anteriormente. & Todos citados anteriormente. \\
\hline Indústria & $\begin{array}{l}\text { Construção, fabricação, } \\
\text { industrias pesadas e leves, } \\
\text { refinarias, unidades geradoras de } \\
\text { energia, demolições, etc. }\end{array}$ & $\begin{array}{l}\text { Resíduos de processo industrial, sucata, etc. } \\
\text { Resíduos não industriais incluindo } \\
\text { alimentos, refugos, cinzas, resíduos de } \\
\text { demolição e construção, resíduos especiais, } \\
\text { resíduos perigosos. }\end{array}$ \\
\hline Agricultura & $\begin{array}{l}\text { Colheita, pomares, videiras, } \\
\text { leiterias, fazendas, etc. }\end{array}$ & $\begin{array}{l}\text { Resíduos de alimentos estragados, resíduos } \\
\text { de agricultura, refugos, resíduos perigosos. }\end{array}$ \\
\hline
\end{tabular}

Fonte: TCHOBANOGLOUS et al. (1993) 
De acordo com SCHALCH \& LEITE (1995), os resíduos sólidos podem ser classificados segundo a origem considerando-se vários critérios:

\section{- Residencial}

É o chamado resíduo sólido domiciliar, constituído de restos de alimentos, invólucros diversos, com vasilhames, papéis, papelão, plásticos e vidros; varredura, folhagens, ciscos e outros.

\section{- Comercial}

Provenientes de diversos estabelecimentos comerciais, como escritórios, lojas, hotéis, restaurantes, supermercados e outros. É constituído principalmente por: papel, papelão, plásticos, caixas, restos de lavagens e outros.

\section{- Industrial}

Provenientes das diferentes áreas da indústria, portanto, de constituição muito variada.

\section{- Hospitalar}

É constituído de resíduos das diferentes áreas do estabelecimento: cozinha, dos patogênicos, da administração, da limpeza e outros. Do refeitório-cozinha: restos de alimentos e sobras das refeições. Área dos patogênicos: são restos de salas de operação (obstetrícia e diagnósticos,-curativos, medicamentos e bandejas, das áreas de internação e isolamento). Administração, limpeza e outros: papéis, invólucros, varreduras, flores, restos de laboratório, jardins, biotérios, etc.

\section{- Especial}

Constituído por resíduos e materiais produzidos esporadicamente como: animais mortos, restos de podações, folhagens de limpeza de jardins, entulhos.

\section{- Feiras, var̃rição e outros}

Proveniente da varrição regular das ruas, conservação da limpeza de núcleos comerciais, limpeza de feiras, locais de festividades e outros; papéis, cigarros, invólucros jogados nas vias; restos de capinação, areia, cisco, folhas;

Convém observar que o termo resíduos hospitalares foi substituído por resíduos de serviço de saúde pela ABNT-NBR 10.004, a partir de dezembro de 1987, e, atualmente encontra-se inserido entre as definições da NBR 12.807, da associação citada, em vigor desde 1993. 
SARTORI (1995), objetivando uma padronização na caracterização dos resíduos sólidos compilou propostas de diversos autores para classificar os resíduos sólidos, conforme mostra a tabela 2.

TABELA 2 - Critérios de classificação de resíduos sólidos e respectivas classes

\begin{tabular}{|c|c|}
\hline Critério de Classificação & Classes \\
\hline Capacidade de produção de composto & $\begin{array}{l}\text { Matéria orgânica } \\
\text { Matéria inorgânica }\end{array}$ \\
\hline $\begin{array}{l}\text { Origem, fonte e local de produção } \\
\text { (compilação e diferentes autores) }\end{array}$ & $\begin{array}{l}\text { Comercial } \\
\text { Especial } \\
\text { Hospitalar e contaminado } \\
\text { Industrial, industrial não perigoso } \\
\text { Público (de varrição) } \\
\text { Radioativo } \\
\text { Residencial, doméstico, domiciliar } \\
\text { Rural } \\
\text { Urbano }\end{array}$ \\
\hline Tratabilidade & $\begin{array}{l}\text { Biodegradável } \\
\text { Descartável } \\
\text { Reciclável }\end{array}$ \\
\hline Economia & $\begin{array}{l}\text { Aproveitável } \\
\text { Aproveitável para produção de composto } \\
\text { Inaproveitável } \\
\text { Recuperável }\end{array}$ \\
\hline Grau de biodegradabilidade & $\begin{array}{l}\text { Facilmente degradável } \\
\text { Moderadamente degradável } \\
\text { Dificilmente degradável } \\
\text { Não degradável } \\
\end{array}$ \\
\hline Incineração & $\begin{array}{l}\text { Combustível } \\
\text { Incombustível }\end{array}$ \\
\hline Índice de recuperação energética & $\begin{array}{l}\text { Materiais de reutilização direta ou alto } \\
\text { indice de recuperação energética }\end{array}$ \\
\hline Natureza dos serviços de limpeza pública & $\begin{array}{l}\text { Domiciliar } \\
\text { Especial }\end{array}$ \\
\hline Padrão de vida na fonte produtora & $\begin{array}{l}\text { De classe alta } \\
\text { De classe média } \\
\text { De classe baixa }\end{array}$ \\
\hline Ponto de vista sanitário & $\begin{array}{l}\text { Inerte } \\
\text { Orgânico } \\
\end{array}$ \\
\hline
\end{tabular}

FONTE: SARTORI (1995)

SCHALCH (1996), propôs uma classificação, apresentada na figura 1, dos resíduos sólidos, de acordo com a origem, adaptando os conceitos e as definições dispostas na NBR-10.004. 


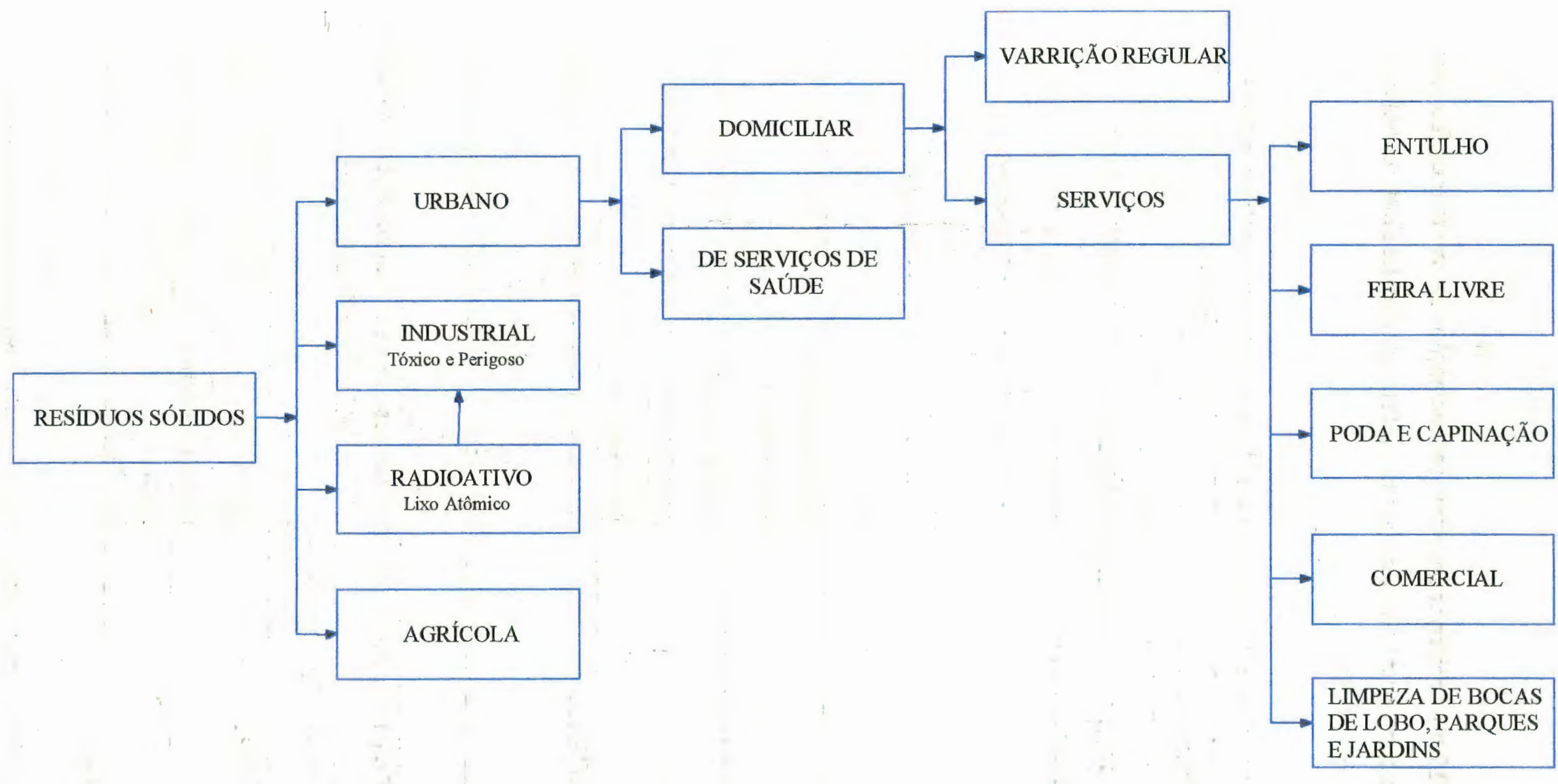

FIGURA 1 - Classificação dos Resíduos Sólidos

Fonte: SCHALCH (1996), Adaptada da definição da ABNT-NBR - 10.004 
Dadas as classificaçõè dos resíduos sólidos, propostas por diversos autores, optou-se no presente trabalho, por aquelas de LEITE (1997), adaptada da ABNTNBR 10004.

Para o autor, normalmente os resíduos podem ser classificados, ségundo a origem como:

\section{- Urbanos}

Incluem o resíduo domiciliar gerado nas residências, o resíduo comercial produzido em escritórios; lojas, hotéis, supermercados, restaurantes e outros estabelecimentos afins, os resíduos de serviços, oriundos da limpeża pública urbana, além dos resíduos de varrição das vias pública, limpezas de galerias, terrenos, córregos, praias, feiras, podas, capinação;

\section{- Industriais}

Correspondem aos resíduos gerados nos diversos tipos de indústrias de processamentos. Em função da periculosidade oferecida por alguns desses resíduos, o seguinte agrupamento é proposto pela ABNT-NBR 10.004 (1987):

Resíduos de Clàsse I (perigosos): pelas suas características de inflamabilidade, corrosividade, reatividade, toxidade e patogenicidade, podem apresentar riscos à saúde pública, provocando ou contribuindo para o aumento da mortalidade ou apresentarem efeitos adversos ao meio ambiente, quando manuseados ou dispostos de forma inadequada;

Resíduos Classe II (não inertes); incluem-se nesta classe os resíduos potencialmente biodegradáveis ou combustíveis;

Resíduo Classe III (inertes): perfazem esta classe os resíduos considerados inertes e não combustíveis.

\section{- Resíduos de serviço de saúde}

São os resíduos produzidos em hospitais, clínicas médicas e veterinárias, laboratórios de análises clínicas, farmácias, centros de saúde, consultórios odontológicos e outros estabelecimentos afins. Esses resíduos podem ser ägrupados em dois níveis distintos:

Resíduos comuns: compreendem os restos de alimentos, papéis, invólucros, etc.

Résíduos sépticos: constituídos de restos de salas de cirurgia, áreas de isolamento, centros de hemodiálise, etc. O seu manuseio, acondicionamento, coleta, 
transporte e destinação final exige atenção especial, devido ao potencial risco que podem oferecer à saúde pública.

- Resíduos de portos, aeroportos, terminais rodoviários e ferroviários

Constituem os resíduos sépticos, que podem conter organismos patogênicos, tais como: materiais de higiene e de asseio pessoal, restos de alimentos, etc., e veicular doenças de outras cidades, estados e países.

- Resíduos agrícolas

Correspondem aos resíduos das atividades da agricultura e da pecuária, como embalagens de adubos, defensivos agrícolas, ração, restos de colheita, esterco animal.

- Entulho

Constitui-se de resíduos da construção civil: demolição, restos de obras, solos de escavações, etc.

- Resíduo radioativo (lixo atômico)

São resíduos provenientes dos combustíveis nucleares. Seu gerenciamento é de competência exclusiva da CNEN - Comissão Nacional de Energia Nuclear.

\subsection{Composição e características dos resíduos sólidos}

\subsubsection{Composição dos resíduos sólidos}

A composição dos resíduos sólidos, tanto do ponto de vista qualitativo como quantitativo, é um dos dados básicos para o devido equacionamento, coleta, transporte, tratamento e destino final; quanto ao aspecto econômico-financeiro serve para mostrar as potencialidades econômicas relacionadas à extração de restos aproveitáveis.

\section{a) Composição qualitativa}

De acordo com ORTH et al. (1976) os resíduos sólidos, de forma geral, são constituídos de três parcelas distintas:

- detritos orgânicos em geral - restos de alimento, vegetais e matéria orgânica em geral.

- detritos inorgânicos e orgânicos relativamente estáveis - papéis, metais, panos, vidros, plásticos, etc. 
- cinzas - resíduos de queima de determinados combustíveis.

Quanto aos componentes pode-se considerar:

- restos de alimentos;

- ciscos (papéis, trapos, metais, plásticos, etc.);

- cinzas;

- excrementos de animais;

- animais mortos;

- resíduos industriais;

- resíduos radioativos;

- resíduos contaminados;

- resíduos de varrição e capinação de vias e logradouros públicos;

- restos de poda de árvore e arbusto;

- restos de materiais de construção;

- veículos abandonados.

b) Composição quantitativa

A composição quantitativa do resíduo sólido varia de um lugar para outro, inclusive entre os diversos bairros de uma mesma cidade. As tabelas 3 e 4 mostram as composições dos resíduos sólidos domésticos a nível nacional e internacional.

TABELA 3 - Composição percentual média do resíduo sólido domiciliar em alguns países

\begin{tabular}{l|ccccc}
\hline \multirow{2}{*}{ País } & \multicolumn{5}{|c}{ Componente (\%) } \\
& Papel & Plástico & Metal & Vidro & Outros \\
\hline Brasil & 25,00 & 3,00 & 4,00 & 3,00 & 65,00 \\
EUA & 41,00 & 6,50 & 8,70 & 8,20 & 35,60 \\
Malásia & 23,73 & 11,22 & 4,22 & 3,18 & 57,65 \\
Holanda & 22,50 & 6,00 & 6,70 & 14,50 & 50,30 \\
Turquia & 11,00 & 4,30 & 1,70 & 1,70 & 81,30 \\
Alemanha & 18,80 & 5,80 & 3,80 & 10,40 & 61,20 \\
\hline
\end{tabular}

Fonte: CONSONI \& PERES (1995) 
TABELA 4 - Composição percentual média do resíduo sólido domiciliar de algumas capitais brasileiras

\begin{tabular}{l|lllll}
\hline \multicolumn{1}{c|}{ Cidade } & \multicolumn{5}{c}{ Componente (\%) } \\
& Papel & Plástico & Metal & Vidro & Outros \\
\hline São Paulo & 14,43 & 12,08 & 3,24 & 1,10 & 69,15 \\
Rio de Janeiro & 27,00 & 13,00 & 3,00 & 2,00 & 55,00 \\
Salvador & 19,00 & 11,00 & 4,00 & 4,00 & 62,00 \\
Fortaleza & 22,59 & 8,20 & 7,34 & 3,32 & 58,55 \\
Porto Alegre & 24,92 & 3,12 & 2,65 & 1,68 & 67,63 \\
Distrito Federal & 26,17 & 2,37 & 3,20 & 2,83 & 65,43 \\
Belo Horizonte & 16,77 & 1,90 & 3,22 & 2,07 & 76,04 \\
\hline
\end{tabular}

Fonte: Adaptada de CONSONI \& PERES (1995)

A tabela 5 apresenta a composição física dos resíduos sólidos urbanos da cidade de São Carlos realizada por GOMES (1989), utilizando amostras coletadas de setores representativọs dos resíduos sólidos gerados.

TABELA 5 - Composição física dos resíduos sólidos urbanos da cidade de São Carlos

\begin{tabular}{l|c}
\hline Componente & Média Final (\%) \\
\hline Matéria orgânica & 56,7 \\
Papel & 21,3 \\
Vidro & 1,1 \\
Metal & 5,4 \\
Plástico & 8,5 \\
Trapos & 3,4 \\
Madeira, couro, borracha & 2,3 \\
Inertes & 1,3 \\
Total & 100 \\
\hline
\end{tabular}

Fonte: GOMES (1989) 


\subsubsection{Características dos resíduos sólidos}

O estudo das características dos resíduos sólidos também constitui um dos fatores básicos na determinação das soluções adequadas ao problema, principalmente no que se refere à coleta, tratamento e disposição final. Estas características, que podem ser fisicas, químicas e biológicas, estão relacionadas fundamentalmente à composição do resíduo sólido.

SARTORI (1995), a fim de buscar a melhor forma para avaliar os fatores e parâmetros que intervém na caracterização dos resíduos sólidos, identificou e agrupou os fatores principais em seis subgrupos, conforme a tabela 6 .

\section{TABELA 6 - Fatóres e parâmetros intervenientes na caracterização dos resíduos sólidos}

\begin{tabular}{|c|c|}
\hline Fator & Parâmetro \\
\hline$\overline{\text { Econ }}$ & Poder aquisitivo, renda "per capita", padrão de vida; \\
\hline Geográfico & $\begin{array}{l}\text { Clima, características da cidade, estação do ano, localização } \\
\text { gëográfica; }\end{array}$ \\
\hline Histórico & $\begin{array}{l}\text { Política éconômica, situação político-social (guerra, economia), } \\
\text { grau ou estágio de industrialização e de investimento; }\end{array}$ \\
\hline Operacional & $\begin{array}{l}\text { Área relativa de produção de resíduos sólidos, disciplina e controle } \\
\text { nos pontos de produção, coleta (tipo, eficiência, equipamentos e } \\
\text { freqüência), leis e regulamentos, população (número de } \\
\text { habitantes), sazonalidade da produção de resíduo sólido, distâncias } \\
\text { e tempos de transporte; }\end{array}$ \\
\hline Social & $\begin{array}{l}\text { Atitudes, costumes, e hábitos da população (hábitos alimentares, } \\
\text { uso de tratamento domiciliares, atividade de catação), nível } \\
\text { educacional, percepção ambiental, representatividade social, } \\
\text { orgánização política; }\end{array}$ \\
\hline Urbano & $\begin{array}{l}\text { Funções urbanas, infra-estrutura urbana, natureza da comunidade, } \\
\text { densidade demográfica. }\end{array}$ \\
\hline
\end{tabular}

Fonte: SARTORI (1995) 


\section{a) Características físicas}

\section{- Massa específica}

É a razão entre a massa e volume dos resíduos; geralmente expressa em $\mathrm{kg} / \mathrm{m}^{3}$. Esta característica, que pode referir-se ao resíduo -solto ou compactado, às vezes também é denominada por alguns autores, como-AMORIM \& AGUIAR ${ }^{2}$ apud ANDRADE (1997), por exemplo, de peso específico ou ainda densidade aparente, como faz JARDIM (1995).

Por ser o resíduo sólido uma substância compressível; o conhecimento da massa específica é de fundamental importância para o dimensionamento dos sistemas de coleta e de tratamento.

Este parâmetro varia inversamente com o padrão de vida da população. Uma população de alta renda produz um resíduo com alto teor de papéis e plásticos e pouca matéria orgânica. Este tipo de resíduos possui um baixa massa específica.

A tabela 7 indica alguns valores de massa específica média para os resíduos sólidos urbanos:

TABELA 7 - Massa específica média de resíduos sólidos de algumas localidades

\begin{tabular}{l|c}
\hline \multicolumn{1}{c|}{ Cidade/País } & Peso específico $\left(\mathrm{kg} / \mathrm{m}^{3}\right)$ \\
\hline São Paulo (1977) & 173 \\
Porto Alegre (1974) & 270 \\
Rio de Janeiro (1975-1976) & 239 \\
Sub-Região Sudeste de São Paulo & \\
Santo André, São Bernardo do Campo, São & \\
Caetano do Sul, Diadema, Mauá, Ribeirão Pires, & \\
Rio Grande da Serra (1972 e 1973) & 184 a 272 \\
Santos (1974) & 187,6 \\
Fortaleza (1975) & 253 \\
Belo Horizonte & 223 \\
Estados Unidos (resíduo compactado) & 180 a 240 \\
Peru-Lima (resíduo compactado) & 500 \\
Singapura (1973) & 180 \\
Índia (1971 e 1973) & 330 a 560 \\
\hline
\end{tabular}

Fonte: OLIVEIRA (1992)

${ }^{2}$ AMORIM, V. P.; AGUIAR, M. I. O. (1979) As características Físicas e químicas do lixo do Distrito Federal. Limpeza Pública apud ANDRADE, J. B. L. (1997) Análise do Fluxo e das Caracteristicas, Fisicas, Químicas e Microbiológicas dos Resíduos de Serviço de Saúde: Proposta de Metodologia para o Gerenciamento em Unidades Hospitalares. São Carlos. 222p. Tese (Doutorado) - Escola de Engenharia de São Carlos, Universidade de São Paulo. 
Assim, de maneira geral, pode-se assumir que o peso específico dos resíduos sólidos urbanos varia de 200 a $500 \mathrm{~kg} / \mathrm{m}^{3}$.

- Teor de umidade

Representa a quantidade de água contida na massa do resíduo sólido. É um parâmetro de grande influência principalmente nos processos de tratamento e destinação final do resíduo sólido.

Segundo TCHOBANOGLOUS et al. (1993), sua determinação é feita mèdiante a colocação da amostra de resíduo para secagem em estufa, obtendo-se o téōí de umidade por meio do uso da fórmula:

$$
\text { Teor de umidade }(\%)=\left(\frac{a-b}{a}\right) * 100
$$

Onde, $\mathrm{a}=$ peso inicial da amostra quando retirada, $\mathrm{kg}$

$\mathrm{b}=$ peso da amostra após secagem, $\mathrm{kg}$

Nos sistemas que visam gerar ou recuperar energia a partir dos resíduos, o teor de umidade tem influênoia notável sobre o poder calorífico dos resíduos, assim como nos tratamentos por processos biológicos, nos quais a umidade atua na velocidade de decomposição dos materiais biodegradáveis presentes na massa de resíduo sólido.

O teor de umidade no resíduo sólido depende diretamente das condições climạ́ticas. No Brasil, o valor médio do teor de umidade do resíduo sólido domiciliar é da ordem de $60 \%$.

\section{- Produção per capita}

A quantidade de resíduo sólido produzido "per capita", está sujeita aos mesmos fatores que influem na variação da composição do resíduo sólido. A determinação da quantidade de resíduo sólido é um dos dados de grande importância no estudo do acondicionamento, coleta, transporte, tratamento e destino final.

O numero de trabalhos até então realizados para determinação da produção per capita de resíduos sólidos domésticos é reduzido. Os resultados obtidos têm sido adotados de maneira generalizada para todo o país e tomando-se por referência as maiores cidades brasileiras, obteve-se a produção média em $0,72 \mathrm{~kg} / \mathrm{hab}$.dia. Outros autores consideram a produção per capita média brasileira $0,50 \mathrm{~kg} / \mathrm{hab}$.dia. 
- Características químicas

As características químicas de maior interesse são principalmente as seguintes:

i) teores de carbono, nitrogênio, fósforo e potássio;

ii) teores de matéria combustível;

iii) $\mathrm{pH}$

A determinação das características químicas fornece elementos de importância para o estudo do tratamento e/ou disposição final do resíduo sólido, particularmente no caso do processo de transformação do resíduo sólido em composto. O composto atua mantendo a umidade do solo, mantendo o húmus da terra, melhorando ou conservando as condições de fertilidade do solo, além de recuperar solos agrícolas exauridos pela ação de fertilizantes aplicados indevidamente; contudo, é importante assinalar também, que o composto não é a rigor um adubo químico, pela pouca quantidade de elementos químicos que possui; atua principalmente como um condicionador do solo.

A relação carbono/nitrogênio $(\mathrm{C} / \mathrm{N})$, teor de umidade e o $\mathrm{pH}$ são importantes no controle da produção do composto, e também na sua aplicação. O teor de matéria combustível ou poder calorífico é de grande interesse no caso da incineração, visando o aproveitamento do potencial energético do resíduo sólido.

\section{- Características microbiológicas}

De acordo com MERCEDES \& PEREIRA NETO (1993), os resíduos orgânicos contém nutrientes protéicos e umidade, que associados à temperatura ambiente, favorecem o desenvolvimento microbiano de várias espécies; esta caracterização é importante para o estudo da população microbiana e dos agentes patogênicos presentes no resíduo sólido urbano.

Vários fatores influenciam o decaimento de populações microbianas no resíduo sólido. Um destes fatores é o processo térmico, que serve de fato para a descontaminação durante a degradação, quando este for utilizado em algum processo de tratamento. 


\subsection{Atividades associadas ao gerenciamento dos resíduos sólidos urbanos}

A evolução contínua que o mundo nos impõe, nas mais diversas atividades econômicas, é fundamentalmente notada no campo da limpeza pública, que pode ser definida de acordo com OLIVEIRA (1992) como:

"Um conjunto de atividades que permite o adequado estado de limpeza de uma cidade, sem prejudicar a qualidade do ambiente".

A preocupação dos poderes públicos se faz crescente na tentativa de encontrar a melhor solução pois, representa hoje, o equilíbrio de uma administração voltada para a saúde pública e a restauração do meio ambiente, pontos incontestáveis para o desenvolvimento urbano.

Segundo TCHOBANOGLOUS et al. (1993) os problemas associados com o gerenciamento de resíduos sólidos na sociedade de hoje são complexos por causa da quantidade e natureza diversa dos resíduos, do desenvolvimento de áreas urbanas, das limitações para os serviços públicos em muitas cidades, dos impactos da tecnologia, e das limitações emergindo em energia e matérias-primas. Como uma conseqüência, se o gerenciamento está sendo realizado de uma maneira eficiente e ordenada, os aspectos fundamentais devem ser identificados, ajustados e entendidos claramente.

Gerenciar os resíduos de forma integrada é articular ações normativas, operacionais, financeiras e de planejamento que uma administração municipal desenvolve, apoiada em critério sanitários, ambientais e econômicos, para coletar, tratar e dispor os resíduos de uma cidade, ou seja, acompanhar de forma criteriosa todo o ciclo dos resíduos, da geração à disposição final, empregando técnicas e tecnologias compatíveis com a realidade local.

Para PRANDINI et al. (1995), gerenciar os resíduos urbanos de forma integrada significa ter consciência de que todas as ações e operações envolvidas no gerenciamento estão interligadas, influenciando umas às outras:

- coleta mal planejada encarece o transporte;

- transporte mal dimensionado, além de gerar prejuízos e reclamações, prejudica as formas de tratamento e de disposição final; 
- tratamento mal dimensionado não atinge os objetivos; tornando-se alvo fácil de críticas.

De acordo com GALVEZ (1979) é função fundamental de todo Departamento de Limpeza pública a coleta, transporte e disposição final em forma sanitária, de maneira que não constitua perigo nenhum para a saúde pública.

Os métodos empregados devem evitar todo tipo de poluição mas, além disso, é preciso cuidar do aspecto estético da cidade.

A tabela 8 e a figura 2 sugerem ações obrigatórias e recomendáveis para o gerenciamento integrado de resíduos sólidos e a figura 3 operações a serem efetuadas na área de resíduos sólidos domiciliares.

TABELA 8 - Ações obrigatórias para o gerenciamento integrado de resíduos sólidos

\begin{tabular}{|c|c|c|}
\hline \multicolumn{2}{|c|}{ Serviço de Limpéża Pública } & Metas \\
\hline Limpeza & $\begin{array}{l}\text { Acondicionamento, } \\
\text { coleta e transporte }\end{array}$ & Coletar e transportar o resíduo sólido \\
\hline $\begin{array}{l}\text { Destinação } \\
\text { (disposição) }\end{array}$ & $\begin{array}{l}\text { Lixão ou aterro } \\
\text { controlado }\end{array}$ & $\begin{array}{l}\text { Remediar o lixão } \\
\text { Implantar aterro sanitário }\end{array}$ \\
\hline $\begin{array}{l}\text { final do resíduo } \\
\text { sólido }\end{array}$ & Aterro sanitário & $\begin{array}{l}\text { Assegurar que a operàção atenda padrões } \\
\text { técnicos e ambientaìs, o que inclúi a } \\
\text { reutilização da área no futuro }\end{array}$ \\
\hline
\end{tabular}

Fonte: Adaptada de JARDIM (1995) 


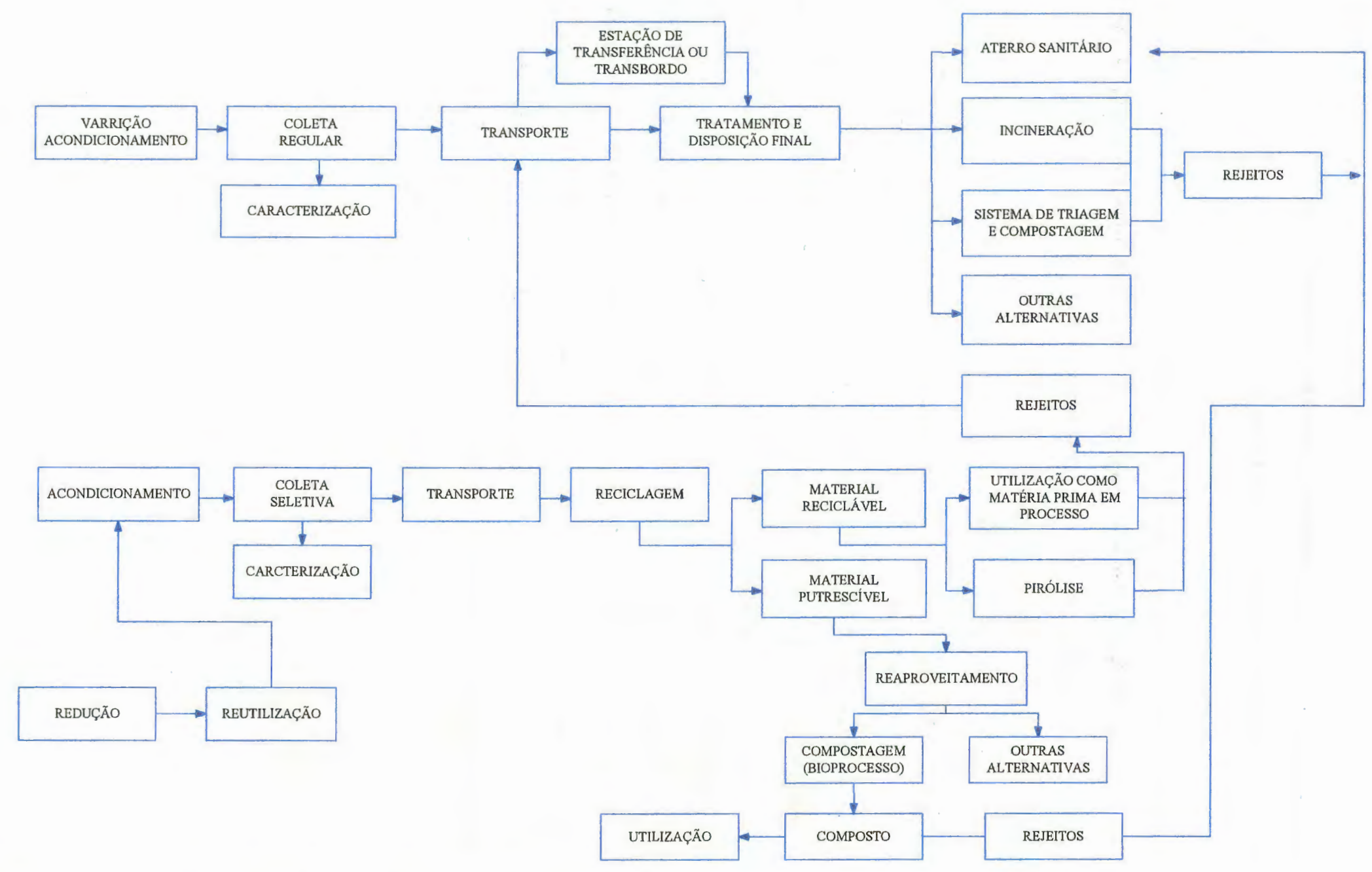

FIGURA 2 - Operações efetuadas na área de resíduos sólidos domiciliares Fonte: SCHALCH (1996) 


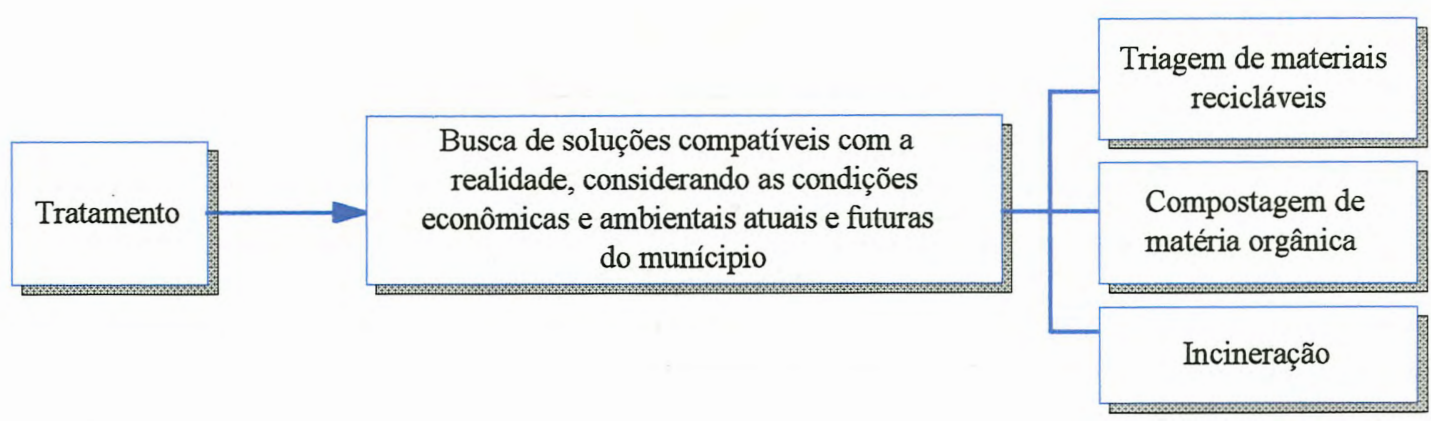

FIGURA 3 - Ações recomendáveis para o gerenciamento de resíduos sólidos Fonte: JARDIM (1995)

Alguns fatores responsáveis pela má operacionalização dos serviços, podem ser citados, tais como: deficiências administrativas, equipamentos inadequados, modelos gerenciais arcaicos e a falta de capacitação técnica do pessoal vinculado à limpeza pública. A inexistência de processo educacional que deve ser efetivado no corpo técnico responsável pelos serviços de limpeza, e mesmo na população beneficiada pelos serviços, é outro aspecto de suma importância para o sucesso da implantação de planos de gerenciamento dos resíduos sólidos.

Segundo TCHOBANOGLOUS et al. (1993), as atividades associadas com o gerenciamento de resíduos sólidos, desde o ponto de geração até a disposição final, são agrupados dentro de seis elementos funcionais: (1) Geração de resíduos sólidos; (2) Acondicionamento e processamento na fonte; (3) Coleta; (4) Separação, processamento e transformação (5) Transferência e transporte; (6) Disposição final; ilustradas na figura 4. 


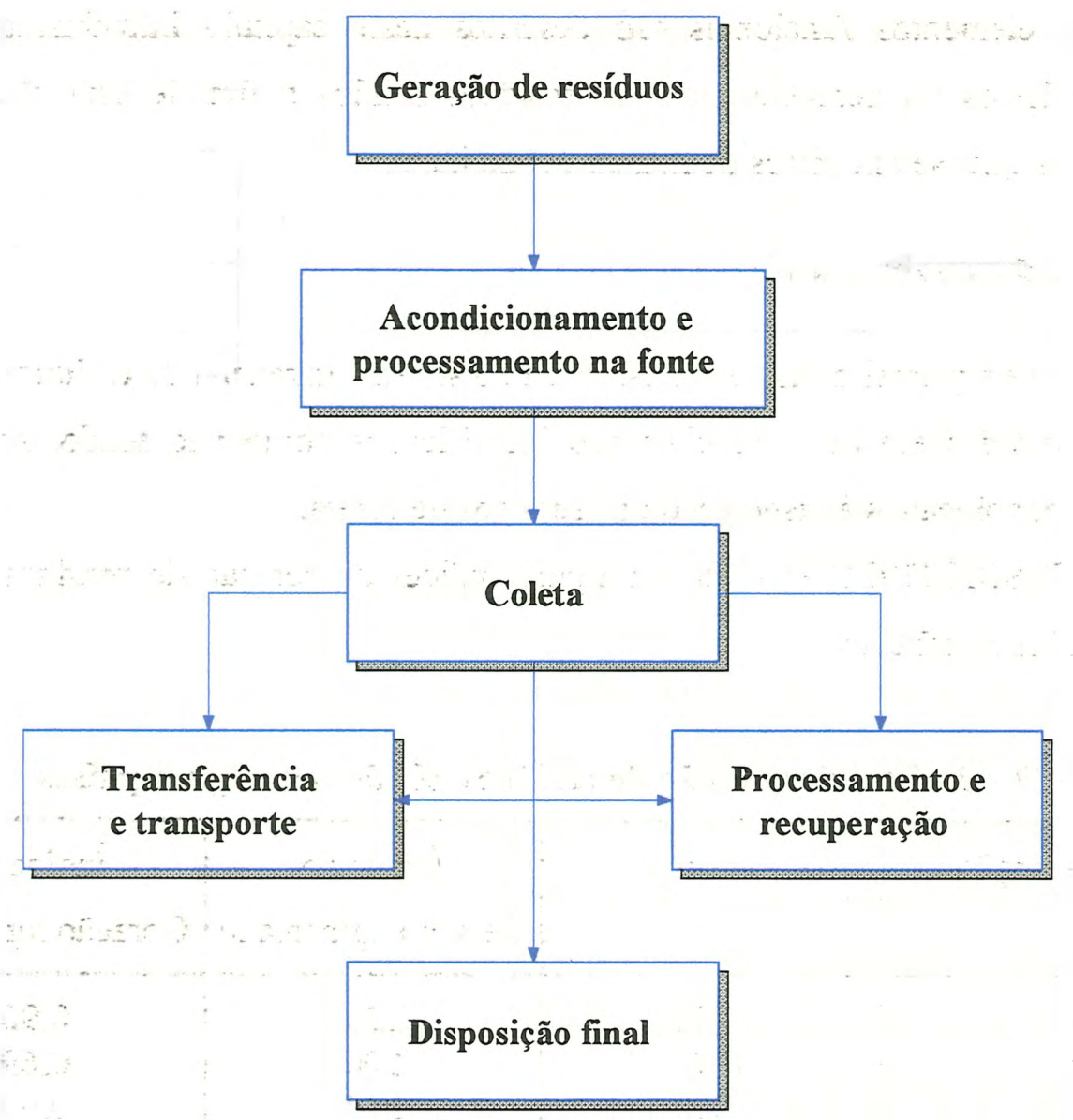

FIGURA 4 - Inter-relação entre os elementos funcionais do gerenciamento dos resíduos sólidos

Fonte: TCHOBANOGLOUS et al. (1993)

O gerenciamento dos resíduos sólidos está associado ao controle destes elementos gerenciais, de acordo com princípios de saúde pública, econômicos, de engenharia, de conservação, estéticos, e de proteção ao meio ambiente, sendo também responsável pelas atitudes públicas.

Considerando cada elemento funcional separadamente, é possível;

- identificar os aspectos fundamentais e suas inter-relações;

- desenvolver, quantificar relações para propor comparações técnicas, análise e avaliações.

A separação em elementos funcionais é importante porque permite o desenvolvimento de uma estrutura que facilita a avaliação de impactos de alterações propostas e futuros avanços tecnológicos. 
Os elementos funcionais são descritos neste capítulo introduzindo assim aspectos físicos do gerenciamento de resíduos sólidos a fim de estabelecer uma estrutura na qual sejam vistos de maneira combinada.

\subsubsection{Geração de resíduos}

Esta é a primeira fase a ser estudada no sistema gerencial de resíduos sólidos. Inclui atividades em que materiais são identificados como não tendo mais valor econômico, colocados à disposição dos serviços de coleta.

WILSON (1981) estabeleceu alguns índices de geração de resíduos sólidos, apresentados na tabela 9 .

TABELA 9 - Índices de geração de resíduos sólidos em alguns países

\begin{tabular}{l|c|c|c}
\hline \multicolumn{1}{c|}{ Localização } & Ano & $\begin{array}{c}\text { Índice de } \\
\text { Geração kg/hab.ano }\end{array}$ & $\begin{array}{c}\text { Índice de } \\
\text { Geração kg/hab.dia }\end{array}$ \\
\hline Bélgica & 1976 & 220 & 0,90 \\
Finlândia & 1978 & 200 & 0,69 \\
França & 1977 & 280 & 0,90 \\
Irã & 1978 & 210 & 0,67 \\
Itália & 1977 & 430 & 1,37 \\
Japão & 1974 & 350 & 1,12 \\
Holanda & 1978 & 450 & 1,44 \\
Suiça & 1977 & 330 & 1,05 \\
Inglaterra & 1967 & 350 & 1,12 \\
EUA & 1975 & 800 & 2,56 \\
Alemanha & 1977 & 250 & 0,80 \\
\hline
\end{tabular}

Fonte: Adaptada de WILSON (1981)

PEREIRA NETO \& MESQUITA (1994) descreveram três fatores básicos para a geração de resíduos urbanos: o crescimento populacional, associado ao aumento da geração "per capita" e o desenvolvimento industrial. Apresentaram ainda a evolução dos índices de geração dos resíduos sólidos urbanos em algumas localidades, conforme a tabela 10 . 
TABELA 10 - Evolução do índice de geração de resíduos sólidos urbanos em algumas localidades (kg/hab.dia)

\begin{tabular}{c|c|c|c}
\hline Localidade & \multicolumn{3}{|c}{ Ano } \\
& 1975 & 1985 & 1990 \\
\hline Nova York* & 0,80 & 1,50 & - \\
Lisboa & & 0,76 & 0,79 \\
Londres & 0,60 & 0,85 & - \\
Madrid & - & - & 1,00 \\
Atenas & - & - & 1,00 \\
Lima & 0,45 & 0,60 & - \\
Quito & 0,40 & 0,65 & - \\
São Paulo & 0,50 & 0,80 & - \\
\hline
\end{tabular}

*Existem áreas em Nova York em que a produção chega a $3 \mathrm{~kg} / \mathrm{hab}$.dia

Fonte: Adaptada de PEREIRA NETO \& MESQUTTA (1994)

A Pesquisa Nacional de Saneamento Básico - PNSB, 1989, realizada pelo Instituto Brasileiro de Geografia e Estatística - IBGE, editada em 1991, mostrou o crescimento populacional, bem como o aumento do grau de urbanização que não foi acompanhado de medidas necessárias para dar aos resíduos gerados por esta população um destino adequado. São 241.614 toneladas de resíduo sólido produzido diariamente no país, incluindo os vários tipos de resíduos. A tabela 11 apresenta dados referentes à produção de resíduo sólido no Brasil por tipo de resíduo e a tabela 12 a quantidade de resíduos sólidos (residenciais e comerciais) gerados em diferentes países.

TABELA 11 - Produção diária de resíduos sólidos no Brasil

\begin{tabular}{l|c}
\hline Tipo de Resíduo & t/dia \\
\hline Resíduos Domiciliares & 96.000 \\
Resíduos Industriais & $32.055,42$ \\
Resíduos Comerciais & $21.745,26$ \\
Inerte & $91.813,32$ \\
Total & $241.614,00$ \\
\hline
\end{tabular}

Fonte: MENDONÇA (1997) 
TABELA 12 - Quantidade de resíduos sólidos (residenciais e comerciais) gerados em diferentes países

\begin{tabular}{l|c}
\hline Localidade & Quantidade \\
\hline Reino Unido & 20 milhões de $t / a n o$ \\
Alemanha Ocidental & 20 milhões de $t / a n o$ \\
França & 12,5 milhões de $t / a n o$ \\
Japão & 85 milhões de $t / a n o$ \\
Estados Unidos & 150 milhões de $t$ /ano \\
\hline
\end{tabular}

Fonte: WILSON (1981)

LIMA (1991) citou alguns fatores que influenciam a origem e formação dos resíduos sólidos:

- número de habitantes do local;

- área relativa de produção;

- variações sazonais;

- condições climáticas;

- hábitos e costumes da população;

- nível educacional;

- poder aquisitivo;

- tempo de coleta;

- eficiência da coleta;

- tipo de equipamento de coleta;

- disciplina e controle dos pontos produtores;

- leis e regulamentações específicas.

LIMA (1991) destacou a importância da componente econômica, pois, quando ocorrem variações na economia de um sistema, seus reflexos são percebidos nos locais de disposição e tratamento dos resíduos. As migrações periódicas nas férias de verão e inverno, também são responsáveis pelas variações na quantidade e qualidade do lixo. Nestes períodos, com a paralisação das atividades escolares, ocorrem mudanças na rotina dos estabelecimentos comerciais e industriais, principalmente de cidades potencialmente turísticas, o que obriga as autoridades competentes a reforçarem o sistema de coleta. 
De acordo com GODOI (1997), a quantidade de resíduos sólidos gerados tem importância - fundamental para os aspectos que envolvem seu gerenciamento. A geração e a coleta constituem a condição básica para a determinação dos diversos programas de minimização dos resíduos, além de fornecerem subsídios para:

- dimensionamento da frota;

- definição dos roteiros de coleta;

- as únidades̀ de rècuperação de material e as de disposição final.

TCHOBANOGLOUS et al. (1993) descreveram métodos normalmente utilizados para avaliar a quantidade de resíduos:

- análise do número de descargas: neste método, são registrados o número de descargas feitas pelo coletor, a rota percorrida, o tipo de resíduo coletado e o volume aproximado num período pré-determinado;

- análise de peso e volume: é realizada através de registros de um sistema de pesagem, em que são cadastrados os pesos dos caminhões de coleta, as características básicas dos coletores, o volume interno e o peso bruto dos caminhões, além da origem de cada um. Esse sistema traz valores médios interessantes, quie devem ser analisados em função do objetivo a que se destina;

- análise estatística da quantidade de resíduos: é o método mais preciso, em que é realizado o balanço de massa dos materiais em cada fonte geradora, possibilitando um bom conhecimento de todos os componentes, método importante para o dimensionamento dos programas de minimização de resíduos e para a coleta seletiva.

TCHOBANOGLOUS et al. (1993) indicaram alguns fatores que podem influenciar a taxa de geração de resíduos sólidos:

- redução na fonte e atividades de reciclagem;

- atitudes públicas e legislação;

- atores físicos e geográficos.

\subsubsection{Separação, acondicionamento e processamento na fonte}

Estes elementos gerenciais constituem a primeira etapa do processo de remoção dos resíduos sólidos, nos quais a forma de acondicionar ou mesmo 
processar é determinada pela quantidade, composição e tipo de coleta. Podem ter um efeito significativo nas características dos resíduos, nos elementos funcionais subseqüentes, na saúde pública, em atitudes públicas relativas a operação do sistema de gerenciamento de resíduos.

RUBBO (1978) destacou um fato histórico referente ao acondicionamento de resíduos. De acordo com o autor, a primeira exigência legal determinando o uso de recipiente metálico, data de 7 de março de 1884, foi promulgada pelo prefeito de Paris, M. Poubelle, nome pelo qual ficaram sendo chamados, até hoje, os recipientes na França. Esta exigência só foi regulamentada em 23 de setembro de 1926.

De uma maneira geral os recipientes utilizados são estanques, resistentes e compatíveis com os equipamento de coleta; a tabela 13 apresenta formas de acondicionamento, sendo a escolha feita de acordo com o tipo de resíduo.

TABELA 13 - Formas de acondicionamento

\begin{tabular}{|c|c|c|c|}
\hline Formas de Acondicionamento & \multicolumn{3}{|c|}{ Tipos de Recipientes } \\
\hline Pequenos Volumes & \multicolumn{3}{|c|}{$\begin{array}{l}\text { Cestos coletores de calçada } \\
\text { Recipientes basculantes } \\
\text { Recipientes basculantes em carrinhos } \\
\text { Tambores } \\
\text { Sacos plásticos }\end{array}$} \\
\hline \multirow[t]{2}{*}{ Grandes Volumes } & \multirow[t]{2}{*}{$\begin{array}{l}\text { Containers } \\
\text { Coletores }\end{array}$} & \multicolumn{2}{|c|}{ Basculável estacionário } \\
\hline & & Intercambiável & $\begin{array}{l}\text { Caixa Brooks } \\
\text { Caixa Dempster } \\
\text { Caçamba Coletora }\end{array}$ \\
\hline
\end{tabular}

Fonte: JARDIM (1995)

Para o serviço de coleta domiciliar, a utilização de sacos plásticos no acondicionamento dos resíduos apresentam algumas vantagens, tais como:

- requer menor esforço dos coletores;

- reduz tempo de coleta;

- impede absorção de água de chuva;

- diminui a poluição sonora. 
Os sacos plásticos são, na maioria das cidades brasileiras,-os mais utilizados. A Associação Brasilêira de Normas Técnicas - ABNT, através da NBR 9190 (1985) apresenta a classificação dos sacos plásticos para o acondicionamento dos:resíduos quanto a finalidade, espécie, capacidade e tonalidade e dispõe sobre as especificações de sacos plásticos para o acondicionamento de resíduos sólidos na NBR 9191 (1992).

Os containers também são utilizados para armazenar os resíduos de conjuntos prediais, supermercados, feiras livres, escolas; etc.

Na Dinamarca, relata CANASSA (1992), os sacos de papel grosso resistentes a umidade são muito utilizados para o acondicionamento dos resíduos sólidos domiciliares. Esse tipo de embalagem permite a evaporação da umidade, o que não acontece com os sacos plásticos. Assim é possível a redução do peso dos resíduos, como também o aumento da vida útil dos equipamentos de coleta, transporte e processamento destes resíduos.

Em alguns países como Canadá, Estados Unidos e Europa, os resíduos acondicionados ainda são depositados em pequenos abrigos fechados, com ventilaçã̀o e drenagem, agrupando assim os detritos de um conjunto de casas, blocos residenciais ou quarteirão. Em alguns casos um recipiente de grandes dimensões, que constitui uma caçamba móvel de um caminhão atende conjuntos prediais, residenciais ou mesmo centros comerciais.

A REVISTA LIMPEZA PÚBLICA (1997) apresentou um anuncio da empresa alemã PIONNER PLASTICS, que implantou no Brasil a $1^{a}$ indústria de contêineres plásticos da América Latina. Estes já estão sendo utilizados em grandes cidades como Rio de Janeiro e São Paulo. Algumas vantagens do sistema de acondicionamento da PIONNER PLASTICS são citadas a seguir:

- alta durabilidade;

- os containers fecham hermeticamente;

- o resíduo fica protegido e não se espalha com a ação de animais ou com a chuva;

- o mau cheiro não se propaga;

- a coleta é mecanizada pela adaptação de elevadores nos caminhões. 
TCHOBANOGLOUS et al (1993) enfatizaram a importância do acondicionamento num sistema de manejo de resíduos sólidos domiciliares. Os principais fatores a serem considerados no acondicionamento foram: os efeitos nos componentes dos resíduos com armazenamento; o tipo de recipiente ou embalagem utilizado; a localização do estoque; e os aspectos de salubridade e estética envolvidos.

De acordo com SCHALCH (1995), a forma de acondicionamento de resíduos pode variar em função de alguns fatores:

- características dos resíduos;

- quantidade;

- localização do domicílio;

- horário e freqüência da coleta.

\subsubsection{Coleta}

\section{a) Aspectos gerais}

Os resíduos; após o seu acondicionamento, são depositados em locais apropriados ou nas vias públicas para serem posteriormente coletados.

A operação unitária da coleta consiste em remover os resíduos dos locais onde foram acondicionados. Pórtanto, esta operação engloba desde a partida do veículo da garagem e inclui todo o percurso gasto na viagem.

A REVISTA BIO (1997) publicou os últimos levantamentos do IBGE (1995), 28 milhões dos 38,9 milhões de domicílios têm seus resíduos sólidos coletados, dos quais 27,2 milhões estão na região urbana e apenas 778 mil na área rural. Esses números, considerados otimistas por alguns técnicos, indicam que $71,9 \%$ das residências tem o serviço de coleta de resíduos. Do total de domicílios existentes, cerca de 10,9 milhões têm outro tipo de destino para os resíduos, sendo 4 milhões na área urbana e 6,7 milhões na área rural.

YOSHIMURA (1990) relatou que os resíduos sólidos brasileiros se deterioram muito rápido devido ao seu grau de umidade $e$, principalmente porque em geral o clima é quente. Mesmo nos municípios em que existem varrição e coleta mais ou menos regular, mas a destinação não é adequada, surgem problemas que afetam diretamente a saúde pública, tais como: assoreamento de rios e canais, porque ali se 
despejam os resíduos; ocasionando ainda poluição das águas; contaminação dos lençóis de água que abastecem os poços domésticos; poluição atmosférica provocada pela emissão de gases e odor provenientes dos.lixões; aumento do número de insetos e roedores que transmitem doenças; presença inoportuna de pessoas em busca de materiais recicláveis.

A gravidade desses problemas é de ordem econômica e social, que desembocam na saúde pública levando assim a maioria das prefeituras a considerar mais a questão da coleta dos resíduos sólidos.

Quanto aos aspectos institucionais de acordo com CUNHA et al. (1995) é importante distinguir que a realização da coleta dos resíduos sólidos urbanos é incumbência da municipalidade. Consiste na prestação de serviço essencial que não se apresenta como um serviço facultativo, e sim como um dever da administração.

Nas cidades médias e pequenas prevalece a administração direta. Nas cidades grandes existe a tendência de se criarem entidades autônomas, empresas públicas, autarquias ou sociedades de economia mista que possuem um sistema administrativo independente da burocracia municipal, objetivando uma maior agilidade e autonomia operacional e administrativa. Porém, ainda que as atividades administrativas, de formulação e políticas e de planificação estejam sob a responsabilidade do município, observa-se na parte operacional, uma crescente concessão dos serviços a empresas privada.

Existe uma grande diversidade de serviços relativos à limpeza urbana, cada um com suas peculiaridades operacionais e de medição. PENIDO \& MANSUR (1997) apresentaram alguns dos pontos que devem ser permanentemente controlados/fiscalizados, devendo a Prefeitura estabelecer suas prioridades em função das atuais necessidades, tais como:

- peso do resíduo sólido coletado por setor;

- distribuição e verificação dos serviços por horários e freqüência;

- otimização do trajeto e horários de transferências visando a minimização dos problemas de trânsito;

- quantitativo e tipo dos veículos e equipamentos envolvidos;

- condição da frota utilizada (idade e estado geral); 
- condições de estanqueidade dos veículos quanto ao chorume armazenado nas bacias de carga;

- condições de segurança no transporte dos coletores (garis) no caminhão de coleta;

- adequação da frota aos padrões de emissão de fumaça negra e de ruídos;

- produtividade da frota coletora;

- padrão de qualidade dos serviços;

- controle de absenteísmo;

- condições de trabalho dos empregados (higiene e segurança do trabalho);

- quantidade e capacitação profissional do pessoal empregado;

- aferição do volume de serviços extraordinários/emergenciais;

- quilometragem produtiva e improdutiva da frota coletora;

- consumo de combustíveis/lubrificantes;

- manutenção dos veículos e equipamentos (sistemáticas e custős);

- estado de conservação/limpeza da frota;

- vida útil de pneus e câmaras;

- uniformes e equipamentos de proteção individual-EPI's;

- ponto de retirada de containers;

- pontos críticos (locais de lançamento freqüente de resíduos pela população).

b) Tipos de coleta

CANASSA (1992) cita que a operação de coleta de resíduos sólidos dividese em dois tipos:

\section{- Sistema convencional de coleta}

Este tipo está associado à coleta de resíduos sólidos domiciliares, comerciais, de limpeza das vias públicas, etc. Em função do tipo de acondicionamento feito, pode-se utilizar de dois processos:

i) Coleta ao longo das vias públicas

Neste tipo de coleta o veículo coletor percorre todas as ruas, onde os resíduos são dispostos, normalmente em pequenos recipientes. Este processo é realizado observando-se a freqüência necessária, o período do dia mais adequado, além de outros parâmetros. 
ii) Coleta em pontos previamente determinados

Para coleta de grande volumes de resíduos acondicionados em containers (feiras; supermercados, escolas; etc.) emprega-se a coleta em pontos- previamente determinados. Neste caso, o veículo coleta os resíduos armazenados em determinados pontos específicos, os quais, poderão ser basculados por um veículo para descarga ou removidos, dependendo de suas características.

A coleta aó longo das vias públicas é o processo mais utilizado para se coletar a maioria dos resíduos sólidos urbanos. Alguns países desenvolvidos se utilizam da coleta em pontos previamente determinados para realizar a coleta dos resíduos sólidos domiciliares.

\section{- Sistema especial de coleta}

Todos os resíduos contaminados, a exemplo dos resíduos de serviço de saúde, radioativos, etc.; são coletados por este sistema. Neste caso os resíduos são acondicionados em recipientes específicos e coletados de forma separada de outros tipos de resíduos sólidos urbanos e por veículos utilizados somente para este tipo de atividade: $\mathbf{O}$ processo utilizado é semelhante ao da coleta de containers, isto é, o sistema que coleta em locais específicos.

\subsubsection{Coleta domiciliar}

\section{a) Histórico}

Quando se formava uma cidade, a parte de limpeza pública geralmente era deixada por conta dos moradores. Eram grandes terrenos, bastante espaço, e o resíduo sólido domiciliar geralmente era disposto no quintal servindo de adubo a uma horta, ou de pasto às criações domésticas.

A cidade continuava crescendo, formava-se um núcleo central, um "cinturãoverde", de chácaras e granjas, para abastecimento da população. Então os chacareiros começaram a retirar o resíduo sólido das casas, por seus próprios meios, geralmente uma carrocinha. Mas o desenvolvimento continuado da cidade tornou inexeqüível essa solução. Não havia mais chacareiros suficientes para retirar todo o resíduo sólido produzido, pois os mesmos passavam a se especializar, preferindo atender a hotéis, pensões e restaurantes. 
A REVISTA LIMPEZA.PÚBLICA.(1977.) apresentou um artigo que enumera alguns fatos que marcaram o desenvolvimento dos-serviços de limpeza pública no Brasil, exemplificando particularmente a cidade de São Paulo, que sofreu um dos crescimentos urbanos mais acelerados do mundo, o que exigiu investimentos no setor de limpeza pública, podendo assim ser tomada como um exemplo histórico.

São Paulo atingiu esse estágio em 1869, quando era uma cidade provinciana, mas já tendo superado a marca dos 30.000 habitantes. Mesmo sem uma infraestrutura, a Câmara Municipal teve como prioridade a ser atendida a coleta de resíduo sólido domiciliar, e decidiu assim pela contratação de um particular que teria como estímulo a possibilidade de lucro.

Iniciou-se então oficialmente o serviço de limpeza pública em São Paulo, a 16 de julho de 1869. O sistema implantado floresceu, já no início da república, quando os contratos tinham se tornado rotineiros, e a cidade era administrada por Intendentes, antecessores dos prefeitos, já aparecera a necessidade de concorrência pública para a contratação, e já fora instituída a taxa de resíduo sólido.

Em 03 de outubro de 1914 foi promulgado o Ato $n^{\circ} 721$, organizando o serviço de limpezá pública a ser operado diretamente pela Municipalidade. Objetivando implantar e estruturar tudo o que era estabelecido pelo Ato $\mathrm{n}^{\circ} 721$, em 1918, São Paulo teve o primeiro Diretor de Limpeza Pública.

$\mathrm{O}$ Ato $\mathrm{n}^{\circ} 721$ não foi apenas a origem, mas praticamente a única legislação pertinente, de forma global, à questão da limpeza pública, pois só veio a ser revogado pela Lei $\mathrm{n}^{\circ} 7775$, de 13 de setembro de 1972. Esteve portanto, durante 58 anos regendo a vida do município, no que refere a limpeza pública.

O sistema inicial adotado previa a coleta e a destinação final dos resíduos sólidos, a varrição das ruas, a lavagem e desinfestação, a capina, a limpeza de bueiros e galerias, enfim, qualquer coisa que se relacionasse a limpeza da cidade. Os meios disponíveis eram os da época, ou seja, equipamentos de tração animal.

Em 1940, quando esse tipo de tração atingiu o seu apogeu, contava a prefeitura com cerca de 1500 animais, e toda uma estrutura de apoio para os mesmos, com veterinários, tratadores, cavalariços, uma selaria para confecção e reparos nos arreios, cocheiras, pastos. A coleta utilizando a tração animal foi realizada até 1968 , nesta época a indústria nacional já estava capacitada a fornecer até veículos com 
caçambas compactadoras. Umas das primeiras caçambas a ser adotada-com sucesso foi do tipo triturador, de patente alemã.

O pioneirismo da concessão de serviços no -Brasil coube à Prefeitura do Município de São Paulo, em 1969, quando contratou empresas privadas para os serviços de coleta domiciliar, nas áreas da Vila Prudente é Brooklin.

SILVESTRE JUNIOR (1978) relata que o sucesso desses serviços está intimamente ligado aos atos preliminares para a sua concessão. A esse respeito, em 1966, na reunião anual do "Institute for Solid Wastes", órgão da "American Public Works Association" foi destacada uma sessão sobre coleta de resíduos, e chegou-se a conclusão que: com um edital e um contrato preparado criteriosamente, é possível servir melhor à população utilizando serviços terceirizados.

Aspectos históricos da evolução dos tipos de veículos utilizados para coleta de resíduos sólidos são mostrados na tabela 14.

TABELA 14 - Évolução dos equipamentos utilizados para coleta de resíduos sólidos

\begin{tabular}{l|l}
\hline Ano & Tipo de veículo utilizado \\
\hline 1900 & Veículo de tração animal \\
\hline Aproximadamente em 1925 & Caminhão motorizado \\
\hline 1935 & $\begin{array}{l}\text { Surge em Paris o primeiro carro coletor } \\
\text { compactador }\end{array}$ \\
\hline 1968 & $\begin{array}{l}\text { Veículo com caçambas compactadoras } \\
\text { começaram a ser utilizados no Brasil }\end{array}$ \\
\hline em 1998 & $\begin{array}{l}\text { Veículo de coleta equipado com } \\
\text { mecanismo de descarga para recipientes } \\
\text { de armazenagem de resíduos (containers). }\end{array}$ \\
\hline
\end{tabular}

Fonte: Adaptada da Revista Limpeza Pública (1977)

b) Definição

A ABNT, através da NBR 12980/93, define: coleta regular dos resíduos domiciliares, formados por resíduos gerados em residências, estabelecimentos 
comerciais, industriais, públicos e de prestação de serviços, cujos volumes e características sejam compatíveis com a legislação municipal vigente.

\section{c) Objetivos da coleta domiciliar}

De acordo com CANASSA (1992) a operação de coleta visa recolher todos os resíduos sólidos gerados pela comunidade, de forma organizada, segura e econômica e, depositá-los em locais de tratamento, ou em estações de transbordo, ou encaminhá-los para a disposição final. Desta maneira os aspectos estético, de saúde pública e de conforto das vias públicas são mantidos ou melhorados evitando a proliferação de vetores, riscos de acidentes e poluição do meio ambiente.

d) Equipamentos de coleta e transporte

Os veículos coletores podem ser divididos em dois tipos: motorizados e não motorizados.

Os veículos não motorizados são os que utilizam a tração animal como força motriz. Estes são utilizados em algumas cidades do interior do país, ou ainda para coleta de resíduos em locais de difícil acesso aos veículos motorizados, a exemplo de algumas favelas do Rio de Janeiro.

Os motorizados, por sua vez, podem ser divididos em compactadores e comuns. Os comuns, por sua vez, podem ser subdividos em tratóres, coletor de caçamba aberta e coletor com carrocerias tipo baú ou prefeitura. De acordo com QUERZOLI (1988) os equipamentos compactadores podem ter sistemas de carga descontínua (os mais comuns) ou contínua. Nos primeiros é preciso parar o sistema de coleta quando o compactador entra em funcionamento, enquanto nos de carga contínua podem ser realizadas as operações de coleta e compactação conjuntamente.

Um sistema de coleta de resíduos sólidos deve ser dimensionado de acordo com a peculiaridade do serviço a ser realizado (tamanho e características da comunidade). Conforme MANSUR (1987), não há sentido em se ter um caminhão compactador em locais de baixa concentração de resíduos quando, muitas vezes, um caminhão comum poderia tranqüilamente resolver o problema, com manutenção muito mais simples e com um investimento bem menor.

Técnicos da área, observam que, para atender cidades com pequena população, os veículos coletores comuns são os mais indicados e, para as cidades maiores, os compactadores. 
Ao adquirir os equipamentos necessários, afirma YOSHEMURA (1990), é fundamental compatibilizá-los com o porte do município. Para isso propõe a seguinte classificação:

- mais de 300.000 habitantes - grande porte;

- de 50.000 a 300.000 habitantes - médio porte;

- até 50.000 habitantes - pequeno porte.

$\mathrm{O}$ autor propõe que em municípios pequenos sejam utilizados dois ou três caminhões coletores compactadores, desde que adequadamente operados e mantidos, cada um deles trabalhando com uma equipe composta por um motorista e três ou quatro catadores (garis). Quanto a escolha dos equipamentos, comenta que após terem sido definidas as necessidades do município, resta escolher no mercado os equipamentos mais adequados e que proporcionem a melhor relação custo-beneficio.

Conforme os Técnicos da CETESB - Companhia de Tecnologia de Saneamento:Ambiental é de máximo interesse analisar as vantagens e desvantagens da escolha dos veículos coletores e as dimensões dos serviços, que variam de acordo com o tamanho, característica e condições das comunidades enfocando aspectos sanitários, econômicos, estéticos e de segurança.

e) Freqüência e horário da coleta

A frequêencia da coleta domiciliar define o tempo decorrido entre duas coletas consecutivas num mesmo local, podendo ser diária exceto aos domingos e feriados ou alternada com folga aos domingos.

Em geral a restrição econômica é um dos fatores determinantes da freqüência da coleta domiciliar.: Quanto maior a freqüência, maior o custo total do serviço.

Há também a preocupação em evitar o acúmulo de resíduos, fator este que influi também na definição da freqüência.

A coleta domiciliar pode ser realizada tanto no período diurno, quanto no período noturno. A programação da coleta em período noturno depende de diversos fatores, entre os quais, o porte a as características de cada município.

Alguns aspectos favoráveis e desfavoráveis da coleta noturna são apresentados a seguir: 


\section{$\Rightarrow$ Aspectos forvoróveis}

- Causa menor interferência em áreas de circulação mais intensa de veículos e pedestres, tais como, avenidas, ruas comerciais, vias de principal acesso, vias com faixa exclusiva de ônibus ou corredores exclusivos.

- Permite maior produtividade dos veículos de coleta; através de maior velocidade média, em decorrência do tráfego em geral.

- Significa uma diminuição da frota de veículos coletores, em decorrência do melhor aproveitamento dos veículos disponíveis, proporcionada pelos turnos.

\section{$\Rightarrow$ Aspectos desfavoráveis}

- O ruído produzido em período noturno, em especial pelo manuseio de recipiente e pela compactação do resíduo.

- Trajeto por vias estreitas, não pavimentadas ou com muito buracos, podendo aumentar o risco de danos e acidentes com os veículos.

- Percurso ao longo de vias mal iluminadas contribuindo para o aumento do risco de acidentes com os coletores (garis), bem como prejuízo na visibilidade da coleta gerando, eventualmente, maior grau de absenteísmo e de rotatividade de mão de obra.

- O uso em dois turnos eleva o desgaste dos veículos e diminui a disponibilidade para manutenção preventiva, podendo acarretar redução da vida útil dos mesmos.

A participação da população é essencial para uma coletä bem sucedida. É fundamental que os dias e horários de coleta, definidos e informados; sejam cumpridos, criando hábitos regulares na população. Medidas educativas, estimulando a participação da população, com intuito de assegurar que o resíduo seja depositado na via pública em dia e horário próximo ao da coleta, evitando sua acumulação indevida.

PAIVA JUNIOR \& GUIMARÃES (1995), em estudos realizados no município de Natal-RN, observaram que apesar da regularidade da coleta domiciliar e do seu alcance, a população continuava jogando resíduos em terrenos baldios, canteiros e praças pública, ao invés de armazená-lo devidamente até a coleta. As 
operações de paleação (retirada manual) e de remoção especial (retirada com auxílio de pá mecânica) eram constantes e faziam parte, inclusive, dos serviços de rotina da empresa responsável pela execução dos serviços de coleta, que no caso é terceirizada.

A situação apresentada por PAIVA JUNIOR \& GUIMARÃES (1995) indica a falta de participação da população, de uma maneira geral, no processo de limpeza, devido a fatores que devem ser bem analisados como, por exemplo, a falta de um amplo programa de educação ambiental que permita uma perfeita integração da comunidade com o processo de limpeza pública.

\section{f) Dimensionamento da frota dos serviços de coleta}

O dimensionamento dos serviços de coleta domiciliar tem como objetivo determinar o número de veículos necessários aos serviços de coleta, bom como os demais elementos que possibilitem o estabelecimento de itinerários.

CUNHA et al. (1995) descreveu as etapas que abrangem o dimensionamento e a programação dos serviços de coleta domiciliar, citadas a seguir:

- Levantamento e coleta de dados: mapas da cidade, veículos disponíveis da frota e respectivas capacidades quando não se tratar de dimensionamento de um novo serviço.

- Localização de pontos importantes para a coleta: garagem de veículo, pontos de descarga, grandes centros geradores de resíduos.

- Determinação do volume e peso específico do resíduo a ser coletado

- Definição dos setores de coleta: regiões homogêneas em termos de geração de resíduo sólido per capita e de uso e ocupação do solo.

- Estimativa e quantidade total de resíduo por setor: em termos de peso e volume; adicionalmente é necessário estimar o número de habitantes de cada setor a partir do número de edificações existentes.

- Estimativa dos parâmetros operacionais: distância da garagem ao setor de coleta, distância setor de coleta/destino final, extensão total das vias a serem percorridas, velocidade média de coleta, velocidade média garagem/setor de coleta/destino final

- Dimensionamento dá frota para cada setor:

A frota pode ser estimada a partir da seguinte fórmula: 


$$
N s=(1 / D) x\{(\mathrm{~L} / \mathrm{Vc})+2 \times(D g / V t)+2 \times[(D d / V t) \times(1 / J) \times(Q / C)]\}
$$

onde:

Ns - frota necessária para coletar em cada setor

J - duração útil da jornada de trabalho da guarnição (em número de horas), desde a saída da garagem até o seu retorno, excluindo tempos improdutivos.

L - extensão total das vias (ruas e avenidas), em km;

Vc - velocidade média da coleta, em $\mathrm{km} / \mathrm{h}$;

Dg - distância entre a garagem e o setor de coleta, em km;

Dd - distância entre o setor de coleta e o ponto de descarga, em km;

Vt - velocidade média no percurso de posicionamento e transferência, em $\mathrm{km} / \mathrm{h}$;

Q - quantidade total de resíduo ser coletada no setor, em $\mathrm{t}$ ou $\mathrm{em}^{3}$;

C - capacidade dos veículos de coleta, em t ou em $\mathrm{m}^{3}$; em geral, adota-se um valor que corresponde a $70 \%$ da capacidade nominal, considerando-se a variabilidade da quantidade a ser coletada.

AGUIAR (1993), apresentou um procedimento matemático que possibilita estimar o tamanho de uma frota de veículos e equipes de trabalho, para coleta e o transportes de resíduos sólidos domiciliares. Este modelo permitiu avaliar custos, bem como a influência de um ou mais parâmetros sobre eles, a medida que simula variações ou alterações no esquema operacional. As variações referem-se a características da cidade tais como forma geométrica, densidade populacional, taxa de geração e composição dos resíduos, distância média entre a cidade e o local de disposição. Alterações dizem respeito à tecnologia utilizada na coleta, periodicidade e velocidade de coleta, localização e viabilidade de implantação de estações de transferência, coleta seletiva e localização da garagem. Para o cálculo do número de veículos de coleta e transporte e da equipe de coleta foram utilizadas as seguintes equações:

- Cálculo do Número de viagens: $\boldsymbol{n}_{\boldsymbol{v}}$

$n_{v}=T_{c t} / t c$

onde:

Tct $=$ tempo diário de operação por veículos de coleta $-\mathrm{h} /$ veículo.dia

tc $=$ tempo de ciclo de veículos de coleta - hora 
- Cálculo do número de veículos de coleta diária $-\mathrm{N}_{\mathrm{vc}}$

$N_{v c}=n_{a} /\left(n_{v} f\right)$

onde:

$\mathrm{n}_{\mathrm{a}}=$ número de áreas de coleta

$\mathrm{n}_{\mathrm{v}}=$ número de viagens diárias - viagem/veículo.dia

$\mathrm{f}=$ intervalo entre as coletas - dia

- Cálculo do número de viagens diárias para coleta de resíduos sólidos seco: $\boldsymbol{n}_{\mathrm{vls}}$

$n_{v l s}=T_{c t s} / t_{c l s}$

onde:

$T_{\text {ctls }}=$ tempo diário de operação por veículo de coleta de resíduos sólidos seco - hora/veículo:dia

$\mathrm{t}_{\mathrm{c} \text { ls }}=$ tempo de ciclo de veículos de coleta de resíduo sólido - seco

- Cálculo do número de veículos para coleta de resíduo sólido seco:

$N_{v c l s}=n_{a l s} /\left(n_{v l s} f_{l s}\right)$

Onde:

$\mathrm{n}_{\text {als }}=$ número de áreas de coleta de resíduo sólido seco - adimensional

$\mathrm{n}_{\mathrm{vls}}=$ número de viagens diárias para coleta de resíduos sólido secoviagem/veículo.dia

$\mathrm{f}_{\mathrm{ls}}=$ intervalo entre coletas de resíduo seco - dia

- Cálculo do número de motoristas: $\boldsymbol{N}_{t m}$

$N_{t m}=f_{r m}(N v c+N c a+N v c l s)$

Onde:

$f_{\mathrm{rm}}=$ fator de majoração - reservas de motoristas

$\mathrm{N}_{\mathrm{vc}}=$ Número de veículos de coleta - veículo

$\mathrm{N}_{\mathrm{ca}}$ = Número de carretas para transporte entre o acesso à rodovia e o local de descarga - ve

$\mathrm{N}_{\mathrm{vcls}}=$ Número de veículos de coleta de resíduo sólido seco - veículo

- Cálculo do número de garis: Ntg

$N$ tg $=F_{r g}(N v c n g+N v c l s n g l s)$

Onde:

$F_{r g}=$ Fator de majöração - reserva de garis 
$\mathrm{N}_{\mathrm{vc}}=$ Número de veículos de coleta - veículo

$\mathrm{n}_{\mathrm{g}} \quad$ = número de garis de uma equipe de coleta

$\mathrm{N}_{\mathrm{vcls}}=$ Número de veículos de coleta de resíduo sólido seco - veículo

$\mathrm{n}_{\mathrm{gls}}=$ número de garis para a coleta de resíduo sólido seco

\section{g) Definição dos roteiros de coleta}

É o trajeto que o veículo coletor deverá percorrer dentro de-um mesmo setor de coleta, num mesmo período, transportando o máximo de resíduo com um mínimo percurso improdutivo, com menor desgaste possível do veículo e da equipe de coleta.

Dá-se o nome de percurso improdutivo aos trechos percorridos em que o veículo não realiza coleta.

Para a definição dos itinerários CUNHA et al. (1995) recomenda alguns critérios e regras práticas: início da coleta próximo a garagem; término da coleta próximo a área de descarga; coleta em sentido descendente quando feita em vias íngremes, evitando maior desgaste físico da guarnição e do motor do veículo; percurso contínuo (coleta nos dois lados da rua) e nas ruas de tráfego intenso, evitar o cruzamento da vias pela guarnição.

WOLMER (1982) estabelece algumas alternativas que podem ser adotadas para as ruas em que não haja possibilidade de tráfego de veículo coletor, seja em decorrência de suas dimensões, da sua inclinação, das condições de pavimentação ou ainda de obras provisórias. São as seguintes:

- trajetória a pé, pela equipe de garis, para recolhimento dos resíduos; é viável quando a distância de transporte não é excessiva (até no máximo $100 \mathrm{~m}$ ) ou quando se trata de medidas provisórias, ocasionadas por obras na rua;

- centralização dos recipientes, pelos moradores, na esquina da via em que o tráfego seja possível; alternativa resultante em ganho de tempo para o serviço, mas invariavelmente em reclamações por parte dos ocupantes do imóvel da esquina, ou na frente de cuja a residência ou estabelecimento se faça o ponto de acumulação;

- instalação de container basculante ou intercambiável.

O projeto de coleta deverá ser dinâmico, acompanhado periodicamente visando observar se há variação da geração de resíduos em cada setor, se novas ruas 
foram pavimentadas etc., para efeito de alterações ou ajustes nos roteiros originais ou, até mesmo, nos setores de coleta.

\subsubsection{Processamento e recuperação}

Segundo TCHOBANOGLOUS et al. (1993), esta etapa de processamento e rëcuperação inçlui técnicàs, equipamentos e infra-estruturas utilizadas para promover a eficiência de outros elementos funcionais, a fim de recuperar materiais utilizáveis, ou mesmo cónv̌erter os resíduos em produtos ou energia.

TCHOBANOGLOUS et al. (1993), classificou algumas técnicas de processamento e recuperação:

- redução mecânica de volume (compactação);

- reduçãó química de volume (incineração);

- reduçã̃o mécânica de granulometria (trituração);

- separação dos componentes (manual ou mecânica).

A fração orgânica dos resíduos sólidos urbanos pode ser transformada por uma variedade de processos químicos e biológicos. O processo de transformação química mais comum é a combustão utilizada em conjunto com a recuperação de energia em forma de calor. Já, o processo de transformação biológica mais utilizado é a compostagem.

A seleção de um conjunto de processos dependerá dos objetivos a serem alcançados com o gérenciaménto dos resíduos sólidos.

\subsubsection{Transferência e transporte}

A operação unitária de transferência e transporte compreende o deslocamento de ida do veículo ao local de disposição final, para descarga dos resíduos, e o seu retorno ao primeiro ponto da próxima viagem. Esta operação inclui, conseqüentemente, o tempo total de viagem, desde o último ponto de coleta ao local de dîsposição final e o retorno ao primeiro pontó de coleta da próxima viagem.

Quando for necessário, por questões econômicas, realizar a transferência dos resíduos do veículo coletor para um transportador, de acordo com CANASSA (1992) nesta situação ocorrerão dois processos distintos de transporte: 
- transporte do último ponto de coleta, como descrito acima, à estação de transferência e o retorno ao primeiro ponto da próxima viagem de coleta;

- transporte de resíduos da estação de transferência ao local de destino final.

\subsubsection{Destino final}

O último elemento funcional do sistema-de gerenciamento de resíduos sólidos é a disposição.

Atualmente, a técnica mais utilizada para o destino final adequado dos resíduos sólidos urbanos é o aterro sanitário. A Associação Brasileira de Normas Técnicas - ABNT, através da NBR 8419, define:

\footnotetext{
"Aterro sanitário de resíduos sólidos urbanos, consiste na técnica de disposição de resíduos sólidos urbanos no solo, sem causar danos ou riscos à saúde pública e à segurança, minimizando os impactos ambientais, método este que utiliza princípios de engenharia para confinar os resíduos sólidos a menor área possivel e reduzi-los ao méenor volume permissível, cobrindo-os com uma camada de terra na conclusão de cada jornada de trabalho ou a intervalos menores se for necessário". (ABNT, 1985, p.1)
}

Para LEITE (1997), a aplicação deste processo é difundida em quase todo o mundo, por se apresentar como solução mais econômica, quando comparada com outros processos (compostagem, incineração, por exemplo), que exigem grandes investimentos para a construção e para a manutenção da estrutura técnicoadministrativa de operação. A utilização de outros métodos de disposição final não descarta a existência de aterros sanitários, uma vez que esses sistemas produzem resíduos, que não são aproveitáveis, ou ainda por fator de segurança, na ocorrência de imprevistos que paralisem as instalações.

A maioria das cidades brasileiras confundem aterro sanitário com "vazadouros", "lixões", etc., métodos que, desprovidos de critérios técnicos ou ambientais, são condenados sob o ponto de vista sanitário.

De acordo com artigo publicado pela REVISTA BIO (1997), 76\% dos resíduos produzidos no país são jogados em lixões e outros $13 \%$ nos locais chamados 
aterros controlados-(locais onde os resíduos são confinados, sem técnicas básicas-de engenharia, que preservem o meio ambiente). Apenas $10 \%$ do total são colocados em aterros sanitários, técnica esta que oferece melhores condições estruturais de minimizar os danos ambientais.

De acordo com a Pesquisa Nacional de Saneamento Básico - PNSB, realizada pelo IBGE (1989); editada em 1991, $76 \%$ ficam a céu aberto (lixão) e $24 \%$ recebem tratamento mais adequado. Desses últimos $14 \%$, ficam em aterros controlados (apenas recebem algumas melhorias - cobertura diária), $10 \%$ em aterro sanitário, $0,9 \%$ se destinam a compostagem e $0,1 \%$ a usinas de incineração, conforme ilustra a figura 5 .

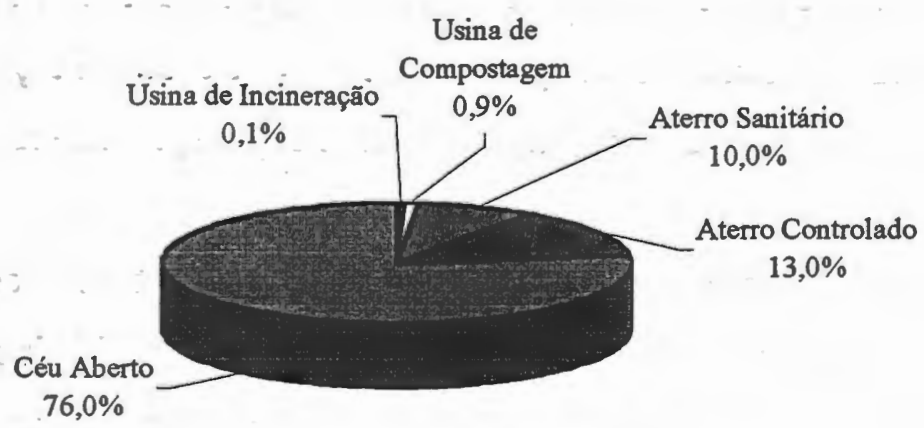

FIGURA 5 - Disposição final dos resíduos sólidos no Brasil Fonte: IBGE (1989)

Como $90 \%$ dos resíduos sólidos brasileiros são dispostos em lixões, há condições propícias para a proliferação de vetores, criando dessa forma uma via de acesso de agentes patogênicos oriundos dos resíduos sólidos, como moscas, ratos, baratas. Além disso, o dano ambiental também é grande, decorrente da falta de controle dos líquidos e gases resultantes da decomposição dos resíduos que podem contaminar o solo, ar e água.

\subsection{Legislações e normas}

LEITE (1997) relatou que no Brasil, embora o município tenha autonomia político-administrativa, deve, antes de agir, observar os princípios e normas 
constitucionais e a legislação federal, estadual e municipal. Portanto, os projetos. e programas que envolvam o gerenciamento dos resíduos devem estar adequados às normas e às leis.

No aspecto institucional resume-se, de certa forma, à atuação integrada do SISNAMA - Sistema Nacional do Meio Ambiente, criado com a Lei $n^{\circ} 6.938 / 81$, que representa um conjunto articulado de órgãos, entidades, regras e práticas da União, dos Estados, do Distrito Federal e dos Municípios responsáveis pela proteção da qualidade ambiental.

A Constituição de 1988, em seu artigo 23, incisos III, IV, VI e.VII, confere aos municípios a competência para a proteção ambiental, em comum com a União e os Estados. Entretanto, a competência outorgada aos municípios permanece mais no âmbito da execução da legislação em vigor do que no âmbito de criar leis sobre o assunto. Porém, a norma do artigo 30, Inciso II da Constituição, reconhece aos municípios a competência para suplementar a legislação federal e a estadual em matéria ambiental.

De acordo com LEITE (1997) a implementação de programas de gerenciamento dos resíduos sólidos urbanos exige uma quantidade de parâmetros que devem ser observados, e raras são as leis que sejam abrangentes o suficiente para contemplar todos os aspectos envolvidos.

MOISÉS et al. (1995) destacou algumas questões a serem consideradas em um programa de gerenciamento de resíduos sólidos:

- aspectos econômicos, financeiros e administrativos;

- questões sociais, culturais e participativas da comunidade;

- educação, saúde e saneamento;

- poluição do ar, água e solo;

- fiscalização e controle sobre produtos produzidos e comercializados.

O gerenciamento dos resíduos sólidos está inserido num conjunto de ações do poder local que visam o bem-estar da população e a proteção do meio ambiente. Num âmbito mais restrito, como denomina MOISÉS et al. (1995), faz parte das ações de saneamento ambiental, que tem por objetivo eliminar as condições nocivas que possam afetar a saúde pública. Estas ações interagem intimamente com a 
população, constituindo assim um fator decisivo para a qualidade de vida e desenvolvimento social.

Os resíduos sólidos não. são contemplados por uma disciplina normativa temática, ao contrário de outros temas ligados a questão ambiental. Segundo estudos realizados pela FUNDUNESP (1995), essa lacuna, tem gerado conflitos, principalmente na temática que se refere ao tratamento e à disposição final dos resíduos, colaborando para isso, entre outros, os seguintes motivos:

- os municípios não possuem, na sua maioria, sistemas de tratamento e disposição final adequados e com isso tornam-se poluidores e, não raramente, ao tentarem contornar o problema em seu território, encontram resistências do Estado e/ou da União, no tocante ao licenciamento ambiental (conflito intergovernamental vertical);

- os municípios vizinhos têm dificuldades para encontrar locais adequados para a correta disposição de seus resíduos, gerando problemas entre geradores e receptores (conflito intergovernamental horizontal);

- a forma do consórcio intermunicipal não está ainda suficientemente consolidada, principalmente no âmbito político-institucional, gerando dificuldades internas aos governos municipais, principalmente na aprovação de recursos orçamentários a serem aplicados em outros municípios (conflito político).

Segundo o. Programa das Nações Unidas para o desenvolvimento - PNUD (1993); a ausência de um conjunto de textos legais consolidados, que abranja os diferentes aspectos que a questão dos resíduos sólidos envolve, contribui negativamente para o equacionamento do problema. Poucos municípios dispõem sobre o assunto de forma a atender seus interesses específicos, enquanto outros nem mesmo se posicionam sobre o tema, o que tem tornado impraticável uma solução conjunta ou em larga escala. Os poucos textos legais utilizados são portarias e instruções baixadas pelo poder executivo, quase sempre inaplicáveis devido à falta de instrumentos adequados ou de recursos que viabilizem sua implementação.

O município, embora tenha autonomia político-administrativa, necessita observar os princípios e normas constitucionais e a legislação federal, estadual e 
municipal, para que dessa forma procure se adequar- os projetos e programas que envolvam o gerenciamento dos resíduos.

LEITE (1997) apresentou uma- seleção dos principais documentos legais no âmbito federal e estadual (Estado de São Paulo) e as normas técnicas sobre o meio ambiente, listados a seguir:

\subsubsection{A legislação federal}

Lei n. ${ }^{\circ}$ 6.168, de 9 de dezembro de 1974 - Cria o Fundo de Apoio ao Desenvolvimento Social-FAS, e dá outras providências.

Lei n. ${ }^{\circ}$ 6.803, de 2 de julho de 1980 - Dispõe sobre as diretrizes básicas para o zoneamento industrial nas áreas críticas de poluição, e dá outras providências.

Lei n. ${ }^{\circ}$ 6.938, de 31 de agosto de 1981 - Disciplina a Política Nacional de Meio Ambiente, estabelecendo objetivos e mecanismos para sua aplicação (regulamentada pelo Decreto n. $^{\circ} 88351$, de 01 de junho de 1983).

Lei n. ${ }^{\circ}$ 7.347, de 27 de julho de 1985 - Disciplina a ação civil pública por danos causados ao meio ambiente.

Lei n. ${ }^{\circ} 7.802$, de 11 de julho de 1989 - Dispõe sobre agrotóxicos (regulamentada pelo Decreto $\mathrm{n}^{\circ} 98816$ de 02 de janeiro de 1990).

Lei n. ${ }^{\circ}$ 7.804, de 18 de julho de 1989 - Disciplina o crime ecológico (altera a Lei $\left.\mathrm{n}^{\circ} 6.938\right)$.

Lei n. ${ }^{\circ}$ 9.433, de 8 de janeiro de 1997 - Dispõe sobre a política nacional de recursos hídricos, estabelecendo as bacias hidrográficas como unidades fisicoterritoriais para o planejamento.

Resolução do CONAMA n. 001 , de 23 de janeiro de 1986 - Trata dos Estudos de Impacto Ambiental (EIA) e Relatórios de Impacto sobre o Meio Ambiente (RIMA)

Resolução do CONAMA n. ${ }^{\circ}$ 20, de 18 de junho de 1986 - Estabelece a classificação dos rios do Brasil no que se refere ao controle da poluição e estabelece os limites e condições para o lançamento de efluentes.

Resolução do CONAMA n. ${ }^{\circ}$ 005, de 15 de junho de 1988 - Dispõe sobre o licenciamento de obras de saneamento. 
Resolução do CONAMA n. ${ }^{\circ}$ 006, de 15 de junho de 1988 - Exige o estabelecimento dos inventários dos tipos e quantidades dos resíduos gerados pelas empresas.

Resolução do CONAMA n.ำ 008, de 19 de setembro de 1991 - Veta a entrada de materiais residuais destinados à disposição final e incineração no país.

Resolução do CONAMA n.o 005 de 05 de agosto de 1993 - Dispõe sobre resíduos sólidos oriundos dos serviços de saúde, portos e aeroportos.

Resolução do CONAMA n. ${ }^{\circ}$ 009, de 31 de agosto de 1993 - Dispõe sobre óleos usados.

Resolução do CONAMA n. 007 , de 04 de maio de 1994 - Dispõe sobre a importação e exportação de resíduos à luz da Convenção de Basiléia.

\subsubsection{A legislação estadual (Estado de São Paulo)}

Lei n. $^{\circ}$ 898, de 18 de dezembro de 1975 - Disciplina o uso do Solo para proteção de mananciais, cursos e reservatórios de água e demais recursos hídricos de interesse da região metropolitana da grande São Paulo.

Lei n. ${ }^{\circ}$ 997, de 31 de mạio de 1976 - Dispõe sobre o controle da poluição do meio ambiente.

Lei n. ${ }^{\circ} 1172$, de 17 de novembro de 1976 - Delimita as áreas de proteção relativas aos mananciais, cursos e reservatórios de água, a que se refere 0 artigo 22 da Lei n. $^{\circ} 898 / 75$, estabelece normas de restrição de uso em tais áreas e dá providências correlatas.

Decreto $n^{0}$ 38. 514, de 5 de abril de 1994 - Autoriza a Secretaria de Ciência e Tecnologia e Desenvolvimento Econômico a celebrar convênios com Consórcios Intermunicipais ou municípios para a implantação de Usinas de Compostagem de resíduos sólidos urbanos.

Deliberação Consema ñ 20, de 10 de agosto de 1990 - Aprova o Projeto 130/89 e a Norma de Critérios de exigência de EIA/RIMA para sistemas de Disposição de Resíduos Sólidos Domiciliares, Industriais e Serviços de Saúde

Existem outras leis complementares e decretos, tanto no nível federal como no estadual e municipal, que mantêm relações diretas com as questões dos resíduos sólidos e podem ser consultadas nos órgãos ambientais competentes. 


\subsubsection{Normas Técnicas Brasileiras (NBR) da Associação Brasileira de Normas} Técnicas (ABNT)

NBR 10004 Resíduos sólidos, com anexos que definem, por categoria, os resíduos considerados perigosos (1987).

NBR 10005 Lixiviação de resíduos (1987).

NBR 10006 Solubilização de resíduos (1987).

NBR 10007 Amostragem de resíduos (1987).

NBR 10157 Aterros de resíduos perigosos - critérios (1987).

NBR 7500 Símbolos de risco e manuseio para o transporte e armazenagem de materiais.

NBR 7501 Transporte de cargas perigosas - terminologia.

NBR 7502 Transporte de cargas perigosas - classificação

(números da ONU).

NBR 8371 Ascaréis para transformadores e capacitores.

NBR 8418 Projetos de aterros de resíduos industriais perigosós.

NBR 8419 Projetos de aterros sanitários de resíduos sólidos urbanos.

NBR 9190 Sacos plásticos para acondicionamento de lixo - Classificação

NBR 9191 Sacos plásticos para acondicionamento de lixo - Especificação

A Associação Brasileira de Normas Técnicas é representante do Brasil junto a "Internacional Oganization for Standartization" (Organização Internacional de Normatização-ISO). A ISO é uma federação mundial fundada em 1946 para promover o desenvolvimento de normas internacionais na indústria, comércio e serviços. Todas as normas desenvolvidas pela ISO são voluntárias; não há instrumentos legais para forçar os países a adotá-las.

As normas da série ISO 14000 fornecem à administração dos negócios uma estrutura para gerenciar os impactos ambientais. As normas incluem uma variedade de disciplinas ambientais, incluindo o sistema de gestão básico, auditỏria, avaliação de desempenho, selos, avaliação do ciclo de vida e aspectos ambientais em normas de produto.

De acordo com HEMENWAY \& GILDERSLEEVE (1995) as normas ISO são dividas em duas categorias: 
- Avaliação da organização - Sistema de Gerenciamento Ambiental (SGA), Auditoria Ambiental e Avaliação de Desempenho Ambiental (ADA);

- Avaliação do produto - Avaliação do ciclo de vida (ACV), rotulagem ambiental $e$ aspectos ambientais nas normas dos produtos (AANP).

O Sistema de Gerenciamento Ambiental (SGA) é o aspecto da estrutura administrativa global da organização que endereça o impacto imediato e a longo prazo de seus produtos, serviços e processos no meio ambiente. Fornece ordem e consistência nas metodologias organizacionais, através da alocação de recursos, definição de responsabilidades e avaliação contínua de práticas, procedimentos e processos. O SGA é essencial para a habilidade da organização em prever e satisfazer as expectativas de desempenho ambiental crescente, assegurando connformidàde contínua com as exigências nacionais e internacionais.

As normas ambientais internas, quando estiverem inteiramente elaboradas e aprovadas, constituirão uma série, já esboçada pela ISO.

VALLE (1995) apresentou os grupos de normas e sua respectiva numeração e denominação, apresentadas na tabela 15 .

TABELA 15 - Grupos de normas da família ISO-14000

\begin{tabular}{|c|c|c|}
\hline $\begin{array}{l}\text { Grupo de } \\
\text { Normas }\end{array}$ & $\begin{array}{l}\text { Número da } \\
\text { Norma }\end{array}$ & Título da Norma \\
\hline $\begin{array}{l}\text { Gestão Ámbiental } \\
\text { (subcomitê SC1) }\end{array}$ & ISO 14000 & $\begin{array}{l}\text { Guia para os Princípios, Sistemas e Técnicas de Suporte da Gestão } \\
\text { Ambiental } \\
\text { Sistemas de Gestão Am̄biental - Especificação e Diretrizes para Uso }\end{array}$ \\
\hline $\begin{array}{l}\text { Auditoria } \\
\text { Ambiental } \\
\text { (subcomitê SC2) }\end{array}$ & $\begin{array}{l}\text { ISO } 14010 \\
\text { ISO } 14011 \\
\text { ISO } 14012 \\
\text { ISO } 14014 \\
\text { ISO } 14015\end{array}$ & $\begin{array}{l}\text { Diretrizes para Auditoria Ambiental - Princípios Gerais de Auditoria } \\
\text { Ambiental } \\
\text { Diretrizes para a Auditoria Ambiental - Procedimentos de Auditoria } \\
\text { Parte } 1 \text { - Auditoria de Sistemas de Gestão Ambiental } \\
\text { Parte } 2 \text { - Auditoria de Conformidade } \\
\text { Diretrizes para Auditoria Ambiental - Critérios de Qualificação para } \\
\text { Auditores Ambientais } \\
\text { Diretrizes para Revisões Ambientais Iniciais } \\
\text { Diretrizes para Análise Ambiental do Local }\end{array}$ \\
\hline $\begin{array}{c}\text { Rotulagem } \\
\text { Ambiental } \\
\text { (subcomitê SC3) }\end{array}$ & $\begin{array}{l}\text { ISO } 14020 \\
\text { ISO } 14021 \\
\text { ISO } 14022 \\
\text { ISO } 14023 \\
\text { ISO } 14024\end{array}$ & $\begin{array}{l}\text { Rotulagem Ambiental - Princípios Básicos } \\
\text { Rotulagem Ambiental - Termos e Definições } \\
\text { Rotulagem Ambiental - Símbolos } \\
\text { Rotulagem Ambiental - Metodologias para Testes e Verificação } \\
\text { Rotulagem Ambiental - Princípios Guia/Prática do Programa }\end{array}$ \\
\hline
\end{tabular}


TABELA 15 - Grupos de normas da família ISO-14000

\begin{tabular}{|c|c|c|}
\hline $\begin{array}{l}\text { Grupo dē } \\
\text { Normas }\end{array}$ & $\begin{array}{l}\text { Número da } \\
\text { Norma }\end{array}$ & Título da Norma \\
\hline $\begin{array}{l}\text { Avaliação de } \\
\text { Desempenho } \\
\text { Ambiental } \\
\text { (subcomitê SC4) }\end{array}$ & ISO 14031 & Metodologia de Avaliação do Desempenho Ambiental \\
\hline $\begin{array}{l}\text { Análise do Ciclo de } \\
\text { Vida (subcomitê } \\
\text { SC5) }\end{array}$ & $\begin{array}{l}\text { ISO } 14040 \\
\text { ISO } 14041 \\
\text { ISO } 14042 \\
\text { ISO } 14043\end{array}$ & $\begin{array}{l}\text { Análise do Ciclo de Vida - Princípios Gerais e Códigos de Práticas } \\
\text { Análise do Ciclo de Vida - Análise de Inventários } \\
\text { Análise do Ciclo de Vida - Análise de Impactos } \\
\text { Análise do Ciclo de Vida - Análise de Melhorias }\end{array}$ \\
\hline $\begin{array}{c}\text { Termos e } \\
\text { Definições } \\
\text { (subcomitê SC6) }\end{array}$ & ISO 14050 & 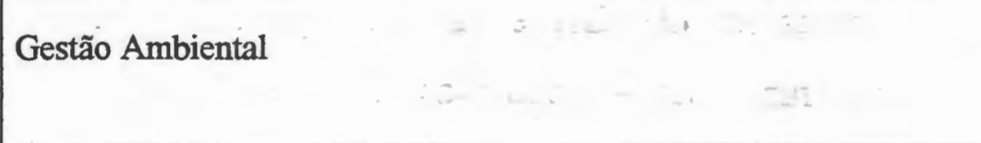 \\
\hline $\begin{array}{l}\text { Aspectos } \\
\text { Ambientais de } \\
\text { Normas para } \\
\text { Produtos (grupo de } \\
\text { trabalho especial } \\
\text { WG) }\end{array}$ & ISO 14060 & $\begin{array}{l}\text { Princípios para a inclusão de Aspectos Ambientais em Normas para } \\
\text { Produtos }\end{array}$ \\
\hline
\end{tabular}

\subsection{O Sistema de Informação Geográfica-SIG}

\subsubsection{Conceitos básicos}

Conhecer alguns conceitos básicos auxilia a compreensão do que é um sistema de informação geográfica; propostos por TEIXEIRA et al. (1992), são citados a seguir:

- Entidades - elementos ou objetos tomados como unidades básicas para a coleta de dados. Os dados, por sua vez, relacionam-se com os atributos, que caracterizam e fornecem significado à unidade estudada (como exemplo, pode-se tomar um lugar geográfico qualquer como entidade, e suas características de solo, vegetação, etc. como alguns de seus atributos).

- Sistema - arranjo de entidades (elementos ou coisas) relacionadas ou conectadas, de tal forma a constituir uma unidade ou todo organizado, com características próprias e subordinadas a processos de transformação conhecidos. 
- Dados - são um conjunto de valorès, numéricos: ou não; sem significado próprio.

- Informação - é o conjunto de dados que possuem significado para determinado uso ou aplicação.

- Análise Espacial - conjunto de técnicas que réquer o acesso tanto aos atributos (propriedảes, valores medidos) como a sua localização (posição geográfica) através de relações topológicas e que estabelecem a relação espacial existente entre cada feição geográfica (pontos, linhas e polígönos):

- Informação Geográfica - conjunto de dados cujo significado contém associações ou relações de natureza espacial.

\subsubsection{Histórico}

O desenvolvimento dos sistemas de informação geográfica está diretamente relacionado com avanços na área de computação, cuja história tem como marco as décadas de 40 e 50, quando foram desenvolvidos equipamentos e métodos que viabilizaram a implementação de rotinas para automação de determinados processos de análise espacial.

De acordo com CALIJURI \& ROHM (1993) o primeiro Sistema de Informações Geográficas (SIG) surgiu no Canadá, na década de 60 e mostrava a necessidade que as agências governamentais voltadas para o meio ambiente daquele país tinham, já naquela época, de mapear suas reservas naturais. Outro objetivo era efetuar múltiplas análises a respeito do seu meio ambiente como um todo, sendo necessário o processamento de grande quantidade de dados criados pelo inventário de terras canadenses.

O primeiro sistema a reunir as características básicas de SIG foi implementado no Canadá, em 1964, sendo chamado Canadian Geographic Information System. Em seguida, foram desenvolvidos os sistemas New York Landuse and Natural Resourses Information Sytems em 1967 e Minnesota Land Management Information System em 1969. A aplicação desses sistemas restringiu-se 
às agências federais e estaduais do governo americano e canadense, em virtude dos custos elevados e dos problemas de implementação.

Nas década posteriores ocorreram avanços consideráveis em equipamentos e software, permitindo o desenvolvimento de sistemas mais potentes e novas aplicações. A computação gráfica também obteve consideráveis avanços, popularizando sistemas do tipo AM/FM (Automated Mapping/Facilities Management) e principalmente os CAD's (Computer Aided Design).

Sistemas do tipo CAD consistem basicamente em uma ferramenta de desenho digital e não necessariamente de processamento de informação espacial. Um CAD geralmente possui funções que permitem a representação precisa de linhas e formas, podendo ser utilizado, por exemplo, na digitalização de mapas e cartas.

CÂMARA (1994) afirma que a capacidade de armazenar a topologia, estrutura de relacionamentos espaciais (vizinhança, proximidade, pertinência) que se pode estabelecer entre objetos geográficos de um mapa, difere um SIG de um CAD.

DANTAS et al. (1996) em análises de artigos de diversos autores, observaram que a partir da década de 80 , o crescimento do setor industrial e comercial do SIG, juntamente com a diminuição dos recursos disponíveis para pesquịsas, provocaram mudanças significativas nos rumos da aplicação do SIG. Diversas são as empresas dedicando-se ao desenvolvimento de novas tecnologias de SIG e essa competitividade propiciou o aparecimento de diversos produtos, cada vez mais sofisticados e atrativos para os usuários.

Os autores avaliam que desta forma, esta fase evolutiva caracteriza-se pela busca contínua do melhor aproveitamento do potencial de análise do SIG. Em fases anteriores o SIG foi utilizado para manipular/visualizar banco de dados e posteriormente para realizar operações analíticas com dados numéricos, sempre partindo de dados estatísticos obtidos através de pesquisas. $\mathrm{Na}$ fase atual a capacidade de realização da análise espacial, tem sido apontada como fundamental para distinção entre outros sistemas de informação e o SIG.

\subsubsection{Definição}

O Sistema de Informação Geográfica-SIG pode ser definido como uma coleção organizada de hardware, software, dados geográficos e pessoal, projetado 
para eficientemente, capturar, armazenar, atualizar, manipular, analisar e apresentar todas as informações referenciadas geograficamente.

Constitui-se basicamente em um mapeador temático automatizado, onde as informações obtidas são representadas na formá de "níveis de informação" ou "layers" e tais características se unem à potencialidade dos bancos de dados automatizados.

Todavia pode-se considerar o SIG como um tipo de sistema de informação, que envolve de forma sistêmica e interativa banco de dados, tecnologia-e pessoal, sendo capaz de realizar análises espaciais, armazenar, manipular, visualizar e operar dados geóreferenciados para obtenção de novas informações. Essa concepção de SIG proposta por DANTAS et al. (1996) é representada na figura 6.

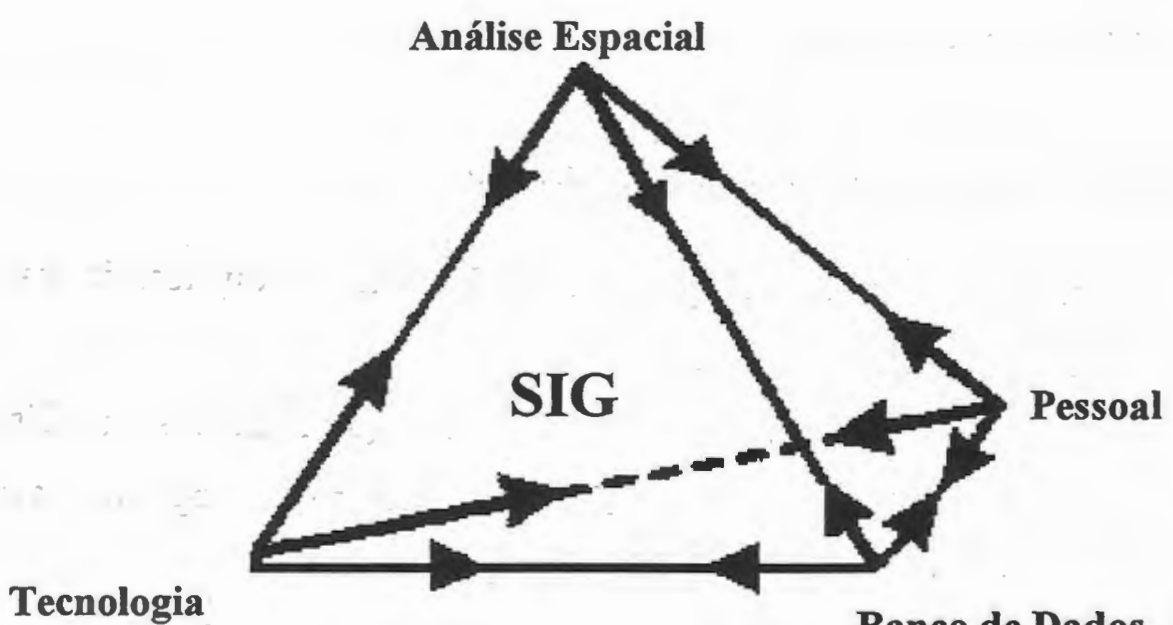

FIGURA 6 - Elementos de um Sistema de Informação Geográfica-SIG Fonte: DANTAS et al. (1996)

Os SIGs combinam os avanços das cartografias automatizadas, dos sistemas de manipulação de banco de dados e do sensoriamento remoto, com o desenvolvimento metodológico em análise geográfica, para produzir um conjunto distinto de procedimentos analíticos que auxiliam no gerenciamento e na atualização constante das informações disponiveis.

O SIG é uma tecnologia que oferece ferramental operacional no auxilio e agilização dos procedimentos de planejamento, gerência e de tomadas de decisão, e 
que por isso vem sendo utilizado de forma cada vez mais promissora em diferentes áreas.

Segundo TEIXEIRA et al. (1992), os SIGs gerenciam e integram banco de dados e arquivos geográficos (linhas, pontos e áreas). Baseiam-se numa tecnologia de coleta, armazenamento, análise e tratamento de dados espaciais e temporais e na geração de informações.

CÂMARA (1994) afirma que os SIGs destinam-se à manipulação de informações, que se apresentam na forma de dados referenciados espacialmente, e de atributos. Além da possibilidade de lidar com diversas projeções cartográficas, os SIGs possuem capacidade de tratar as relações espaciais entre objetos geográficos (identifica a topologia) e estas podem ser obtidas através de algoritmos. Os SIGs são ferramentas para modelagens e simulações diversas, portanto não constituem um simples inventário de informação.

\subsubsection{Fontes de dados e estruturas de representação}

Os dados utilizados em um SIG podem ser originários de diversas fontes, que podem ser classificadas genericamente em:

- Primárias - levantamentos diretos em campo (topográficos, geodésicos, cadastrais), produtos de sensoriamento remoto (fotografias aéreas, imagens orbitais), recenseamentos e vídeos;

- Secundárias - mapas e estatísticas, derivados das fontes primárias (mapas).

A maneira como o software armazena e representa os dados na tela tem importante papel no tipo de análise espacial que se pretende conduzir, razão pela qual existem no mercado diferentes programas baseados em duas estruturas de representação de dados espaciais: raster e vetorial.

De acordo com SILVA et al. (1996) a estrutura raster baseia-se na divisão do espaço em uma malha regular, formando uma matriz de pequenos pontos (ou células) aos quais são associados as informações alfanuméricas. A estrutura vetorial (também denominada vector) considera o espaço de forma contínua, tentando reproduzir as dimensões e forma de maneira mais fiel possível, considerando que todos os pontos no espaço têm coordenadas exatas. Isso introduz grande complexidade matemática na 
representação dos elementos espaciais, mas garante um grau de precisão muito maior do que no caso das estruturas raster. Estas representações estão ilustradas na figura 7.

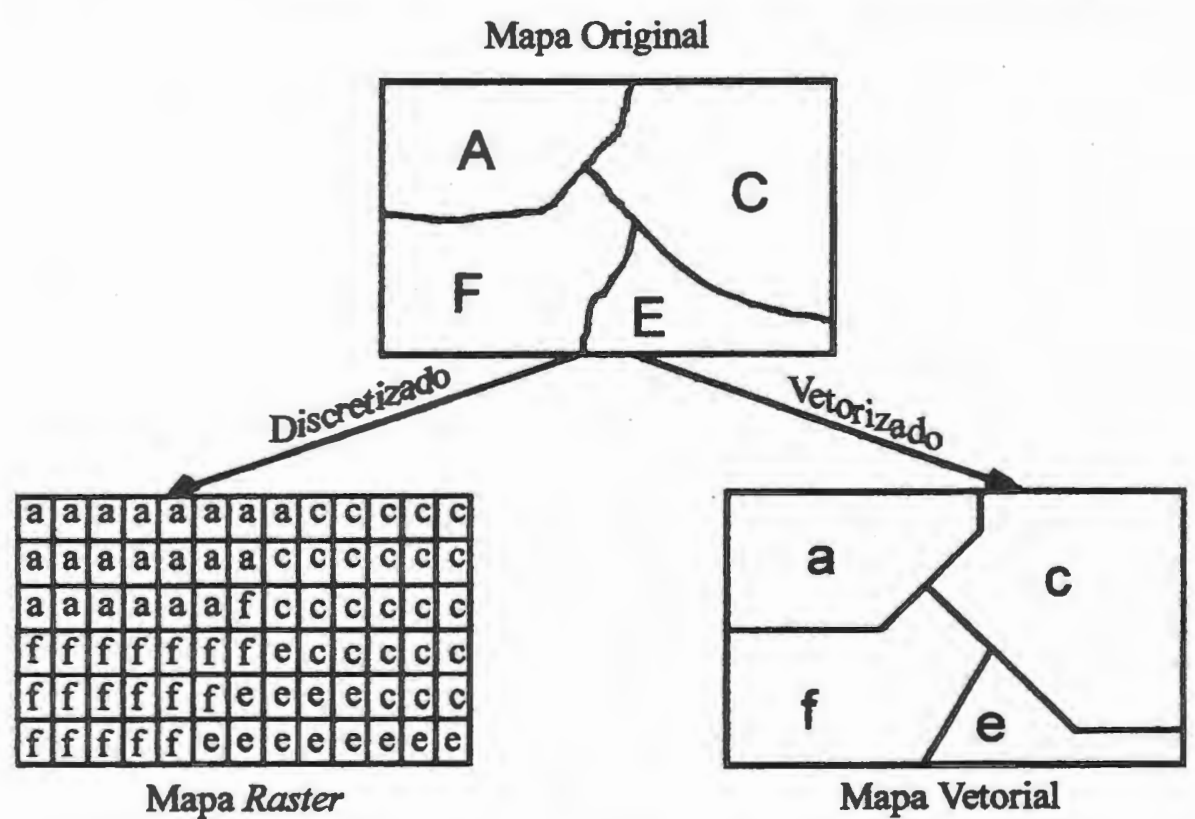

FIGURA 7 - Formas de representações dos dados

Fonte: TEIXEIRA et al. (1992)

As vantagens e desvantagens da utilização das estruturas raster e vetorial são apresentadas na tabela 16.

TABELA 16 - Vantagens e desvantagens das estruturas raster e vetorial

\begin{tabular}{l|l|l}
\hline \multicolumn{1}{c|}{ Formato } & \multicolumn{1}{|c}{ Vantagens } & \multicolumn{1}{|c}{ Desvantagens } \\
\hline Raster & $\begin{array}{l}\text { Estrutura de dados simples } \\
\text { Eficiência em análises de de } \\
\text { superposição de áreas } \\
\text { Boa representação da variabilidade } \\
\text { espacial } \\
\text { Eficiência na manipulação de de } \\
\text { imagens digitais }\end{array}$ & $\begin{array}{l}\text { Estrutura pouco compacta } \\
\text { Dificil representação das relações } \\
\text { topológicas } \\
\text { Saídas gráficas com má delineação }\end{array}$ \\
\hline Vetorial & $\begin{array}{l}\text { Estrutura de dados compacta } \\
\text { Eficiência na representação e análise } \\
\text { das relações topológicas } \\
\text { Saídas gráficas com boa definição de de } \\
\text { traços }\end{array}$ & $\begin{array}{l}\text { Estrutura de dados complexa } \\
\text { áficil análise na superposição de } \\
\text { áreas } \\
\text { Representação regular da da } \\
\text { variabilidade espacial } \\
\text { Difícil análise de imagens digitais }\end{array}$ \\
\hline
\end{tabular}

Fonte: BRAVO \& CERDA (1995) 


\subsubsection{Componentes de um SIG}

De acordo com TEIXEIRA et al. (1992) os SIGs são compostos por:

- Banco de dados - programas de gerenciamento que permitem executar rotinas de manutenção e controle e pela base de dados físicas que é composta de arquivos, onde os dados estudados são armazenados. Constitui a parte essencial da composição de um SIG, são constituídos de uma coleção de mapas e informações digitais relacionadas às feições da superficie terrestre; o gerenciamento dos bancos de dados é a principal qualidade dos SIGs;

- Conjunto de software - destinado à execução de operações sobre os dados (análise espacial);

- Hardware: constituído de equipamentos necessários para desempenhar a função de coleta de dados na forma digital, processamento e apresentação das informações. Os SIGs em geral admitem periféricos, e os utilizados para entrada, armazenamento de saída de dados são apresentados nas figuras 8,9 e 10 . 


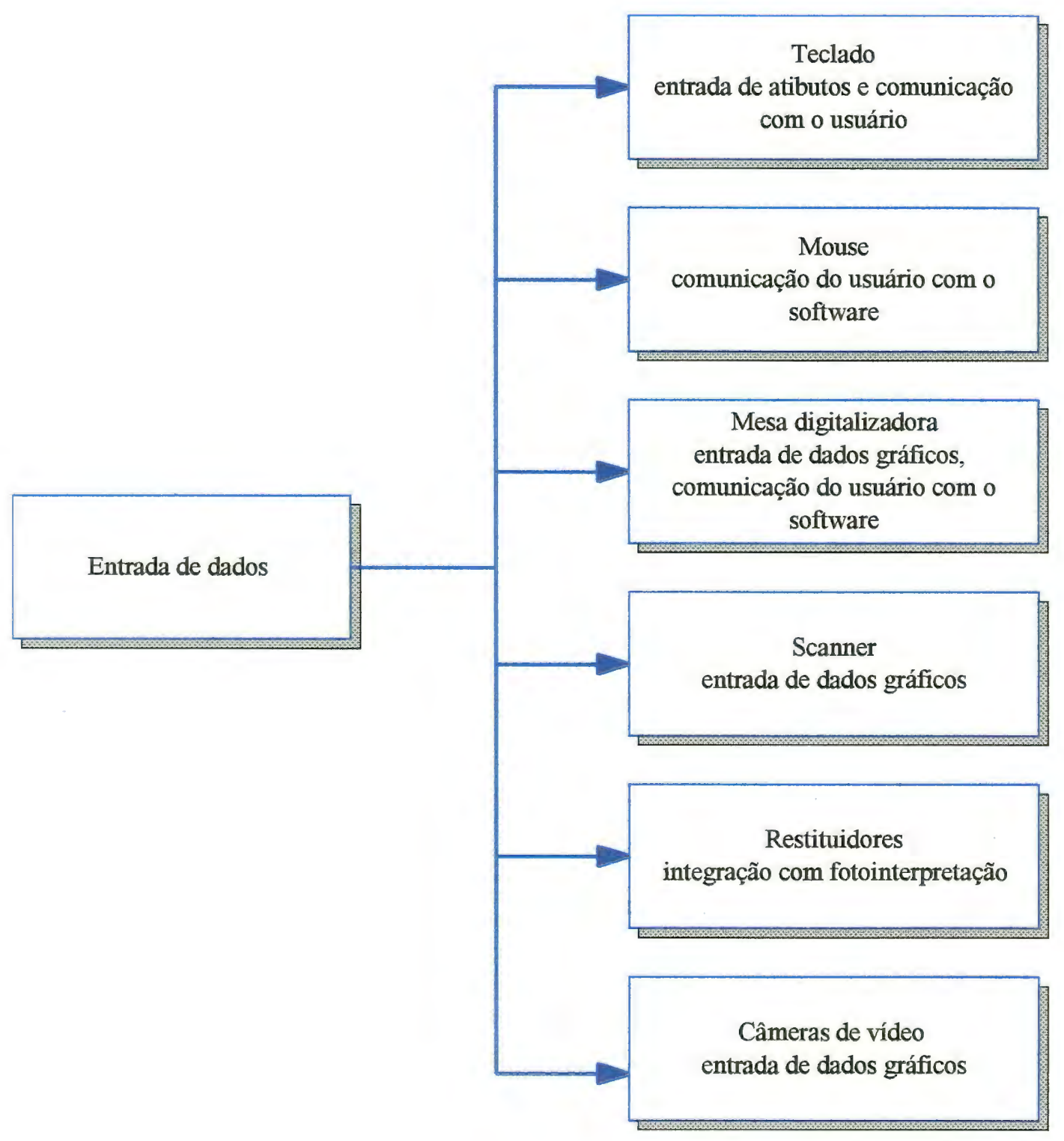

FIGURA 8 - Equipamentos periféricos utilizados para entrada de dados

Fonte: Adaptada de TEIXEIRA et al. (1992) 


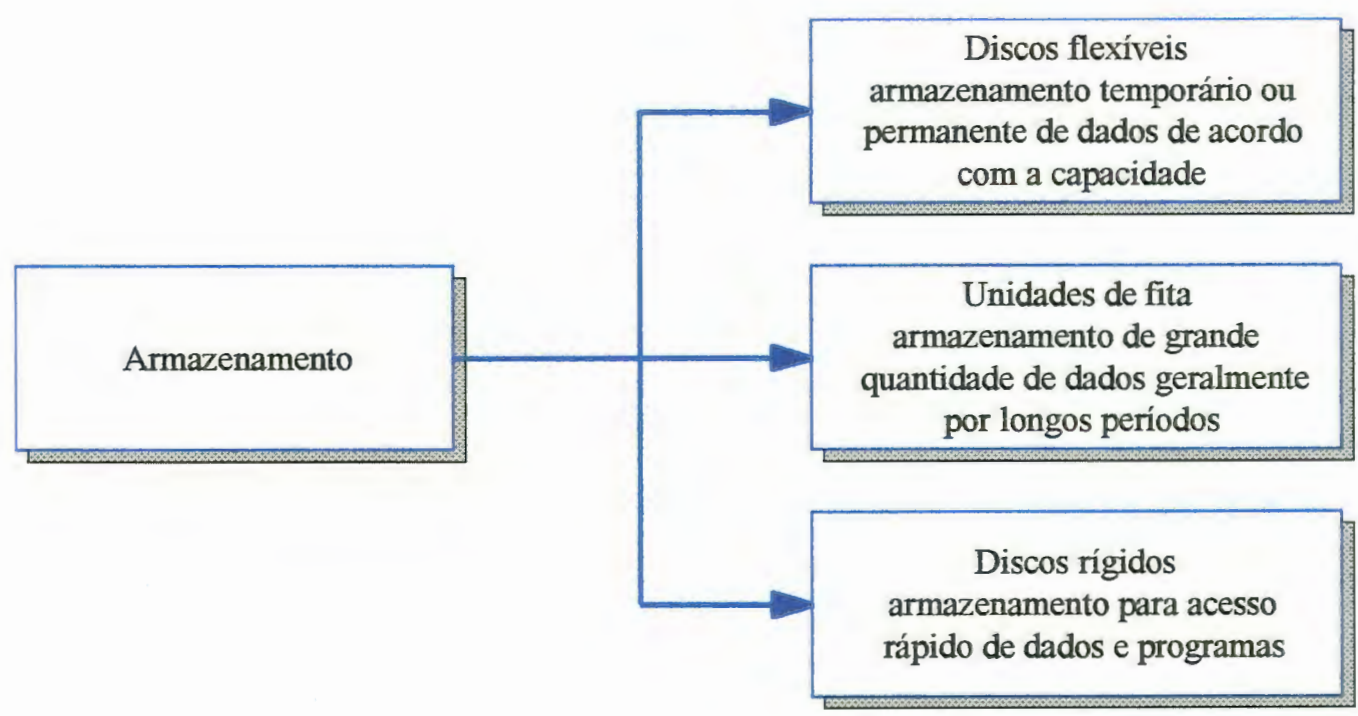

FIGURA 9 - Equipamentos periféricos utilizados para armazenamento de dados Fonte: Adaptada de TEIXEIRA et al. (1992)

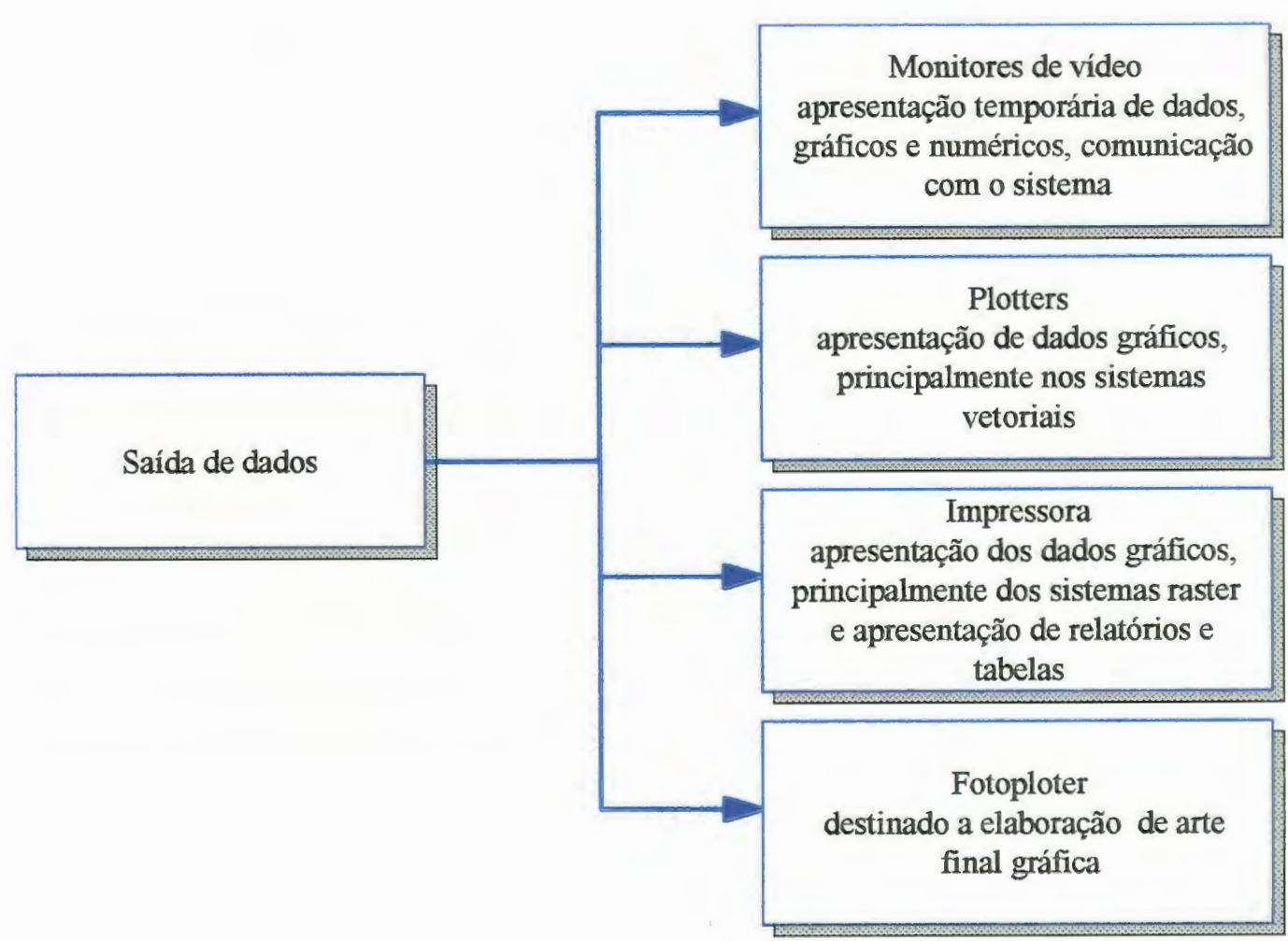

FIGURA 10 - Equipamentos periféricos utilizados para saída de dados Fonte: Adaptada de TEIXEIRA et al. (1992) 


\subsubsection{Funções e vantagens}

CÂMARA (1994) apresentou as principais funções de um SIG, citadas a seguir:

- integrar informações espaciais de dados cartográficos, censitários e de cadastramento, imagens de satélite, redes e modelos numéricos de terreno, numa única base de dados;

- cruzar informações através de algoritmos de manipulação para gerar mapeamentos derivados;

- consultar, recuperar, visualizar e permitir saídas gráficas para o conteúdo da base de dados geocodificados.

De acordo com CALIJURI \& ROHM (1993), as principais vantagens que justificam a útilização de um sistema de informação geográfica são:

- formato digital de dados (fisicamente compactado);

- custo menor para manutenção e extração dos dados manipulados;

- maior velocidade de acesso;

- maior flexibilidade de manipulação dos dados, graças ao uso de ferramentas computacionais;

- manipulação simultânea de informações espaciais e atributos de maneira relacionada;

- possibilidade de realização de testes analíticos de modelos conceituais de modo rápido e preciso, facilitando avaliações científicas em grande áreas num curto período de tempo;

- possibilidade de análises temporais;

- desenho cartográfico com uso de ferramentas gráficas e interativas;

- maior eficiência em relação às análises efetuadas manualmente, como análises digitais de terrenos, cálculos de declividades, sobreposição de mapas, etc.

\subsubsection{Fases de implantação}

Para MEIRA \& CALIJURI (1995) a implantação do sistema, de maneira geral, envolve algumas fases distintas que são: 
- descrição dos requisitos básicos do sistema;

- levantamento e avaliação das bases de dados envolvidas;

- definição das entidades gráficas a serem digitalizadas;

- definição do processo de digitalização e da forma de representação;

- geração de imagens básicas e derivadas;

- estruturação dos bancos de dados descritivos;

- conexão dos dados espaciais e descritivos;

- desenvolvimento de aplicativos;

- avaliação de resultados.

\subsubsection{Estrutura do sistema}

MEIRA \& CALIJURI (1995) informam que, de uma maneira geral, os SIGs são compostos de dois elementos básicos: um banco de dados espaciais e um banco de dados de atributos. O banco de dados espaciais descreve as características geográficas da superficie do terreno (forma e posição) e o banco de dados de atributos descreve as características.

As atribuições do SIG são executadas desde que existam alguns componentes básicos tais como:

- subsistema de aquisição de dados: coleta e processamento de dados espaciais derivados de mapas existentes, imagens de satélite, etc.;

- subsistema de armazenamento e recuperação: organiza os dados espaciais de forma a permitir acesso rápido e atualização dos bancos de dados;

- subsistema de manipulação e análise de dados: produz estimativas, modela e executa simulações, etc.;

- subsistema de relatórios de dados: apresenta saída de modelos espaciais na forma de tabelas, mapas ou figuras, englobando tanto os dados originais quanto os dados manipulados. 


\subsubsection{Aplicação do Sistema de Informação Geográfica-SIG no gerenciamento} urbano

Conforme HUXHOLD (1991) o SIG é implantado basicamente para: apoiar a administração municipal e o planejamento urbano de forma compatível com a crescente demanda de serviços; oferecer um melhor acesso do público aos procedimentos administrativos e ao planejamento urbano; proporcionar confiabilidade e precisão das informações gráficas e não gráficas necessárias aos diversos setores e entidades; possibilitar a organização das informações, armazenadas com uma referência geográfica padrão, de modo que cada organismo forneça e atualize seu próprio banco de dados; facilitar a integração entre os órgãos envolvidos na elaboração e implementação do projeto e criar e prover um instrumento eficiente para o ordenamento, planejamento e controle do desenvolvimento urbano.

FERRARI (1997) analisou a utilização dos SIGs baseando-se na classificação das atividades de uma organização, que podem ser em três níveis:

- Operacional: o benefício imediato do uso de SIGs no suporte a atividades do nível operacional é a eficiência, ou seja, a execução das atividades que já vem sendo realizadas manualmente (sem apoio de SIGs), só que de maneira mais eficiente, gastando menos recursos.

- Gerencial: o uso do SIG no nível gerencial pode gerar outros tipos de benefícios a longo prazo: retorno financeiro, melhoria de imagem, benefícios à população e outros. Mas esses são benefícios indiretos, conseqüência do benefício imediato que é a eficácia administrativa.

- Estratégico: as atividades do nível estratégico são aquelas que contribuem diretamente para o cumprimento dos objetivos fundamentais da organização.

Os SIGs podem ser utilizados nos três níveis de atividades, sendo estas com características distintas, também serão distintos os benefícios do uso do SIG em cada um dos níveis.

De acordo com PAREDES (1994) o SIG não é apenas aquisição, gerenciamento, análise e exibição de resultados, mas também é uma ferramenta de suporte para muitas funções de decisão, sobretudo na análise e na execução política 
dos problemas, uma vez que os técnicos, planejadores e administradores possuem a responsabilidade de prover informações selecionadas e transferir suas idéias e recomendações para a comunidade que, ao final, cumprirá e usufruirá os resultados dessa decisão.

Dentre as aplicações de um SIG no gerenciamento urbano pode-se citar as seguintes, de interesse para a temática deste trabalho:

- sub-sistema de vias: são os dados sobre a intensidade da interação e sobre as vias fisicas que permitem essa interação, podendo ser classificadas assim:

$\Rightarrow$ infra-estrutura das vias: sistema viário urbano e coleta de resíduos sólidos;

$\Rightarrow$ informação a construir: volume e direção dos fluxos de interação; capacidade das vias para acomodar fluxo e determinação dos limites de capacidade.

$\Rightarrow$ unidades de medidas: comprimento e capacidade das redes em cada unidade espacial; quantidade de usuários em cada unidade espacial e capacidade das instalações centrais.

- planejamento urbano: classificação das vias, sentido de tráfego; planejamento de rotas de transporte otimizadas.

- limpeza pública: plano de coleta domiciliar otimizado, no que se refere a roteirização, programação e monitoramento, bem como aspectos ambientais em que a atividade se insere.

\subsection{Roteirização e programação de coleta domiciliar}

\subsubsection{Conceitos básicos}

Com a finalidade de apresentar noções fundamentais, que permitam a melhor compreensão e análise da revisão bibliográfica sobre a temática, roteirização de veículos, buscou-se a complementação com um referencial teórico. Os conceitos básicos e definições apresentados podem ser encontrados em CANASSA (1992) e GRACIOLLI (1994). 


\section{a) Grafo}

Um grafo $G$ é definido como sendo um par ordenado $(V, E)$ onde $V$ é um conjunto e $E$ uma relação binária sobre $V$. Os elementos $V$-são denominados vértices ou nós, e os pares ordenados de $E$ são denominados arestas ou arcos do grafo. A representação de um grafo é através de pontos e linhas.

A-representação por grafos se constitui numa ferramenta muito simples, natural e poderosa em pesquisa operacional, especificamente em problemas de roteamento. A fim de exemplificar o mapeamento de uma rede viária para representação em um grafo, apresentou-se a figura 11.

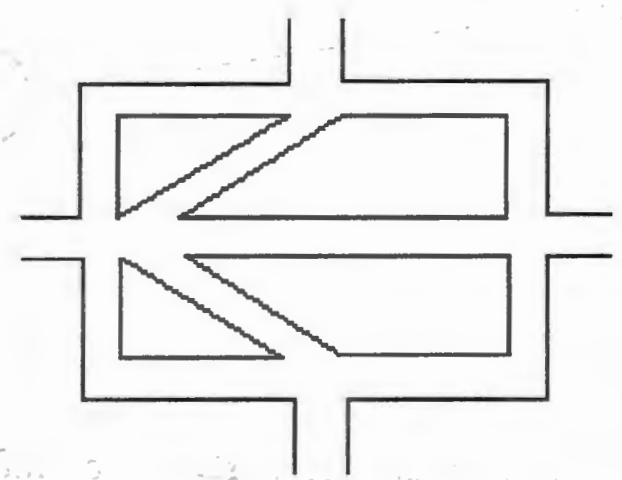

(a) Rede Viária

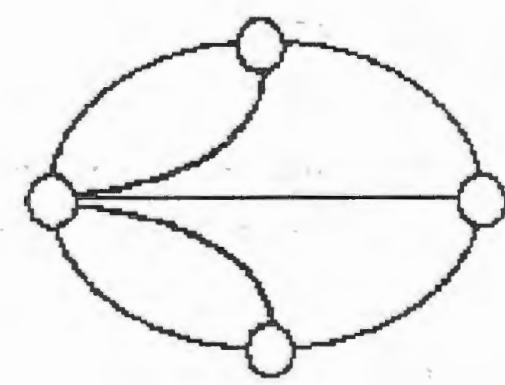

(b) Grafo correspondente da rede viária

FIGURA 11 - Representação de uma rede viária e seu grafo Fonte: GRACIOLLI (1994)

\section{b) Grafo orientado}

Se todas as linhas tem sentido, o que usualmente é mostrado por uma seta, elas são chamadas de arcos e o grafo resultante é denominado de grafo orientado, ilustrado na figura 12.

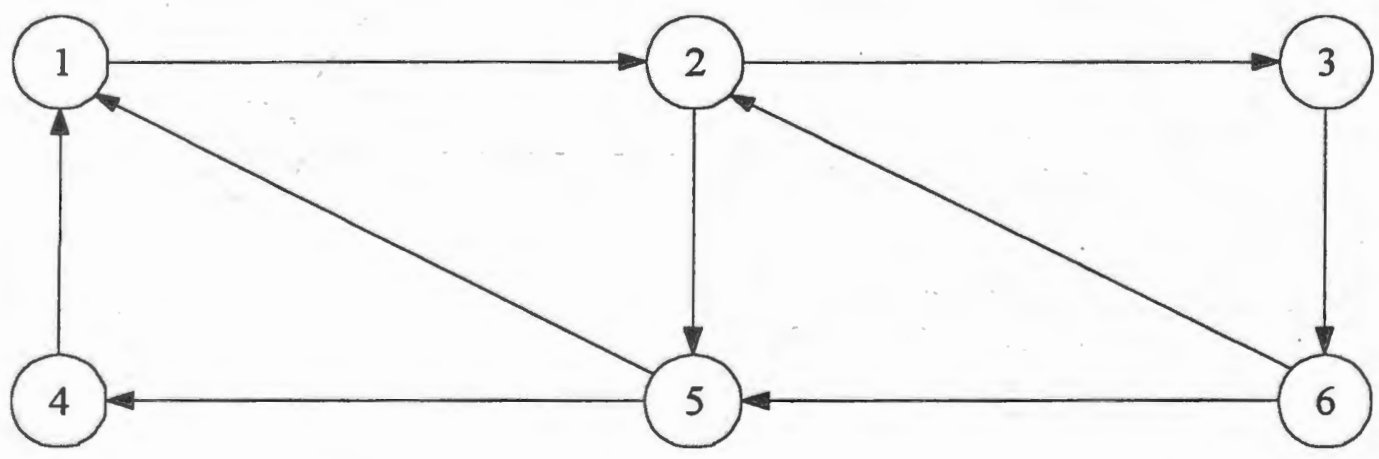

FIGURA 12 - Grafo ou rede orientada

Fonte: CANASSA (1992) 
c) Grafo não orientado

Se todas as linhas estão sem orientação, então elas são chamadas de arestas e o grafo resultante é denominado grafo não orientado, ilustrado na figura 13.

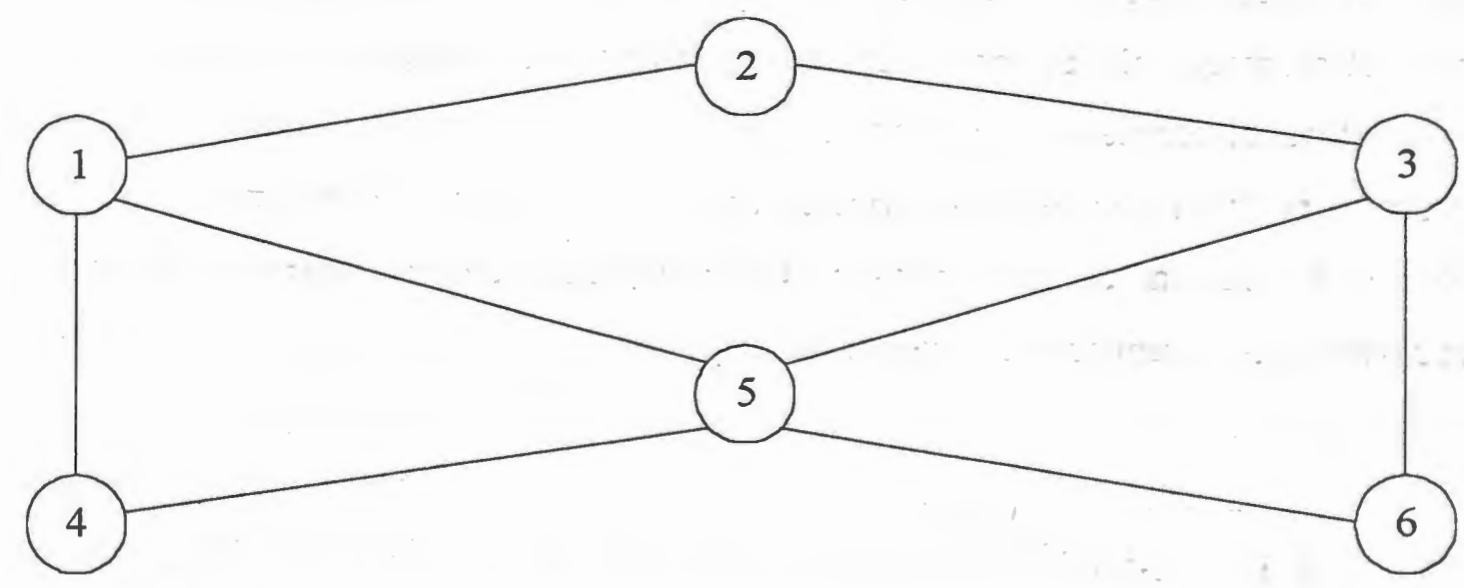

FIGURA 13 - Grafo ou rede não orientada Fonte: CANASSA (1992)

\section{d) Grafo misto}

Se existirem linhas orientadas e linhas não orientadas, ou seja, se o grafo for composto tanto por arcos como por arestas, então o grafo resultante é denominado de grafo misto, ilustrado na figura 14.

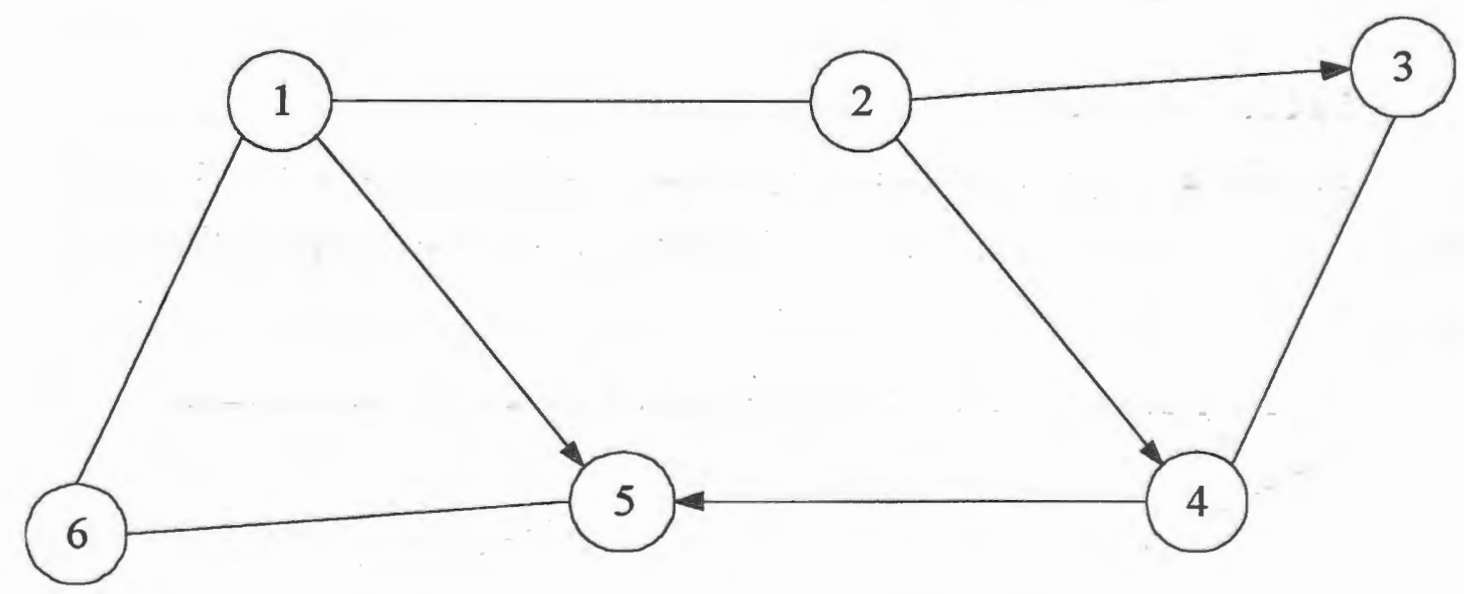

FIGURA 14 - Grafo ou rede mista Fonte: CANASSA (1992) 


\section{e) Grau de um vértice}

O grau de um vértice pode ser par ou ímpar se o número de arcos (ou arestas) incidentes ao mesmo for par ou impar.

\section{f) Grafo conexo}

Diz-se que um gráfo é conexo se existe pelo menos um caminho entre qualquer par de vértices.

\section{g) Grafos e caminhos eulerianos}

É o percurso que utiliza todas as arestas/arcos da rede uma única vez. Quando tratar-se redes eulerianas deve-se levar em consideração que os vértices devem possuir o número de arcos que entram igual ao número de arcos que saem.

\subsubsection{Métodos que não utilizam técnicas matemáticas}

Muitos autores apresentaram propostas para estabelecimento de roteiros de veículos de coleta, estas baseadas na experiência particular e na aplicação de alguns recursos técnicos, porém nenhuma técnica matemática foi utilizada. Trata-se de métodos intuitivos, baseados em parâmetros topográficos e geográficos dos setores ou áreas a serem coletadas.

GALVEZ (1979) realizou um estudo na municipalidade de Santiago do Chile, no qual fez uma análise dos roteiros dos caminhões coletores. Com linha cheia foram marcadas as ruas nas quais o caminhão estava coletando, e com linha pontilhada aquelas nas quais o caminhão só se transladava de um ponto para outro. Por meio de diferentes aproximações modificou-se o roteiro, para que as linhas pontilhadas fossem as mais curtas possíveis, o que eqüivale a eliminar percursos improdutivos, ou seja, tempo morto. Neste estudo conseguiu-se uma redução no tempo de coleta.

Neste estudo o caminhão não entrava em todas as ruas, as ruas consideradas curtas eram percorridas pelo coletor (gari) que trazia os resíduos até a esquina onde o caminhão coletor esperava. Esta operação chamada de "alcance" era marcada com uma seta e uma linha cheia delgada.

Se após estudado o roteiro, o caminhão levasse uma carga menor que sua capacidade, trocava-se alguma rua com pouca produção de resíduo por outra vizinha que tivesse mais, se ainda lhe restasse tempo, simplesmente agregavam-se outras 
ruas. Se completasse a capacidade antes de cumprir a jornada de trabalho, procediase ao inverso, trocando as ruas com muito resíduo por outras com menos.

Estes métodos tornaram possível que na municipalidade de Santiago do Chile, as 119 rotas existentes fossem reduzidas a 66.

PHILIPI JUNIOR (1986), em trabalho realizado para a CETESB, propôs que a escolha dos roteiros deve ser realizada baseando-se em estudos das ruas, observando-se o grau de intensidade do tráfego, tipo de pavimentação, acidentes da área, declividades existentes e outros parâmetros. Então, com uma planta da cidade e a densidade demográfica das quadras, juntamente com outros fatores, calcula-se os roteiros e o tempo gasto na coleta.

O roteiro, segundo o autor, deve iniciar o mais próximo possível da garagem ou local de agrupamento de pessoal. As ruas de mão única e de tráfego intenso não devem ser coletadas nas horas de maior movimento.

Conforme PARAGUASSÚ \& VERAS (1986) para elaboração de roteiros deve-se utilizar uma planta da área em estudo, de preferência na escala 1:5000. Sobre esta planta se sobrepõe uma folha de papel transparente na qual se desenha com linha cheia os segmentos produtivos, ou seja, os trechos de ruas onde há resíduos para serem coletados. Os segmentos não produtivos, ou seja, nos trechos de ruas onde não há resíduos para serem coletados (apenas deslocamento de veículo), são desenhados com linhas pontilhadas. Nas ruas onde o veículo coletor não tem acesso, e os garis vão buscar os resíduos, os trechos devem ser anotados com linhas contínuas mais finas, para diferenciar dos outros trechos considerados.

No caso de áreas onde ocorrer a necessidade de se realizar-vários roteiros, conforme especificado por PARAGUASSÚ \& VERAS (1986), deve-se utilizar uma folha transparente par cada roteiro, fazendo uma diferenciação também por cores no traçado de cada roteiro. Após a confecção completa do desenho sobre o papel transparente, fazem-se várias cópias do mesmo, e sobre cada uma desenha-se uma alternativa de roteiros. Completado o conjunto de, alternativas, escolhe-se a que fornece a menor distância a ser percorrida pelos veículos coletores.

HICKMAN (1981) apresentou quais os objetivos que se pode melhorar para balancear as rotas dos caminhões coletores de resíduos sólidos: 
- estimar o número de veículos e equipes de coleta em sistemas novos ou que estão passando por processos de reformas;

- desenvolver ou avaliar o custo de serviços terceirizados;

- avaliar o rendimento da equipe de coleta, em conjunto ou individualmente;

- balancear a quantidade de trabalho a ser realizado pelos coletores;

- determinar o tamanho ótimo de novas frotas de veículos ou otimizar o uso da existente.

O balanceamento das rotas é acompanhado pela análise de cada componente em um dia de trabalho, este tempo total (Y) pode ser calculado utilizando-se a seguinte fórmula:

$Y=t g s+t c t+n v(t s d f+t d f s+t d)-t d f s+t d g+t p r+t p$,

onde:

tgs = tempo da garagem para o setor de coleta

tct $=$ tempo de coleta total

$\mathrm{nv}=$ número de viagens

tsdf = tempo do setor de coleta para a disposição final

tdfs = tempo entre a disposição final para o setor de coleta

td $=$ tempo de descarga

tdg = tempo da área de disposição para garagem

tpr $=$ tempo de paradas

tp = tempo perdido (almoço)

\subsubsection{Métodos que utilizam técnicas matemáticas}

O desenvolvimento de rotas tem sido facilitado pela disponibilidade de ferramentas provenientes de técnicas da heurística. Utilizam programas computacionais designados especificamente para propor, selecionar e programar roteiros de coleta.

O problema matemático clássico que auxilia a roteirização e a programação da cớleta domiciliar é conhecido como Problema do carteiro chinês (Chinese postman problem-CPP). Consiste em achar um caminho de comprimento mínimo 
que passe ao menos uma vez por cada trecho de rua que compreende o setor de coleta. O veículo coletor deve sair de um nó (garagem) e voltar a ele cobrindo toda a rede de forma a minimizar a extensão total percorrida. $\mathrm{O}$ problema do carteiro chinês escolhe uma rota de forma racional, garantindo que o percurso total seja mínimo, considerando que haverá trechos a serem percorridos mais de uma vez.

Este problema, segundo EISELT et al. (1995). foi elaborado por Euler em 1736 e, por esta razão, sua solução é denominada de "caminho euleriano".

De acordo com LARSON \& ODONI (1981) Euler tentou encontrar uma maneira na qual um desfile religioso pudesse cruzar as setes pontes sobre o rio Pregel (figura 15), na cidade de Kalingrad, situada na Rússia, exatamente uma vez. Euler também deduziu alguns resultados que motivaram estudos que buscassem uma solução aproximada para o problemas do carteiro chinês.

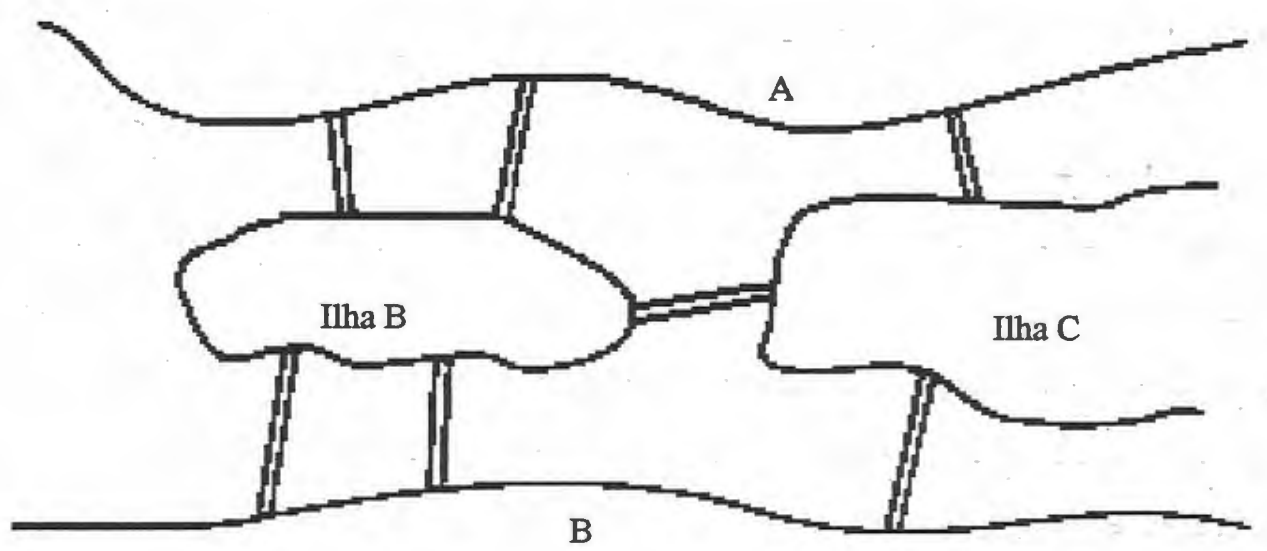

\section{FIGURA 15 - $O$ problema das setes pontes em Kalingrad Fonte: LARSON \& ODONI (1981)}

Para EISELT et al. (1995) o primeiro autor que apresentou solução para redes não orientadas, publicado em 1962, foi o matemático Mei Guan (ou Kwan Mei-Ko) que, durante a revolução cultural chinesa, trabalhou como carteiro, daí a origem do nome "problema do carteiro chinês".

MARKS \& STRICKER (1971) identificaram os problemas encontrados na análise de roteirização de veículos em serviços prestados pelo setor público, por exemplo a coleta de resíduos sólidos, cujo problema básico envolvido refere-se a rotas de mínimo custo em redes viárias. Este problema pode ser resolvido pelo já 
citado "problema do carteiro chinês", que no entanto não é facilmente adaptado para muitos serviços urbanos, pois não permite que muitas restrições sejam inseridas.

No caso da coleta de resíduos sólidos os autores citam algumas restrições, por exemplo, no que se refere a capacidade-do veículo, não podendo ser feita uma única viagem cobrindo todas as vias da cidade, visto que quando o veículo estiver cheio deve se dirigir ao local de destinação final. A cidade deve ser dividida em áreas de coleta e para cada uma das áreas determinar uma viagem completa. Ainda consideram restrições referentes a decisões sobre tamanho e número de equipes, freqüềncia; etc.

MARKS \& STRICKER (1971); novamente, fizeram a descrição matemática do problema do carteiro chinês. Analisaram um problema real usando como cenário a cidade de Cambridge, Massachusetts, com o objetivo de otimizar as rotas dos setores de coleta, identificando uma série de problemas referentes a coleta de resíduos sólidos, tais como: a divisão das áreas de coleta, onde muitas vezes trechos de uma rota avançavam sobre outra; uso ineficiente da frota conduzindo à nècessidade de contratar o serviço de empresas particulares em períodos onde a quantidade de resíduos aumentava;-definição das rotas de coleta feita pelo motorista que, embora familiarizado com o seu setor de coleta, deixava de coletar muitas ruas.

LIEBMAN $^{3}$ et al. apud CANASSA (1992), elaboraram procedimentos para planejar os roteiros dos veículos coletores de resíduos sólidos, consideraram que o problema poderia: ser dividido em três partes:

- divisão da área total em áreas menores, cada uma gerando a carga do veículo coletor;

- determinação do percurso em cada setor;

- agregação dos setores e respectivas viagens, para determinar o turno diário de trabalho de cada veículo e sua guarnição.

Os autores-desenvolveram uma nova proposta para a otimização dos roteiros, fundamentados na seguinte heurística: o menor valor possível da somatória das distâncias, percorridas por todos os veículos de coleta em uma rede, é o comprimento

\footnotetext{
${ }^{3}$ LIEBMAN, J. C:- MALE, J:-W.: WATHNE, M. (1978) Minimum Cost in Refuse Vehicle Routes. Journal of Environmental Engineering Division, p. 1-14, fev. apud CANASSA, E. M. Planejamento de roteiros dos veículos coletores de resíduos sólidos urbanos. Florianópolis. 135p. Dissertação (Mestrado). Universidade Federal de Florianópolis, 1992.
} 
mínimo que pode ser atravessado, se ele tiver capacidade para coletar a rede em uma única viagem.

Mas como o volume de resíduos gerados é normalmente superior a capacidade de carga de um veículo coletor, concluíram que os trechos de ruas, componentes de uma rede de coleta, são reatravessadas por dois motivos:

- para definir a rede de menor comprimento (rede euleriana);

- para definir os caminhos que levam, o veículo, ao início do percurso de coleta e do seu fim ao local de descarga.

O trabalho proposto apresentou solução somente para redes não orientadas e cujos locais de entrada e saída, dos veículos coletores, estejam posicionados no mesmo vértice.

CHINPLUNKAR et al. (1981), com o objetivo de reduzir os custos de coleta de resíduos sólidos da cidade de Bombay na Índia, realizaram uma proposta heurística para a solução do problema de m-carteiros chineses incorporando algumas características existentes nas cidades dos países em desenvolvimento, tais como:

- a rede de coleta de resíduos é geralmente de natureza mista, isto é, constituída de ruas de mão única e de mão dupla;

- redefinições dos setores de coleta para acomodar mais do que uma viagem a um veículo coletor. Um roteiro compreendendo-duas viagens de coleta é definido como o caminho seqüencial que engloba os seguintes percursos: garagem, setor de coleta para uma primeira viạgem, local de disposição, novamente setor de coleta para a segunda viagem, local de disposição e garagem.

- inclusão de um número apropriado de garagens/vértices iniciais para começar a coleta e um número adequado de vértices de saída da rede de coleta para o(s) local (is) de disposição;

- uma extensão do serviço em pontos que requerem uma freqüência de coleta mais do que uma vez ao dia;

- uma consideração sobre entrar e sair da área de coleta por vértices diferentes.

MANDL (1979) apresentou uma lista de diversos tipos de problemas de roteirização de veículos e descreveu alguns algoritmos desenvolvidos para 
solucioná-los. Forneceu os teoremas básicos e descreveu dois algoritmos: o algoritmo E para definir um circuito euleriano, e o algoritmo $\mathrm{CP}$, para resolver o problema do carteiro chinês.

EDMONDS \& JONHSON ${ }^{4}$ apud CANASSA (1992) elaboraram a teoria de "Matching"-e propuseram a solução do problema do carteiro chinês para redes não orientadas, redes orientadas e redes mistas. Mas no caso de redes mistas, apresentaram somente solução para redes onde todos os vértices possuem grau par. $\mathrm{O}$ surgimento de modelos para a solução do "problema do carteiro chinês" teve impulso com o desenvolvimento desta teoria:

MATION (1984) utilizou as técnicas de resolução do "problema do carteiro chinês". para redes orientadas, na otimização da coleta do bairro de Botafogo, na cidade do Rio de Janeiro. O autor fez um levantamento de algumas restrições associadas às leis de trânsito e manobras de veículos e apresentou soluções que se adaptam aos algoritmos que determinam a rota final. Apresentou uma abordagem profunda do assunto, porém de forma complicada e não operacional.

THOMAZ et al. (1984) fizeram uma aplicação do problema do carteiro chinês para a coleta domiciliar de resíduos sólidos da cidade de Fortaleza. $\mathrm{O}$ trabalho serviu de auxilio para a escolha da melhor alternativa para a coleta, transporte e destinação final.

BELTRAMI \& BODIN ${ }^{5}$ e BODIN et al..6 apud EISELT et al. (1995) descreveram sistemas computacionais para planejamento do sistema de coleta de resíduos sólidos. O estudo de-BELTRAMI \& BODIN foi aplicado em Nova York, o segundo projeto de BODIN foi para a cidade de Oyster Bay. Os autores descrevem uma aplicação real do problema dos carteiro chinês na qual podem ser englobadas rotas ótimas de coleta e operações eficientes e econômicas.

\footnotetext{
${ }^{4}$ EDMONDS, J., JOHNSON, E. L. Matching, Euler tours and chinese postman. Mathematical Programming, v.25, n.3, pp. 355-357, jul/set. 1986. apud CANASSA, E. M. Planejamento de roteiros dos veículos coletores de residuos sólidos urbanos. Dissertação (Mestrado). Universidade Federal de Florianópolis, 1992.

${ }^{5}$ BELTRAMI, E. L., L. D. BODIN. 1974. Networks and Vehicle Routing for Municipal Waste Collection. Networks 4, 65-94. apud EISELT, H. A; GENDREAU, M.; LAPORTE, G. Arc Routing Problems, Part II: The Rural Póstman Problem. Operation Research 43, n 3, p. 401.

${ }^{6}$ BODIN, L. D., G. FAGIN, R. WELEBNY and J. GREENBERG. 1989. The Design of Computerized Sanitation Vehicle Routing and Sheduling System for the Town of Oyster Bay, New York. Comput. \& Opns. Res. 16, 45-54. apud ibidem, p. 401.
} 
HUXHOLD (1991) mostra a aplicação de um sistema de informação geográfica para a definição de novas rotas de coleta da cidade de Bureau-EUA. A extensão da rota foi definida em função do número de domicílios que seria atendido pela equipe de coleta.

CANASSA (1992) apresentou um modelo para realizar o planejamento dos roteiros de coleta de resíduos sólidos urbanos. Trata-se de um estudo que visa minimizar os percursos realizados pelos veículos coletores e melhorar a utilização da capacidade de carga dos mesmos.

DHINGRA \& GEORGE (1998), objetivando uma modelação para coleta e transporte de resíduos, desenvolveram um modelo para otimizar o sistema de coleta de resíduos sólidos, este foi aplicado para um estudo de caso em um área da grande Bombay-Índia. $O$ estudo foi desenvolvido em duas fases, na fase 1 um modelo. foi formulado para otimizar a distância improdutiva de viagem dos setores de coleta para as áreas de disposição. $\mathrm{Na}$ fase 2 o objetivo era otimizar viagens improdutivas dos veículos em diferentes setores de coleta. Este objetivo foi alcançado utilizando-se de ferramentas provenientes de métodos heurísticos. A nível macro o modelo foi aplicado para otimizar a coleta e.transporte para a região e a nível micro foi aplicado para encontrar as rotas ótimas nos setores de coleta no norte da cidade.

A maioria dos casos de gerenciamento de resíduos sólidos são complexos e envolvem importantes aspectos que não podem ser modelados como um simples problema do carteiro chinês.

Pacotes de software computacionais tệm sido desenvolvidos, permitindo que muitas restrições sejam consideradas.

O mais elementar deles requer entrada de dados manuais e uso de distâncias euclidianas para estimar distâncias de viagens e tempos de coleta. Um dos mais sofisticados é um sistema de informação geográfica que possui algoritmos para roteirização de veículos.

COSTA (1982) propôs um sistema de informação para a determinação de rotas de distribuição e bens de serviços, no caso a coleta de resíduos sólidos urbanos. Foi realizado um estudo sobre os objetos que deveriam ser representados no computador e as estruturas de dados que seriam utilizados nessa representação, possibilitando assim uma implementação eficiente dos algoritmos envolvidos na 
solução do pröblemas. O objetivo principal do sistema consiste em obter uma rota que passe por todas as ruas de uma zona pré-determinada da cidade pelo menos uma vez, minimizando a distância percorrida pelo coletor sem realizar serviço. Algumas aplicações foram feitas, utilizando dados reais referentes a áreas pré-definidas das cidades de Fortaleza e Aracaju.

Neste sistema os custos foram considerados de duas formas diferentes:

- Os custos são lineares cồm relação à distância. Nesse caso foi admitido que minimizando a distância minimiza-se os custos;

- Além da distância, os custos são determinados por outros fatores, tais como condições de trânsito e do pavimento:

Segundo STOKES \& MARUCCI (1995) muitas agências de transporte dos EUA têm se interessado pela aplicação do SIG para transporte, mas as recentes aplicações têm sido em pequena éscala, ou seja, em projeto piloto. Os autores afirmam que a tecnologia ainda está imatura e requer mais pesquisas e desenvolvimento, para que se possa utilizar toda a tecnologia disponível em um sistema de informação geográfica.

PARAFINA (1995) propôs a utilização de um Sistema de Informação Geográfica SIG/TransCAD na cidade de Austin, Texas, com o objetivo de consolidar o conhecimento das bases de dados de rota e integrar com outras funções que fazem parte do gerenciamento de resíduos. Antes do programa ser implementado as rotas eram geradas manualmente e supervisionadas pelo analista de rota. Na roteirização manual é difícil estimar a quantidade de resíduo coletada por cada caminhão e distribuir o peso igualmente pela equipe de coleta (garis). Esta situação causava dificuldade no gerenciamento de operáções diárias; por exemplo, algumas equipes terminavam o itinerário em 3 horas enquanto outras levavam mais de 8 horas. Com a aplicação do SIG as rotas eram geradas de acordo com o tipo de serviço (coleta regular; coleta de material reciclável e coleta especial para resíduos de jardinagem) e tempo diário de serviço do caminhão coletor.

As rotas eram subdivididas em rotas menores (micro rota) baseando-se nas seguintes restrições: o itinerário deveria ser percorrido por um caminhão em oito horas de trabalho incluiindo o percurso da estação de transferência até a área de coleta, e a carga a ser coletăda não deverià exceder a capacidade do caminhão. 
Considerações importantes foram integradas tais como conversões à esquerda e retorno em "U", não abordados na maioria dos trabalhos publicados sobre roteirização de veículos.

Todos os itens abordados foram utilizados como restrições para a escolha do menor caminho a ser percorrido pelo caminhão coletor. O SIGT/TransCAD estabeleceu o apoio funcional e especializou a estrutura de dados e funções no sistema de coleta e transporte de resíduos sólidos. O objetivo deste trabalho de PARAFINA (1995) é produzir um empreendimento de base de dados geográficos acessível a toda área de trabalho. Embora a ênfase do programa implantado seja a roteirização, a meta é prover informações para gerenciamento da coleta e transporte de resíduos sólidos envolvendo empreendedor e cliente, sendo o desenvolvimento e manutenção do sistema de trabalho um continuo empreendimento.

TRUCH \& ANDERSON (1996) desenvolveram para a cidade de CalgaryEUA, um projeto de rota para coleta de resíduos sólidos utilizando um Sistema de Informação Geográfica. O projeto com início em 1996 levará aproximadamente 3 anos para conclusão, e a última meta será o desenvolvimento de um verdadeiro projeto de capacidade macro heurístico.

Também existe um potencial com GPS/SIG para construir um projeto de micro heurística. Um projeto de macro heurística indicará a melhor rota entre a área de disposição dos resíduos e a área de serviço e o projeto de micro heurística, o melhor modo para dirigir a rota inteira incluindo as áreas de serviço.

Porém, o grupo reconheceu que muitos projetos de SIG falharam, porque o tempo para obter vantagens reais foi muito longo. Uma prioridade foi dada tendo um sistema de produção completamente operacional no menor tempo possível. Qualquer aspecto do projeto que possa ser executado simultaneamente ou emprestado de outros projetos, seriam utilizados pạa "alcançar o mais rápido" desenvolvimento. Esta aproximação foi usada nas "Fases Um e Dois" e seria incorporada nas duas fases restantes do processo. A flexibilidade total para o projetista de rota é a chave global para o projeto do sistema.

A fase um (Route96) consistiu em um projeto piloto que testaria a viabilidade técnica de um projeto modificado dos processos históricos para coleta residencial. A fase dois (em desenvolvimento/1996) consistiu em definir o último modelo de dados 
exigido para dirigir todos os aspectos de projeto de rota; incorporando os atributos da coleta comercial no modelo residencial; e trazendo estas partes para produção total dentro de um ano. A fase três incluiria atendimento a população e o projeto de coleta comercial. A fase quatro traria a coleta residencial em um projeto de macro heurística e avaliação dos potenciais de GPS/SIG a bordo de computadores nos veículos de coleta (micro heurística).

CHANG, LU \& ẆEI (1997) demonstraram a tecnologia dos SIGs de uma maneira prática e integrada para o gerenciamento dos resíduos sólidos. Este estudo desenvolveu múltiplos objetivos, modelos de programação combinados para roteirização e programação de veículos, para gerenciamento de sistemas de resíduos sólidos sintetizados dentro de um ambiente SIG. A integração de modelos matemáticos de programação foram demonstrados através da aplicação em uma área especifica de Taiwan.

O primeiro passo deste estudo foi determinar uma rede padrão em cada subdistrito. Este foi acompanhado pela criação de uma base de dados utilizando o SIG, ARC/INFO em uma workstation SUN SPARC 20/50. Esta base de dados contém arquivos lineares representados em mapas de ruas do distrito de Lin-Ya. A distribuição da população corrente e a localização dos pontos de coleta foram armazenados para cada link da rede. O segundo passo foi determinar a média da geração de resíduos sólidos sobre todos os links da rede. A base de dados deveria então ser manipulada para sumarizar a taxa de geração padrão e a requerida ao longo de cada link. Este valores foram armazenados como um atributo do link no sistema.

O terceiro passo foi aplicar um modelo de programação para otimizar a roteirização e a programação utilizando uma base de dados de SIG. Finalmente, o quarto passo mostra um resultado analítico de interação em ambiente SIG, análise referente a dados estatísticos e quantidade de dados requeridos.

Base de dados econômicos e ambientais sobre o gerenciamento de resíduos sólidos foram coletados nas agências governamentais. A rede de coleta para cada distrito foi digitalizada e preparada como um layer. Embora a origem e o destino possam ser marcadas com o mouse, assim como os endereços que são automaticamente designados por coordenadas geográficas, esta análise fixa nós de 
origem e destino para cada subdistrito de acordo com a destinação final (aterro sanitário ou incinerador).

Neste estudo, foi considerada a minimização de três fatores:

- distância total de coleta;

- custos operacionais de coleta;

- tempo total de coleta.

O procedimento permitiu análise de alternativas na coleta de resíduos antes de selecionar o cenário final de operação, contribuindo para um gerenciamento eficaz e condizente com a proposta do estudo. 


\section{MATERIAIS E MÉTODOS}

O trabalho proposto seguiu uma projeção analítica, dividindo-se em duas etapas principais:

- Elaboração e distribuição de questionário para municípios brasileiros;

- Equacionamento dos dados para aplicação do software (descrição de hardware e software a serem utilizados; aprendizado do software; obtenção, entrada e processamento dos dados).

Os itens citados anteriormente são descritos a seguir.

\subsection{Elaboração e distribuição de questionário para municípios brasileiros}

Esta etapa constitui-se na elaboração de um questionário padrão (Cf. ANEXO A) e em sua distribuição às Prefeituras brasileiras (Cf. ANEXO B).

$O$ envio de questionário teve como objetivo adquirir informações referentes às características dos sistemas de coleta domiciliar de municípios de médio porte (quantidade de resíduos gerados, freqüência da coleta, tipo e capacidade dos veículos coletores, método utilizado para dividir os setores de coleta, métodos e técnicas utilizadas para definir roteiros do caminhão coletor, guarnição de coleta, etc.) e situalos frente a municípios de grande e pequeno porte. $\mathrm{O}$ desconhecimento de dados específicos sobre a questão da coleta domiciliar em todas as suas etapas, incluindo aqui a questão da roteirização dos veículos, justifica esta caracterização, que servirá de base para trabalhos futuros, objetivando assim buscar alternativas compatíveis com a realidade dos municípios.

De acordo com PEIXOTO (1997) não existe nenhuma definição sobre o que venha a ser município de pequeno, médio e grande porte, sobretudo quando se discute o tamanho destes baseado no número de habitante. Assim para aplicação, do questionário, analisou-se a classificação proposta por SANCHES (1988) apresentada na tabela 17 . 
TABELA 17 - Classificação dos municípios brasileiros

\begin{tabular}{l|l}
\hline Tipo & Número de Habitantes \\
\hline Metrópoles Nacionais & $>3.000 .000$ \\
Metrópoles Regionais & 1.000 .000 a 3.000 .000 \\
Grandes & 500.000 a 1.000 .000 \\
Médios & 50.000 a 500.000 \\
Pequenos & 20.000 a 50.000 \\
\hline
\end{tabular}

Fonte: SANCHES (1988) adaptado de Estudo Publicados pelo GEIPOT-Empresa

Brasileira de Planejamento dos Transportes.

De acordo com a divisão político administrativa vigente em 1996 existiam no país 4974 municípios. A tabela 18 apresenta a distribuição da população nesses municípios.

TABELA 18 - Distribuição da população nos municípios brasileiros em 1996

\begin{tabular}{l|r|r|r|r}
\hline \multirow{2}{*}{$\begin{array}{c}\text { Número de } \\
\text { Habitantes }\end{array}$} & \multicolumn{2}{|c|}{ Número de Municípios } & \multicolumn{2}{|c}{$\%$} \\
\cline { 2 - 5 } & \multicolumn{1}{|c|}{ Simples } & Acumulado & \multicolumn{1}{c}{ Simples } & Acumulado \\
\hline Total Brasil & 4974 & & & \\
Superior a 5.000 & 2 & 2 & 0,04 & 0,04 \\
De 5.000.000 a 1.000 .000 & 9 & 11 & 0,18 & 0,22 \\
De 1.000 .000 a 500.000 & 14 & 25 & 0,28 & 0,50 \\
De 500.000 a 200.000 & 70 & 95 & 1,41 & 1,91 \\
Inferior a 200.000 & 4879 & 4974 & 98,09 & 100,00 \\
\hline
\end{tabular}

Fonte: Fundação IBGE (1996)

No presente trabalho optou-se por enviar o questionário à municípios que tinham acima de 46.828, em 1996 (Cf. ANEXO B) abrangendo um total de 514, que representam 10,15\% do total de municípios brasileiros (4974 - Cf. tabela 17) correspondendo, na maioria, a municípios de médio porte conforme a classificação proposta anteriormente. A tabela 19 mostra a distribuição da população nos municípios amostrados. 
TABELA 19 - Distribuição da população dos municípios amostrados

\begin{tabular}{l|r|r|l}
\hline Número de Habitantes & $\begin{array}{l}\text { Número de } \\
\text { Municípios }\end{array}$ & $\%$ & Tipo \\
\hline Superior a 1.000.000 & 11 & 2,14 & Metrópoles Nacionais e \\
& 16 & 3,11 & Regionais \\
Cidades Grandes \\
De 500.000 a 50.000 & 453 & 88,13 & Cidades Médias \\
Inferior a 50.000 & 34 & 6,61 & Cidades Pequenas \\
Total de municípios amostrados & 514 & 100,00 & \\
\hline
\end{tabular}

\subsection{Equacionamento dos dados para aplicação do software}

\subsubsection{Descrição de software e hardware a serem utilizados}

O software utilizado foi o TransCAD, versão 3.0c for Windows. De acordo com LOUREIRO \& RALSTON (1996) foi o primeiro pacote desenvolvido especialmente para ser utilizado como ferramenta de planejamento, gerência, operação e análise de sistemas de transporte, incorporando além de funções básicas de um SIG, rotinas específicas para a solução de problemas de logística, pesquisa operacional e de transporte em geral. Estas rotinas permitem aos usuários aplicar não só funções básicas de análise de rede como também resolver problemas convencionais de roteamento. $\mathrm{O}$ software TransCAD fornece acessibilidade à base de dados geográficos e de transporte, possibilitando que esses elementos sejam combinados de diferentes maneiras, adaptável aos problemas de roteirização de veículos, objeto deste trabalho.

Os equipamentos utilizados para processamento e apresentações das informações foram:

- CPU: pentium 100MHZ, 128 MB de memória RAM e um disco rígido de 4GB com sistema operacional Windows 95;

- versão acadêmica do programa TransCAD;

- impressora jato de tinta colorida, série 850 da HP. 


\subsubsection{Aprendizado do software}

Esta etapa foi realizada através dos tutoriais propostos por SILVA \& WAERDEN (1997) e CALIPER (1996).

O primeiro é um pacote de auto instrução composto por 10 capítulos, dividido em três partes principais:

- criação de arquivos bases para início de uma aplicação;

- utilização de ferramentas básicas dos SIGs oferecidas pelo software;

- manuseio de ferramentas específicas utilizadas para análise de planejamento de transporte.

$\mathrm{Na}$ primeira parte são abordadas a criação de diferentes tipos de bases de dados (pontos, linhas, áreas). Nesta foi possível utilizar ferramentas, como mudança de estilos de mapa, mudança de escala, legenda e criação de arquivos geográficos, e também perceber a diferença entre arquivos geográficos e mapas, bem como trabalhar com camadas (layers), modificar bases de dados, exibir e ocultar camadas.

$\mathrm{Na}$ segunda parte foram mostradas maneiras diferentes para criar mapas temáticos, apresentar diferentes bases associadas a um mapa, exibir/ocultar/desfazer seleções, utilizando-se de vários métodos de seleção de dados (seleção por pontos, círculos, forma, condição), agregar informações espaciais e confecção de mapas.

$\mathrm{Na}$ terceira parte foram estudadas ferramentas específicas para o planejamento de transportes, operações básicas como o tratamento de matrizes, criação, edição e apresentação de resultados em mapas e análise de redes. A partir de uma base de dados de linhas foi possível criar uma rede de transporte e solucionar uma variedade de problemas como, por exemplo, encontrar caminhos mínimos.

Com o estudo deste tutorial foi possível familiarizar-se com as ferramentas dos SIGs e também fortalecer conhecimentos básicos para a utilização do software.

A figura 16 apresenta a descrição dos capítulos do tutorial proposto por SLVA \& WAERDEN (1997) para o software TransCAD 3.0. 


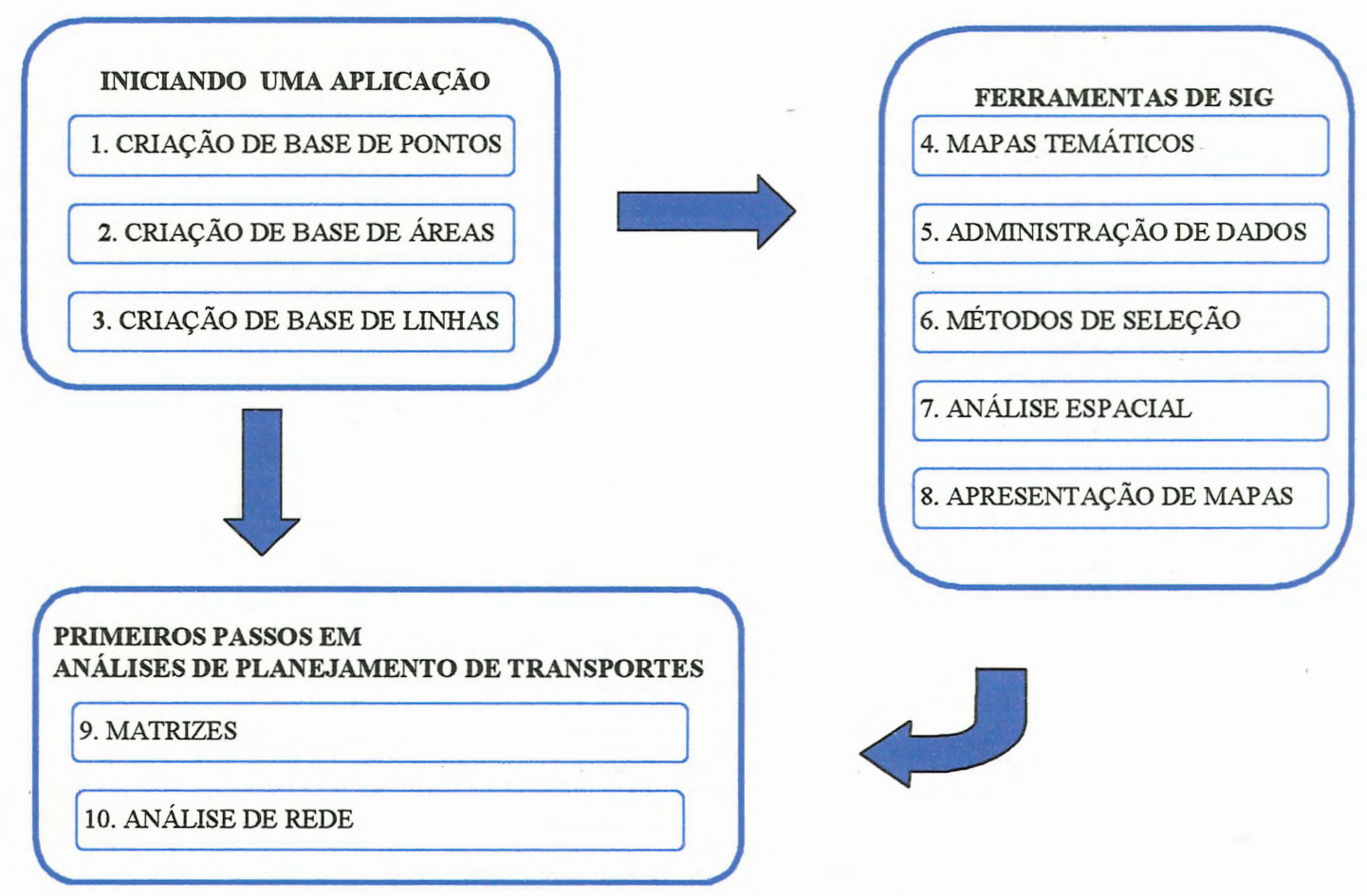

FIGURA 16 - Descrição dos capítulos do tutorial para o software TransCAD 3.0 Fonte: SILVA \& WAERDEN (1997)

Os tutoriais propostos por CALIPER (1996) exemplificam casos gerais relativos aos problemas de roteirização de veículos. A explicação apresenta-se de forma superficial, comprometendo a compreensão do usuário e a aplicação efetiva do software.

\subsubsection{Obtenção, entrada e processamento dos dados}

As informações referentes ao sistema viário da cidade foram obtidas através de plantas cedidas pela prefeitura, em escala 1:10.000, de acordo com MARQUES (1998) baseadas em levantamento aerofotogramétrico de 1988.

A digitalização da base geográfica, contendo camadas de pontos e linhas, foi realizada em um projeto anterior com auxílio de uma mesa digitalizadora, utilizando recursos do software TransCAD (SILVA et al., 1996). Para o início do presente trabalho estava disponível o mapa da cidade em formato digital e a base de dados constituída de informações básicas referentes a cada link, tais como: um número identificador e o comprimento. A figura 17 mostra a imagem vetorial do sistema viário digitalizado. 


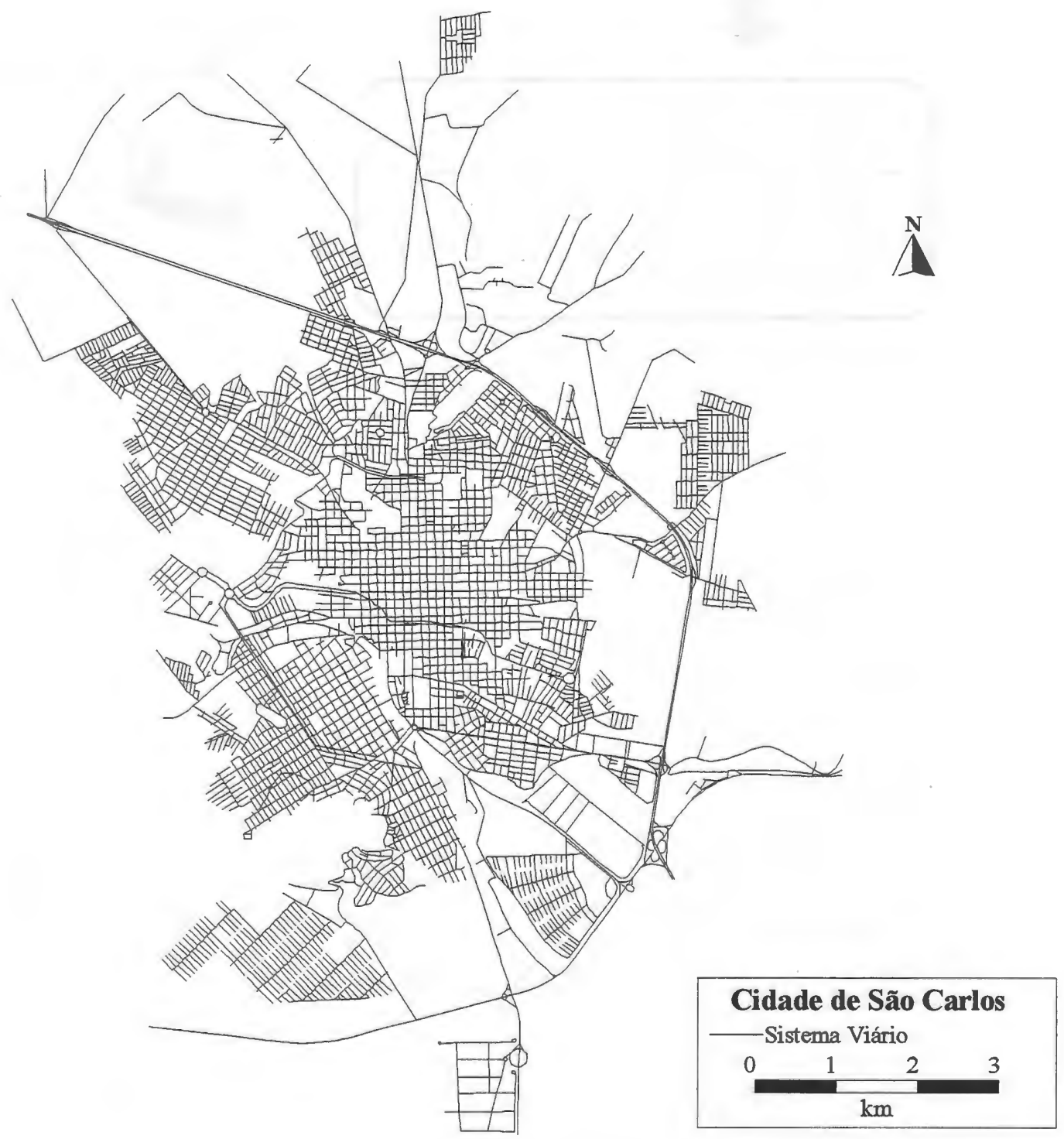


Posteriormente foram realizadas:

- nomeação dos logradouros;

- atualização do sistema viário;

- levantamento do sentido de fluxo dos links;

- delimitação do setores de coleta;

- identificação dos links que seriam servidos pelo serviço de coleta;

- localização da garagem;

- preenchimento da base de dados.

Estas etapas serão descritas a seguir:

a) Nomeação dos logradouros

Com base em um mapa, os nomes dos logradouros foram digitalizados por um equipe de 6 pessoas, e em três semanas a base estava pronta. A figura 18 ilustra a representação do nome dos logradouros.

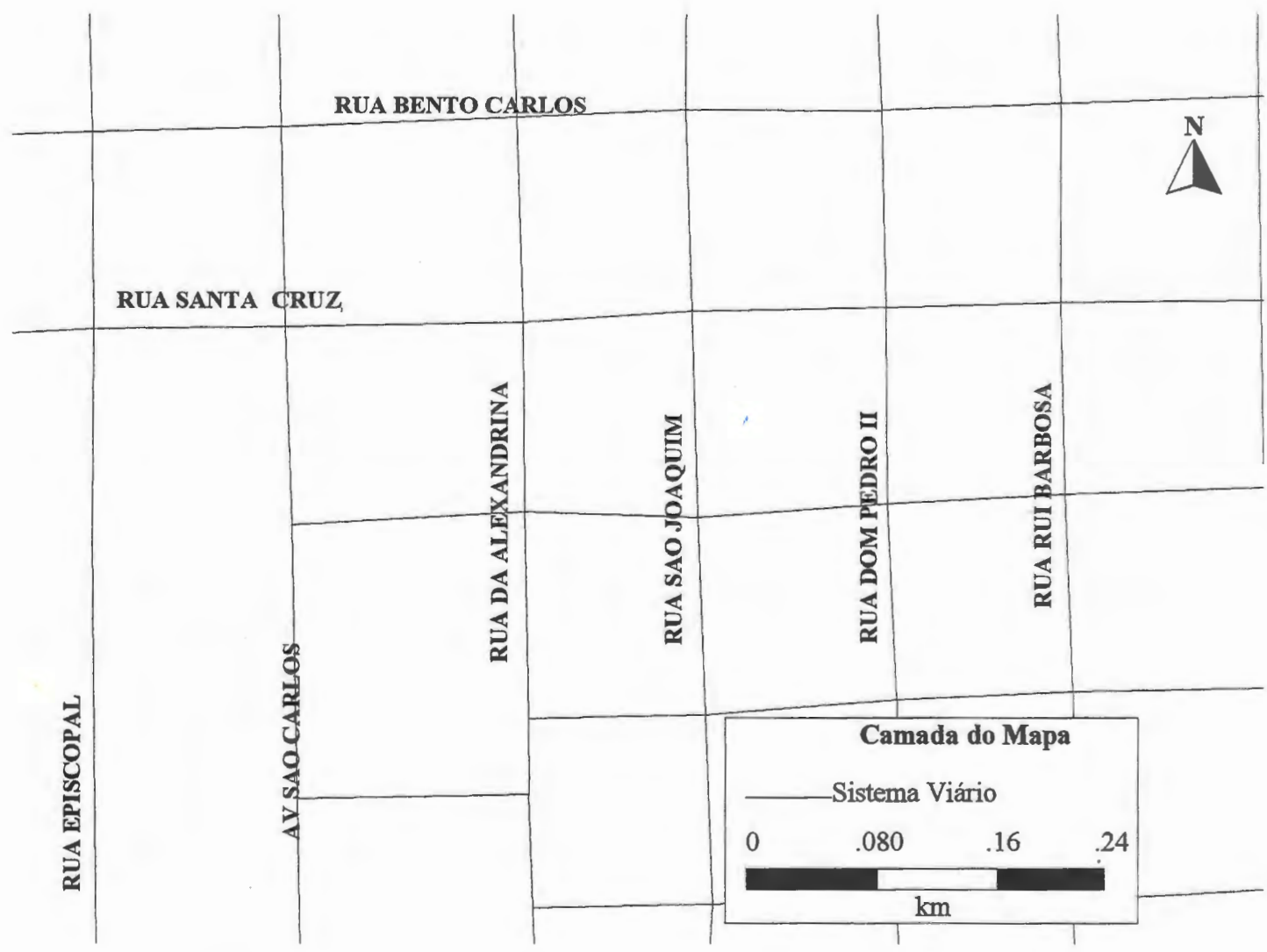

FIGURA 18 - Representação do nome dos logradouros 
b) Atualização do sistema viário

Foi realizado um levantamento de campo a fim de identificar as ruas não existentes no mapa e a serem incluídas. Utilizando ferramentas para edição de mapas, algumas ruas foram digitalizadas direto na tela do computador, e outras apagadas, em ambos os casos, sempre com auxílio do mouse.

c) Levantamento do sentido de fluxo dos links

Esta fase foi imprescindível devido a aplicação que se pretendia realizar, roteirização de veículos. O levantamento foi feito com um veículo particular, os sentidos anotados manualmente em um mapa, e posteriormente acrescentados a base de dados. Utilizando o procedimento da rede de trabalho (Procedures/Networks) que tem disponível uma opção "sentido dos links" (link direction), permitiu-se na rua selecionada, o sentido escolhida; informação referente à direção dos links é automaticamente adicionada a base de dados.

d) Delimitação dos setores de coleta

Dados referentes a área de estudo foram obtidos junto à empresa responsável pela execução dos serviços de coleta e transporte de resíduos sólidos domiciliares. A partir das ferramentas de seleção procedeu-se a entrada dessas informações na base de dados.

e) Identificação dos links que seriam servidos

Na camada de linhas, foram identificados os links que seriam servidos pelo serviço de coleta. Nas ruas sem saída considerou-se a seguinte situação - o coletor poderia percorrer a rua, recolher os resíduos e transportá-los até o caminhão coletor, evitando a execução de manobras.

f) Localização da garagem

Seleção do nó, na camada de pontos, que identificava a localização da garagem .

g) Preenchimento da base de dados

Quanto aos campos compunham a base de dados, optou-se por utilizar os propostos pela CALIPER (1996) para facilitar a utilização dos procedimentos a serem adotados no estudo de caso.

As tabelas 20 e 21 identificam os campos a serem preenchidos na base de dados das camadas de linhas e-pontos. 
TABELA 20 - Campos a serem preenchidos na base de dados da camada de linhas

\begin{tabular}{l|l|l}
\hline Campo & Tipo & Função \\
\hline ID & Inteiro & $\begin{array}{l}\text { Registro que identifica a } \\
\text { camada de linhas }\end{array}$ \\
\hline Dir & Inteiro & $\begin{array}{l}\text { Registro que indica a } \\
\text { sentido de fluxo do link. }\end{array}$ \\
\hline Nome & Inteiro & $\begin{array}{l}\text { Utilizado para identificar a } \\
\text { rua no relatório de } \\
\text { itinerário }\end{array}$ \\
\hline Serviço * & Inteiro & $\begin{array}{l}\text { Registro que identifica o } \\
\text { link no qual o serviço de } \\
\text { coleta é requerido, e o } \\
\text { setor de coleta ao qual o } \\
\text { link pertence. }\end{array}$ \\
\hline Garagem & Inteiro & O ID da garagem \\
\hline
\end{tabular}

Fonte: CALIPER (1996)

TABELA 21 - Campos a serem preenchidos na base de dados da camada de pontos

\begin{tabular}{l|l|l}
\hline Campo & Tipo & Função \\
\hline ID & Inteiro & $\begin{array}{l}\text { Registro que identifica a } \\
\text { camada de pontos }\end{array}$ \\
\hline
\end{tabular}

Fonte: CALIPER (1996)

O campo marcado com um asterisco na tabela 19 , é representado na base de dados por um par de arquivos, indicando dados relevantes em duas direções ao longo de cada link, denominados bidirecionais.

Deve-se preencher o campo referente ao sentido no qual o link seria atravessado, assegurando que o serviço de coleta seria realizado em único passe. Se o sentido adotado coincidir com a direção topológica, sentido no qual as coordenadas foram armazenadas, deve-se preencher somente o campo referente ao "Serviço AB" 
e, se o sentido adotado não coincidir com a direção topológica, somente o campo "Serviço BA".

Quanto ao sentido dos links, o número "0" (zero) na base de dados indica que a rua é de mão dupla, número "1" (hum) indica que o sentido de fluxo coincide com a direção topológica do link e o número "-1" (menos hum) indica que a sentido de fluxo não coincide com a direção topológica do link.

Para efeito de ilustração a figura 19 apresenta parte da base de dados da camada de linhas.

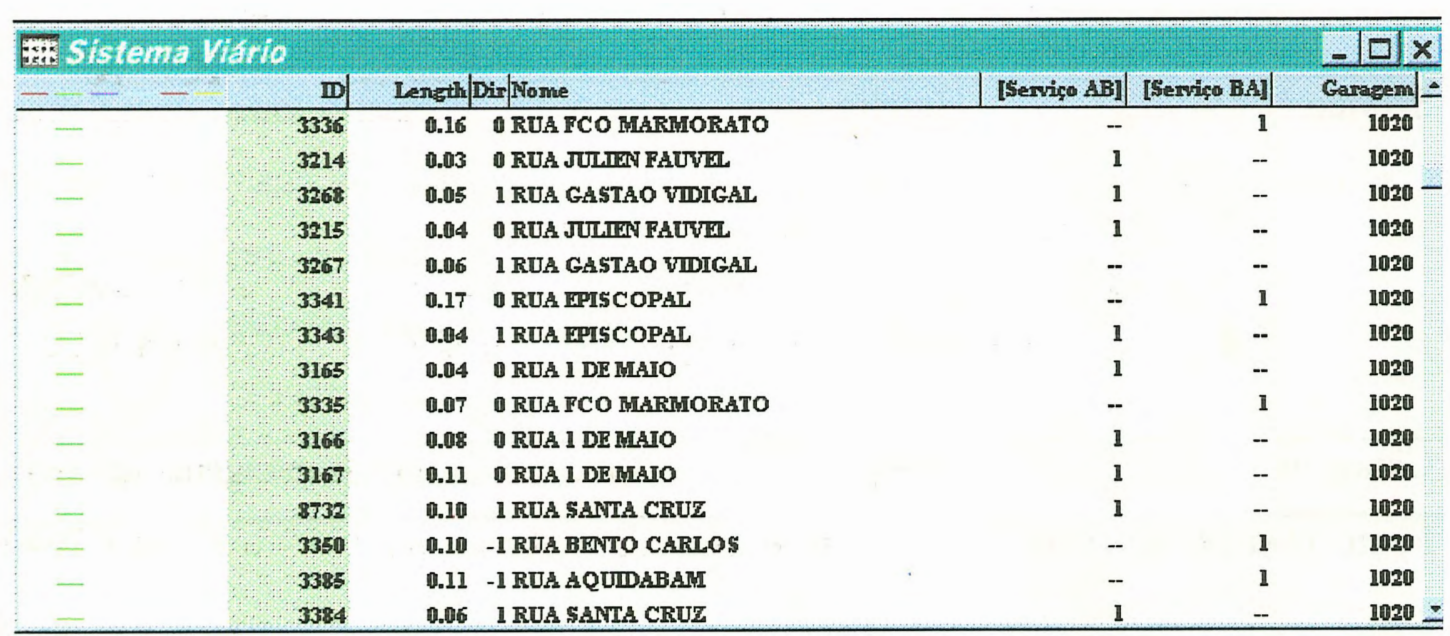

FIGURA 19 - Base de dados da camada de linhas

Nas ruas de sentido único o campo "Serviço $A B$ " deve ser preenchido quando o valor da direção for igual a "1" e "Serviço BA" quando for igual a "-1". A visualização dos sentidos de fluxos dos links são ilustrados na figura 20. 


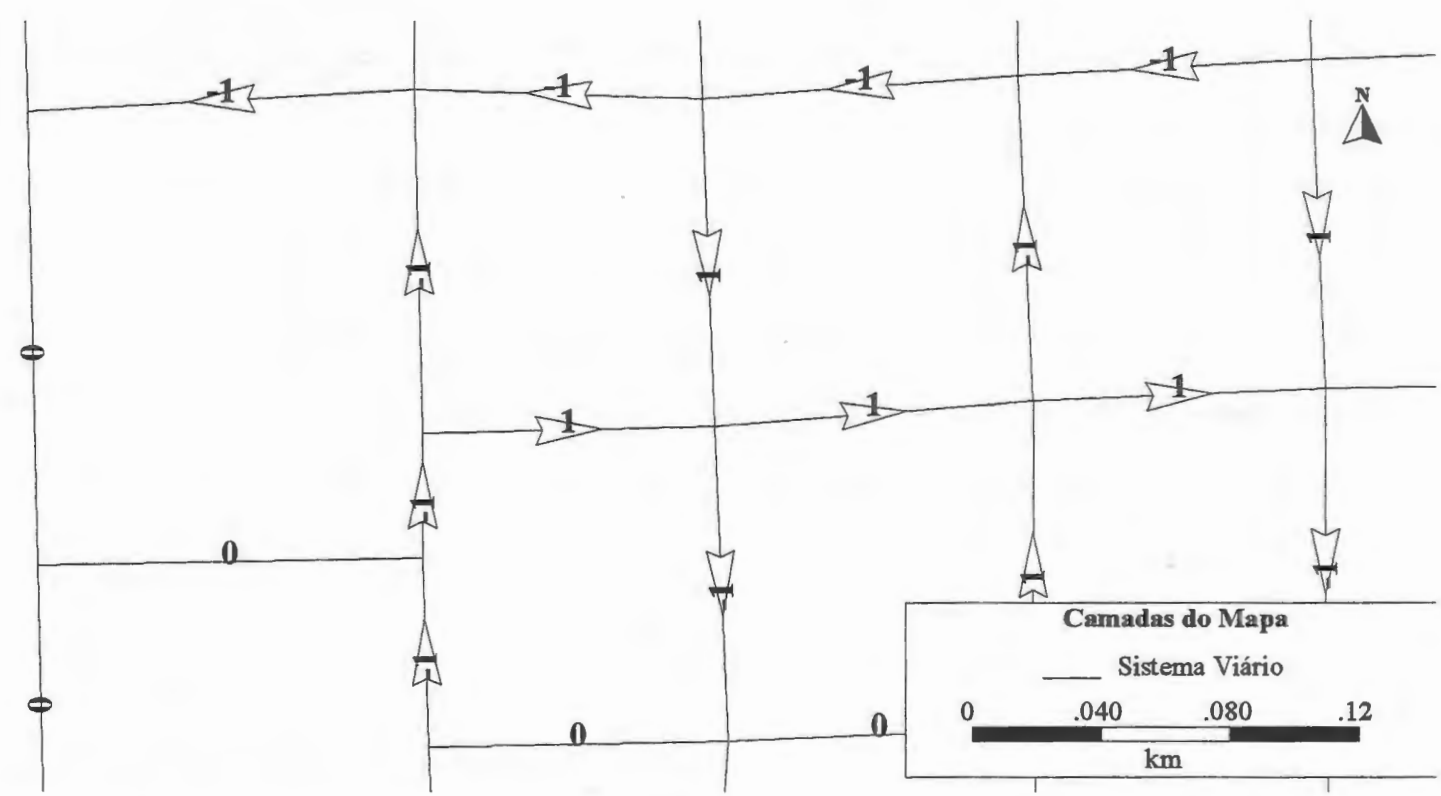

FIGURA 20 - Sentido de fluxo dos links

Obs.: O número "0" identifica as ruas de mão dupla

O número"1" (sentido de fluxo coincide com a direção topológica) e "-1" (sentido de fluxo não coincide com a direção topológica) identificam as ruas de sentido único

Com a base de dados pronta, antes de executar as rotinas foi criada um rede de transporte a partir das informações armazenadas. A rede possui 4.620 nós e 7040 links.

Completada esta etapa partiu-se para aplicação da rotina de roteamento em arco (Arc Routing) onde foram realizadas simulações, objetivando estabelecer um perfil de trabalho a ser aplicado no estudo de caso.

\subsubsection{Rotina - roteamento em arco (Arc Routing)}

O TransCAD inclui um procedimento de roteamento em arco, com ferramentas para mostrar e trabalhar com rotas, que atravessam um conjunto de links em uma rede de transporte.

Como a maioria dos procedimentos de análise em redes de transportes, a rotina de roteamento em arco pode minimizar distância ou tempo e também considerar restrições de movimento, como por exemplo proibir "manobras em U".

O procedimento de roteamento em arco satisfaz a condição estabelecida por Euler que "para atravessar um conjunto de links em uma rede direcionada 
exatamente uma vez e retornar ao ponto de saída, todo nó da rede deve ter o mesmo número de arcos (links) que entram e que saem".

O TransCAD utiliza o método de programação linear para este tipo de análise. $\mathrm{O}$ algoritmo toma como solução inicial um número mínimo de nós a serem carregados, verificando se a solução pode ser melhorada. Pára de carregar, quando consegue ligar o nó de origem ao de destino utilizando-se o número mínimo possível de links, minimizando o número de links percorridos sem realização de serviço.

Para aplicação na rotina foram escolhidos alguns atributos:

- comprimento minimizado (minimize length);

- serviço $\mathrm{AB}$ ou BA (Service Flag), tendo em vista que somente um atributo deve ser escolhido, pois em se tratando de arquivo bidirecional, uma vez escolhido um atributo a rota será traçada para o correspondente;

- código de serviço (service code) que corresponde ao número do setor. O TransCAD traça uma rota para cada setor, por exemplo se fosse escolhido o código 1 , o procedimento iria construir a rota servindo todos os links do Setor 1;

- sistema de rota (route system);

- relatório de itinerário (itinerary reports);

- características do menor caminho; para visualizar na base de dados do sistema de rotas a distância em percurso de serviço produtivo (service length) e trajeto sem realização de coleta (deadhead length).

$\mathrm{O}$ TransCAD resolve o problema de roteirização em arco; exibe relatórios de saída de dados (output reports) e o sistema de rota. A visualização da rota na tela. não se apresenta de uma forma clara, não sendo possível acompanhar visualmente o roteiro do caminhão e o software não possui uma ferramenta que melhore este problema. Assim, a consulta ao relatório de itinerário se faz indispensável, quando se deseja obter mais detalhes sobre a rota do caminhão no setor de coleta. 


\section{ESTUDO DE CASO}

\subsection{Aspectos gerais}

A cidade de São Carlos, localizada próxima a região central do estado de São Paulo, foi escolhida como área de estudo; uma cidade de porte médio com aproximadamente 175.000 habitantes.

A execução dos serviços de coleta e transporte de resíduos sólidos domiciliares é terceirizada, sendo a empresa VEGA Sopave, a responsável. Esta executa este serviço deste 1980.

Com o aumento da população, conseqüentemente cresceu a produção de resíduos. A empresa ao longo deste anos veio ampliando seus serviços e melhorando equipamentos, visando assim o melhor atendimento da comunidade. ANDREOTTI $(1998)^{7}$ apresentou alguns dados históricos referentes à produção de resíduos sólidos, citados a seguir:

- Produção diária de resíduos sólidos (valores médios)

Novembro/1980 até $1981-60$ t/dia

$1982-80$ t/dia

$1983-100 \mathrm{t} / \mathrm{dia}$

$1995-110 \mathrm{t} /$ dia

$1997-140 \mathrm{t} / \mathrm{dia}$

- Setores de coleta

Até 1989 eram 12 setores de coleta

Desde 1992 são 17 setores de coleta

\footnotetext{
${ }^{7}$ ANDREOTTI, E.C. (1998). Gerente Operacional-VEGA Sopave Engenharia Ambiental, Comunicação Pessoal, São Carlos, SP.
} 
- Tamanho da frota

1980 - 1989 eram 5 caminhões compactadores com capacidade de 7 a $8 \mathrm{t}$ 1989 - 1996 passaram a ser 6 caminhões com capacidade de 7 a $8 \mathrm{t}$ Maio/1997 - toda a frota foi substituída; atualmente (junho 1998) são 7 caminhões com capacidade de $10 \mathrm{t}$. Esta medida se fez necessária, pois a frota anterior (idade média 8 anos) não estava em bom estado de conservação, causando uma série de problemas operacionais que prejudicavam a execução dos serviços.

Os roteiros de coleta são definidos pelo motorista do caminhão com auxílio do gerente de operações que, pela própria experiência de trabalho, procura estabelecer roteiros que minimizem o percurso total de coleta. Mas não existe nenhum registro (em mapas) sobre os itinerários.

Quanto aos critérios da escolha da área de estudo foram considerados principalmente os aspectos listados a seguir:

- porte do município;

- facilidades para a realização do trabalho de campo;

- estrutura oferecida pelo centro de pesquisa (universidade);

- disponibilidade de uma base de dados implantada em um sistema computacional.

\subsection{Considerações sobre o local de aplicação do software}

Para fins da aplicação do software escolheu-se a área central de coleta da cidade de São Carlos, composta por 5 setores; a freqüência de coleta é diária e no período noturno, cada setor produz em média $13 \mathrm{t} /$ dia.

A divisão dos setores utilizada foi fornecida pela VEGA Sopave, e são denominados Setor 1, 2, 3, 4 e 5 respectivamente, a sua localização é apresentada na figura 21, e podem ser visualizados com detalhe nas figuras $22,23,24,25$ e 26. 


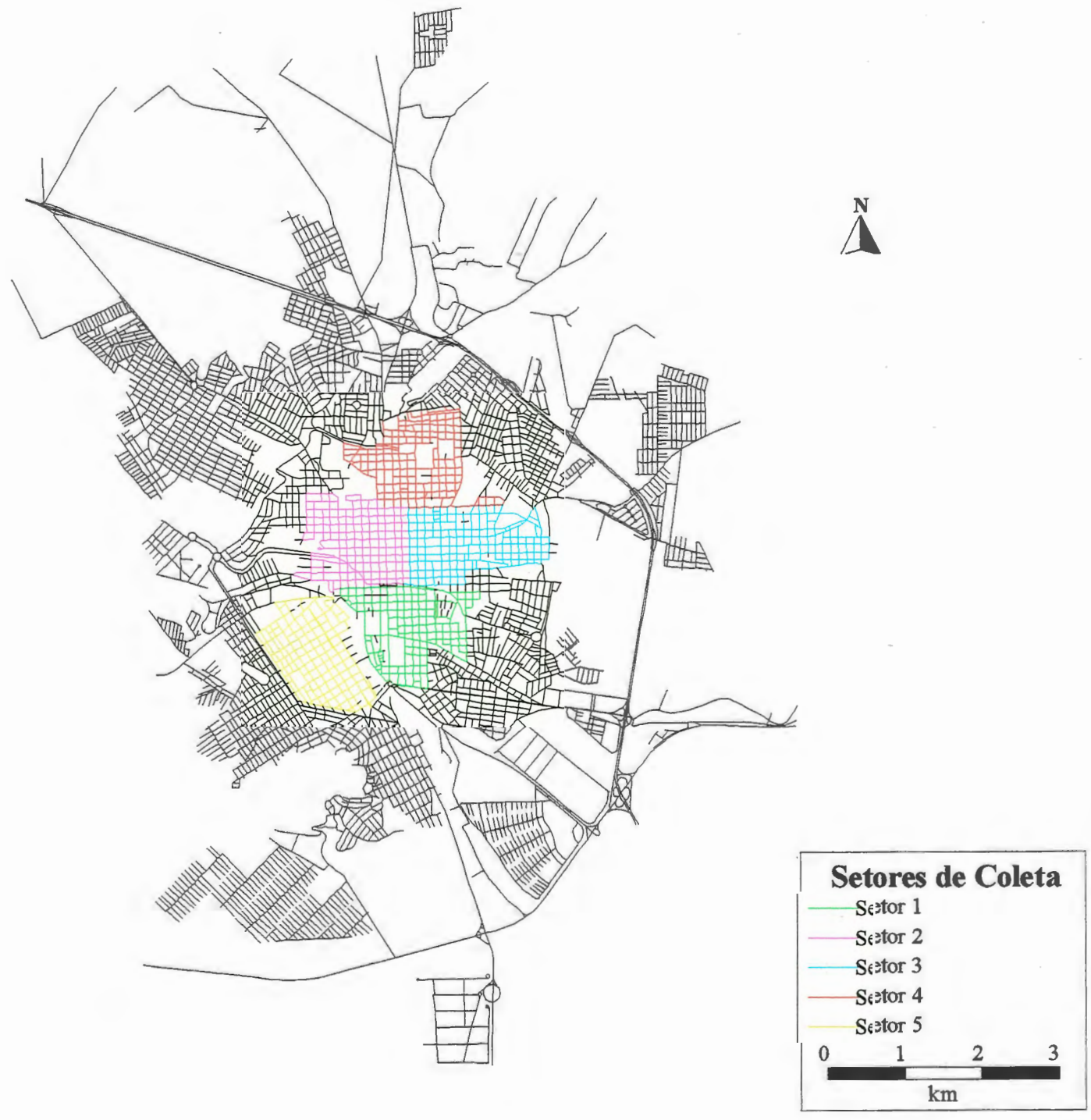

FIGURA 21 - Localização dos setores de coleta escolhidos para área de estudo 


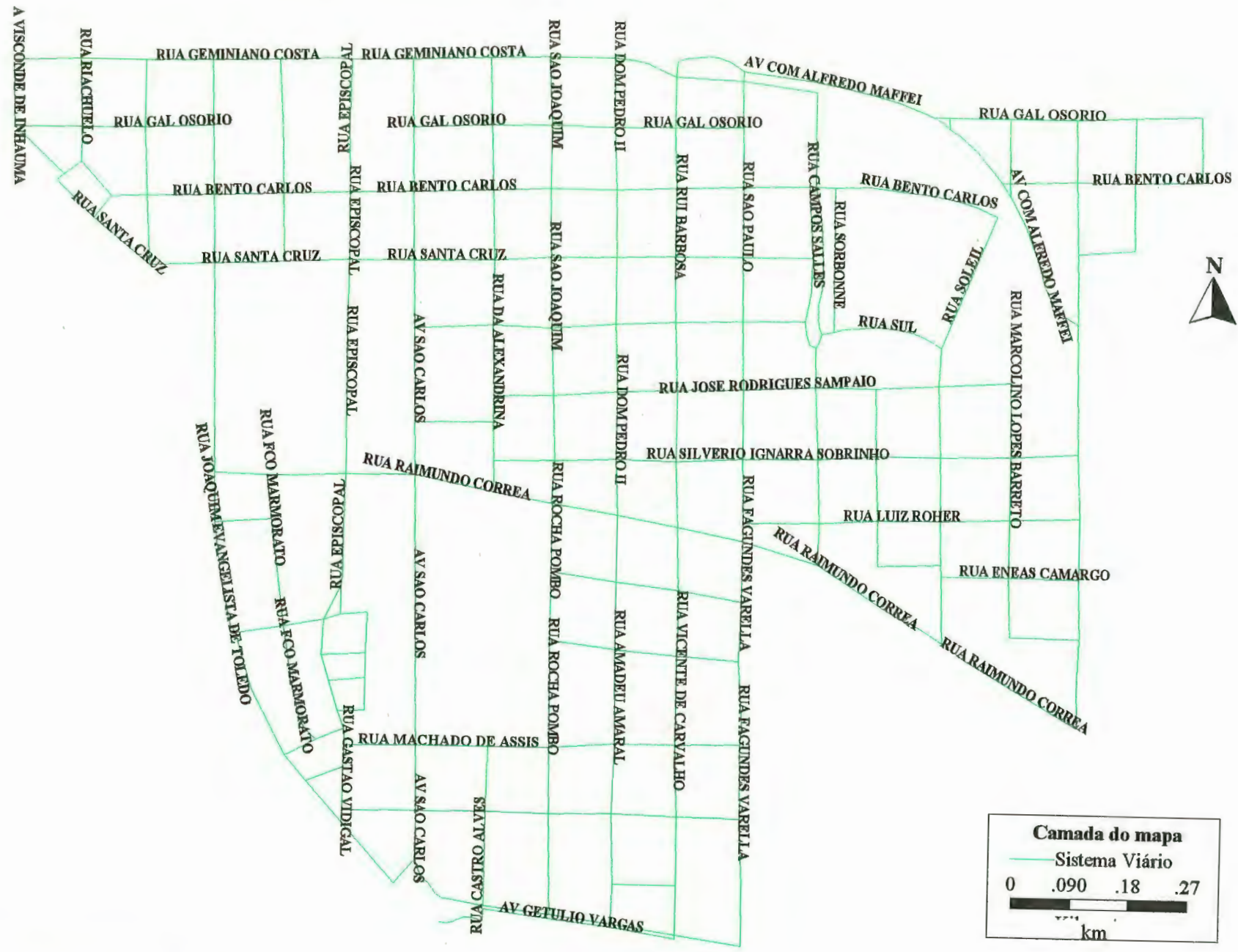

FIGURA 22 - Setor de Coleta 1 


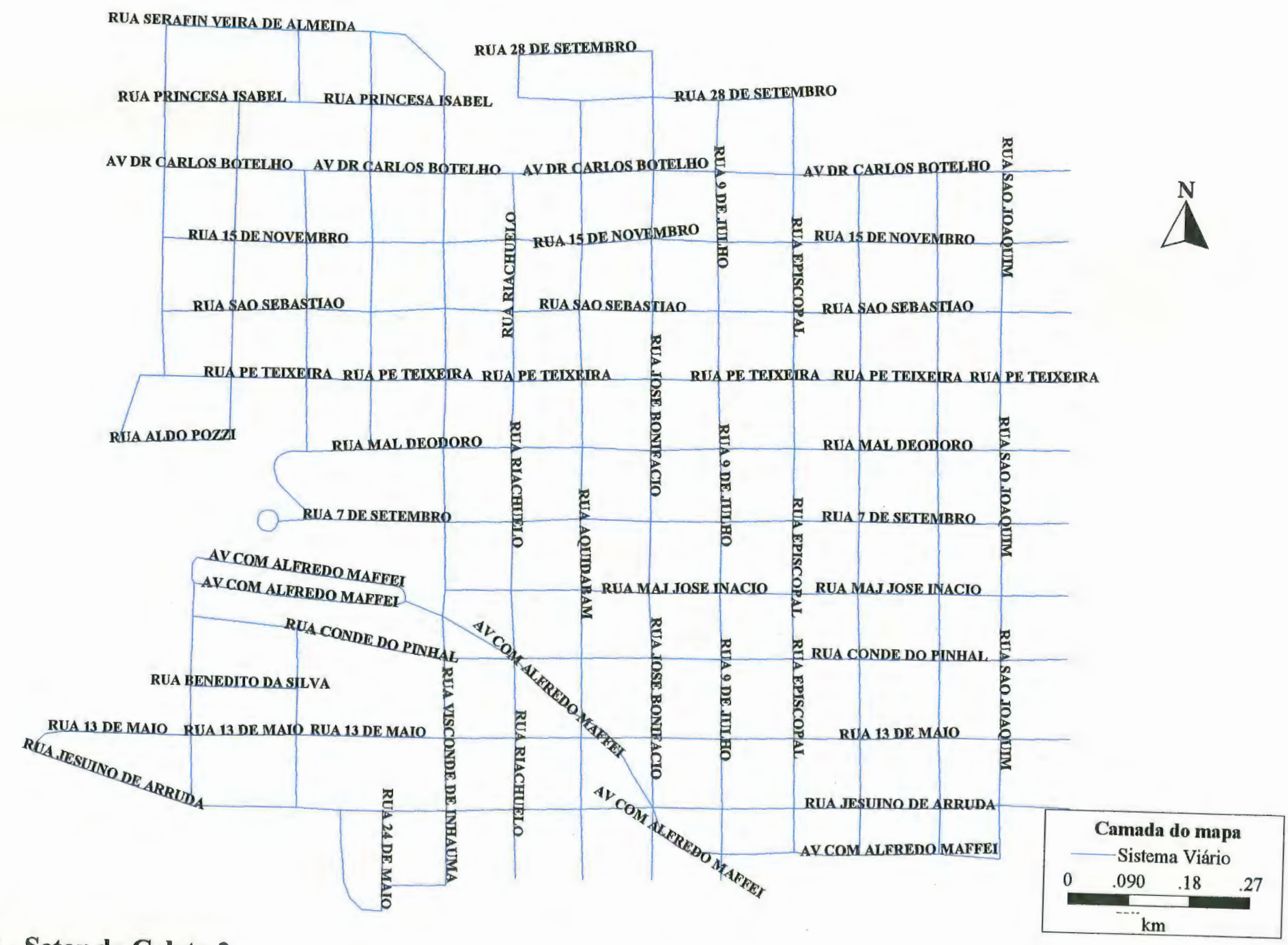

FIGURA 23 - Setor de Coleta 2 


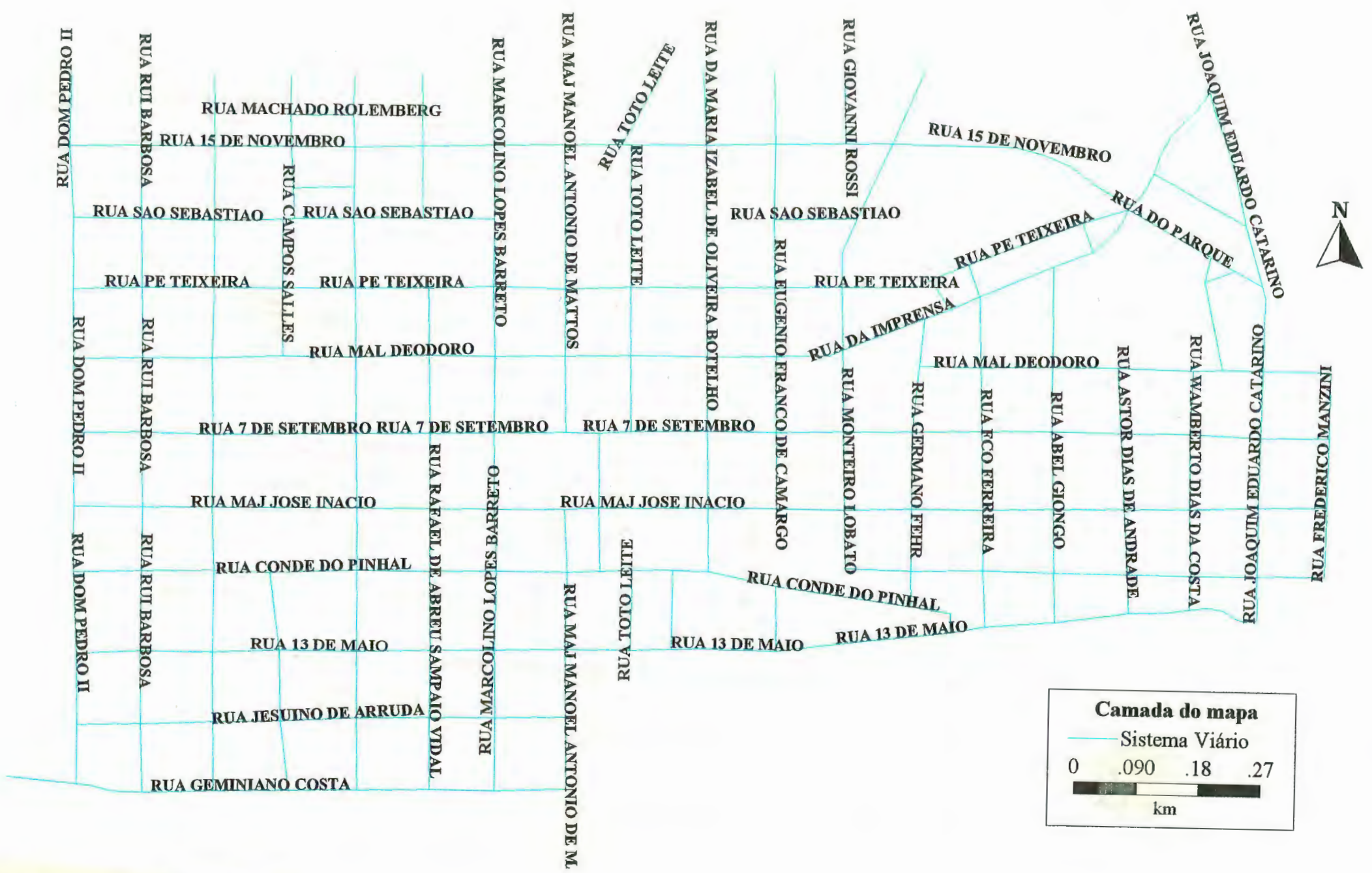

FIGURA 24 - Setor de Coleta 3 


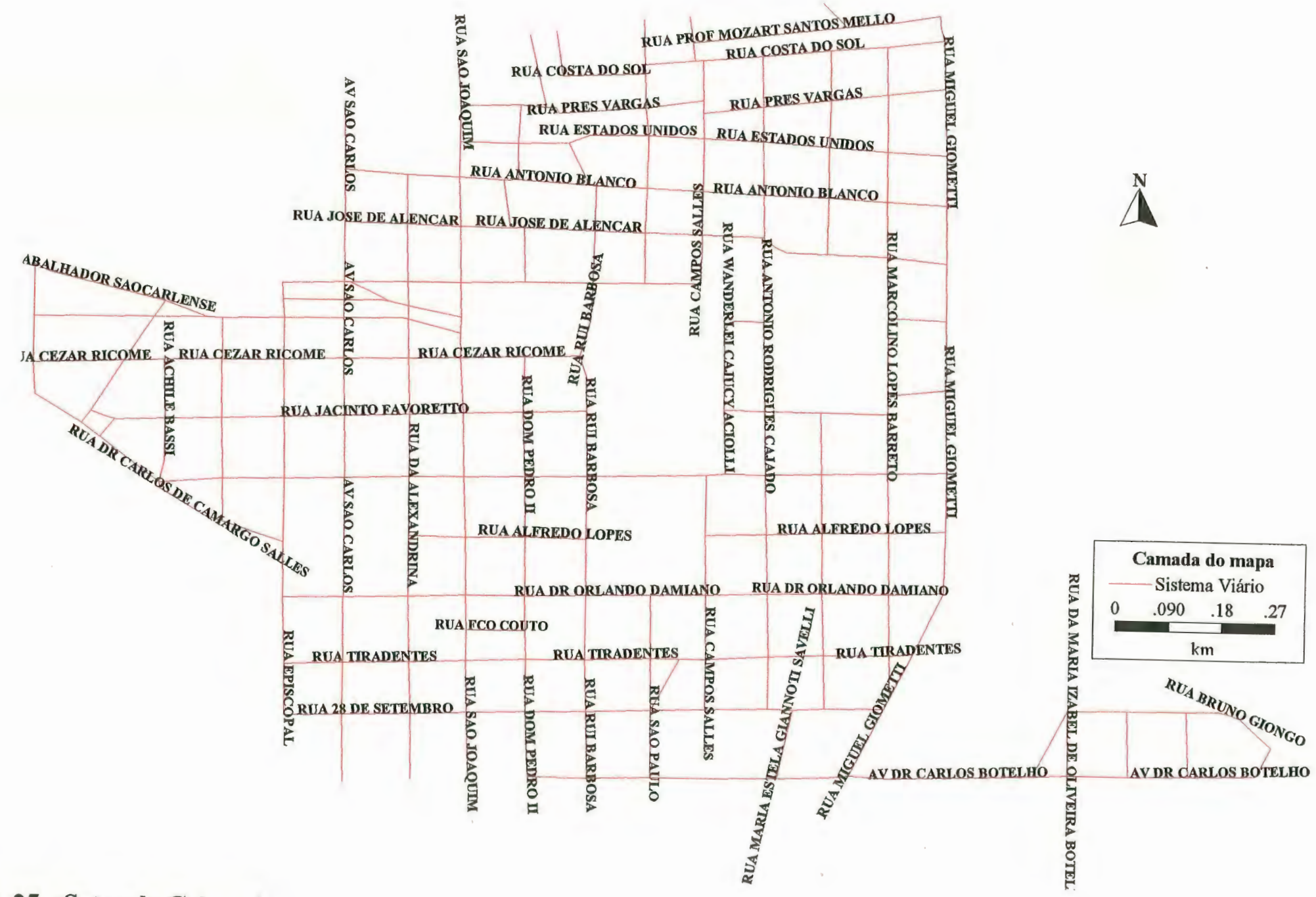

FIGURA 25 - Setor de Coleta 4 

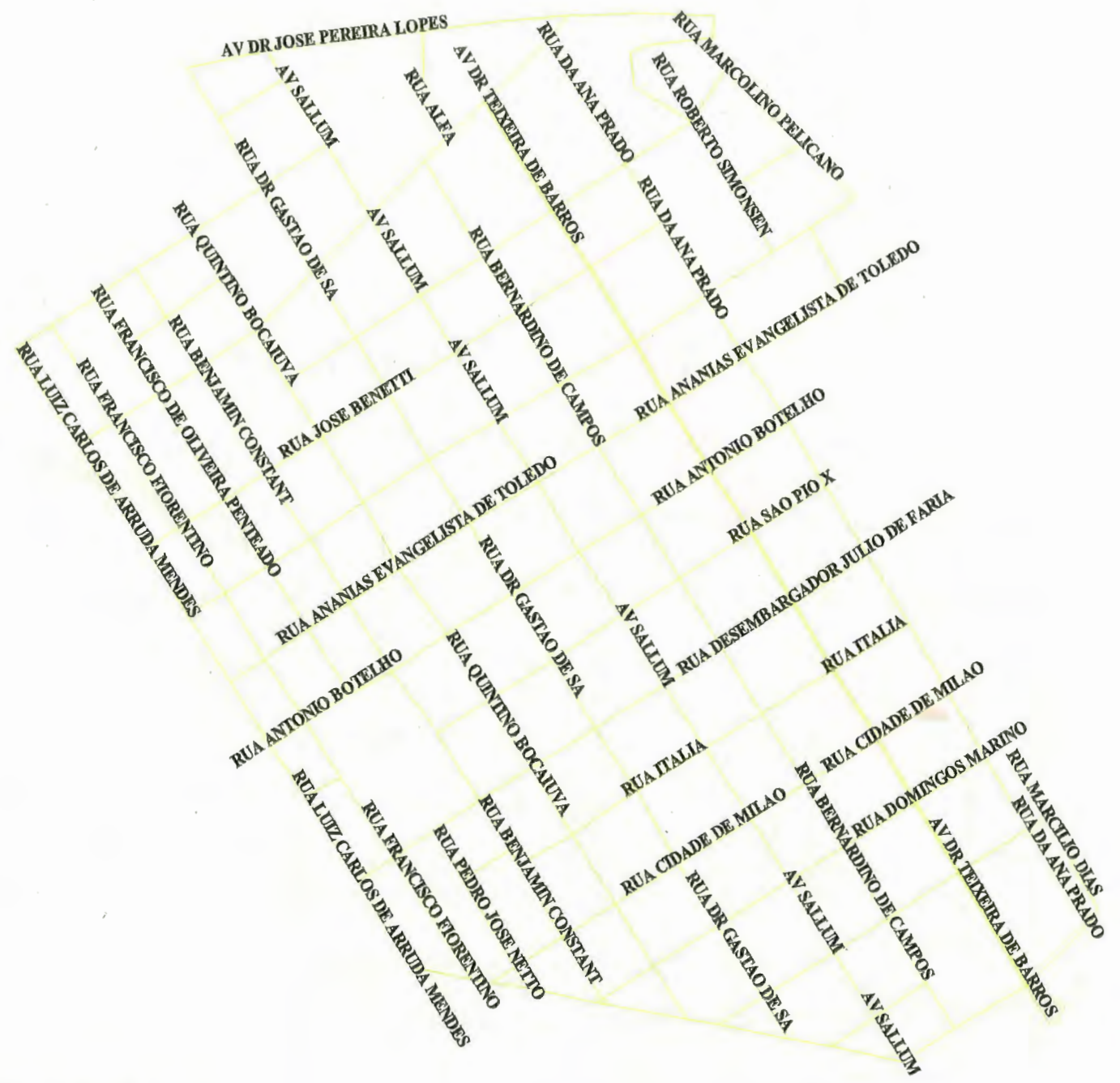

FIGURA 26 - Setor de Coleta 5 


\subsection{Aplicação da rotina de roteamento em arco}

Com a base de dados pronta e atualizada, criou-se a rede de transportes considerando restrições de movimentos em toda a rede, em particular o retorno em "U".

Aplicou-se a metodologia apresentada no presente trabalho, onde o objetivo seria minimizar a distância total percorrida.

Partindo para a aplicação da rotina foram traçados um itinerário de coleta para cada setor, cuja representação gráfica pode ser visualizada na figura 27.

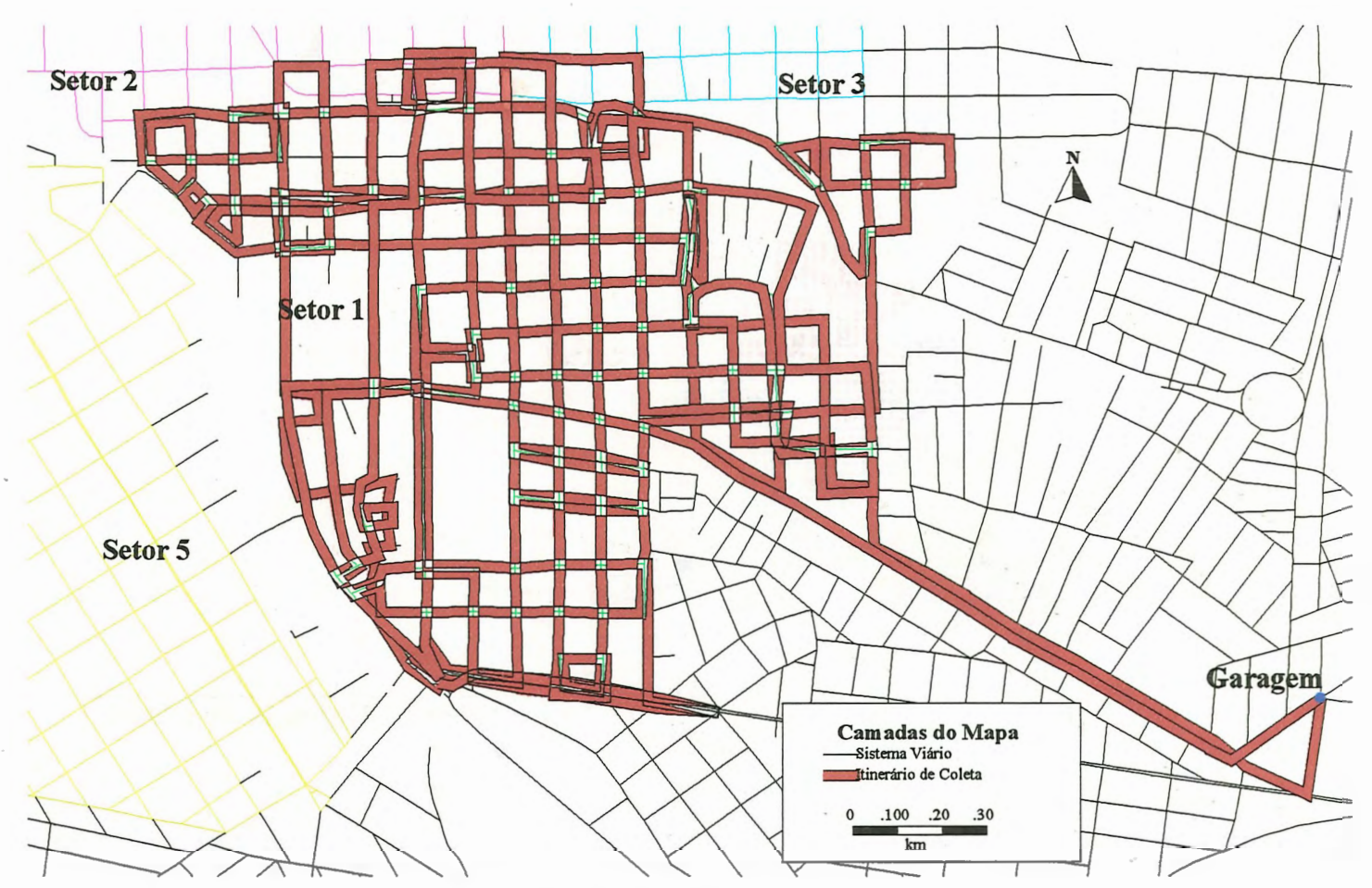

FIGURA 27 - Itinerário de coleta no setor

Para a aplicação da rotina foi necessário criar mais seleções na camada de pontos, que viessem a representar a localização da área de disposição final e a seleção dos nós que compunham cada setor de coleta, a fim de calcular a distância média entre:

- garagem VEGA Sopave até a área de disposição final (aterro Guaporé).

- setor de coleta e a garagem da VEGA Sopave;

- setor de coleta até o aterro.

As seleções da camada de pontō são mostradas na figura 28. 


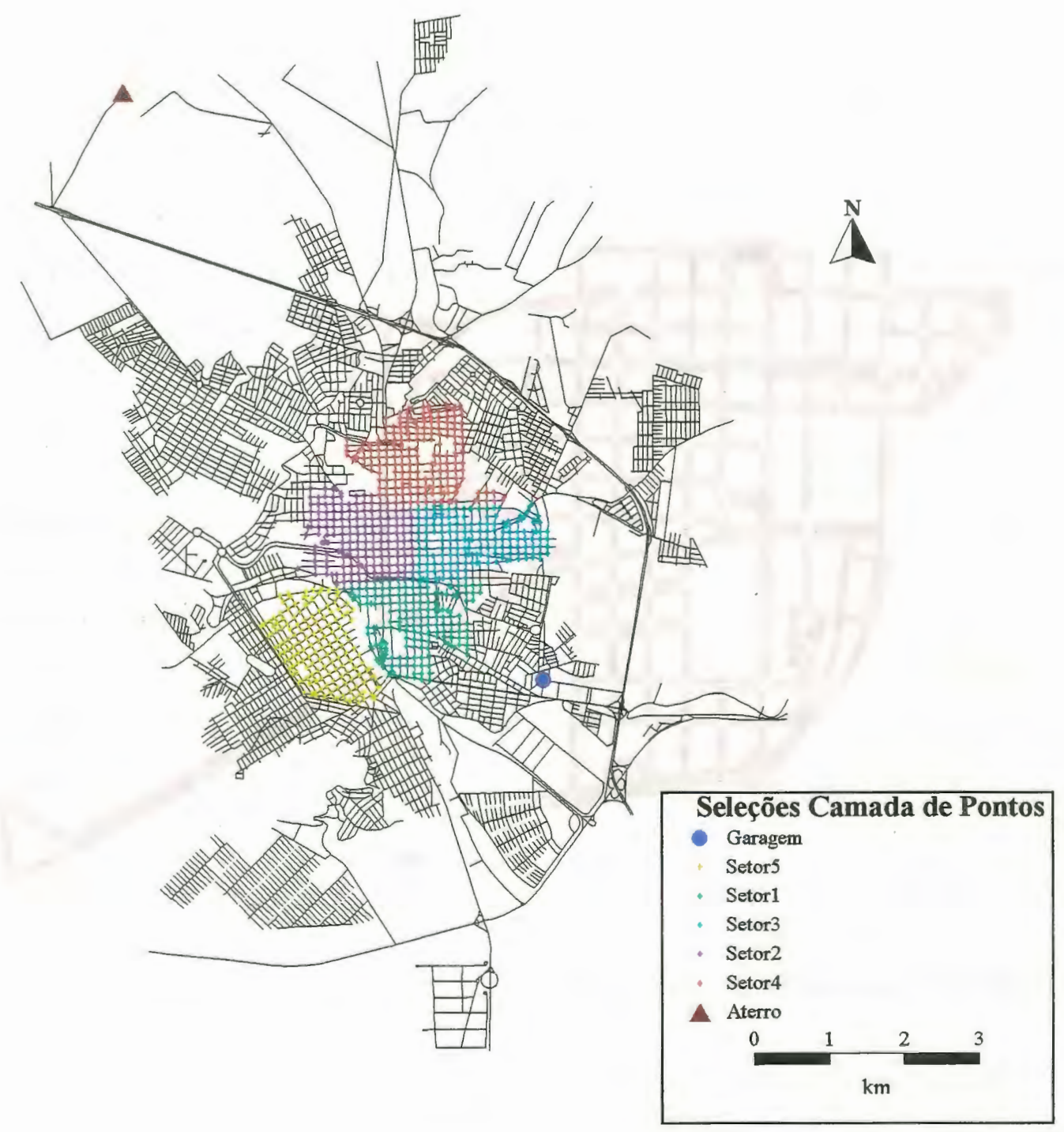


O TransCAD tem um procedimento para calcular caminhos mínimos, tendo apenas uma origem e um destino, ou mesmo uma origem e vários destinos; assim estes procedimentos se adequaram aos seguintes cálculos:

- caminho mínimo entre a garagem (origem) e o início da coleta (destino);

- caminhos mínimos entre o setor de coleta (interseções/origem) e a garagem (destino);

- caminho mínimo entre a garagem (origem) e o aterro (destino);

- caminhos mínimos entre o setor de coleta (interseções/origem) e o aterro (destino).

O cálculo desses caminhos mínimos acrescentado aos resultados fornecidos pela rotina foram utilizados para o cálculo de parâmetros operacionais para cada setor, sendo possível comparar com os resultados de uma situação real. Os parâmetros calculados são listados na tabela 22 e detalhados a seguir:

TABELA 22 - Parâmetros operacionais

\begin{tabular}{l|c|c}
\hline \multicolumn{1}{c|}{ Parâmetros } & Símbolo & Unidade \\
\hline Percurso de Coleta Total & PCT & $\mathrm{km}$ \\
Percurso de Coleta em cada viagem & PCV & $\mathrm{km}$ \\
Percurso de Coleta no Setor de Coleta & PCS & $\mathrm{km}$ \\
Percurso Vazio & PVA & $\mathrm{km}$ \\
Percurso Cheio & PCH & $\mathrm{km}$ \\
Extensão total dos links em cada setor & ET & $\mathrm{km}$ \\
\hline
\end{tabular}

Percurso de Coleta Total (PCT) - é o somatório das distâncias, em km, percorridas pelo caminhão durante a operação de coleta.

Percurso de Coleta em cada viagem (PCV) - é o somatório das distâncias, em $\mathrm{km}$, percorridas pelo caminhão durante a operação de coleta em cada viagem.

Percurso de Coleta no Setor (PCS) - é o somatório das distâncias, em km, percorridas, realizando serviço, pelo caminhão durante a operação de coleta em cada setor. 
Percurso Vazio (PVA) - é o somatório dos deslocamentos, em, km, com o veículo vazio:

- saída da garagem até o início da coleta na $1^{a}$ viagem;

- retorno do aterro até o local de início da $2^{\mathrm{a}}$ viagem (e também da $3^{\mathrm{a}}$, quando houver);

- retorno do aterro até a garagem após a descarga da última viagem.

Percurso cheio (PCH) - é o somatório dos deslocamentos, em $\mathrm{km}$, com o caminhão carregado:

- término de cada viagem até o aterro.

Extensão total dos links em cada setor (ET) - é o somatório dos comprimentos, em $\mathrm{km}$, de todos os links que pertencem a um setor de coleta.

Calculou-se também a quilometragem de repetição de passagem no setor, que é o somatório dos deslocamentos, em $\mathrm{km}$, sem realizar serviço, ou seja, são os deslocamentos sobre links que já foram servidos pelo serviço de coleta.

Como resultado da rotina, o TransCAD fornece o sistema de rota e dois relatórios. Um detalha o itinerário a ser percorrido pelo veículo coletor e o outro apresenta todos os dados de entrada e saída.

Os resultados obtidos pelo TransCAD foram utilizados para o cálculo dos parâmetros citados, considerando 1, 2 e 3 viagens, respectivamente, em cada setor de coleta. Esta seria parte do trajeto efetuado pelo veículo coletor, desde o ponto inicial da coleta até o local de descarga e retorno ao novo ponto inicial. Caso fosse a primeira viagem de um itinerário, incluiria a saída da garagem até o ponto inicial e se fosse a última viagem, o retorno até a garagem.

Assim, considerando os parâmetros calculados a partir dos dados fornecidos pela VEGA Sopave, foi possível realizar uma avaliação das distâncias percorridas.

\subsubsection{Problemas observados}

Nas simulações realizadas percebeu-se diversas limitações para aplicação da rotina de roteamento em arco (arc routing), por se tratar de um ferramental novo no planejamento de transportes e ainda com poucas aplicações em roteamento de veículos de coleta domiciliar, comentadas a seguir: 
- Quanto às restrições de manobras (à direita e à esquerda ) o software não se mostrou eficiente e nesta aplicação não foram consideradas restrições para esse tipo de movimento, pois quando estas restrições eram consideradas para a rede de trabalho a rotina não funcionava.

- A escolha do sentido que se deveria atravessar as ruas de mão dupla complicava sobremaneira a aplicação, a que se propôs as seguintes situações:

a) Baseando-se na declividade do link este deveria ser atravessado do ponto mais alto para o mais baixo.

b) Alternar o sentido em que o link deveria ser atravessado, neste a declividade não foi considerada, ou seja, um seria atravessado direção leste/oeste e outro para oeste/leste; em outra situação um na direção norte/sul e outro para sul/norte, a figura 29 ilustra esta situação.

A segunda situação se ajustou melhor a aplicação, necessitando ainda de um artificio. Algumas ruas de mão dupla se tornaram de mão única, pois sem este artifício a rotina também não funcionava.

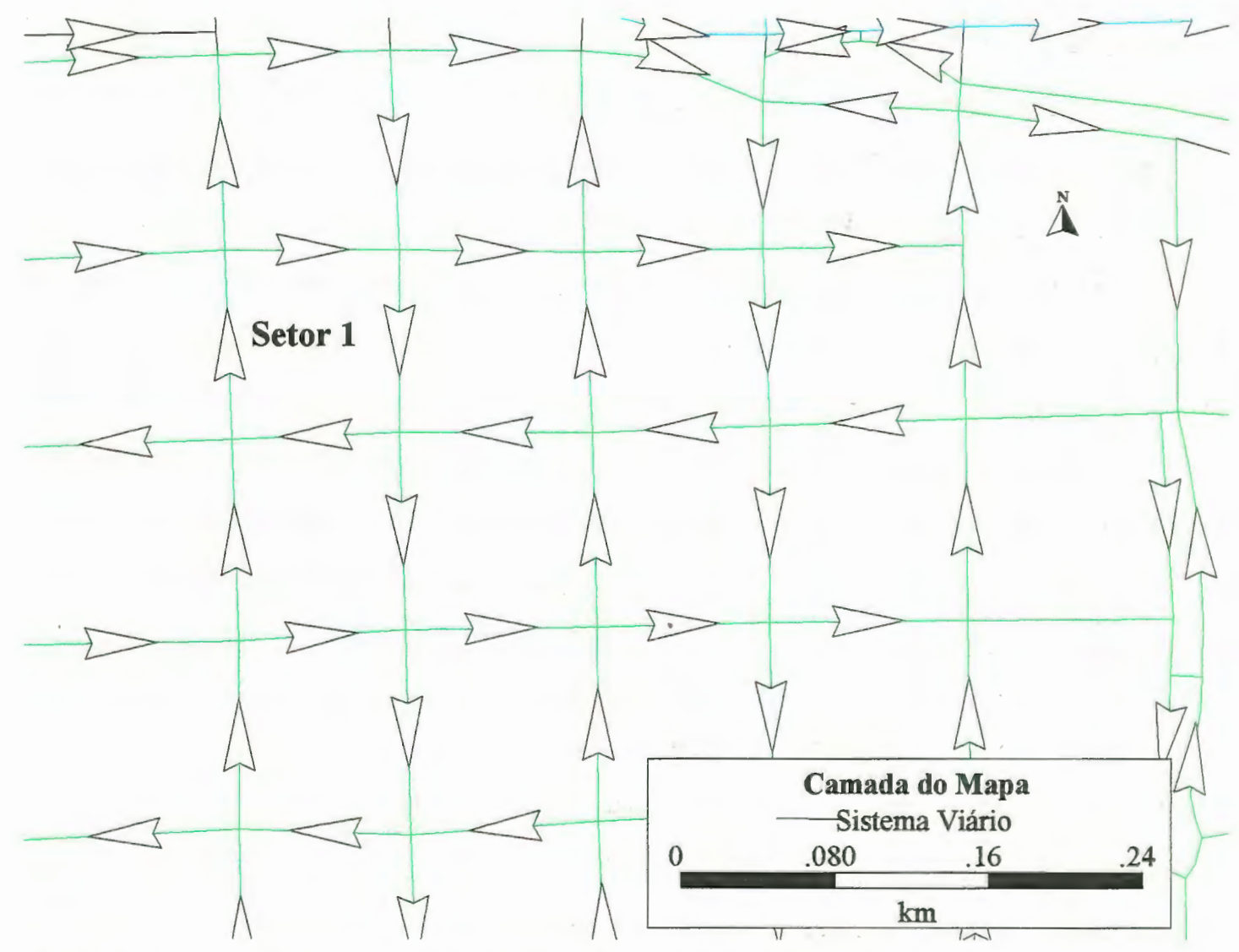

FIGURA 29 - Sentido em que o link deveria ser atravessado 
A identificação dos problemas, relativos ao sentido no qual os links deveriam ser atravessados eram feitas por tentativas até a rotina funcionar e posteriormente realizavam-se ajustes que possibilitariam obter resultados satisfatórios. Quando foi escolhido o sentido de travessia do link observou-se com detalhe se os nós tinham ao menos uma entrada e uma saída.

- Não foi possível considerar, nas simulações, utilizando a rotina arc routing, a ida até o local de descarga. $\mathrm{O}$ TransCAD considera que veículo coletor sai de um ponto (garagem), percorre o setor de coleta e volta ao nó de origem (garagem). Na cidade de São Carlos esta não seria a situação real, pois quando o caminhão completa a $1^{\mathrm{a}}$ viagem dirige-se até a garagem para realizar a pesagem. Vai para o aterro, volta para o setor de coleta para o início da $2^{a}$ viagem e, se tiver a $3^{a}$ viagem, repete o trajeto. Assim para o cálculo das distância adicionais não consideradas na aplicação da rotina, foi necessário utilizar os procedimentos de caminho mínimo (shortest path) e múltiplos caminhos mínimos (multiple paths).

- A dificuldade de obtenção de dados junto à empresa responsável pelos serviços de coleta e transporte de resíduos sólidos da cidade de São Carlos dificultou a realização de uma análise mais abrangente do sistema. Os dados fornecidos de forma limitada, dificultaram a comparação com os resultados obtidos pelo TransCAD.

Os problemas observados para a implementação de rotas, retratam a dificuldade de se fazer aplicações sobre roteirização de veículos de coleta domiciliar, devido a inúmeras restrições que devem ser consideradas, e muitas vezes o software limita certas considerações, já citadas anteriormente. Esta aplicação teve por objetivo apresentar e questionar a utilização dos SIGs, como um ferramental operacional, na definição de roteiros para os veículos coletores, trazendo assim uma contribuição para os municípios que pretendem utilizá-lo no planejamento dos sistemas de coleta e transporte de resíduos sólidos domiciliares. 


\section{RESULTADOS E DISCUSSÃO}

\subsection{Características dos sistemas de coleta domiciliar}

Foram recebidos 68 questionários (Cf. Anexo C) que correspondem a $13,45 \%$ do total enviado (514), e os referidos dados considerados representativos. De acordo com ESTEFANEL $^{8}$ (1997) este tipo de amostragem pode ser considerada representativa se os questionários respondidos corresponderem a no mínimo $10 \%$ do total enviado.

As respostas dos questionários foram armazenadas em planilhas utilizando-se o software Microsoft EXCEL (Cf. Anexo C).

A tabela 23 apresenta o percentual de questionários recebidos estabelecendo comparação com o porte dos municípios.

TABELA 23 - Porcentagem de questionários recebidos

\begin{tabular}{l|c|c|c}
\hline Tipo/Município & Questionários enviados & \multicolumn{2}{|c}{ Questionários recebidos } \\
\cline { 3 - 4 } & & Total & $\%$ \\
\hline Metrópoles Nacionais e & 11 & 3 & 27,27 \\
Regionais & 16 & 2 & 12,50 \\
Grande & 453 & 59 & 13,22 \\
Médio & 34 & 5 & 14,70 \\
Pequeno & & 5 & \\
\hline
\end{tabular}

${ }^{8}$ ESTEFANEL, V. (1997). Consultor de Estatística e Informática, Comunicação Pessoal, Santa Maria, RS. 
Como um dos objetivos deste trabalho é caracterizar sistemas de coleta de cidades de médio porte, procedeu-se a análise dos resultados mais detalhadas somente para estes municípios e as respostas dos questionários dos demais municípios encontra-se em anexo. Justifica-se o envio de questionários para as metrópoles regionais, município grandes e pequenos pois a finalidade é situar a questão da coleta domiciliar nos municípios de médio porte dentro de um contexto mais amplo.

A análise dos questionários foi prejudicada por alguns fatores, tais como:

- algumas respostas preenchidas à mão não eram legíveis;

- falta de uma padronização dos termos relativos a coleta domiciliar, bem como a utilização de termos regionais.

Considerando quatro aspectos da coleta domiciliar (geral, técnico, social e sanitário) procedeu-se a análise dos questionários.

A tabela 24 apresenta um resumo dos aspectos gerais de sistemas de coleta. Os resultados indicam que, em média, $90 \%$ da população dos municípios são atendidas pelo serviço de coleta domiciliar produzindo $1.754,53 \mathrm{t}$ /dia de resíduo.

Quanto à caracterização dos resíduos, na maioria das cidades não existe nenhum tipo de estudo.

Com relação à disposição final, tem-se procurado dar um destino adequado utilizando-se do aterro sanitário.

A execução dos serviços, na maioria dos casos, é de responsabilidade da prefeitura; nota-se também que onde o serviço é terceirizado a prefeitura não dispõe de muitos dados operacionais. Algumas prefeituras enviaram cartas com endereço da empresa responsável pela execução e não o questionário respondido, pelo que se conclui que o importante é que o serviço seja realizado sem se preocupar com questões que estão relacionadas com a coleta domiciliar, mesmo sendo esta a sua responsabilidade. 
TABELA 24 - Aspecto geral dos sistemas de coleta domiciliar nos municípios de médio porte

\begin{tabular}{|c|c|}
\hline Parâmetros & Característica \\
\hline População atendida & $90 \%$ \\
\hline Resíduo coletado & $1.754,53 \mathrm{t} / \mathrm{dia}$ \\
\hline Serviço & $\begin{array}{l}29 \text { - municípios tem serviço próprio } \\
27 \text { - municípios tem serviço terceirizado } \\
3 \text { - municípios tem serviço parcialmente } \\
\text { terceirizado }\end{array}$ \\
\hline Caracterização dos resíduos & $\begin{array}{l}45 \text { - não existe nenhum tipo de } \\
\text { caracterização } \\
12 \text { - já realizaram algum tipo de estudo } \\
2 \text { - não forneceram informações }\end{array}$ \\
\hline Tipo de disposição final & $\begin{array}{l}25 \text { - aterro sanitário } \\
19 \text { - lixão } \\
12 \text { - aterro controlado } \\
1 \text { - aterro sanitário e controlado } \\
2 \text { - não forneceram informações }\end{array}$ \\
\hline
\end{tabular}

A tabela 25 apresenta um resumo dos aspectos técnicos. Nota-se que os municípios operam com frotas antigas, que dificultam a execução do serviço, bem como colocam em risco a qualidade dos mesmos, além de exigir maior manutenção. Algumas cidades optaram por reformar a frota antiga a adquirir veículos novos; muitas possuem algum tipo de equipamento de pesagem (balança eletrônica ou outro tipo). A setorização da cidade é feita com base em parâmetros que permitem utilizar a capacidade máxima dos veículos coletores. A velocidade de coleta média é inferior a $10 \mathrm{~km} / \mathrm{h}$ e a distância do setor de coleta/destino em mais de $50 \%$ dos municípios é inferior a $15 \mathrm{~km}$. Quanto a freqüência de coleta, utilizam a coleta diária para áreas centrais da cidade, considerando-se uma maior produção de resíduos.

Quanto aos procedimentos utilizados para a definição de roteiros, em 62\% dos municípios são traçados manualmente com base na experiência da equipe de trabalho e considerando alguns parâmetros tais como: 
- o volume de resíduo a ser coletado

- volume de tráfego;

- sentido de fluxo das ruas;

- distância a ser percorrida;

- topografia (declividade);

- inicio da coleta em um ponto próximo da garagem;

- condições do pavimento favoráveis ao tráfego.

Os municípios que utilizam programas computacionais não detalharam os procedimentos adotados prejudicando a análise.

TABELA 25 - Aspecto técnico de sistemas de coleta domiciliar nos municípios de médio porte

\begin{tabular}{|c|c|}
\hline Parâmetros & Número de municípios - Característica \\
\hline Tipo de veículo utilizado & $\begin{array}{l}25 \text { - somente veículo compactador } \\
4 \text { - somente veículo Basculante } \\
24 \text { - utilizam frota diversificada } \\
\text { (incluindo trator agrícola, veículo de } \\
\text { tração animal e poliguindaste) } \\
6 \text { - Não forneceram informações }\end{array}$ \\
\hline Idade média da frota & $\begin{array}{l}17 \text { - menos de } 5 \text { anos } \\
21 \text { - mais de } 5 \text { anos } \\
13 \text { - mais de } 10 \text { anos } \\
8 \text { - não forneceram informações }\end{array}$ \\
\hline Equipamento de pesagem & $\begin{array}{l}28 \text { - possui algum tipo de equipamento } \\
14 \text { - não existe } \\
17 \text { - não forneceram informações }\end{array}$ \\
\hline Manutenção de veículos & $\begin{array}{c}53 \text { - fazem algum tipo de manutenção } \\
\text { (rotineira, corretiva e preventiva) } \\
6 \text { - não forneceram informações }\end{array}$ \\
\hline $\begin{array}{l}\text { Parâmetros para dividir os setores de } \\
\text { coleta }\end{array}$ & $\begin{array}{l}39 \text { - utilizam algum tipo de parâmetro } \\
\text { (capacidade do veículo, produção de } \\
\text { resíduos, distância a ser percorrida e } \\
\text { o tempo necessário para execução } \\
\text { do serviço) } \\
20 \text { - não forneceram informações }\end{array}$ \\
\hline Velocidade média de coleta & $\begin{array}{l}12 \text { - menor que } 10 \mathrm{~km} / \mathrm{h} \\
2 \text { - maior que } 10 \mathrm{~km} / \mathrm{h} \\
27 \text { - não forneceram informações }\end{array}$ \\
\hline $\begin{array}{l}\text { Distância média setor } \\
\text { coleta/disposição final }\end{array}$ & $\begin{array}{l}30 \text { - menor que } 15 \mathrm{~km} \\
24 \text { - acima de } 15 \mathrm{~km} \\
5 \text { - não forneceram informações }\end{array}$ \\
\hline
\end{tabular}


TABELA 25 - Aspecto técnico de sistemas de coleta domiciliar nos municípios de médio porte

\begin{tabular}{l|l}
\hline Parâmetros & Número de municípios - Característica \\
\hline Freqüência de coleta & 26 - coleta diária e alternada \\
& 18 - somente coleta alternada \\
& 10 - somente coleta diária \\
& 5 - não forneceram informações \\
\hline Método para definir roteiros de coleta & 36 - traçam a rota manualmente \\
& 2 - utilizam programa computacional \\
& 1 - parcialmente manual \\
& 20 - não forneceram informações \\
\hline
\end{tabular}

Os aspectos social e sanitário apresentados na tabela 26 mostram que as guarnições de coleta são compostas basicamente de 1 motorista e 3 ou 4 coletores (garis); em $49,14 \%$ dos municípios recebem algum tipo de treinamento e 57,62 \% oferecem algum tipo de serviço social aos funcionários.

Os registros de acidentes durante a operação de coleta em $66,10 \%$ dos municípios ocorre devido ao mal acondicionamento dos resíduos, o que levou alguns municípios a realizarem campanhas educativas junto à comunidade em favor da diminuição de acidentes, que muitas vezes provoca o afastamento do empregado. Alguns ainda indicam que a pior causa de acidentes é devido ao erro humano por-não se preocupar com a utilização dos equipamentos de proteção individual, disponível para os funcionários em $79,66 \%$ do municípios.

O serviço de limpeza da frota tem sido prejudicado pelo fato de estar sempre em serviço; alguns municípios informaram que realizam este tipo de serviço, mas ainda está longe de ser satisfatório. Em 49,15\% dos municípios é realizada a limpeza diária dos veículos e nas demais os serviço são alternado, e também com intervalo de limpeza superior a uma semana ou conforme a necessidade.

TABELA 26 - Aspectos social e sanitário dos sistemas de coleta domiciliar nos municípios de médio porte

\begin{tabular}{l|l}
\hline Parâmetros & Número de municípios - Característica \\
\hline Guarnição de Coleta & 21 - 1 motorista e 4 coletores (garis) \\
& 21 - 1 motorista e 3 coletores (garis) \\
$4-1$ motorista e 2 coletores (garis) \\
& 13 - não forneceram informações
\end{tabular}


TABELA 26 - Aspecto social e sanitário dos sistemas de coleta domiciliar nos municípios de médio porte

\begin{tabular}{l|c}
\hline Parâmetros & Número de municípios - Característica \\
\hline Tipo de treinamento dado aos operários & $\begin{array}{c}29 \text { - oferecem algum tipo de treinamento } \\
\text { (tipo: palestras e cursos) }\end{array}$ \\
& $\begin{array}{c}10 \text { - não oferecem nenhum tipo de } \\
\text { treinamento }\end{array}$ \\
20 - não forneceram informações
\end{tabular}

A contribuição das prefeituras e empresas responsáveis pela execução da coleta domiciliar foi um fator importante para a efetivação desta fase do trabalho, sem as quais não seria possível realizar as análises propostas.

\subsection{Resultados da rotina de roteamento em arco}

Os resultados da rotina foram processados no software Microsoft EXCEL, for Windows versão 97, para obtenção dos parâmetros operacionais. O relatório de itinerário e o relatório de entrada e saída de dados estão no ANEXO D.

Utilizando os recursos do EXCEL foram desenvolvidas planilhas para introdução dos dados, fornecidos pela VEGA Sopave e os obtidos na rotina de roteamento em arco (arc routing) para o processamento e análise dos mesmos. 
Os parâmetros operacionais calculados com os dados fornecidos pela VEGA Sopave são apresentados nas tabelas $27,28,29,30$ e 31 e os obtidos a partir do resultado da rotina (arc routing) nas tabelas $32,33,34,35$ e 36 , mostradas a seguir: 
TABELA 27 - Parâmetros operacionais de coleta para o Setor 1, obtidos a partir de dados fornecidos pela VEGA Sopave

\begin{tabular}{|c|c|c|c|c|c|c|c|c|c|c|c|c|}
\hline \multirow[b]{2}{*}{ Cálculo das Distâncias Percorridas (km) } & \multicolumn{12}{|c|}{ Amostras Consideradas } \\
\hline & $23 / 3$ & $24 / 3$ & $25 / 3$ & $26 / 3$ & $27 / 3$ & $28 / 3$ & $13 / 4$ & $14 / 4$ & $15 / 4$ & $16 / 4$ & $17 / 4$ & $18 / 4$ \\
\hline Garagem - Setor & 2 & 2 & 2 & 2 & 2 & 2 & 2 & 2 & 4 & 2 & 2 & 2 \\
\hline D istância Percorrida no Setor ( $1^{a}$ viagem) & 12 & 17 & 29 & 25 & 17 & 26 & 12 & 25 & 26 & 25 & 18 & 45 \\
\hline Setor - Garagem ( $1^{a}$ viagem $)$ & 2 & 2 & 2 & 2 & 2 & 2 & 2 & 2 & 4 & 2 & 2 & 2 \\
\hline Garagem - A terro & 16 & 17 & 17 & 17 & 17 & 17 & 16 & 16 & 17 & 16 & 17 & 16 \\
\hline A terro-Setor & 18 & 17 & 17 & 17 & 17 & 18 & 18 & 18 & - & 18 & 17 & - \\
\hline D istância Percorrida no Setor ( $2^{a}$ viagem $)$ & 15 & 17 & 13 & 15 & 17 & 15 & 15 & 15 & - & 16 & 18 & - \\
\hline Setor - Garagem ( $2^{a}$ viagem $)$ & 2 & 2 & 3 & 3 & 3 & 3 & 2 & 3 & - & 3 & 2 & - \\
\hline Garagem - A terro & 16 & 17 & 17 & 17 & 17 & 17 & 16 & 17 & - & 17 & 17 & - \\
\hline A terro-Setor & 18 & - & - & - & - & - & 18 & - & - & - & - & - \\
\hline D istância Percorrida no Setor ( $3^{a}$ viagem $)$ & 8 & - & - & - & - & - & 8 & - & - & - & - & - \\
\hline Setor - Garagem $\left(3^{\text {a }}\right.$ viagem $)$ & 3 & - & - & - & - & - & 3 & - & - & - & - & - \\
\hline Garagem - A terro & 16 & - & - & - & - & - & 16 & - & - & - & - & - \\
\hline A terro-Garagem (térm ino da coleta) & 16 & 17 & 16 & 16 & 16 & 16 & 16 & 16 & 16 & 16 & 17 & 17 \\
\hline Distância Total Percorrida ( $\mathrm{km})$ & 144 & 108 & 116 & 114 & 108 & 116 & 144 & 114 & 67 & 115 & 110 & 82 \\
\hline \multicolumn{13}{|l|}{ Parâm etros Analisados (km) } \\
\hline Percurso de Coleta-PCL $1^{\text {a }}$ Viagem & 50 & 55 & 67 & 63 & 55 & 65 & 50 & 63 & 67 & 63 & 56 & 82 \\
\hline Percurso de Coleta-PCL $2^{a}$ Viagem & 51 & 53 & 49 & 51 & 53 & 51 & 51 & 51 & - & 52 & 54 & - \\
\hline Percurso de Coleta-PCL $3^{a}$ Viagem & 43 & - & - & - & - & - & 43 & - & - & - & - & - \\
\hline Percurso de Coleta Total & 144 & 108 & 116 & 114 & 108 & 116 & 144 & 114 & 67 & 115 & 110 & 82 \\
\hline Percurso de Coleta no Setor & 35 & 34 & 42 & 40 & 34 & 41 & 27 & 40 & 26 & 41 & 36 & 45 \\
\hline Número de Viagens- NVG & 3 & 2 & 2 & 2 & 2 & 2 & 3 & 2 & 1 & 2 & 2 & 1 \\
\hline Percurso Vazio-PVA & 54 & 36 & 35 & 35 & 35 & 36 & 54 & 36 & 20 & 36 & 36 & 19 \\
\hline Percurso Cheio- $\mathrm{PCH}$ & 55 & 38 & 39 & 39 & 39 & 39 & 55 & 38 & 21 & 38 & 38 & 18 \\
\hline
\end{tabular}


TABELA 28 - Parâmetros operacionais de coleta para o Setor 2, obtidos a partir de dados fornecidos pela VEGA Sopave

\begin{tabular}{|c|c|c|c|c|c|c|c|c|c|c|c|c|}
\hline \multirow[b]{2}{*}{ Cálculo das Distâncias Percorridas (k m) } & \multicolumn{12}{|c|}{ A mostras Consideradas } \\
\hline & $23 / 3$ & $24 / 3$ & $25 / 3$ & $26 / 3$ & $27 / 3$ & $28 / 3$ & $13 / 4$ & $14 / 4$ & $15 / 4$ & $16 / 4$ & $17 / 4$ & $18 / 4$ \\
\hline Garagem-Setor & 4 & 3 & 3 & 4 & 4 & 4 & 2 & 3 & 4 & 4 & 3 & 3 \\
\hline Distância Percorrida no Setor ( $1^{a}$ viagem) & 14 & 20 & 16 & 18 & 16 & 31 & 12 & 19 & 18 & 16 & 19 & 31 \\
\hline Setor - Garagem ( $1^{a}$ viagem $)$ & 5 & 2 & 4 & 5 & 5 & 4 & 2 & 4 & 5 & 4 & 4 & 3 \\
\hline Garagem - Aterro & 16 & 17 & 17 & 16 & 17 & 17 & 16 & 17 & 16 & 17 & 17 & 17 \\
\hline A terro-Setor & 19 & 19 & 20 & 21 & 21 & - & 18 & 20 & 21 & 21 & 21 & - \\
\hline D istância Percorrida no Setor ( $2^{a}$ viagem $)$ & 19 & 13 & 20 & 12 & 19 & - & 15 & 12 & 14 & 13 & 14 & - \\
\hline Setor - Garagem ( $2^{a}$ viagem $)$ & 3 & 4 & 3 & 3 & 4 & - & 2 & 4 & 4 & 4 & 6 & - \\
\hline Garagem - Aterro & 17 & 16 & 17 & 17 & 17 & - & 16 & 16 & 16 & 16 & 15 & - \\
\hline A terro-Setor & - & - & - & - & - & - & 18 & - & - & - & - & - \\
\hline Distância Percorrida no Setor ( $3^{a}$ viagem) & - & - & - & - & - & - & 8 & - & - & - & - & - \\
\hline Setor-Garagem $\left(3^{a}\right.$ viagem $)$ & - & - & - & - & - & - & 3 & - & - & - & - & - \\
\hline Garagem - A terro & - & - & - & - & - & - & 16 & - & - & - & - & - \\
\hline A terro-Garagem (térm ino da coleta) & 17 & 17 & 16 & 16 & 16 & 17 & 16 & 17 & 17 & 17 & 16 & 16 \\
\hline Distância Total Percorrida (k m) & 114 & 111 & 116 & 112 & 119 & 73 & 144 & 112 & 115 & 112 & 115 & 70 \\
\hline \multicolumn{13}{|l|}{ Parâmetros Analisados ( $\mathrm{km}$ ) } \\
\hline Percurso de Coleta - PCL $1^{a} \mathrm{Viagem}$ & 58 & 61 & 60 & 64 & 63 & 73 & 50 & 63 & 64 & 62 & 64 & 70 \\
\hline Percurso de Coleta - PCL $2^{a} \mathrm{Viagem}$ & 56 & 50 & 56 & 48 & 56 & & 51 & 49 & 51 & 50 & 51 & 0 \\
\hline Percurso de Coleta - PCL $3^{a} \mathrm{Viagem}$ & - & - & - & - & - & - & 43 & - & - & - & - & - \\
\hline Percurso de Coleta Total & 114 & 111 & 116 & 112 & 119 & 73 & 144 & 112 & 115 & 112 & 115 & 70 \\
\hline Percurso de Coleta no Setor & 33 & 33 & 36 & 30 & 35 & 31 & 27 & 31 & 18 & 29 & 33 & 31 \\
\hline $\mathrm{Núm}$ ero de Viagens - N V G & 3 & 2 & 2 & 2 & 2 & 2 & 3 & 2 & 1 & 2 & 2 & 1 \\
\hline Percurso Vazio-PVA & 40 & 39 & 39 & 41 & 41 & 21 & 54 & 40 & 42 & 42 & 40 & 19 \\
\hline Percurso $\mathrm{Cheio}-\mathrm{PCH}$ & 41 & 39 & 41 & 41 & 43 & 21 & 55 & 72 & 41 & 41 & 42 & 20 \\
\hline
\end{tabular}


TABELA 29 - Parâmetros operacionais de coleta para o Setor 3, obtidos a partir de dados fornecidos pela VEGA Sopave

\begin{tabular}{|c|c|c|c|c|c|c|c|c|c|c|c|c|}
\hline \multirow[b]{2}{*}{ Cálculo das D istâncias Percorridas ( $\mathrm{km}$ ) } & \multicolumn{12}{|c|}{ Amostras Consideradas } \\
\hline & $23 / 3$ & $24 / 3$ & $25 / 3$ & $26 / 3$ & $27 / 3$ & $28 / 3$ & $13 / 4$ & $14 / 4$ & $15 / 4$ & $16 / 4$ & $17 / 4$ & $18 / 4$ \\
\hline Garagem-Setor & 3 & 4 & 4 & 3 & 4 & 3 & 4 & 4 & 4 & 3 & $\overline{4}$ & $\overline{4}$ \\
\hline Distância Percorrida no Setor ( $1^{a}$ viagem) & 13 & 21 & 21 & 21 & 20 & 21 & 12 & 22 & 26 & 20 & 19 & 6 \\
\hline Setor - Garagem $\left(1^{a}\right.$ viagem $)$ & 4 & 2 & 2 & 2 & 3 & 2 & 3 & 2 & 4 & 3 & 2 & 4 \\
\hline Garagem - A terro & 15 & 17 & 17 & 17 & 16 & 17 & 16 & 17 & 17 & 16 & 17 & - \\
\hline A terro-Setor & 19 & 18 & 19 & 18 & 19 & 19 & 20 & 18 & - & 19 & 19 & - \\
\hline Distância Percorrida no Setor ( $2^{a}$ viagem) & 14 & 14 & 14 & 13 & 13 & 13 & 19 & 14 & - & 16 & 18 & 31 \\
\hline Setor - Garagem $\left(2^{a}\right.$ viagem $)$ & 4 & 4 & 4 & 4 & 4 & 3 & 3 & 12 & - & 3 & 3 & 3 \\
\hline Garagem - Aterro & 16 & 16 & 16 & 16 & 16 & 17 & 17 & 17 & - & 17 & 17 & 17 \\
\hline Aterro-Setor & 21 & - & - & - & - & - & 18 & - & - & - & - & - \\
\hline Distância Percorrida no Setor ( $3^{a}$ viagem) & 7 & - & - & - & - & - & 6 & - & - & - & - & - \\
\hline Setor - Garagem ( $3^{\text {a }}$ viagem $)$ & 4 & - & - & - & - & - & 10 & - & - & - & - & - \\
\hline Garagem - A terro & 16 & - & - & - & - & - & 17 & - & - & - & - & - \\
\hline Aterro-Garagem (término da coleta) & 16 & 16 & 16 & 17 & 16 & 16 & 16 & 16 & 16 & 16 & 17 & 16 \\
\hline Distância Total Percorrida (k m) & 152 & 112 & 113 & 111 & 111 & 111 & 161 & 122 & 67 & 113 & 116 & 81 \\
\hline \multicolumn{13}{|l|}{ Parâm etros Analisados $(\mathrm{km})$} \\
\hline Percurso de Coleta - PCL $1^{\text {a }}$ Viagem & 54 & 62 & 63 & 61 & 62 & 62 & 55 & 63 & 67 & 61 & 61 & 14 \\
\hline Percurso de Coleta - PCL $2^{a}$ Viagem & 55 & 50 & 50 & 50 & 49 & 49 & 57 & 59 & - & 52 & 55 & 69 \\
\hline Percurso de Coleta - PCL $3^{a} \mathrm{Viagem}$ & 43 & - & - & - & - & - & 49 & - & - & - & - & - \\
\hline Percurso de Coleta Total & 152 & 112 & 113 & 111 & 111 & 111 & 161 & 122 & 67 & 113 & 116 & 83 \\
\hline Percurso de Coleta no Setor & 34 & 35 & 35 & 34 & 33 & 34 & 31 & 36 & 26 & 36 & 37 & 37 \\
\hline Númerode Viagens - N VG & 2 & 2 & 2 & 2 & 2 & 2 & 2 & 2 & 2 & 2 & 2 & 2 \\
\hline Percurso Vazio - PVA & 59 & 38 & 39 & 38 & 39 & 38 & 58 & 38 & 20 & 38 & 40 & 22 \\
\hline Percurso Cheio- $\mathrm{PCH}$ & 59 & 39 & 39 & 39 & 39 & 39 & 66 & 48 & 21 & 39 & 39 & 24 \\
\hline
\end{tabular}


TABELA 30 - Parâmetros operacionais de coleta para o Setor 4, obtidos a partir de dados fornecidos pela VEGA Sopave

\begin{tabular}{|c|c|c|c|c|c|c|c|c|c|c|c|c|}
\hline \multirow[b]{2}{*}{ Cálculo das D istâncias Percorridas ( $\mathrm{km})$} & \multicolumn{12}{|c|}{ Amostras Consideradas } \\
\hline & $23 / 3$ & $24 / 3$ & $25 / 3$ & $26 / 3$ & $27 / 3$ & $28 / 3$ & $13 / 4$ & $14 / 4$ & $15 / 4$ & $16 / 4$ & $17 / 4$ & $18 / 4$ \\
\hline Garagem - Setor & 4 & 4 & 4 & 4 & 4 & 4 & 4 & 4 & 3 & 4 & 4 & 4 \\
\hline Distância Percorrida no Setor ( $1^{a}$ viagem) & 21 & 20 & 23 & 24 & 30 & 36 & 21 & 35 & 31 & 19 & 28 & 37 \\
\hline Setor - Garagem ( $1^{a}$ viagem $)$ & 7 & 9 & 4 & 5 & 7 & 4 & 7 & 2 & 7 & 4 & 7 & 11 \\
\hline Garagem - A terro & 17 & 17 & 17 & 16 & 17 & 17 & 17 & 17 & 16 & 16 & 16 & 16 \\
\hline Aterro-Setor & 20 & 20 & 21 & 21 & 21 & - & 20 & - & 21 & 20 & 20 & - \\
\hline Distância Percorrida no Setor ( $2^{a}$ viagem $)$ & 18 & 20 & 8 & 8 & 9 & - & 19 & - & 13 & 17 & 16 & - \\
\hline Setor - Garagem ( $2^{\text {a }}$ viagem $)$ & 5 & 4 & 4 & 5 & 4 & - & 6 & - & 4 & 4 & 4 & - \\
\hline Garagem - A terro & 17 & 17 & 16 & 17 & 17 & - & 17 & - & 16 & 17 & 16 & - \\
\hline A terro-Setor & - & - & - & - & - & - & - & - & - & - & - & - \\
\hline Distância Percorrida no Setor ( $3^{a}$ viagem) & - & - & - & - & - & - & - & - & - & - & - & - \\
\hline Setor - Garagem $\left(3^{a}\right.$ viagem $)$ & - & - & - & - & - & - & - & - & - & - & - & - \\
\hline Garagem - A terro & - & - & - & - & - & - & - & - & - & - & - & - \\
\hline Aterro-Garagem (término da coleta) & 16 & 16 & 16 & 16 & 16 & 16 & 16 & 16 & 16 & 16 & 17 & 17 \\
\hline Distâ+A 85 ncia Total Percorrida (km) & 125 & 127 & 97 & 116 & 125 & 77 & 127 & 74 & 127 & 117 & 128 & 85 \\
\hline \multicolumn{13}{|l|}{ Parâm etros A nalisados ( $\mathrm{km}$ ) } \\
\hline Percurso de Coleta - PCL $1^{\text {a }}$ Viagem & 69 & 70 & 69 & 70 & 79 & 77 & 69 & 58 & 78 & 63 & 75 & 68 \\
\hline Percurso de Coleta - PCL $2^{a}$ Viagem & 56 & 57 & 28 & 46 & 46 & - & 42 & & 49 & 54 & 53 & - \\
\hline Percurso de Coleta - PCL $3^{a}$ Viagem & - & - & - & - & - & - & - & - & - & - & - & - \\
\hline Percurso de Coleta Total & 125 & 127 & 97 & 116 & 125 & 77 & 111 & 58 & 127 & 117 & 128 & 68 \\
\hline Percurso de Coleta no Setor & 39 & 40 & 31 & 32 & 39 & 36 & 40 & 35 & 44 & 36 & 44 & 37 \\
\hline $\mathrm{Númerode} \mathrm{Viagens-NVG}$ & 2 & 2 & 2 & 2 & 2 & 2 & 2 & 2 & 2 & 2 & 2 & 2 \\
\hline Percurso Vazio - PVA & 40 & 40 & 41 & 41 & 41 & 20 & 40 & 20 & 40 & 40 & 41 & 21 \\
\hline Percurso Cheio- $\mathrm{PCH}$ & 46 & 47 & 25 & 43 & 45 & 21 & 47 & 19 & 43 & 41 & 43 & 27 \\
\hline
\end{tabular}


TABELA 31 - Parâmetros operacionais de coleta para o Setor 5, obtidos a partir de dados fornecidos pela VEGA Sopave

\begin{tabular}{|c|c|c|c|c|c|c|c|c|c|c|c|c|}
\hline \multirow{2}{*}{ Cálculo das D istâncias Percorridas ( $\mathrm{km}$ ) } & \multicolumn{12}{|c|}{ Amostras Consideradas } \\
\hline & $23 / 3$ & $24 / 3$ & $25 / 3$ & $26 / 3$ & $27 / 3$ & $28 / 3$ & $13 / 4$ & $14 / 4$ & $15 / 4$ & $16 / 4$ & $17 / 4$ & $18 / 4$ \\
\hline Garagem-Setor & 3 & 3 & 3 & 3 & 3 & 2 & 3 & 3 & 3 & 3 & 3 & 3 \\
\hline Distância Percorrida no Setor ( $1^{a}$ viagem ) & 10 & 20 & 19 & 11 & 19 & 20 & 11 & 19 & 19 & 19 & 20 & 21 \\
\hline Setor-Garagem ( $1^{a}$ viagem) & 3 & 3 & 3 & 3 & 3 & 3 & 3 & 3 & 3 & 3 & 3 & 3 \\
\hline Garagem - A terro & 18 & 16 & 17 & 18 & 16 & 17 & 18 & 16 & 17 & 17 & 16 & 17 \\
\hline Aterro-Setor & 17 & 19 & 19 & 19 & 2 & 19 & 19 & 20 & 19 & 19 & 19 & 19 \\
\hline Distância Percorrida no Setor ( $2^{a}$ viagem $)$ & 12 & 11 & 10 & 22 & 28 & 12 & 11 & 11 & 12 & 11 & 12 & 10 \\
\hline Setor - Garagem $\left(2^{a}\right.$ viagem $)$ & 3 & 3 & 3 & 3 & 4 & 3 & 3 & 3 & 17 & 3 & 3 & 3 \\
\hline Garagem - A terro & 16 & 18 & 18 & 16 & 17 & 17 & 17 & 17 & 3 & 17 & 17 & 18 \\
\hline Aterro-Setor & 19 & - & - & - & - & - & 20 & - & - & - & - & - \\
\hline Distância Percorrida no Setor ( $3^{a}$ viagem $)$ & 11 & - & - & - & - & - & 9 & - & - & - & - & - \\
\hline Setor - Garagem ( $3^{\text {a }}$ viagem $)$ & 3 & - & - & - & - & - & 3 & - & - & - & - & - \\
\hline Garagem - A terro & 18 & - & - & - & - & - & 18 & - & - & - & - & - \\
\hline A terro - Garagem (término da coleta) & 16 & 17 & 16 & 16 & 16 & 16 & 16 & 17 & 33 & 16 & 16 & 16 \\
\hline Distância Total Percorrida (km) & 149 & 110 & 108 & 111 & 108 & 109 & 151 & 109 & 126 & 108 & 109 & 110 \\
\hline \multicolumn{13}{|l|}{ Parâmetros Analisados ( $\mathrm{km})$} \\
\hline Percurso de Coleta-PCL 1 ${ }^{\text {a }}$ Viagem & 51 & 61 & 61 & 54 & 43 & 61 & 54 & 61 & 61 & 61 & 61 & 63 \\
\hline Percurso de Coleta-PCL 2a Viagem & 50 & 49 & 47 & 57 & 65 & 48 & 51 & 48 & 65 & 47 & 48 & 47 \\
\hline Percurso de Coleta-PCL $3^{a}$ Viagem & 48 & - & - & - & - & - & 46 & 40 & - & - & - & - \\
\hline Percurso de Coleta Total & 149 & 110 & 108 & 111 & 108 & 109 & 151 & 149 & 126 & 108 & 109 & 110 \\
\hline Percurso de Coleta no Setor & 33 & 31 & 29 & 33 & 47 & 32 & 31 & 30 & 19 & 30 & 32 & 31 \\
\hline Núm ero de Viagens - NVG & 3 & 2 & 2 & 2 & 2 & 2 & 3 & 2 & 2 & 2 & 2 & 2 \\
\hline Percurso Vazio - PVA & 55 & 39 & 38 & 38 & 21 & 37 & 58 & 69 & 55 & 38 & 38 & 38 \\
\hline Percurso Cheio- PCH & 61 & 40 & 41 & 40 & 40 & 40 & 62 & 70 & 40 & 40 & 39 & 41 \\
\hline
\end{tabular}


TABELA 32 - Parâmetros operacionais de coleta para o Setor 1, obtidos a partir dos resultados da rotina de roteamento em arco (arc routing). *

\begin{tabular}{|c|c|c|c|}
\hline \multirow{2}{*}{ Cálculo das Distâncias Percorridas (km) } & \multicolumn{3}{|c|}{ Amostras Consideradas } \\
\hline & 1 & 2 & 3 \\
\hline $\begin{array}{l}\text { Garagem - Setor } \\
\text { Distância Percorrida no Setor ( } 1^{\mathrm{a}} \text { viagem) } \\
\text { Setor - Garagem ( } 1^{\mathrm{a}} \text { viagem) } \\
\text { Garagem - Aterro } \\
\text { Aterro - Setor } \\
\text { Distância Percorrida no Setor ( } 2^{\mathrm{a}} \text { viagem) } \\
\text { Setor - Garagem ( } 2^{\mathrm{a}} \text { viagem) } \\
\text { Garagem - Aterro } \\
\text { Aterro - Setor } \\
\text { Distância Percorrida no Setor ( } 3^{\mathrm{a}} \text { viagem) } \\
\text { Setor - Garagem ( } 3^{\mathrm{a}} \text { viagem) } \\
\text { Garagem - Aterro } \\
\text { Aterro - Garagem (término da coleta) } \\
\text { Distância Total Percorrida (km) }\end{array}$ & $\begin{array}{c}1,35 \\
41,91 \\
1,18 \\
12,11 \\
- \\
- \\
- \\
- \\
- \\
- \\
- \\
- \\
12,68 \\
69,23\end{array}$ & $\begin{array}{c}1,35 \\
41,91 \\
2,27 \\
12,11 \\
10,07 \\
- \\
1,18 \\
12,11 \\
- \\
- \\
- \\
- \\
12,68 \\
93,68\end{array}$ & $\begin{array}{c}1,35 \\
41,91 \\
2,27 \\
12,11 \\
10,07 \\
- \\
2,27 \\
12,11 \\
10,07 \\
- \\
1,18 \\
12,11 \\
12,68 \\
118,13\end{array}$ \\
\hline \multicolumn{4}{|l|}{ Parâmetros Analisados (km) } \\
\hline $\begin{array}{l}\text { Percurso de Coleta - PCL } 1^{\mathrm{a}} \text { Viagem } \\
\text { Percurso de Coleta - PCL } 2^{\mathrm{a}} \text { Viagem } \\
\text { Percurso de Coleta - PCL } 3^{\mathrm{a}} \text { Viagem } \\
\text { Percurso de Coleta Total } \\
\text { Percurso de Coleta no Setor } \\
\text { Número de Viagens - NVG } \\
\text { Percurso Vazio - PVA } \\
\text { Percurso Cheio - PCH } \\
\end{array}$ & $\begin{array}{c}- \\
- \\
- \\
69,23 \\
41,91 \\
1 \\
14,03 \\
13,29 \\
\end{array}$ & $\begin{array}{c}- \\
- \\
- \\
93,68 \\
41,91 \\
2 \\
24,10 \\
27,67 \\
\end{array}$ & $\begin{array}{c}- \\
- \\
- \\
118,13 \\
41,91 \\
3 \\
34,17 \\
42,05 \\
\end{array}$ \\
\hline
\end{tabular}

* A distância percorrida no setor não é dividida por viagem 
TABELA 33 - Parâmetros operacionais de coleta para o Setor 2, obtidos a partir dos resultados da rotina de roteamento em arco (arc routing). *

\begin{tabular}{|c|c|c|c|}
\hline \multirow[b]{2}{*}{ Cálculo das Distâncias Percorridas (km) } & \multicolumn{3}{|c|}{ Amostras Consideradas } \\
\hline & 1 & 2 & 3 \\
\hline Garagem - Setor & 3,05 & 3,05 & $3 ; 05$ \\
\hline Distância Percorrida no Setor ( $1^{a}$ viagem) & 37,37 & 37,37 & 37,37 \\
\hline Setor - Garagem ( $1^{a}$ viagem $)$ & 2,77 & 2,27 & 2,27 \\
\hline Garagem - Aterro & 12,11 & 12,11 & 12,11 \\
\hline Aterro - Setor & - & 10,07 & 10,07 \\
\hline Distância Percorrida no Setor ( $2^{\mathrm{a}}$ viagem) & - & - & - \\
\hline Setor - Garagem ( $2^{\mathrm{a}}$ viagem $)$ & - & 2,77 & 2,27 \\
\hline Garagem - Aterro & - & 12,11 & 12,11 \\
\hline Aterro - Setor & - & - & 10,07 \\
\hline Distância Percorrida no Setor ( $3^{\mathrm{a}}$ viagem) & - & - & - \\
\hline Setor - Garagem ( $3^{\mathrm{a}}$ viagem $)$ & 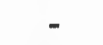 & - & 2,77 \\
\hline Garagem - Aterro & - & - & 12,11 \\
\hline Aterro - Garagem (término da coleta) & 12,68 & 12,68 & 12,68 \\
\hline Distância Total Percorrida (km) & 65,21 & 92,43 & 116,88 \\
\hline \multicolumn{4}{|l|}{ Parâmetros Analisados (km) } \\
\hline Percurso de Coleta - PCL $1^{a}$ Viagem & - & - & - \\
\hline Percurso de Coleta - PCL $2^{\mathrm{a}}$ Viagem & - & - & - \\
\hline Percurso de Coleta - PCL $3^{a}$ Viagem & - & - & - \\
\hline Percurso de Coleta Total & 65,21 & 92,43 & 116,88 \\
\hline Percurso de Coleta no Setor & 37,37 & 37,37 & 37,37 \\
\hline Número de Viagens - NVG & 1 & 2 & 3 \\
\hline Percurso Vazio - PVA & 15,73 & 25,80 & 35,87 \\
\hline Percurso Cheio - PCH & 14,88 & 29,26 & 43,64 \\
\hline
\end{tabular}

* A distância percorrida no setor não é dividida por viagem 
TABELA 34 - Parâmetros operacionais de coleta para o Setor 3, obtidos a partir dos resultados da rotina de roteamento em arco (arc routing).*

\begin{tabular}{|c|c|c|c|}
\hline \multirow[b]{2}{*}{ Cálculo das Distâncias Percorridas (km) } & \multicolumn{3}{|c|}{ Amostras Consideradas } \\
\hline & 1 & 2 & 3 \\
\hline Garagem - Setor & - & 1,8 & - \\
\hline Distância Percorrida no Setor ( $\left(1^{a}\right.$ viagem) & - & 40,53 & - \\
\hline Setor - Garagem ( $\left(1^{2}\right.$ viagem $)$ & - & 2,83 & - \\
\hline Garagem - Aterro & - & 12,11 & - \\
\hline Aterro - Setor & - & 9,8 & - \\
\hline Distância Percorrida no Setor ( $2^{\mathrm{a}}$ viagem) & - & - & - \\
\hline Setor - Garagem ( $2^{\mathrm{a}}$ viagem) & - & 2,21 & - \\
\hline Garagem - Aterro & - & 12,11 & - \\
\hline Aterro - Setor & - & - & - \\
\hline Distância Percorrida no Setor ( $3^{a}$ viagem) & - & - & - \\
\hline Setor - Garagem ( $\left(3^{\mathrm{a}}\right.$ viagem $)$ & - & - & - \\
\hline Garagem - Aterro & - & - & - \\
\hline Aterro - Garagem (término da coleta) & - & 12,68 & - \\
\hline Distância Total Percorrida (km) & - & 94,07 & - \\
\hline \multicolumn{4}{|l|}{ Parâmetras Analisados (km) } \\
\hline Percurso de Coleta - PCL $1^{3}$ Viagem & - & - & - \\
\hline Percurso de Coleta - PCL $2^{\mathrm{a}}$ Viagem & - & - & - \\
\hline Percurso de Coleta - PCL $3^{\mathrm{a}}$ Viagem & - & - & - \\
\hline Percurso de Coleta Total & - & 94,07 & - \\
\hline Percurso de Coleta no Setor & - & 40,53 & - \\
\hline Número de Viagens - NVG & - & 2 & - \\
\hline Percurso Vazio - PVA & - & 24,28 & - \\
\hline Percurso Cheio - PCH & - & 29,26 & - \\
\hline
\end{tabular}

* A distância percorrida no setor não é dividida por viagem 
TABELA 35 - Parâmetros operacionais de coleta para o Setor 4, obtidos a partir dos resultados da rotina de roteamento em arco (arc routing).*

\begin{tabular}{|c|c|c|c|}
\hline \multirow[b]{2}{*}{ Cálculo das Distâncias Percorridas (km) } & \multicolumn{3}{|c|}{ Amostras Consideradas } \\
\hline & 1 & 2 & 3 \\
\hline Garagem - Setor & - & 3,22 & - \\
\hline Distância Percorrida no Setor ( $l^{\mathrm{a}}$ viagem) & - & 48,74 & - \\
\hline Setor - Garagem ( $\left(1^{a}\right.$ viagem) & - & 4,48 & - \\
\hline Garagem - Aterro & - & 12,11 & - \\
\hline Aterro- Setor & - & 8,51 & - \\
\hline Distância Percorrida no Setor ( $2^{a}$ viagem) & - & - & - \\
\hline Setor - Garagem ( $2^{\mathrm{a}}$ viagem) & - & 3,43 & - \\
\hline Garagem - Aterro & - & 12,11 & - \\
\hline Aterro - Setor & - & - & - \\
\hline Distância Percorrida no Setor ( $3^{\mathrm{a}}$ viagem) & - & - & - \\
\hline Setor - Garagem ( $3^{\mathrm{a}}$ viagem) & - & - & - \\
\hline Garagem - Aterro & - & - & - \\
\hline Aterro - Garagem (término da coleta) & - & 12,68 & - \\
\hline Distância Total Percorrida (km) & - & 105,28 & - \\
\hline \multicolumn{4}{|l|}{ Parâmetros Analisados (km) } \\
\hline Percurso de Coleta - PCL $1^{2}$ Viagem & - & - & - \\
\hline Percurso de Coleta - PCL $2^{a}$ Viagem & - & - & - \\
\hline Percurso de Coleta - PCL $3^{a}$ Viagem & - & - & - \\
\hline Percurso de Coleta Total & - & 105,28 & - \\
\hline Percurso de Coleta no Setor & - & 48,74 & - \\
\hline Número de Viagens - NVG & - & 2 & - \\
\hline Percurso Vazio - PVA & - & 24,41 & - \\
\hline Percurso Cheio - PCH & - & 32,13 & - \\
\hline
\end{tabular}

*A distância percorrida no setor não é dividida por viagem 
TABELA 36 - Parâmetros operacionais de coleta para o Setor 5, obtidos a partir dos resultados da rotina de roteamento em arco (arc routing).*

\begin{tabular}{|c|c|c|c|}
\hline \multirow[b]{2}{*}{ Cálculo das Distâncias Percorridas (km) } & \multicolumn{3}{|c|}{ Amostras Consideradas } \\
\hline & 1 & 2 & 3 \\
\hline Garagem - Setor & - & 2,84 & 2,84 \\
\hline Distância Percorrida no Setor ( $1^{\mathrm{a}}$ viagem) & - & 36,51 & 36,51 \\
\hline Setor - Garagem ( $1^{\mathrm{a}}$ viagem $)$ & - & 3,63 & 3,63 \\
\hline Garagem - Aterro & - & 12,11 & 12,11 \\
\hline Aterro - Setor & - & 10,13 & 10,13 \\
\hline Distância Percorrida no Setor ( $2^{\mathrm{a}}$ viagem) & - & - & - \\
\hline Setor - Garagem ( (2a viagem) & - & 3,43 & 3,63 \\
\hline Garagem - Aterro & - & 12,11 & 12,11 \\
\hline Aterro - Setor & - & - & 10,13 \\
\hline Distância Percorrida no Setor ( $3^{\mathrm{a}}$ viagem) & - & - & - \\
\hline Setor - Garagem ( $3^{\mathrm{a}}$ viagem) & - & - & 3,43 \\
\hline Garagem - Aterro & - & - & 12,11 \\
\hline Aterro - Garagem (término da coleta) & - & 12,68 & 12,68 \\
\hline Distância Total Percorrida (km) & - & 93,44 & 119,31 \\
\hline \multicolumn{4}{|l|}{ Parâmetros Analisados (km) } \\
\hline Percurso de Coleta - PCL $1^{\mathrm{a}}$ Viagem & - & - & - \\
\hline Percurso de Coleta - PCL $2^{a}$ Viagem & - & - & - \\
\hline Percurso de Coleta - PCL $3^{a}$ Viagem & - & - & - \\
\hline Percurso de Coleta Total & - & 93,44 & 119,31 \\
\hline Percurso de Coleta no Setor & - & 36,51 & 36,51 \\
\hline Número de Viagens - NVG & - & 2 & 3 \\
\hline Percurso Vazio - PVA & - & 25,65 & 35,78 \\
\hline Percurso Cheio - PCH & - & 31,28 & 47,02 \\
\hline
\end{tabular}

*A distância percorrida no setor não é dividida por viagem 
As informações constantes nas tabelas apresentadas anteriormente permitiram uma avaliação quantitativa dos parâmetros operacionais do serviço de coleta domiciliar. FERNANDES et al. (1995) recomendam que a análise deve sempre ser feita com base nos dados de uma semana de operação, pois este é o ciclo em que o processo de coleta se repete, levando-se em conta naturais oscilações entre os parâmetros no intervalo de uma semana. Isso é importante porque a massa coletada não se distribui uniformemente entre os dias de coleta $e$, conseqüentemente as distâncias percorridas pelo caminhão coletor não são as mesmas. No presente trabalho considerou-se somente 2 semanas de operação, não sendo possível realizar uma análise estatística dos dados e sim, uma comparação entre os parâmetros obtidos.

Nos parâmetros das tabelas $27,28,29,30$ e 31 é possível observar que as distâncias percorridas variam diariamente, mas nas tabelas $32,33,34,35$ e 36 isso não é facilmente observado, pois no presente trabalho não foram consideradas a produção de resíduos ao longo de cada link e capacidade do caminhão coletor e sim, uma situação na qual o caminhão deveria percorrer todos os links a fim de realizar o serviço, considerando uma viagem.

As simulações foram realizadas baseadas nos dados da VEGA. Por exemplo, se em um determinado dia da semana o caminhão da VEGA realizasse o serviço em 3 viagens, para o calculado dos parâmetros operacionais a partir da aplicação da rotina (arc routing) se considerariam 3 viagens, e assim por diante, estabelecendo uma comparação dos valores obtidos para cada setor.

Os percursos totais obtidos com os parâmetros da VEGA foram em geral superiores aos obtidos com a rotina. Para melhor visualização dos dados foram construídos gráficos (figuras 30 a 34) utilizando-se os parâmetros operacionais. Estes são apresentados e comentados a seguir: 


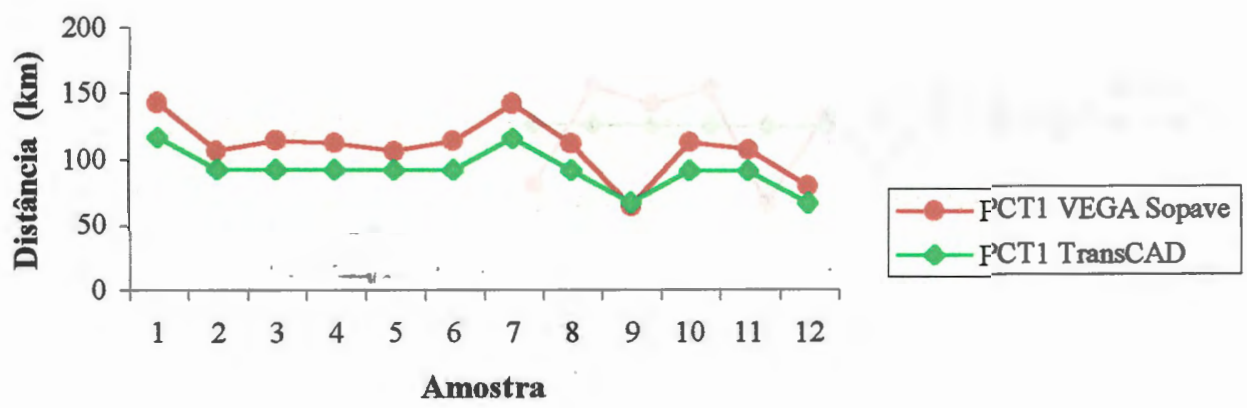

FIGURA 30 - Percurso de Coleta Total no Setor 1 (PCT1)

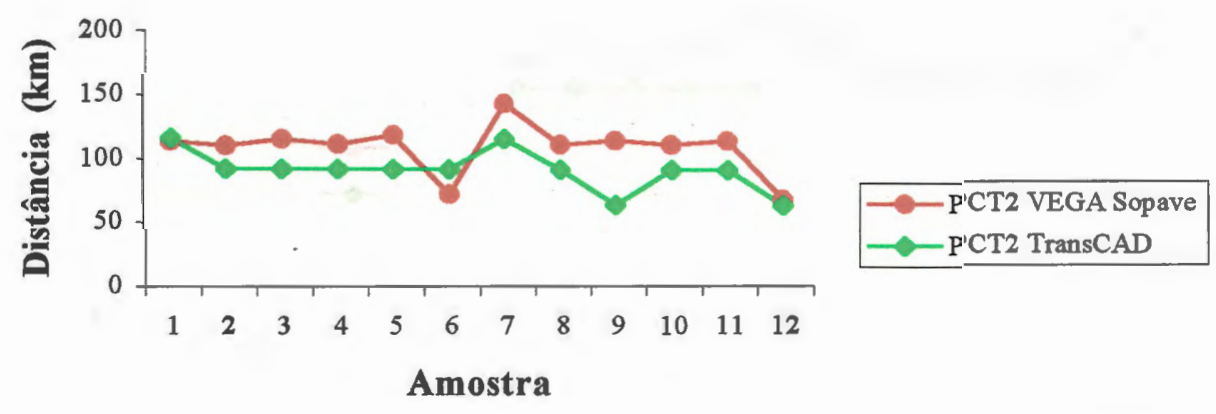

FIGURA 31 - Percurso de Coleta Total no Setor 2 (PCT2)

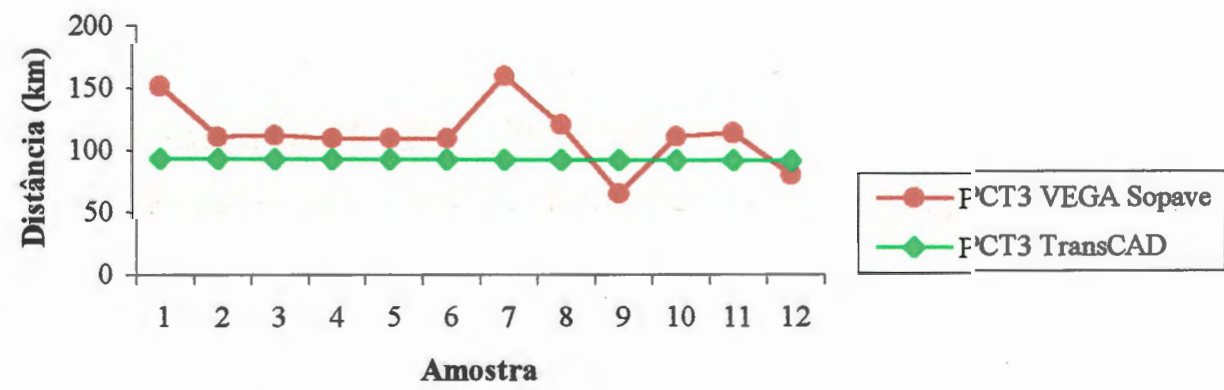

FIGURA 32 - Percurso de Coleta Total no Setor 3 (PCT3) 


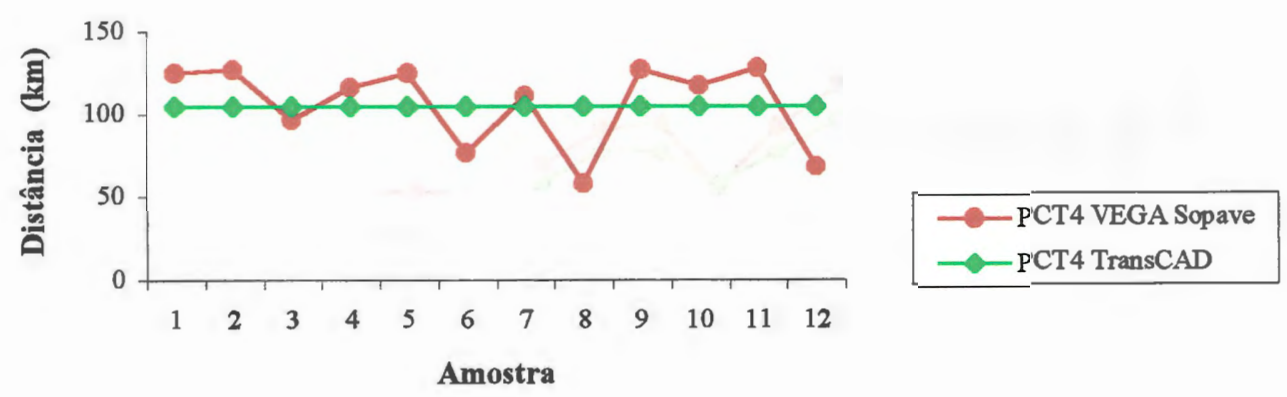

FIGURA 33 - Percurso de Coleta Total no Setor 4 (PCT4)

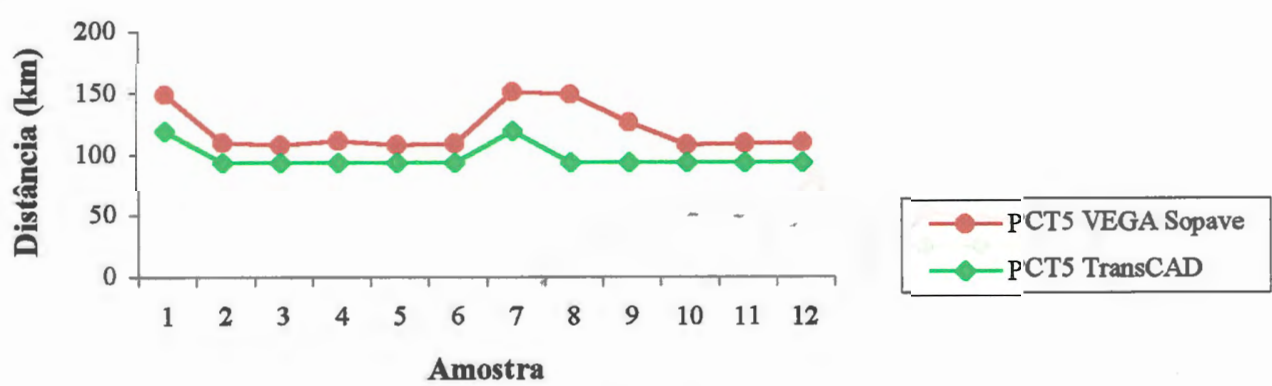

\section{FIGURA 34 - Percurso de Coleta Total no Setor 5 (PCT5)}

$\mathrm{Na}$ figura 33 pode-se observar que a variação das distâncias percorridas, durante o período analisado apresentou um arranjo diferente dos demais. $\mathrm{O}$ setor 4 para a VEGA Sopave é um setor problemático, devido a vários fatores, tais como a configuração das ruas e a extensão do setor.

Para avaliar a distância percorrida no setor construiu-se um gráfico, considerando os percursos de coleta no setor e a extensão total dos links. 


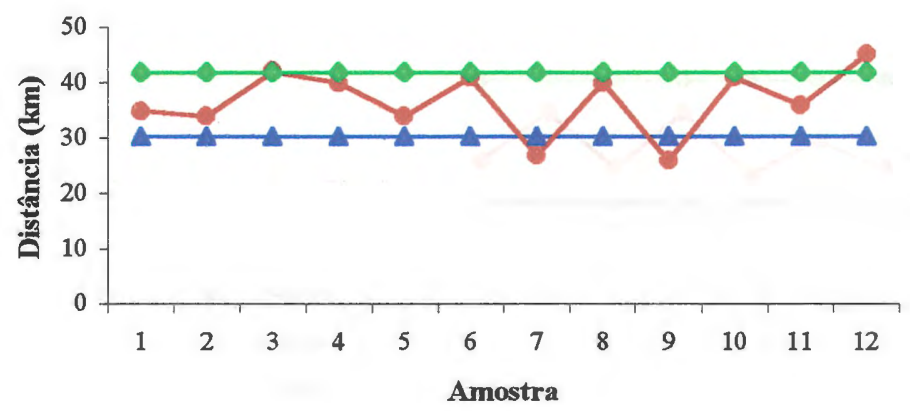

FIGURA 35 - Percurso de Coleta no Setor 1 (PCS1)

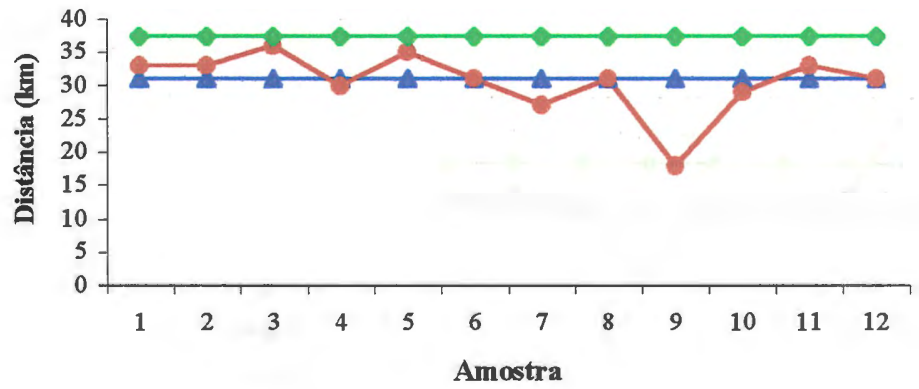

-ET2 dos link

$\longrightarrow$ PCS2 VEGA Sopave

$\rightarrow$ PCS2 TransCAD

FIGURA 36 - Percurso de Coleta no Setor 2 (PCS2)

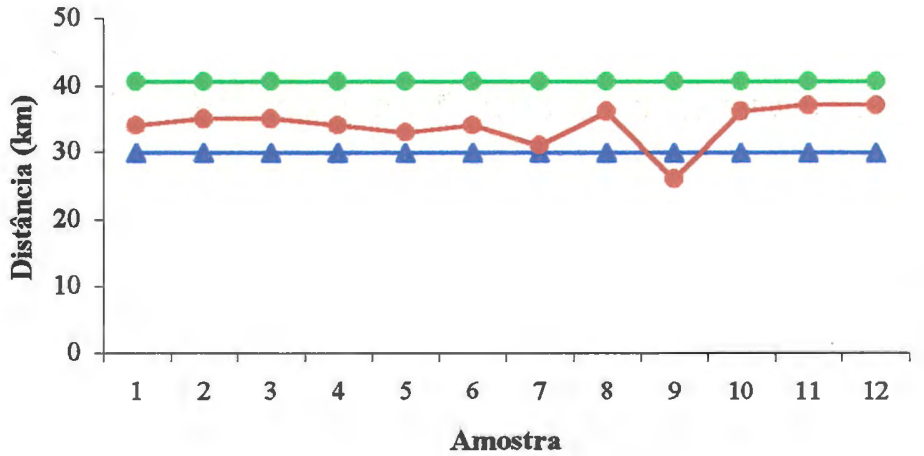

FIGURA 37 - Percurso de Coleta no Setor 3 (PCS3) 


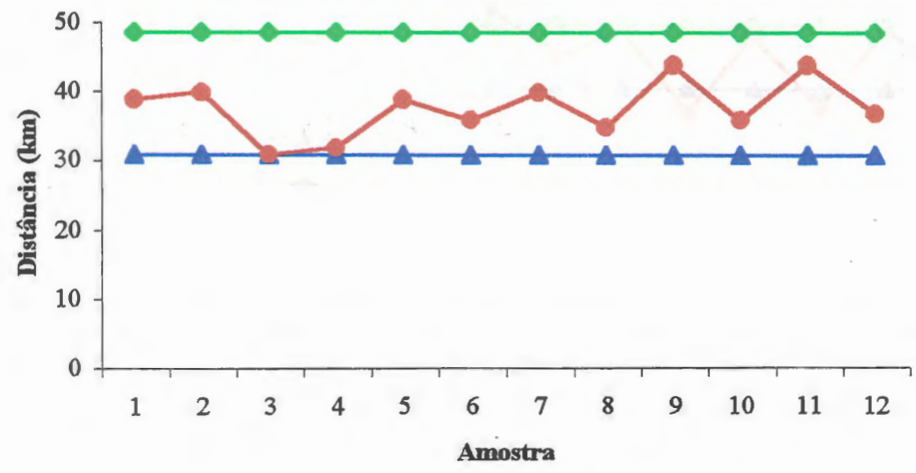

\section{FIGURA 38 - Percurso de Coleta no Setor 4 (PCS4)}

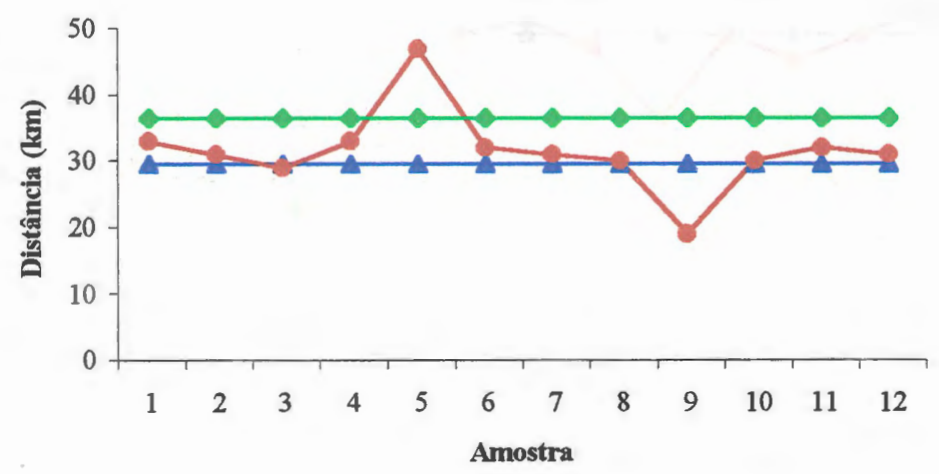

-ET5 dos links

\section{FIGURA 39 - Percurso de Coleta no Setor 5 (PCS5)}

Os parâmetros analisados (PCS TransCAD e PCS VEGA Sopave) foram em geral superiores a extensão total dos links e os parâmetros da VEGA inferiores aos obtidos com a rotina. Esta distância adicional se deve à sobreposição dos links, ou seja, à repetição de links, onde o serviço de coleta já foi realizado. Uma questão a se considerar é que a VEGA Sopave realiza um tipo de serviço diferenciado: muitas ruas são percorridas pelos coletores que transportam os resíduos para as esquinas onde o caminhão coletor passa. Esta situação ocorre quando o caminhão completa a viagem e se dirige à descarga.

Este tipo de coleta denominada coleta de frente não obedece a uma sistemática de trabalho, ficando a equipe de coleta (motorista e coletores) 
responsável pela decisão em quais ruas o serviço irá ocorrer. As equipes tem interesse em realizar este tipo de trabalho, dessa forma a operação de coleta se realizará em menos tempo.

Uma tabela resumo apresentando a extensão total dos links, a distância média percorrida pelo caminhão e também a quilometragem e a porcentagem de repetições dos links já servidos é mostrada a seguir:

TABELA 37 - Extensão total dos links, quilometragem e porcentagem de repetições dos links em cada setor de coleta.

\begin{tabular}{|c|c|c|c|c|c|}
\hline PARAMETROS & Setor 1 & Setor 2 & Setor 3 & Setor 4 & Setor 5 \\
\hline Extensão Total dos links $(\mathrm{km})$ & 30,36 & 30,93 & 29,88 & 30,93 & 29,53 \\
\hline \multicolumn{6}{|l|}{ Vega/Sopave } \\
\hline Distância percorrida no Setor (km) & 36,75 & 30,58 & 34,00 & 37,75 & 32,50 \\
\hline km de repetições & 6,39 & $-0,35$ & 4,12 & 6,82 & 2,97 \\
\hline \% de repetições & 21,05 & $-1,13$ & 13,79 & 22,05 & 10,06 \\
\hline \multicolumn{6}{|l|}{ TransCAD } \\
\hline Distância percorrida no Setor (km) & 41,91 & 37,37 & 40,53 & 48,74 & 36,51 \\
\hline km de repetições & 11,55 & 6,44 & 10,65 & 17,81 & 6,98 \\
\hline \% de repetições & 27,56 & 17,23 & 26,28 & 36,54 & 19,12 \\
\hline
\end{tabular}

De acordo com AGUIAR (1993), tendo em vista que a equipe e coleta quer terminar a tarefa o mais rapidamente possível, é provável que a rota não apresente um nível elevado de repetição de passagem em ruas já servidas. Por outro lado, notase que o uso de um programa de otimização de rotas apresenta uma porcentagem de repetição em torno de $40 \%$. Esta situação foi observada no presente trabalho, onde a porcentagem de repetições da VEGA Sopave ficou na faixa de 10,06\% (Setor 5) à $21,05 \%$ (Setor 4). Com o TransCAD foram obtidos valores superiores, sendo o mínimo de $17,23 \%$ (Setor 2) e o máximo de 36,54\% (Setor 4), e mesmo assim estão em um limite aceitável. $\mathrm{O}$ valor negativo obtido para a quilometragem e porcentagem de repetições no setor 2 (VEGA Sopave) indica que o caminhão não realizou nenhuma repetição de passagem sobre os links.

As figuras 40, 41, 42, 43 e 44 representam o percurso vazio, e o percurso cheio as figuras $45,46,47,48$ e 49 . 


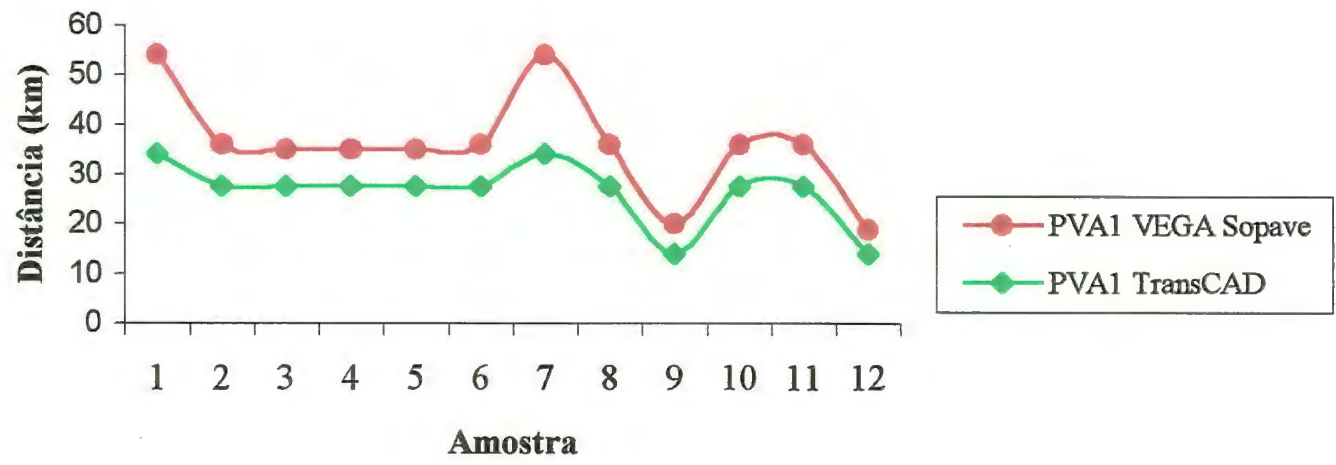

FIGURA 40 - Percurso Vazio no Setor 1 (PVA1)

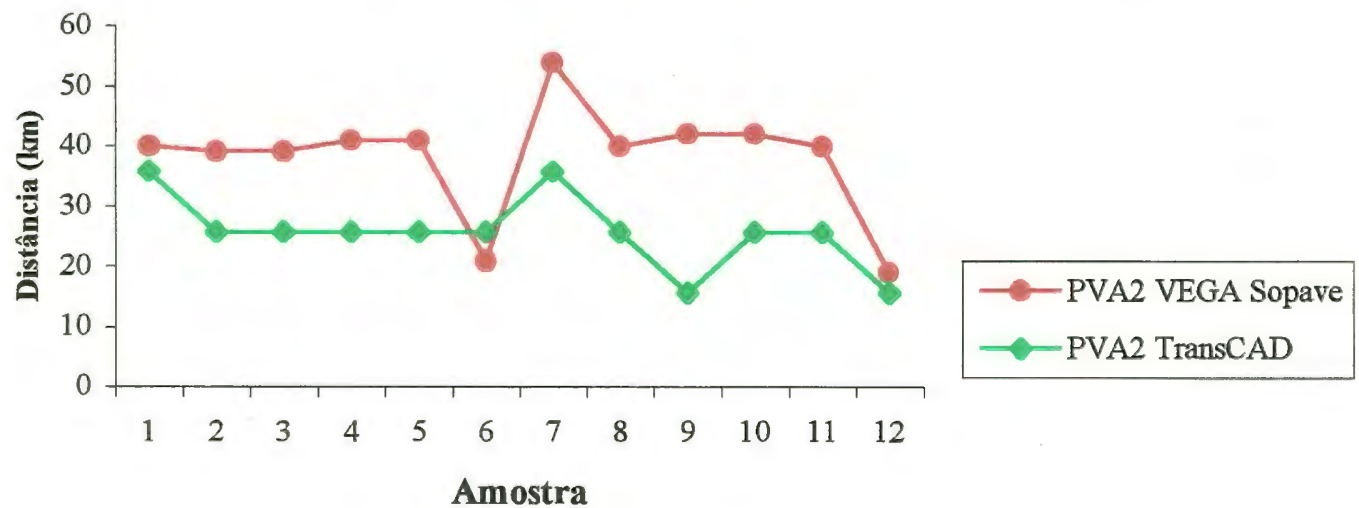

FIGURA 41 - Percurso Vazio no Setor 2 (PVA2)

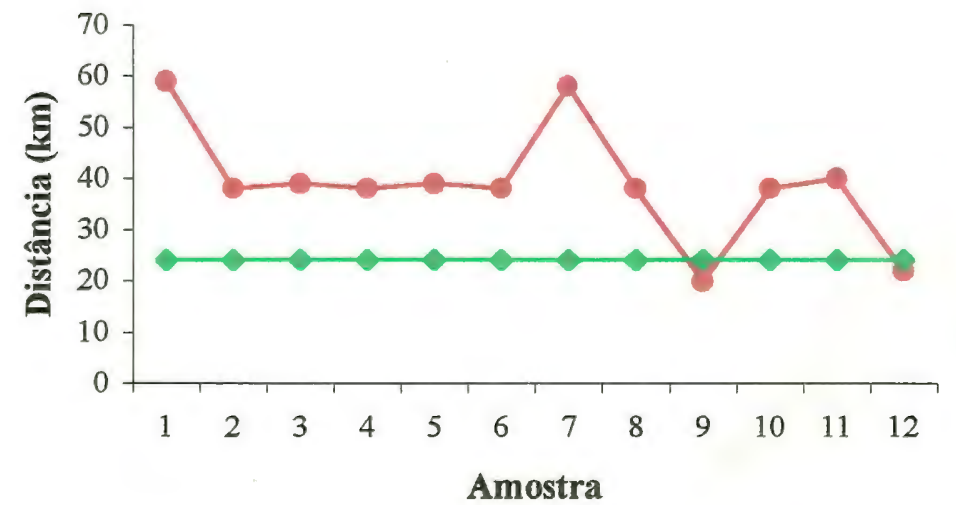

FIGURA 42 - Percurso Vazio no Setor 3 (PVA3) 


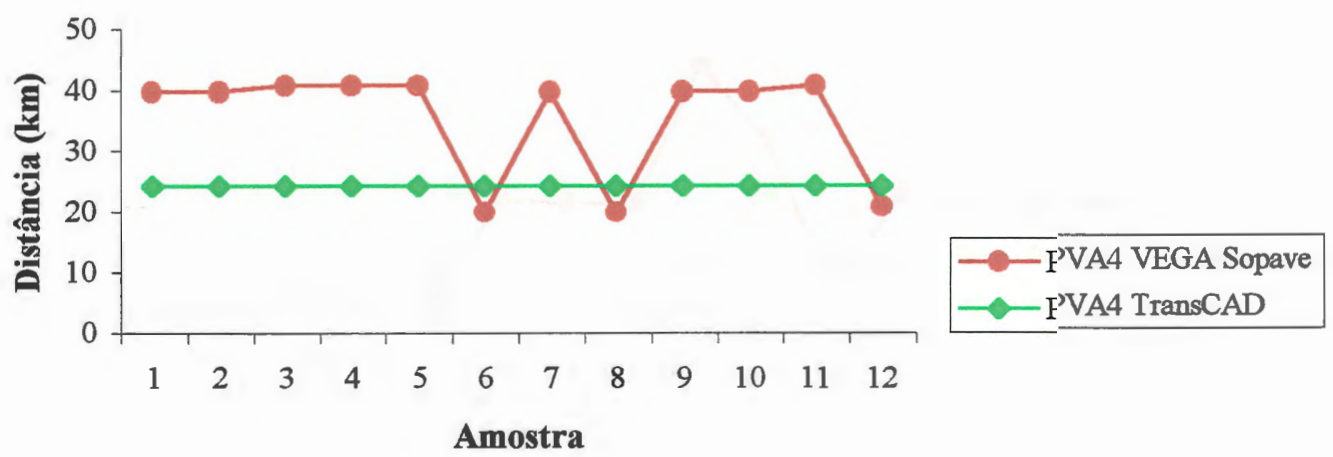

FIGURA 43 - Percurso Vazio no Setor 4 (PVA4)

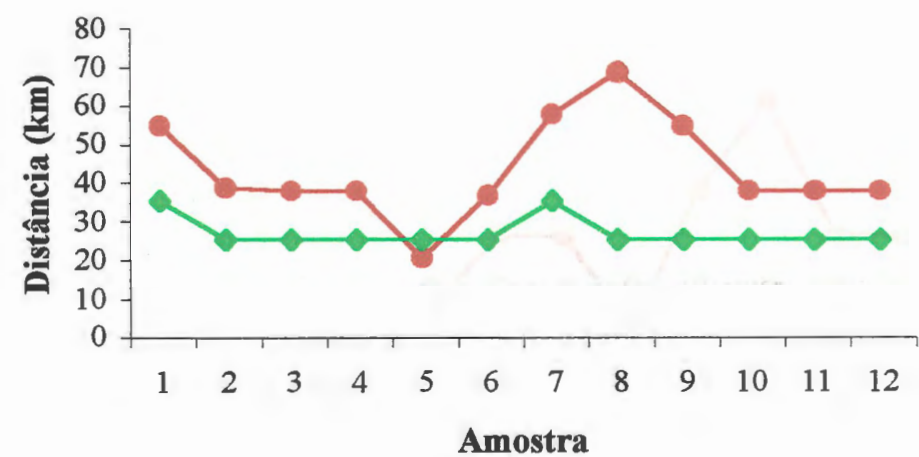

FIGURA 44 - Percurso Vazio no Setor 5 (PVA5)

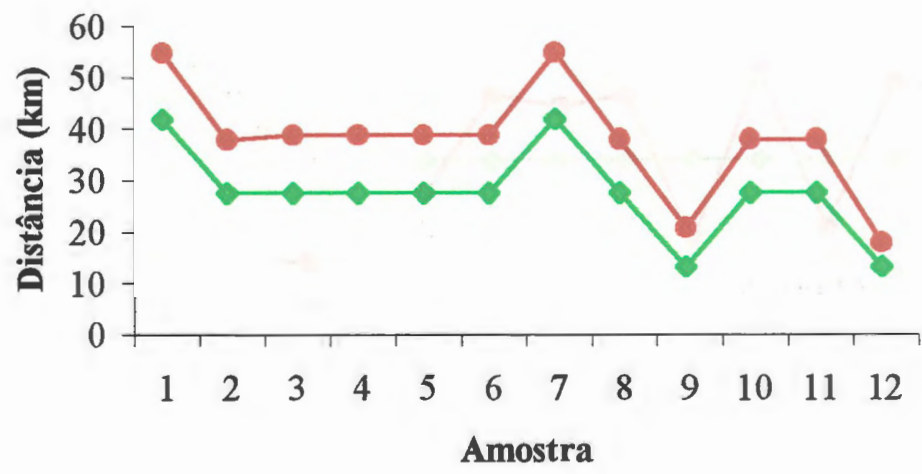




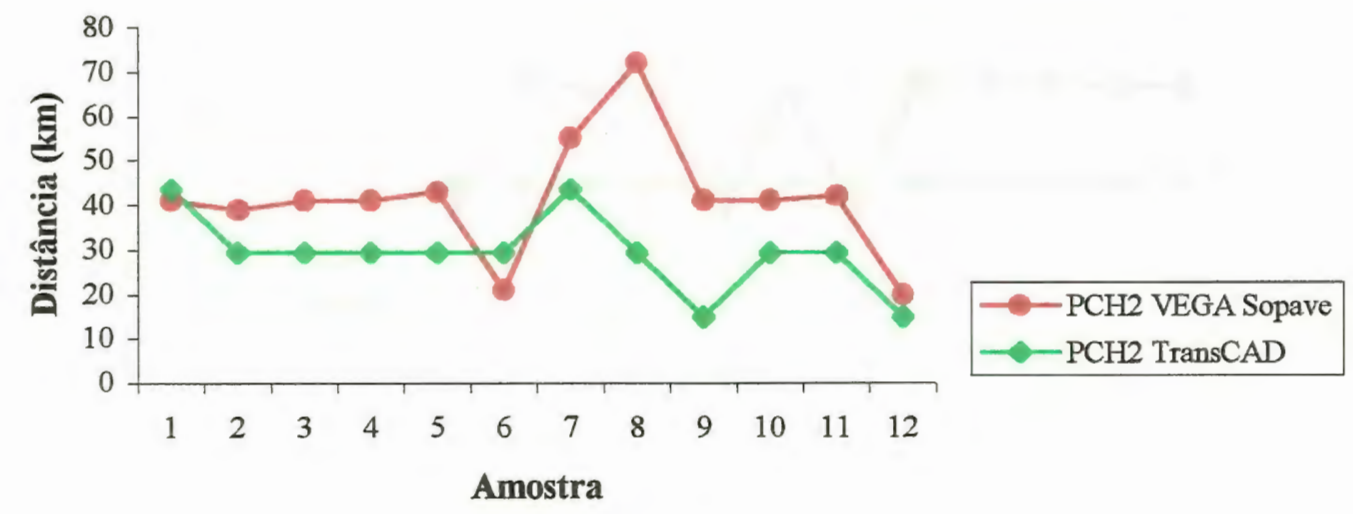

FIGURA 46 - Percurso Cheio no Setor 2 (PCH2)

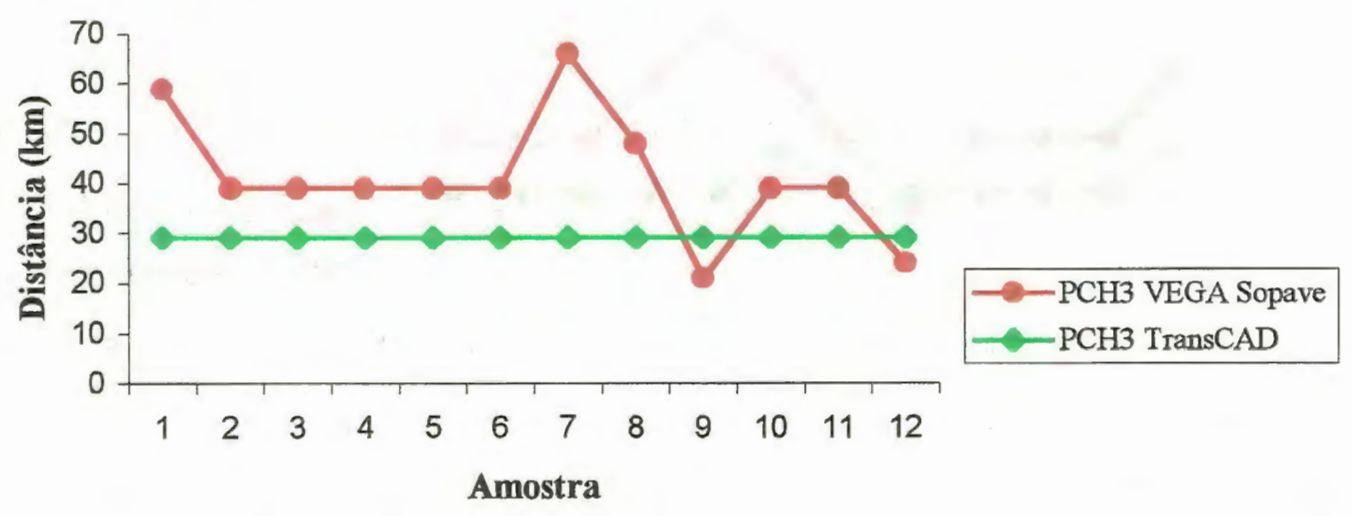

FIGURA 47 - Percurso Cheio no Setor 3 (PCH3)

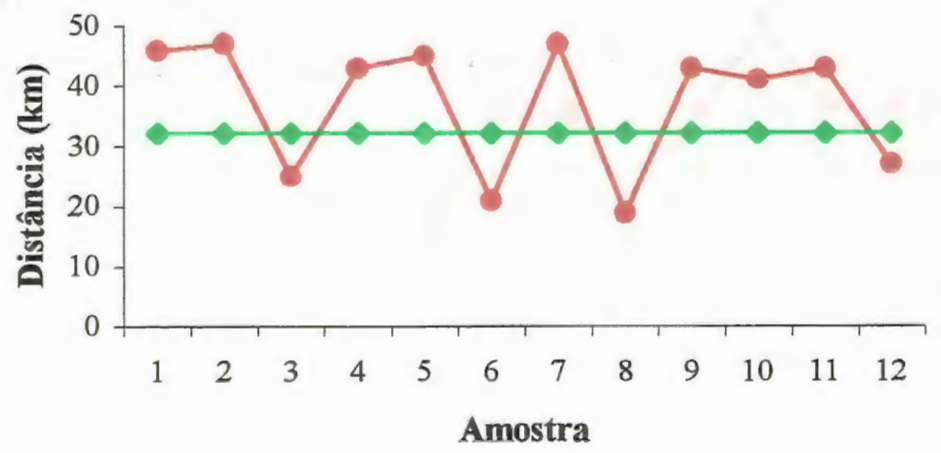

FIGURA 48 - Percurso Cheio no Setor 4 (PCH4) 


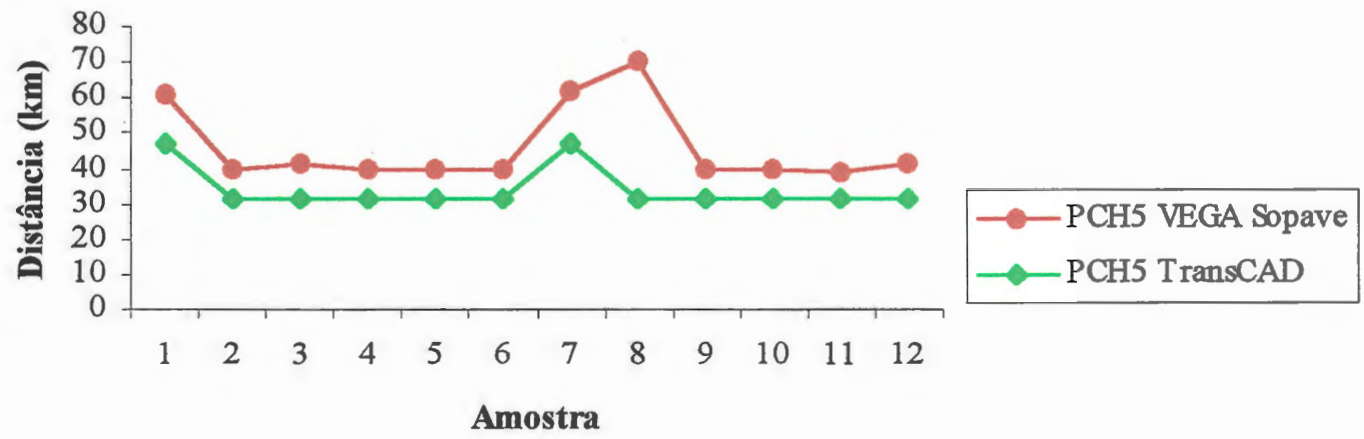

\section{FIGURA 49 - Percurso Cheio no Setor 5 (PCH5)}

O percurso vazio (PVA) e o percurso cheio $(\mathrm{PCH})$ calculados com os dados da rotina foram menores e os gráficos, de maneira geral apresentaram configurações semelhantes. Analisando os gráficos dos percurso cheio observou-se variabilidade de dados no setor 4.

A configuração dos setores de coleta, já apresentados do item 5.2, influencia os parâmetros calculados. O setor 4 apresenta o formato mais irregular das ruas que compõe o setor, o que prejudicou em ambas as situações consideradas, o estabelecimento de roteiros de coleta otimizados. Já o setor 2 apresenta um formato que permitiu obter melhores valores.

A produção de resíduos ao longo dos links é também um fator preponderante quando se procede a análise das distâncias percorridas pelo caminhão. Assim, quanto maior a produção de resíduos, maior a distância percorrida, maior o percurso total de coleta, percurso vazio e percurso cheio. Quanto à distância percorrida no setor, esta não altera muito, porque o motorista não pode prever onde tem resíduos para serem coletados, devendo percorrer todo o setor para evitar a reclamação da comunidade. 


\section{CONCLUSÕES E RECOMENDAÇÕES}

As conclusões foram feitas em função de dois aspectos: o primeiro, relativo a situação dos sistemas de coleta domiciliar dos municípios brasileiros de médio porte e o segundo relativo à aplicação com o Sistema de Informação Geográfica-SIG, ambos de acordo com os objetivos propostos e com base nos resultados obtidos.

\subsection{Sistemas de coleta de resíduos sólidos domiciliares de municípios de médio porte}

Espera-se que a análise desenvolvida apresente a realidade dos aspectos relativos à coleta domiciliar, sendo um referencial para futuras pesquisas. A busca de uma sistemática operacional em que a eficiência e a qualidade técnico-ambiental prevaleçam, justifica a realização da caracterização dos sistema de coleta, para que sejam estabelecidas alternativas gerenciais de acordo com as particularidades dos municípios.

Considerando as características dos sistemas de coleta domiciliar pode-se concluir dos questionários recebidos que:

- Os sistemas de coleta dos municípios de médio porte apresentam características semelhantes às metrópoles regionais, grandes e pequenos municípios.

- Na maioria dos municípios pesquisados a execução é de responsabilidade da prefeitura municipal.

- As formas de disposição final inadequada (lixão e aterro controlado) prevalecem sobre a ambientalmente segura (aterro sanitário).

- A realização de um estudo de caracterização dos resíduos não é prioridade.

- Utilizam, na maioria dos casos, apenas um tipo de veículo. 
- Mais de $57 \%$ operam com uma frota de idade média superior a 5 anos.

- A manutenção dos veículos, seja rotineira, corretiva ou preventiva de modo geral é realizada.

- Onde não existem equipamentos de pesagem procede-se a estimativa dos resíduos coletados considerando a capacidade do veículo e número de viagens realizadas para completar a operação.

- Registraram-se velocidades de coleta superiores a $10 \mathrm{~km} / \mathrm{h}$.

- Os locais de disposição final de maneira geral se localizam a uma distância superior a $10 \mathrm{~km}$ dos setores de coleta.

- A coleta em dias alternados é a mais utilizada.

- Na definição de roteiros para os veículos de coleta prevalece a experiência de trabalho, optando assim pelo emprego de técnicas manuais.

- A guarnição de coleta é composta de 1 motorista e 3 ou 4 coletores.

- A maior parte dos treinamentos ministrados aos funcionários não são de caráter permanente; muitos só recebem orientação quando são admitidos.

- O serviço social prestado é principalmente ó alimentar.

- Acidentes ocorrem devido ao mal acondicionamento dos resíduos e pela falta de uso de equipamentos de proteção individual.

- A questão relativa à limpeza e a manutenção dos veículos é prejudicada, uma vez que os veículos sempre estão em operação.

Diante dessas considerações, recomenda-se:

- A realização de um estudo de caracterização dos resíduos.

- A implantação de uma campanha de prevenção de acidentes junto à população a fim de proceder um acondicionamento adequado aos resíduos e principalmente conscientizar a equipe de trabalho sobre a importância da utilização de equipamentos de proteção individual.

- Sistematizar a fiscalização do Poder Público diante das questões operacionais a que a coleta domiciliar se realiza; principalmente nos municípios onde o serviço é terceirizado, a prefeitura municipal deveria ter mais acesso aos dados operacionais.

- Promover qualificação e valorização profissional da equipe de trabalho envolvida, deste o administrativo até o operacional. 
- Buscar a liberação de recursos para a melhoria dos equipamentos e veículos utilizados na coleta, bem como conscientizar o poder público sobre a sua importância.

\subsection{A aplicação do Sistema de Informação Geográfica}

Embora a aplicação do SIG/TransCAD tenha sido desenvolvida com algumas simplificações verificou-se, através dos resultados obtidos, uma contribuição para o planejamento de roteiros de coleta domiciliar. Assim pode-se concluir:

- Quando se pretende fazer aplicações utilizando um SIG é importante considerar as dificuldades encontradas para a sua utilização, bem como estabelecer contato com pessoas e empresas para troca de experiências, o que seria importante, pois problemas eventuais advindos das aplicações poderiam ser solucionados.

- A partir do estudo de caso foi possível identificar alguns problemas e obstáculos existentes para a implementação de rotas, fornecendo assim, subsídios para aqueles que desejarem fazer aplicações similares.

- As simplificações impostas pela próprio software, comprometeram a obtenção de melhores resultados, estas citadas a seguir:

$\Rightarrow$ Não foi possível considerar restrições de movimento "à direita" ou "à esquerda";

$\Rightarrow$ A distância até o local de descarga não foi considerada na aplicação da rotina de roteamento em arco;

$\Rightarrow$ Mesmo depois de definido o sentido de atravessamento dos links, foi necessário fazer alterações (intervenção do usuário) até que a rotina funcionasse, o que implicava em um gasto de tempo considerável.

- Os percursos totais do caminhão coletor foram inferiores aos calculados a partir de dados de uma situação real;

- Observou-se um nível de repetição de passagem sobre links já servidos menor que 40\%, de acordo com AGUIAR (1995) é considerado satisfatório;

- A utilização de um SIG na roteirização de veículos de coleta domiciliar possuem muitos aspectos a serem explorados, questionados e consolidados, 
mas os resultados obtidos no presente trabalho tem certamente um significado relevante no tratamento das questões relativas ao gerenciamento de resíduos sólidos domiciliares.

\subsection{Propostas para trabalhos futuros}

- Ampliar o estudo de caracterização dos sistemas de coleta a fim de estabelecer parâmetros operacionais.

- Avaliar e estabelecer alternativas para a definição de roteiros em municípios de médio porte, considerando a especificidade local.

- Implementar os procedimentos propostos para o estudo de caso, considerando a produção de resíduos sólidos ao longo de cada link.

- Estabelecer uma parceria com a empresa gerenciadora dos sistema de coleta a fim de aplicar os resultados e identificar problemas que poderiam resultar da execução dos roteiros obtidos com o SIG/TransCAD.

- Avaliar a minimização de custos operacionais equivalentes ao percurso total de coleta resultante da aplicação do SIG/TransCAD. 


\section{ANEXO A \\ QUESTIONÁRIO PADRÃO}

1. Aspecto Geral

COLETA DE RESÍDUOS SÓLIDOS DOMICILIARES

a) Qual é a quantidade total de lixo domiciliar coletado (toneladas/dia) no Município?

b) Qual é a população do município? Qual a porcentagem desta que é atendida pelo serviço de coleta de lixo?

c) A quem compete os serviços de administração, planejamento, controle e execução da coleta de lixo? (indicar o tipo do serviço - próprio ou terceirizado)

d) Que tipo de destinação final é dada ao lixo?

e) Existe algum estudo, a nível regional, de caracterização dos resíduos sólidos domésticos (massa específica, umidade, característica física e físico química)? Em caso afirmativo, indique os valores e o período de avaliação dos dados.

\section{Aspecto Técnico}

a) Descreva os equipamentos de coleta do lixo - tipo, quantidade de veículos, capacidade de carga $(\mathrm{t})$ e volumétrica $\left(\mathrm{m}^{3}\right)$ dos veículos. Informe a existência e localização de equipamentos de pesagens e a idade média da frota.

a.1) Comente sobre manutenção de equipamentos e veículos (rotineira, preventiva ou corretiva), danos mais freqüentes de equipamentos e veículos

b) A cidade é dividida em setores/distritos de coleta? Em função de que parâmetros? Indique a quantidade coletada (toneladas/dia) e o número de vezes, em cada setor de coleta, em que o veículo conclui uma etapa de coleta descarregando no destino final.

b.1) Qual a distância percorrida (quilômetros) pelo caminhão, a velocidade média (quilômetros por hora) durante a operação de coleta e o tempo total necessário (horas) gasto no percurso de coleta? (A resposta deve ser referente a cada setor de coleta) 
b.2) Qual a distância (quilômetros) do centro de massa de cada setor até o destino final?

c) Comente sobre a freqüência e horário da coleta em cada setor.

d) Descreva os procedimentos utilizados para definir a rota/itinerário do caminhão coletor. (Caso não apliquem nenhum procedimento específico detalhar o que está sendo feito, bem como as dificuldades encontradas para definir as rotas/itinerário)

\section{Aspectos Social e Sanitário}

a) Comente sobre a quantidade de operários (mão-de-obra direta e indireta) necessária a operação de coleta, treinamento dado ao pessoal (em serviço, através de cursos e palestras) e o serviço social prestado aos operários (recreativo, alimentar, ambulatorial, etc.).

a.1) Indique o número de pessoas que compõe uma guarnição de coleta (motorista $\mathrm{e}$ coletores de lixo).

a.2) Quais as atividades que geram mais acidentes (número e tipo de acidentes)? Qual o tipo de equipamento de proteção individual usado? Comente sobre a existência de medidas que visem melhorar a qualidade de trabalho.

b) Comente sobre os serviços sanitários (freqüência de limpeza dos caminhões e equipamentos utilizados para estes serviços).

\section{Aspectos Econômico, Financeiro e Administrativo}

a) Indique os custos de investimento ${ }^{1}$ e operação ${ }^{2}$ da coleta domiciliar - Custos Unitários ( $\mathrm{R} \$ / \mathrm{t} / \mathrm{dia})$

${ }^{1}$ Custo médio de investimento, inclui: terreno, planejamento e projeto, obras civis, instalações, equipamentos e veículos (indicar o período de avaliação dos dados).

${ }^{2}$ Custo médio de operação, inclui: mão-de-obra e encargos sociais, equipamentos, veículos, material de consumo e de operação, administração, despesas fixas e variáveis, manutenção, seguros, e outros (indicar o período de avaliação dos dados).

\section{Outras Informações Disponíveis}

Autorizo a utilização das informações contidas neste questionário na dissertação e publicações científicas da Engenheira Sanitarista Kelly Kleyciane Deluqui.

Nome: Assinatura:

Função: Data: 


\begin{tabular}{|c|c|c|}
\hline \multicolumn{3}{|c|}{ ANEXO B } \\
\hline Município & Estado & Número de Habitantes \\
\hline São Paulo & $\mathrm{SP}$ & 9.811 .776 \\
\hline Rio de Janeiro & RJ & 5.533 .011 \\
\hline Salvador & BA & 2.209 .465 \\
\hline Belo Horizonte & MG & 2.091 .170 \\
\hline Fortaleza & $\mathrm{CE}$ & 1.967 .365 \\
\hline Brasília & DF & 1.817 .001 \\
\hline Curitiba & PR & 1.465 .698 \\
\hline Recife & $\mathrm{PE}$ & 1.324 .877 \\
\hline Porto Alegre & RS & 1.286 .251 \\
\hline Manaus & AM & 1.158 .265 \\
\hline Belém & PA & 1.142 .258 \\
\hline Goiânia & GO & 998.520 \\
\hline Guarulhos & SP & 972.766 \\
\hline Campinas & SP & 907.996 \\
\hline São Gonçalo & RJ & 827.967 \\
\hline Nova Iguaçu & RJ & 801.036 \\
\hline São Luís & MA & 781.068 \\
\hline Maceió & $\mathrm{AL}$ & 723.156 \\
\hline Duque de Caxias & $\mathrm{RJ}$ & 712.370 \\
\hline São Bernado do Campo & SP & 658.791 \\
\hline Natal & $\mathrm{RN}$ & 656.244 \\
\hline Teresina & PI & 653.994 \\
\hline Santo André & SP & 625.294 \\
\hline Osasco & SP & 622.374 \\
\hline Campo Grande & MS & 598.216 \\
\hline João Pessoa & PB & 549.270 \\
\hline Jaboatão dos Guararapes & $\mathrm{PE}$ & 528.973 \\
\hline Contagem & MG & 491.268 \\
\hline São José dos Campos & SP & 485.780 \\
\hline Ribeirão Preto & $\mathrm{SP}$ & 452.804 \\
\hline Niterói & RJ & 450.129 \\
\hline Feira de Santana & BA & 449.960 \\
\hline Uberlândia & MG & 437.111 \\
\hline São João de Meriti & $\mathrm{RJ}$ & 433.713 \\
\hline Cuiabá & MT & 433.101 \\
\hline Sorocaba & SP & 431.370 \\
\hline Aracaju & SE & 426.580 \\
\hline Juiz de Fora & MG & 423.913 \\
\hline Londrina & PR & 412.894 \\
\hline Santos & SP & 412.288 \\
\hline Joinville & $\mathrm{SC}$ & 397.987 \\
\hline Belford Roxo & $\mathrm{RJ}$ & 393.520 \\
\hline Campos dos Goytacazes & $\mathrm{RJ}$ & 391.299 \\
\hline Olinda & $\mathrm{PE}$ & 355.741 \\
\hline Mauá & SP & 344.684 \\
\hline Ananindeua & PA & 342.905 \\
\hline Campina Grande & PB & 340.412 \\
\hline Carapicuíba & SP & 328.015 \\
\hline Caxias do Sul & RS & 326.222 \\
\hline São José do Rio Preto & SP & 323.418 \\
\hline Diadema & $\mathrm{SP}$ & 323.221 \\
\hline Moji das Cruzes & SP & 314.947 \\
\hline
\end{tabular}

Fonte: Fundação IBGE (1996) 


\begin{tabular}{|c|c|c|}
\hline Município & Estado & Número de Habitantes \\
\hline Pelotas & $\mathrm{RS}$ & 304.285 \\
\hline Piracicaba & SP & 302.605 \\
\hline Cariacica & ES & 300.085 \\
\hline Vila Velha & ES & 297.052 \\
\hline Porto Velho & RO & 293.815 \\
\hline Jundiaí & SP & 293.237 \\
\hline Bauru & SP & 293.026 \\
\hline Canoas & RS & 284.114 \\
\hline São Vicente & SP & 279.620 \\
\hline Montes Claros & MG & 271.324 \\
\hline Florianópolis & $\mathrm{SC}$ & 268.551 \\
\hline Maringá & PR & 267.878 \\
\hline Petrópolis & $\mathrm{RJ}$ & 267.604 \\
\hline Franca & SP & 266.909 \\
\hline Serra & ES & 266.851 \\
\hline Aparecida de Goiânia & GO & 265.446 \\
\hline Anápolis & GO & 264.873 \\
\hline Vitória & ES & 263.708 \\
\hline Ponta Grossa & PR & 252.674 \\
\hline Betim & MG & 249.795 \\
\hline Santarém & PA & 242.765 \\
\hline Ilhéus & BA & 242.589 \\
\hline Vitória da Conquista & $\mathrm{BA}$ & 241.776 \\
\hline Paulista & PE & 234.706 \\
\hline Uberaba & MG & 232.134 \\
\hline Caruaru & PE & 231.874 \\
\hline Foz do Iguaçu & PR & 231.596 \\
\hline Governador Valadares & MG & 231.077 \\
\hline Blumenau & $\mathrm{SC}$ & 230.988 \\
\hline Limeira & SP & 230.292 \\
\hline Volta Redonda & $\mathrm{RJ}$ & 228.939 \\
\hline Rio Branco & $\mathrm{AC}$ & 228.907 \\
\hline Itaquaquecetuba & SP & 228.533 \\
\hline Imperatriz & MA & $227: 731$ \\
\hline Santa Maria & $\mathrm{RS}$ & 226.226 \\
\hline Guarujá & SP & 226.185 \\
\hline Novo Hamburgo & RS & 225.082 \\
\hline Taubaté & SP & 220.179 \\
\hline Cascavel & PR & 219.623 \\
\hline Macapá & $\mathrm{AP}$ & 214.197 \\
\hline Caucaia & $\mathrm{CE}$ & 208.902 \\
\hline Mossoró & RN & 205.732 \\
\hline Gravataí & RS & 205.657 \\
\hline Ribeirão das Neves & MG & 197.147 \\
\hline Viamão & RS & 195.880 \\
\hline Ipatinga & MG & 195.736 \\
\hline Embu & SP & 195.676 \\
\hline Petrolina & PE & 190.453 \\
\hline Várzea Grande & MT & 190.374 \\
\hline Juazeiro do Norte & $\mathrm{CE}$ & 186.490 \\
\hline Itabuna & BA & 183.237 \\
\hline Taboão da Serra & SP & 182.441 \\
\hline
\end{tabular}

Fonte: Fundação IBGE (1996) 


\begin{tabular}{|c|c|c|}
\hline Município & Estado & Número de Habitantes \\
\hline São Leopoldo & $\mathrm{RS}$ & 180.741 \\
\hline Suzano & SP & 180.703 \\
\hline Magé & RJ & 180.550 \\
\hline Rio Grande & RS & 178.223 \\
\hline Marília & SP & 177.503 \\
\hline Presidente Prudente & SP & 177.236 \\
\hline Barueri & SP & 176.740 \\
\hline São Carlos & SP & 175.295 \\
\hline Arapiraca & AL & 173.351 \\
\hline Juazeiro & BA & 171.904 \\
\hline Divinópolis & MG & 171.562 \\
\hline Nova Friburgo & $\mathrm{RJ}$ & 169.218 \\
\hline Jacareí & SP & 168.030 \\
\hline Americana & SP & 167.901 \\
\hline Sumaré & SP & 167.751 \\
\hline São José dos Pinhais & PR & 167.286 \\
\hline Sete Lagoas & MG & 167.112 \\
\hline Jequié & $\mathrm{BA}$ & 165.361 \\
\hline Barra Mansa & RJ & 164.768 \\
\hline Araraquara & SP & 163.831 \\
\hline Araçatuba & SP & 162.546 \\
\hline Santa Bárbara d'Oeste & SP & 161.020 \\
\hline Alvorada & RS & 160.671 \\
\hline Maracanaú & $\mathrm{CE}$ & 160.088 \\
\hline Criciúma & $\mathrm{SC}$ & 159.033 \\
\hline Itaboraí & $\mathrm{RJ}$ & 156.631 \\
\hline Passo Fundo & RS & 156.352 \\
\hline Nilópolis & RJ & 155.190 \\
\hline Boa Vista & $\mathrm{RR}$ & 154.166 \\
\hline Colombo & PR & 153.583 \\
\hline Dourados & MS & 153.165 \\
\hline Rio Claro & SP & 153.025 \\
\hline Santa Luzia & MG & 152.682 \\
\hline Praia Grande & SP & 150.574 \\
\hline Guarapuava & PR & 149.158 \\
\hline São José & $\mathrm{SC}$ & 147.490 \\
\hline Cachoeiro do Itapemirim & ES & 147.283 \\
\hline Marabá & PA & 147.030 \\
\hline Rondonópolis & MT & 142.221 \\
\hline São Caetano do Sul & SP & 140.808 \\
\hline Lages & $\mathrm{SC}$ & 140.005 \\
\hline Sobral & $\mathrm{CE}$ & 138.274 \\
\hline Cabo de Santo Agostinho & $\mathrm{PE}$ & 137.295 \\
\hline Itajaí & SC & 134.797 \\
\hline Camaçari & BA & 134.768 \\
\hline Itapevi & SP & 133.769 \\
\hline Caxias & MA & 133.710 \\
\hline Chapecó & $\mathrm{SC}$ & 130.458 \\
\hline Teófilo Otoni & MG & 127.214 \\
\hline Cotia & SP & 127.047 \\
\hline Parnaíba & PI & 124.641 \\
\hline Alagoinhas & BA & 122.882 \\
\hline
\end{tabular}

Fonte: Fundação IBGE (1996) 


\begin{tabular}{|c|c|c|}
\hline Município & Estado & Número de Habitantes \\
\hline Teresópolis & $\mathrm{RJ}$ & 122.614 \\
\hline Itu & $\mathrm{SP}$ & 122.544 \\
\hline Indaiatuba & SP & 122.159 \\
\hline Ferraz de Vasconcelos & SP & 121.992 \\
\hline Poços de Caldas & MG & 121.845 \\
\hline Uruguaiana & RS & 121.825 \\
\hline Timon & MA & 118.332 \\
\hline Castanhal & PA & 117.747 \\
\hline Paranaguá & PR & 115.394 \\
\hline Hortolândia & SP & 114.885 \\
\hline Moji-Guaçu & SP & 114.555 \\
\hline Pindamonhamgaba & SP & 114.092 \\
\hline Bagé & RS & 114.091 \\
\hline Sapucaia do Sul & RS & 113.992 \\
\hline Barreiras & $\mathrm{BA}$ & 113.544 \\
\hline Macaé & $\mathrm{RJ}$ & 112.966 \\
\hline Patos de Minas & MG & 112.690 \\
\hline Itapetininga & SP & 111.909 \\
\hline Vitória de Santo Antão & $\mathrm{PE}$ & 111.575 \\
\hline Camaragibe & $\mathrm{PE}$ & 111.190 \\
\hline Itapecerica da Serra & SP & 110.362 \\
\hline Garanhuns & $\mathrm{PE}$ & 110.190 \\
\hline Bragança Paulista & SP & 109.863 \\
\hline Queimados & $\mathrm{RJ}$ & 108.531 \\
\hline Barbacéna & MG & 107.843 \\
\hline Ibirité & MG & 106.773 \\
\hline Abaetetuba & PA & 106.753 \\
\hline Francisco Morato & SP & 106.328 \\
\hline Santa Rita & PB & 105.584 \\
\hline Araguaína & TO & 105.000 \\
\hline Itaituba & PA & 104.896 \\
\hline Luziânia & GO & 104.840 \\
\hline Codó & MA & 104.825 \\
\hline Barretos & SP & 104.782 \\
\hline Colatina & ES & 103.621 \\
\hline Jaú & SP & 103.605 \\
\hline Nossa Senhora do Socorro & SE & 103.496 \\
\hline Linhares & ES & 103.030 \\
\hline Cabo Frio & $\mathrm{RJ}$ & 101.142 \\
\hline Apucarana & PR & 101.005 \\
\hline Catanduva & SP & 100.913 \\
\hline Botucatu & SP & 100.826 \\
\hline Sabará & MG & 100.570 \\
\hline Santa Cruz do Sul & RS & 100.562 \\
\hline Ribeirão Pires & SP & 100.335 \\
\hline Rio Verde & GO & 100.223 \\
\hline Varginha & MG & 100.079 \\
\hline Garatinguetá & SP & 98.094 \\
\hline Franco da Rocha & SP & 97.996 \\
\hline Cubatão & SP & 96.486 \\
\hline Cachoeirinha & RS & 96.451 \\
\hline Araras & SP & 95.943 \\
\hline
\end{tabular}

Fonte: Fundação IBGE (1996) 


\begin{tabular}{|c|c|c|}
\hline Município & Estado & Número de Habitantes \\
\hline Conselheiro Lafaiete & $\overline{M G}$ & 95.726 \\
\hline Lauro de Freitas & $\mathrm{BA}$ & 95.530 \\
\hline Ji-Paraná & RO & 95.456 \\
\hline Araguari & MG & 95.432 \\
\hline Crato & $\mathrm{CE}$ & 95.332 \\
\hline Itabira & MG & 95.229 \\
\hline Teixeira de Freitas & BA & 94.971 \\
\hline Resende & $\mathrm{RJ}$ & 94.104 \\
\hline Paulo Afonso & BA & 93.619 \\
\hline Atibaia & SP & 93.186 \\
\hline Pouso Alegre & MG & 93.151 \\
\hline Coronel Fabriciano & MG & 92.998 \\
\hline Jaraguá do Sul & $\mathrm{SC}$ & 92.849 \\
\hline Passos & MG & 91.801 \\
\hline Angra dos Reis & $\mathrm{RJ}$ & 90.877 \\
\hline Cametá & $\mathrm{PA}$ & 90.387 \\
\hline Toledo & PR & 90.332 \\
\hline Bacabal & MA & 90.140 \\
\hline São Lourenço da Mata & $\mathrm{PE}$ & 89.905 \\
\hline Pinhais & PR & 89.272 \\
\hline Sertãozinho & SP & 88.531 \\
\hline São José do Ribamar & MA & 88.255 \\
\hline Corumbá & MS & 87.832 \\
\hline Ituiutaba & MG & 87.707 \\
\hline Votorantim & SP & 87.186 \\
\hline Ourinhos & SP & 86.881 \\
\hline Salto & $\mathrm{SP}$ & 86.631 \\
\hline Cachoeira do Sul & RS & 86.327 \\
\hline Parnamirim & $\mathrm{RN}$ & 86.312 \\
\hline Guaíba & RS & 86.101 \\
\hline Patos & PB & 86.002 \\
\hline Eunápolis & BA & 85.946 \\
\hline Palmas & TO & 85.901 \\
\hline Barra do Piraí & RJ & 85.726 \\
\hline Santana do Livramento & $\mathrm{RS}$ & 85.611 \\
\hline Jacobina & $\mathrm{BA}$ & 85.459 \\
\hline Birigui & SP & 85.354 \\
\hline Umuarama & PR & 85.279 \\
\hline Poá & $\mathrm{SP}$ & 84.843 \\
\hline Bragança & PA & 84.748 \\
\hline Tatuí & SP & 84.673 \\
\hline Muriaé & MG & 84.486 \\
\hline Senhor do Bomfim & BA & 84.311 \\
\hline Bayeux & PB & 84.178 \\
\hline Tubarão & SC & 83.761 \\
\hline Bento Gonçalves & $\mathrm{RS}$ & 83.167 \\
\hline Assis & $\mathrm{SP}$ & 83.074 \\
\hline Alegrete & RS & 82.485 \\
\hline Campo Largo & PR & 82.443 \\
\hline Itaperuna & $\mathrm{RJ}$ & 82.189 \\
\hline Maranguape & $\mathrm{CE}$ & 82.127 \\
\hline Abreu e Lima & $\mathrm{PE}$ & 81.376 \\
\hline
\end{tabular}

Fonte: Fundação IBGE (1996) 


\begin{tabular}{|c|c|c|}
\hline Município & Estado & Número de Habitantes \\
\hline São Mateus & $\mathrm{ES}$ & 81.318 \\
\hline Erechim & $\mathrm{RS}$ & 81.171 \\
\hline Cambé & PR & 80.863 \\
\hline Itapipoca & $\mathrm{CE}$ & 80.137 \\
\hline Palhoça & $\mathrm{SC}$ & 79.816 \\
\hline Campo Mourão & PR & 79.513 \\
\hline Serrinha & BA & 78.791 \\
\hline Simões Filho & $\mathrm{BA}$ & 78.704 \\
\hline Altamira & PA & 78.702 \\
\hline Itajubá & MG & 78.444 \\
\hline Igatu & $\mathrm{CE}$ & 78.230 \\
\hline Várzea Paulista & $\mathrm{SP}$ & 78.093 \\
\hline Açailândia & $\mathrm{MA}$ & 78.066 \\
\hline Itumbiara & GO & 77.977 \\
\hline Leme & SP & 77.751 \\
\hline Itapeva & SP & 77.656 \\
\hline Ubá & MG & 77.157 \\
\hline Valinhos & SP & 75.868 \\
\hline Ijuí & RS & 75.785 \\
\hline Jandira & SP & 75.442 \\
\hline Valparaíso de Goiás & GO & 75.434 \\
\hline Santo Ângelo & RS & 75.419 \\
\hline Moji-Mirim & SP & 75.373 \\
\hline Esteio & RS & 75.209 \\
\hline São João del Rei & MG & 75.187 \\
\hline Breves & $\mathrm{PA}$ & 75.171 \\
\hline Arapongas & PR & 75.061 \\
\hline Araucária & PR & 74.976 \\
\hline Três Lagoas & MS & 74.766 \\
\hline Valença & BA & 74.720 \\
\hline Lagarto & $\mathrm{SE}$ & 74.254 \\
\hline Araxá & MG & 74.063 \\
\hline Cáceres & MT & 73.677 \\
\hline São João da Boa Vista & SP & 73.674 \\
\hline Lorena & $\mathrm{SP}$ & 73.277 \\
\hline Paranavaí & PR & 72.939 \\
\hline Cacoal & RO & 72.873 \\
\hline Igarassu & PE & 72.811 \\
\hline Lavras & MG & 72.739 \\
\hline Barra do Corda & MA & 72.629 \\
\hline Bebedouro & SP & 72.620 \\
\hline Guarapari & ES & 72.267 \\
\hline Caratinga & MG & 72.178 \\
\hline Santana & $\mathrm{AP}$ & 72.150 \\
\hline Cruzeiro & $\mathrm{SP}$ & 72.118 \\
\hline Itabaiana & $\mathrm{SE}$ & 71.866 \\
\hline Parintins & $\mathrm{AM}$ & 71.787 \\
\hline Almirante Tamandaré & PR & 71.782 \\
\hline Santo Antônio de Jesus & $\mathrm{BA}$ & 71.434 \\
\hline Itatiba & SP & 71.297 \\
\hline Cruz Alta & $\mathrm{RS}$ & 71.132 \\
\hline Itaúna & MG & 70.917 \\
\hline
\end{tabular}

Fonte: Fundação IBGE (1996) 


\begin{tabular}{|c|c|c|}
\hline Município & Estado & Número de Habitantes \\
\hline Serra Talhada & $\mathrm{PE}$ & 70.323 \\
\hline Itaguaí & $\mathrm{RJ}$ & 69.961 \\
\hline Votuporanga & SP & 69.831 \\
\hline Avaré & $\mathrm{SP}$ & 69.568 \\
\hline Jataí & GO & 69.503 \\
\hline Candeias & BA & 69.417 \\
\hline Santa Inês & MA & 68.968 \\
\hline Patrocínio & MG & 68.843 \\
\hline Formosa & GO & 68.679 \\
\hline Guanambi & BA & 68.657 \\
\hline Pará de Minas & MG & 68.619 \\
\hline Ariquemes & RO & 68.474 \\
\hline Caçapava & SP & 68.075 \\
\hline Trindade & GO & 68.037 \\
\hline Paracatu & MG & 67.815 \\
\hline Palmeira dos Índios & $\mathrm{AL}$ & 67.686 \\
\hline Belo Jardim & PE & 67.519 \\
\hline Goiana & PE & 67.252 \\
\hline Caraguatatuba & SP & 67.083 \\
\hline Paragominas & PA & 66.559 \\
\hline Brusque & $\mathrm{SC}$ & 66.554 \\
\hline Japeri & RJ & 66.427 \\
\hline Três Rios & $\mathrm{RJ}$ & 66.293 \\
\hline Matão & SP & 65.721 \\
\hline Francisco Beltrão & PR & 65.686 \\
\hline Gurupi & TO & 65.656 \\
\hline Manacapuru & AM & 65.632 \\
\hline Canindé & $\mathrm{CE}$ & 65.287 \\
\hline Crateús & $\mathrm{CE}$ & 65.254 \\
\hline Araruama & $\mathrm{RJ}$ & 65.253 \\
\hline Unaí & MG & 65.168 \\
\hline Itacoatiara & $\mathrm{AM}$ & 65.006 \\
\hline Pinheiro & MA & 64.589 \\
\hline Porto Seguro & $\mathrm{BA}$ & 64.441 \\
\hline Curvelo & MG & 64.382 \\
\hline Quixadá & $\mathrm{CE}$ & 64.356 \\
\hline Januária & MG & 64.215 \\
\hline Timóteo & MG & 64.214 \\
\hline Araripina & PE & 63.869 \\
\hline Mococa & SP & 63.690 \\
\hline Parauapebas & PA & 63.623 \\
\hline Picos & PI & 63.308 \\
\hline São Borja & RS & 63.089 \\
\hline Campo Formoso & BA & 62.996 \\
\hline Jaboticabal & $\mathrm{SP}$ & 62.952 \\
\hline Tefé & $\mathrm{AM}$ & 62.810 \\
\hline Ipirá & BA & 62.809 \\
\hline Sapiranga & RS & 62.799 \\
\hline Pirassununga & SP & 62.636 \\
\hline Santa Rosa & RS & 62.552 \\
\hline Itamaraju & BA & 62.436 \\
\hline Brumado & BA & 61.994 \\
\hline
\end{tabular}

Fonte: Fundação IBGE (1996) 


\begin{tabular}{|c|c|c|}
\hline Município & Estado & Número de Habitantes \\
\hline Cataguases & $\overline{\mathrm{MG}}$ & 61.964 \\
\hline João Monlevade & MG & 61.715 \\
\hline Gravatá & $\mathrm{PE}$ & 61.696 \\
\hline Ouro Preto & MG & 61.606 \\
\hline Águas Lindas de Goiás & GO & 61.481 \\
\hline Valença & RJ & 61.481 \\
\hline São Roque & SP & 60.992 \\
\hline Três Corações & MG & 60.976 \\
\hline São Gabriel & RS & 60.801 \\
\hline Tupã & SP & 60.728 \\
\hline Lins & SP & 60.720 \\
\hline Itapira & SP & 60.626 \\
\hline Vespasiano & MG & 60.536 \\
\hline Morada Nova & $\mathrm{CE}$ & 60.485 \\
\hline Nova Gama & GO & 60.458 \\
\hline Itanhaém & SP & 60.354 \\
\hline Maricá & $\mathrm{RJ}$ & 60.268 \\
\hline Sarandi & PR & 60.240 \\
\hline Formiga & MG & 59.631 \\
\hline Chapadinha & MA & 59.561 \\
\hline Sousa & PB & 59.318 \\
\hline Manhuaçu & MG & 59.243 \\
\hline Aracruz & ES & 59.079 \\
\hline Fernandópolis & SP & 59.037 \\
\hline Alfenas & MG & 58.951 \\
\hline Piripiri & $\mathrm{PI}$ & 58.739 \\
\hline Arcoverde & PE & 58.689 \\
\hline Tucuruí & PA & 58.642 \\
\hline Castro & PR & 58.537 \\
\hline Icó & $\mathrm{CE}$ & 58.506 \\
\hline Catalão & GO & 58.447 \\
\hline Caçador & $\mathrm{SC}$ & 58.437 \\
\hline Rio Largo & $\mathrm{AL}$ & 58.411 \\
\hline Planaltina & GO & 58.219 \\
\hline Ponta Porã & MS & 58.172 \\
\hline Caieiras & SP & 58.105 \\
\hline Redenção & PA & 58.103 \\
\hline Balneário Camboriú & $\mathrm{SC}$ & 58.085 \\
\hline Ceará-Mirim & RN & 58.036 \\
\hline Pato Branco & PR & 57.724 \\
\hline Camaquã & RS & 57.566 \\
\hline Viçosa & MG & 57.559 \\
\hline Janaúba & MG & 57.470 \\
\hline São Cristóvão & SE & 57.418 \\
\hline Lageado & RS & 57.404 \\
\hline Escada & PE & 57.366 \\
\hline Santana de Paranaíba & SP & 57.329 \\
\hline São Bento do Sul & $\mathrm{SC}$ & 57.096 \\
\hline Telêmaco Borba & PR & 57.047 \\
\hline Aracati & $\mathrm{CE}$ & 56.974 \\
\hline Nova Lima & MG & 56.939 \\
\hline Carazinho & RS & 56.911 \\
\hline
\end{tabular}

Fonte: Fundação IBGE (1996) 


\begin{tabular}{|c|c|c|}
\hline Município & Estado & Número de Habitantes \\
\hline São Gonçalo do Amrante & $\mathrm{RN}$ & 56.898 \\
\hline Venâncio Aires & RS & 56.819 \\
\hline Cruzeiro do Sul & $\mathrm{AC}$ & 56.764 \\
\hline Estância & SE & 56.761 \\
\hline Timbaúba & PE & 56.568 \\
\hline Palmares & $\mathrm{PE}$ & 56.564 \\
\hline Quixeramobim & $\mathrm{CE}$ & 56.382 \\
\hline Santo Amaro & BA & 56.360 \\
\hline Concórdia & $\mathrm{SC}$ & 56.359 \\
\hline Ibiúna & SP & 56.290 \\
\hline São Pedro da Aldeia & $\mathrm{RJ}$ & 56.275 \\
\hline Itaberaba & BA & 56.218 \\
\hline União dos Palmares & $\mathrm{AL}$ & 56.123 \\
\hline Pesqueira & $\mathrm{PE}$ & 55.952 \\
\hline Limoeiro & $\mathrm{PE}$ & 55.844 \\
\hline Paço do Lumiar & MA & 55.383 \\
\hline Amparo & SP & 55.239 \\
\hline Ubatuba & SP & 55.039 \\
\hline Carpina & PE & 55.027 \\
\hline Penedo & AL & 54.451 \\
\hline Ponte Nova & MG & 54.327 \\
\hline Sinop & MT & 54.294 \\
\hline Barcarena & PA & 54.287 \\
\hline Seropédica & RJ & 54.252 \\
\hline Itapetinga & $\mathrm{BA}$ & 54.165 \\
\hline Salgueiro & PE & 53.704 \\
\hline Capanema & PA & 53.675 \\
\hline São Sebastião do Paraíso & MG & 53.599 \\
\hline Andradina & SP & 53.586 \\
\hline Vacaria & RS & 53.522 \\
\hline Coari & $\mathrm{AM}$ & 53.306 \\
\hline Farroupilha & RS & 52.570 \\
\hline Monte Santo & BA & 52.470 \\
\hline Bom Jesus da Lapa & BA & 52.469 \\
\hline Camocim & $\mathrm{CE}$ & 52.463 \\
\hline Piraquara & PR & 52.462 \\
\hline Cianorte & PR & 52.430 \\
\hline Bezerros & $\mathrm{PE}$ & 52.424 \\
\hline Santa Luzia & MA & 52.399 \\
\hline Campo Limpo Paulista & SP & 52.299 \\
\hline Floriano & PI & 52.270 \\
\hline Aquiraz & $\mathrm{CE}$ & 52.248 \\
\hline Irecê & BA & 52.204 \\
\hline Russas & $\mathrm{CE}$ & 51.937 \\
\hline Caicó & $\mathrm{RN}$ & 51.917 \\
\hline Conceição do Coité & BA & 51.910 \\
\hline Guarabira & PB & 51.664 \\
\hline Araci & $\mathrm{BA}$ & 51.531 \\
\hline Penápolis & SP & 51.415 \\
\hline Cajazeiras & PB & 51.388 \\
\hline Tangará da Serra & MT & 51.252 \\
\hline Santiago & RS & 51.064 \\
\hline
\end{tabular}

Fonte: Fundação IBGE (1996) 


\begin{tabular}{|c|c|c|}
\hline Município & Estado & Número de Habitantes \\
\hline Irati & $\mathrm{PR}$ & 51.008 \\
\hline São Francisco & MG & 50.918 \\
\hline Campo Bom & RS & 50.896 \\
\hline Lencóois Paulista & $\mathrm{SP}$ & 50.769 \\
\hline Acará & PA & 50.761 \\
\hline Arujá & SP & 50.754 \\
\hline Araranguá & $\mathrm{SC}$ & 50.579 \\
\hline Euclides da Cunha & BA & 50.347 \\
\hline Coroatá & MA & 50.286 \\
\hline Tauá & $\mathrm{CE}$ & 50.273 \\
\hline Taquaritinga & SP & 50.240 \\
\hline Cascavel & $\mathrm{CE}$ & 50.095 \\
\hline Canguçu & RS & 49.992 \\
\hline Montenegro & RS & 49.877 \\
\hline Registro & SP & 49.785 \\
\hline Cruz das Almas & $\mathrm{BA}$ & 49.607 \\
\hline São Miguel dos Campos & $\mathrm{AL}$ & 49.562 \\
\hline Monte Alegre & PA & 49.503 \\
\hline Mafra & $\mathrm{SC}$ & 49.411 \\
\hline Marituba & PA & 49.322 \\
\hline Canoinhas & $\mathrm{SC}$ & 49.308 \\
\hline Tianguá & $\mathrm{CE}$ & 49.269 \\
\hline Casa Nova & BA & 49.025 \\
\hline Ouricuri & PE & 48.915 \\
\hline Balsas & MA & 48.818 \\
\hline Pirapora & MG & 48.647 \\
\hline Viseu & PA & 48.187 \\
\hline Jaru & RO & 48.135 \\
\hline Ipojuca & $\mathrm{PE}$ & 48.036 \\
\hline Batatais & SP & 47.978 \\
\hline Mairiporã & SP & 47.974 \\
\hline Taquara & $\mathrm{RS}$ & 47.797 \\
\hline Boa Viagem & $\mathrm{CE}$ & 47.770 \\
\hline Rio do Sul & $\mathrm{SC}$ & 47.678 \\
\hline Itapecuru Mirim & MA & 47.587 \\
\hline Barra do Garças & MT & 47.537 \\
\hline São José do Rio Pardo & SP & 47.533 \\
\hline Acopiara & $\mathrm{CE}$ & 47.453 \\
\hline Campo Belo & MG & 47.351 \\
\hline Pedro Leopoldo & MG & 47.299 \\
\hline Catu & BA & 47.259 \\
\hline Três Pontas & MG & 47.244 \\
\hline Coruripe & AL & 47.233 \\
\hline Viana & ES & 47.060 \\
\hline Leopoldina & MG & 46.893 \\
\hline Santa Cruz do Capibaribe & $\mathrm{PE}$ & 46.828 \\
\hline
\end{tabular}

Fonte: Fundação IBGE (1996) 
ANEXO C

QUESTIONÁRIOS RECEBIDOS 
Aspecto Geral da Coleta Domiciliar

\begin{tabular}{|c|c|c|c|c|c|c|c|c|}
\hline Município/Estado & $\begin{array}{c}\mathrm{N}^{0} \text { de } \\
\text { Habitantes }\end{array}$ & $\begin{array}{c}\text { Resíduo } \\
\text { Coletado (ton/dia) }\end{array}$ & $\begin{array}{l}\text { \% de População } \\
\text { Atendida }\end{array}$ & & Serviço & $\begin{array}{l}\text { Caracterização dos } \\
\text { Resíduos do RSD }\end{array}$ & $\begin{array}{c}\text { Tipo de Disposição } \\
\text { Final }\end{array}$ & Fonte de Dados \\
\hline Salvador/BA & 2.209 .465 & 2041 & & 82 & Terceirizado & Existe & Aterro Sanitário & LIMPURB \\
\hline Belo Horizonte/MG & 2.091 .170 & 1223 & & 90 & $\begin{array}{l}\text { Parcialmente } \\
\text { terceirizado }\end{array}$ & Existe & Aterro Sanitário & PM \\
\hline Brasilia/DF & 1.817 .001 & 1873 & & $\mathrm{NI}$ & $\begin{array}{l}\text { Parcialmente } \\
\text { terceirizado }\end{array}$ & NI & Aterro Controlado & SLU \\
\hline São Gonçalo/RJ & 827.967 & 385 & 8 & 85 & $\begin{array}{l}\text { Parcialmente } \\
\text { terceirizado }\end{array}$ & Não Existe & Aterro controlado & PM \\
\hline São Bernado do Campo/SP & 658.791 & 600 & & 99 & Terceirizado & Não Existe & Aterro Sanitário & PM \\
\hline Uberlândia/MG & 437.111 & 300 & & 100 & Terceirizado & Existe & NI & $P M$ \\
\hline Sorocaba/SP & 431.370 & 350 & & 100 & Terceirizado & Não Existe & Aterro Sanitário & PM \\
\hline Santos/SP & 412.288 & 494,35 & & 98 & Próprio & Existe & Aterro Controlado & PRODESAN \\
\hline Joinville/SC & 397.987 & 259 & & 100 . & Terceirizado & Existe & Aterro Sanitário & PM \\
\hline Mauá/SP & 344.684 & 200 & & 95 . & Terceirizado & Não Existe & Aterro Sanitário & PM \\
\hline Piracicaba/SP & 302.605 & 200 & & 95 . & Terceirizado & Não Existe & Aterro Sanitário & PM \\
\hline Jundiai/SP & 293.237 & 300 & & 98 & Terceirizado & Não Existe & Aterro Sanitário & PM \\
\hline Bauru/SP & 293.026 & 200 & & 99 & $\begin{array}{l}\text { Parcialmente } \\
\text { terceirizado }\end{array}$ & Não Existe & Aterro Sanitário & ENDURB \\
\hline Montes Claros/MG & 271.324 & 140 & & 95 . & Próprio & Não Existe & Aterro controlado & PM \\
\hline Florianópolis/SC . & 268.551 & 240 & & 95 & Próprio & Existe & Aterro Sanitário & COMCAP \\
\hline Novo Hamburgo/RS & 225.082 & 150 & & 99 . & Terceirizado & Não Existe & $\mathrm{NI}$ & PM \\
\hline Taboão da Serra/SP & 182.441 & 130 & & $\mathrm{NI}$ & Terceirizado & Não Existe & Aterro Sanitário & PM \\
\hline Suzano/SP & 180.703 & 100 & & 100 & Terceirizado & Não Existe & Aterro Sanitário & PM \\
\hline Divinópolis/MG & 171.562 & 100 & & 92 & Terceirizado & Existe & Lixão & PM \\
\hline São José dos Pinhais/PR & 167.286 & 90 & & 99 . & Terceirizado & Não Existe & Aterro Sanitário & PM \\
\hline Itaboraí/RJ & 156.631 & 100 & & 40 & Terceirizado & Não Existe & Lixão & PM \\
\hline Passo Fundo/RS & 156.352 & 80 & & 97 . & Terceirizado & Não Existe & Aterro Controlado & PM \\
\hline Santa Luzia/MG & 152.682 & 80 & & 88 & Terceirizado & Existe & Aterro Controlado & PM \\
\hline Itajai/SC & 134.797 & 115 & & 100 & Terceirizado & Não Existe & Aterro Sanitário & PM \\
\hline Hortolândia/SP & 114.885 & 80 & & 100 & Terceirizado & NI & Aterro Sanitário & PM \\
\hline Sapucaia do Sul/RS & 113.992 & 70 & & 100 & Parcialmente & Não Existe & Aterro Sanitário & PM \\
\hline Barreiras/BA & 113.544 & 50 & NI & & Terceirizado & Não Existe & Aterro Sanitário & PM \\
\hline Itapetininga/SP & 111.909 & NI & & 95 . & Próprio & Não Existe & Aterro Sanitário & PM \\
\hline
\end{tabular}

NI - Nenhuma Informação 


\begin{tabular}{|c|c|c|c|c|c|c|c|}
\hline Municipio/Estado & $\begin{array}{c}\mathrm{N}^{\circ} \text { de } \\
\text { Habitantes }\end{array}$ & $\begin{array}{c}\text { Resíduo } \\
\text { Coletado (ton/dia) }\end{array}$ & $\begin{array}{c}\text { \% de População } \\
\text { Atendida }\end{array}$ & $\begin{array}{l}\text { Tipo de } \\
\text { Serviço }\end{array}$ & $\begin{array}{l}\text { Caracterização dos } \\
\text { Resíduos do RSD }\end{array}$ & $\begin{array}{l}\text { Tipo de Disposição } \\
\text { Final }\end{array}$ & Fonte de Dados \\
\hline Francisco Morato/SP & $106.328,00$ & 140 & 70 & Próprio & Não Existe & Lixão & PM \\
\hline Varginha/MG & $100.079,00$ & 100 & 98 & Próprio & Não Existe & Aterro Controlado & PM \\
\hline Lauro de Freitas/BA & $95.530,00$ & 110 & 90 & Próprio & Existe & Lixão & PM \\
\hline Itabira/MG & $95.229,00$ & 55 & 93 & Próprio & Existe & Aterro Controlado & ITAURB \\
\hline Resende/RJ & $94.104,00$ & 150 & 95 & Próprio & Não Existe & Aterro Sanitário e Controlad & COMHUR \\
\hline Jaraguá do Sul/SC & $92.849,00$ & 52 & 85 & Terceirizado & Não Existe & Lixão & PM \\
\hline Passos/MG & $91.801,00$ & 40 & 100 & Próprio & Existe & Aterro Sanitário & PM \\
\hline Pinhais/PR & $89.272,00$ & 45 & 98 & Terceirizado & Não Existe & Aterro Sanitário & PM \\
\hline Ituiutaba/MG & $87.707,00$ & 45 & 87 & Próprio & Não Existe & Aterro Controlado & PM \\
\hline Ourinhos/SP & $86.881,00$ & 53,793 & 100 & Próprio & Não Existe & Aterro Sanitário & $\mathrm{SAE}$ \\
\hline Birigui/SP & $85.354,00$ & 40 & 100 & Próprio & Não Existe & Lixão & PM \\
\hline Poá/SP & $84.843,00$ & 65 & 100 & Próprio & Não Existe & Aterro Sanitário & PM \\
\hline Campo Mourão/PR & $79.513,00$ & 45 & 95 & Terceirizado & NI & Lixão & PM \\
\hline Ubá/MG & $77.157,00$ & 60 & NI & Terceirizado & Não Existe & Aterro Controlado & PM \\
\hline Três Lagoas/MS & $74.766,00$ & 50 & 95 & Próprio & Não Existe & Lixão & PM \\
\hline Araxá/MG & $74.063,00$ & 26 & 90 & Próprio & Não Existe & Lixão & PM \\
\hline Lavras/MG & $72.739,00$ & 50 & 75 & Próprio & Não Existe & Aterro Sanitário & PM \\
\hline Bebedouro/SP & $72.620,00$ & 25 & 100 & Próprio & Não Existe & Aterro Controlado & PM \\
\hline Formosa/GO & $68.679,00$ & 30 & 85 & Próprio & Não Existe & Aterro Sanitário & PM \\
\hline Trindade/GO & $68.037,00$ & 40 & 90 & Próprio & Não Existe & Lixão & PM \\
\hline Caraguatatuba/SP & $67.083,00$ & 60 & 90 & Terceirizado & Não Existe & Lixão & PM \\
\hline Paragominas/PA & $66.559,00$ & 30,83 & 53 & $\begin{array}{l}\text { Parcialmente } \\
\text { terceirizado }\end{array}$ & Não Existe & Lixão & PM \\
\hline Gurupi/TO & $65.656,00$ & 30 & 100 & Terceirizado & Não Existe & Aterro Controlado & PM \\
\hline Manacapuru/AM & $65.632,00$ & 36 & 100 & Terceirizado & Existe & Lixão & PM \\
\hline Curvelo/MG & $64.382,00$ & 40 & 60 & Próprio & Não Existe & Lixão & PM \\
\hline Pirassununga/SP & $62.636,00$ & 40 & 100 & Próprio & Não Existe & Aterro Sanitário & PM \\
\hline Maricá/RJ & $60.268,00$ & 60 & 75 & Próprio & Não Existe & Aterro Sanitário & PM \\
\hline Catalão/GO & $58.447,00$ & 25 & 90 & Próprio & Não Existe & Aterro Controlado & PM \\
\hline Rio Largo/AL & $58.411,00$ & 12 & 65 & Próprio & Não Existe & Lixão & PM \\
\hline Ceará Mirim/RN & $58.036,00$ & 18 & 50 & Próprio & Não Existe & Lixão & PM \\
\hline Santo Amaro/BA & $56.360,00$ & 34 & 60 & Próprio & Existe & Lixão & PM \\
\hline
\end{tabular}

NI - Nenhuma Informação 


\begin{tabular}{|c|c|c|c|c|c|c|c|}
\hline Município/Estado & $\begin{array}{c}\mathrm{N}^{\circ} \text { de } \\
\text { Habitantes }\end{array}$ & $\begin{array}{c}\text { Resíduo } \\
\text { Coletado (ton/dia) }\end{array}$ & $\begin{array}{c}\text { \% de População } \\
\text { Atendida }\end{array}$ & $\begin{array}{l}\text { Tipo de } \\
\text { Serviço }\end{array}$ & $\begin{array}{l}\text { Caracterização dos } \\
\text { Resíduos do RSD }\end{array}$ & $\begin{array}{l}\text { Tipo de Disposição } \\
\text { Final }\end{array}$ & Fonte de Dados \\
\hline Concórdia/SC & 56.359 & 30,36 & 100 & Terceirizado & Não Existe & Lixão & PM \\
\hline Farroupilha/RS & 52.570 & 30,78 & 100 & Terceirizado & Existe & Aterro Sanitário & PM \\
\hline Irecê/BA & 52.204 & 30 & 100 & Terceirizado & Não Existe & Lixão & PM \\
\hline Penápolis/SP & 51.415 & 30 & 100 & Próprio & Não Existe & Aterro Sanitário & DAEP \\
\hline Irati/PR & 51.008 & 26 & 90 & Próprio & Não Existe & Aterro controlado & PM \\
\hline Araranguá/SC & 50.579 & 25 & 85,56 & Próprio & Não Existe & Aterro Controlado & $P M$ \\
\hline Euclides da Cunha/BA & 50.347 & 24 & 55 & Próprio & Não Existe & Lixão & PM \\
\hline Registro/SP & 49.785 & 30 & 80 & Próprio & Não Existe & Lixão & PM \\
\hline Ouricuri/PE & 48.915 & 25 & 80 & Próprio & Não Existe & Lixão & PM \\
\hline São José do Rio Pardo/SP & 47.533 & 22 & 95 & Próprio & Não Existe & Aterro controlado & PM \\
\hline
\end{tabular}

NI - Nenhuma 
Aspecto Técnico da Coleta Domiciliar

\begin{tabular}{|c|c|c|c|c|c|c|c|c|c|}
\hline Município/Estado & $\begin{array}{l}\text { Tipo de veículo } \\
\text { utilizado }\end{array}$ & $\begin{array}{l}\text { Idade média } \\
\text { da frota (ano) }\end{array}$ & $\begin{array}{l}\text { Equipamento } \\
\text { de pesagem }\end{array}$ & $\begin{array}{l}\text { Manutenção } \\
\text { dos Veículos }\end{array}$ & $\begin{array}{l}\text { Parâmetros para dividir } \\
\text { os setores de coleta }\end{array}$ & $\begin{array}{c}\text { Velocidade } \\
\text { Média }(\mathrm{km} / \mathrm{h})\end{array}$ & $\begin{array}{l}\text { Distância média } \\
\text { setor de coleta/ } \\
\text { destino final }(\mathrm{km})\end{array}$ & $\begin{array}{c}\text { Frequência de } \\
\text { coleta }\end{array}$ & $\begin{array}{l}\text { Mátodo para } \\
\text { definir a rota }\end{array}$ \\
\hline Salvador/BA & $\begin{array}{l}\text { Compactador e } \\
\text { basculante }\end{array}$ & 15 & Balança & $\begin{array}{l}\text { Rotineira, corretiva e } \\
\text { preventiva }\end{array}$ & $\begin{array}{l}\text { Carga horária, produção de } \\
\text { resíduos e capacidade } \\
\text { do caminhão }\end{array}$ & NI & 11,13 & $\begin{array}{l}\text { Diária e } \\
\text { e alternada }\end{array}$ & $\begin{array}{l}\text { Utilizam } \\
\text { programa } \\
\text { computacio- } \\
\text { nal }\end{array}$ \\
\hline Belo Horizonte/MG & $\begin{array}{l}\text { Compactador } \\
\text { e basculante }\end{array}$ & 5 & Balança & $\begin{array}{l}\text { Rotineira, preventiva e } \\
\text { Corretiva }\end{array}$ & $\begin{array}{l}\text { Produção de resíduos e } \\
\text { capacidade do veículo }\end{array}$ & NI & 14,1 & $\begin{array}{l}\text { Diária } \\
\text { e alternada }\end{array}$ & Manual \\
\hline Brasília/DF & $\begin{array}{l}\text { Compactador e } \\
\text { basculante }\end{array}$ & NI & NI & NI & NI & NI & NI & $\begin{array}{l}\text { Diária } \\
\text { e altemada }\end{array}$ & $\mathrm{NI}$ \\
\hline São,Gonçalo/RJ & $\begin{array}{l}\text { Compactador e } \\
\text { basculante }\end{array}$ & 10 & \begin{tabular}{|l} 
Balança \\
eletrônica
\end{tabular} & Preventiva e corretiva & NI & NI & 13 & Altemada & NI \\
\hline São Bernado do Campo/SP & Compactador & 1 & Balança & Preventivo & $\begin{array}{l}\text { Topografia e distância } \\
\text { a ser percorrida }\end{array}$ & NI & 16 & $\begin{array}{l}\text { Diária } \\
\text { e altemada }\end{array}$ & Manual \\
\hline Uberlândia/MG & Compactador & 3 & $\begin{array}{l}\text { Balança } \\
\text { rodoviária }\end{array}$ & Rotineira e corretiva & Produção de resíduos & 12 & 20 & $\begin{array}{l}\text { Diária } \\
\text { e alternada }\end{array}$ & Manual \\
\hline Sorocaba/SP & Compactador & 5 & Balança & Rotineira e corretiva & $\begin{array}{l}\text { Densidade populacional } \\
\text { e produção de resíduos }\end{array}$ & NI & 15 & $\begin{array}{l}\text { Diária } \\
\text { e alternada }\end{array}$ & Manual \\
\hline Sanţos/SP & Compactador & superior a 4 & Balança & NI & $\mathrm{NI}$ & NI & 10 & NI & Manual \\
\hline Joinville/SC & Compactador & 1,5 & Balança & $\begin{array}{l}\text { Rotineira, preventiva e } \\
\text { Corretiva }\end{array}$ & Produção de resíduos & 12,88 & 16 & $\begin{array}{l}\text { Diária } \\
\text { Altemada }\end{array}$ & Manual \\
\hline Mauá/SP & Compactador & 5 & NI & NI & NI & NI & NI & Alternada & NI \\
\hline Piracicaba/SP & Compactador & 2 & Balança & Preventiva e corretiva & NI & NI & 12 & Alternada & NI \\
\hline Jundiaí/SP & Compacatador & 3 & Balança & Preventiva e corretiva & Produção de resíduos & NI & NI & Alternada & NI \\
\hline Bauru/SP & $\begin{array}{l}\text { Compactador } \\
\text { e basculante }\end{array}$ & 7,5 & Balança & Rotineira & Produção de resíduos & NI & 15 & $\begin{array}{l}\text { Diária e } \\
\text { Alternada }\end{array}$ & Manual \\
\hline Montes Claros/MG & $\begin{array}{l}\text { Compactador } \\
\text { e basculante }\end{array}$ & 6,5 & NI & Corretiva & Distância a ser percorrida & NI & 8 & Alternada & Manual \\
\hline Florianópolis/SC & Compactador & 16 & Balança & Rotineira & NI & NI & NI & $\begin{array}{l}\text { Diária } \\
\text { e alternada }\end{array}$ & Manual \\
\hline
\end{tabular}

NI - Nenhuma Informação 


\begin{tabular}{|c|c|c|c|c|c|c|c|c|c|}
\hline Município/Estado & $\begin{array}{l}\text { Tipo de veículo } \\
\text { utilizado }\end{array}$ & $\begin{array}{l}\text { Idade média } \\
\text { da frota (ano) }\end{array}$ & $\begin{array}{l}\text { Equipamento } \\
\text { de pesagem }\end{array}$ & $\begin{array}{l}\text { Manutenção } \\
\text { dos Veículos }\end{array}$ & $\begin{array}{l}\text { Parâmetros para dividir } \\
\text { os setores de coleta }\end{array}$ & $\begin{array}{l}\text { Velocidade } \\
\text { Média }(\mathrm{km} / \mathrm{h})\end{array}$ & $\begin{array}{l}\text { Distância média } \\
\text { setor de coleta/ }\end{array}$ & $\begin{array}{c}\text { Frequência de } \\
\text { coleta }\end{array}$ & $\begin{array}{l}\text { Método para } \\
\text { definir a rota }\end{array}$ \\
\hline Novo Hamburgo/RS & Compactador & 2 & Balança & Preventiva & $\begin{array}{l}\text { Distância a ser percorrida e } \\
\text { produção de resíduos }\end{array}$ & 10 & 10,9 & NI & Manual \\
\hline Taboão da Serra/SP & $\begin{array}{l}\text { Compactador } \\
\text { e basculante }\end{array}$ & NI & Balança & Preventiva e corretiva & Produção de Resíduos & 15 & 18 & Alternada & Manual \\
\hline Suzano/SP & Compactador, & 3 & NI & Rotineira e preventiva & Tempo de coleta & 6 & 30 & $\begin{array}{l}\text { Diária } \\
\text { e alternada }\end{array}$ & Manual \\
\hline Divinópolis/MG & $\begin{array}{l}\text { basculantes, } \\
\text { veículo de tração } \\
\text { animal } \\
\text { e poliguindaste }\end{array}$ & 12 & Balança & Corretiva & $\begin{array}{l}\text { Produção de resíduos e } \\
\text { capacidade do caminhão }\end{array}$ & 13 & 11 & $\begin{array}{l}\text { Diária } \\
\text { e alternada }\end{array}$ & Manual \\
\hline São José dos Pinhais/PR & Compactador & 4 & Balança & NI & Distância a ser percorrida & NI & 30 & NI & NI \\
\hline Itaborai/RJ & $\begin{array}{l}\text { Compacatador } \\
\text { e poliguindaste }\end{array}$ & 3 & Não existe & Preventiva e corretiva & NI & NI & 6 & Alternada & NI \\
\hline Passo Fundo/RS & Compactador & 4 & Balança eletrôn & Corretiva & Capacidade do Caminhão & 9 & 15 & $\begin{array}{l}\text { Diária } \\
\text { e alternada }\end{array}$ & NI \\
\hline Santa Luzia/MG & Basculante & NI & Não existe & Corretiva & Densidade populacional & 8 & 14 & $\begin{array}{l}\text { Diária } \\
\text { e alternada }\end{array}$ & Manual \\
\hline Itajai/SC & Compactador & 6 & NI & Preventiva & Capacidade do Caminhão & 15 & 30 & $\begin{array}{l}\text { Diária } \\
\text { e altemada }\end{array}$ & Manual \\
\hline Hortolândia/SP & $\begin{array}{l}\text { Compactador } \\
\text { e basculante }\end{array}$ & NI & NI & Rotineira & Capacidade do Caminhão & NI & 17 & Diária & NI \\
\hline Sapucaia do Sul/RS & Compactador & 3 & Balança & Rotineira & Produção de resíduos & NI & 10 & $\begin{array}{l}\text { Diária } \\
\text { e alternada }\end{array}$ & $\begin{array}{l}\text { Utilizaram } \\
\text { programa } \\
\text { computacio- } \\
\text { nal }\end{array}$ \\
\hline Barreiras/BA & Compactador & 5 & Balança & NI & NI & NI & 27 & $\begin{array}{l}\text { Diária } \\
\text { e alternada }\end{array}$ & NI \\
\hline Itapetininga/SP & Basculante & Varia de 15 a 7 & Balança & NI & NI & NI & NI & Alternada & Manual \\
\hline Francisco Morato/SP & $\begin{array}{l}\text { Compactador } \\
\text { e basculante }\end{array}$ & 12 & Não existe & Corretiva & NI & 18 & 8 & Diária & Manual \\
\hline
\end{tabular}

NI - Nenhuma Informação 


\begin{tabular}{|c|c|c|c|c|c|c|c|c|c|}
\hline Município/Estado & $\begin{array}{c}\text { Tipo de veículo } \\
\text { utilizado }\end{array}$ & $\begin{array}{l}\text { Idade média } \\
\text { da frota (ano) }\end{array}$ & $\begin{array}{l}\text { Equipamento } \\
\text { de pesagem }\end{array}$ & $\begin{array}{l}\text { Manutenção } \\
\text { dos Veículos }\end{array}$ & $\begin{array}{l}\text { Parâmetros para dividir } \\
\text { os setores de coleta }\end{array}$ & $\begin{array}{c}\text { Velocidade } \\
\text { Média }(\mathrm{km} / \mathrm{h})\end{array}$ & $\begin{array}{l}\text { Distância média } \\
\text { setor de coleta/ } \\
\text { destino final }(\mathrm{km})\end{array}$ & $\begin{array}{c}\text { Frequência de } \\
\text { coleta }\end{array}$ & $\begin{array}{l}\text { Método para } \\
\text { definir a rota }\end{array}$ \\
\hline Varginha/MG & Compactador & Varia de 13 a 7 & Não existe & Corretiva & $\begin{array}{l}\text { Capacidade e distância a } \\
\text { ser percorrida pelo caminhão }\end{array}$ & 7 & 7 & $\begin{array}{l}\text { Diária } \\
\text { e alternada }\end{array}$ & Manual \\
\hline Lauro de Freitas/BA & $\begin{array}{l}\text { Compactador, } \\
\text { basculante e } \\
\text { poliguindaste }\end{array}$ & Varia de 10 a 4 & Não existe & Rotineira & NI & 7 & 6 & Diária & Manual \\
\hline Itabira/MG & $\begin{array}{l}\text { Compactador } \\
\text { e basculante }\end{array}$ & Varia de 4 a 19 & Balança & $\begin{array}{l}\text { Rotineira, preventiva e } \\
\text { corretiva }\end{array}$ & $\begin{array}{l}\text { Capacidade do Caminhão e } \\
\text { produção de resíduos }\end{array}$ & 5 & 15,5 & $\begin{array}{l}\text { Diária } \\
\text { e alternada }\end{array}$ & Manual \\
\hline Resende/RJ & Compactador & NI & NI & NI & Número de habitantes & 10 & 17,5 & Diária & Manual \\
\hline Jaraguá do Sul/SC & Compactador & 3 & Balança & Preventiva & Distância a ser percorrida & 15 & 15 & $\begin{array}{l}\text { Diária } \\
\text { e alternada }\end{array}$ & Manual \\
\hline Passos/MG & Compactador & Varia de 5 a 14 & Não existe & Rotineira e corretiva & Fator sócio-econômico & 10 & 10 & $\begin{array}{l}\text { Diária } \\
\text { e altemada }\end{array}$ & Manual \\
\hline Pinhais/PR & Compactador & 3 & Balança & Conforme a necessidade & Produção de resíduos & 10 & 48 & Altemada & $\begin{array}{l}\text { Utilizam } \\
\text { programa } \\
\text { computacio- } \\
\text { nal }\end{array}$ \\
\hline Ituiutaba/MG & $\begin{array}{l}\text { Compactador } \\
\text { e basculante }\end{array}$ & Varia de 7 a 10 & Balança & Rotineira & Produção de resíduos & 15 & 14,5 & $\begin{array}{l}\text { Diária } \\
\text { e altemada }\end{array}$ & Manual \\
\hline Ourinhos/SP & $\mathrm{NI}$ & NI & Balança & Corretiva & $\begin{array}{l}\text { Produção de resíduos e } \\
\text { Capacidade do Caminhão }\end{array}$ & 13,6 & 7 & 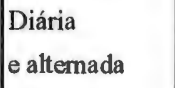 & Manual \\
\hline Birigui/SP & Compactador & NI & NI & Corretiva & Produção de resíduos & 5 & 13 & Alternada & NI \\
\hline Poá/SP & NI & 9 & Balança & Preventiva & NI & 10 & 35 & Alternada & NI \\
\hline Campo Mourão/PR & $\mathrm{NI}$ & 5 & NI & Preventiva & $\mathrm{NI}$ & 32 & 37 & NI & NI \\
\hline Ubá/MG & $\begin{array}{l}\text { Compactador } \\
\text { e basculante }\end{array}$ & 2 & Não existe & Preventiva & Não informado & 15 & 17,6 & $\begin{array}{l}\text { Diária } \\
\text { e altemada }\end{array}$ & Manual \\
\hline Três Lagoas & $\begin{array}{l}\text { Compactador e } \\
\text { basculante e }\end{array}$ & 12 & Não existe & Rotineira & Distância a ser percorrida & 15 & 6,6 & $\begin{array}{l}\text { Diária e } \\
\text { alternada }\end{array}$ & Manual \\
\hline Araxá/MG & NI & 6 & NI & Corretiva & NI & NI & 15 & Diária & Manual \\
\hline Lavras/MG & Compactador & 8 & Não existe & Corretiva & Produção de resíduos & 12 & 15 & Altemada & NI \\
\hline Bebedouro/SP & Compactador & 10 & NI & Rotineria & NI & 20 & 10 & Diária & Manual \\
\hline
\end{tabular}

NI - Nenhuma Informação 


\begin{tabular}{|c|c|c|c|c|c|c|c|c|c|}
\hline Município/Estado & $\begin{array}{c}\text { Tipo de veículo } \\
\text { utilizado }\end{array}$ & $\begin{array}{l}\text { Idade média } \\
\text { da frota (ano) }\end{array}$ & $\begin{array}{l}\text { Equipamento } \\
\text { de pesagem }\end{array}$ & $\begin{array}{l}\text { Manutenção } \\
\text { dos Veículos }\end{array}$ & $\begin{array}{l}\text { Parâmetros para dividir } \\
\text { os setores de coleta }\end{array}$ & $\begin{array}{c}\text { Velocidade } \\
\text { Média }(\mathrm{km} / \mathrm{h})\end{array}$ & $\begin{array}{l}\text { Distância média } \\
\text { setor de coleta/ } \\
\text { destino final }(\mathrm{km})\end{array}$ & $\begin{array}{c}\text { Frequência de } \\
\text { coleta }\end{array}$ & $\begin{array}{l}\text { Método para } \\
\text { definir a rota }\end{array}$ \\
\hline Formosa/GO & $\begin{array}{l}\text { Compactador } \\
\text { e basculante }\end{array}$ & Varia de 10 a 26 & Não existe & Corretiva & $\begin{array}{l}\text { Disponibilidade de } \\
\text { equipamento }\end{array}$ & 10 & 15 & Alternada & NI \\
\hline Trindade/GO & $\begin{array}{l}\text { Compactador } \\
\text { e basculante }\end{array}$ & Varia de 5 a 10 & NI & Rotineira & Produção de resíduos & 5 & 17,5 & $\begin{array}{l}\text { Diária } \\
\text { e Alternada }\end{array}$ & NI \\
\hline Caraguatatuba/SP & NI & 3 & Balança & Rotineira e preventiva & NI & 10 & NI & $\begin{array}{l}\text { Diária } \\
\text { e Alternada }\end{array}$ & NI \\
\hline Paragominas/PA & $\begin{array}{l}\text { Compactador } \\
\text { e basculante }\end{array}$ & 12 & Balança & Corretiva & Produção de resíduos & 4,8 & 3,6 & $\begin{array}{l}\text { Conforme } \\
\text { a necessidade }\end{array}$ & Manual \\
\hline Gurupi/TO & Compactador & 1 & NI & Preventivas & Produçăo de resíduos & NI & 9 & $\begin{array}{l}\text { Diária } \\
\text { e alternada }\end{array}$ & Manual \\
\hline Manacapuru/AM & Basculante & 7 & Balança & Corretiva & Distância a ser percorrida & 9 & 6 & Diária & Manual \\
\hline Curvelo/MG & $\begin{array}{l}\text { Compactador } \\
\text { e basculante }\end{array}$ & Varia de 1 a 10 & Balança & $\begin{array}{l}\text { Rotineira, preventiva e } \\
\text { Corretiva }\end{array}$ & Distância a ser percorrida & NI & 20 & Altemada & Manual \\
\hline Pirassununga/SP & Compactador & 11 & NI & Rotineira & NI & NI & 4 & Alternada & NI \\
\hline Maricá/RJ & $\begin{array}{l}\text { Compactador } \\
\text { e basculante }\end{array}$ & 12 & Não existe & Corretiva & $\begin{array}{l}\text { Produção de resíduos } \\
\text { e capacidade } \\
\text { do veículo }\end{array}$ & NI & 6 a 40 & Aiternada & Manual \\
\hline Catalão/GO & $\begin{array}{l}\text { Compactador } \\
\text { e basculante }\end{array}$ & 6 & Não existe & Rotineira e preventiva & NI & NI & 6 & Diária & Manual \\
\hline Rio Largo/AL & $\begin{array}{l}\text { Basculante } \\
\text { e trator agricola }\end{array}$ & 13 & Não existe & Rotineira & NI & NI & 7 & Diária & NI \\
\hline Ceará Mirim/RN & NI & 2 a 10 & Não existe & Rotineira & Produção de resíduos & NI & 3 & Alternada & Manual \\
\hline Santo Amaro/BA & \begin{tabular}{|l} 
Basculante \\
e trator agricola
\end{tabular} & NI & NI & Rotineira & NI & NI & 2,9 & NI & NI \\
\hline Concórdia/SC & Compactador & 4 & $\begin{array}{l}\text { Balança de } \\
\text { particular }\end{array}$ & Rotineira & Produção de resíduos & NI & 7,5 & $\begin{array}{l}\text { Diária } \\
\text { e alternada }\end{array}$ & Manual \\
\hline Farroupilha/RS & Compactador e base & Varia de 3 a 19 & $\begin{array}{l}\text { Balança } \\
\text { eletrônica }\end{array}$ & $\begin{array}{l}\text { Rotineira, preventiva e } \\
\text { Corretiva }\end{array}$ & $\begin{array}{l}\text { Produção de resíduos } \\
\text { e distância a ser } \\
\text { percorrida }\end{array}$ & NI & 3 & $\begin{array}{l}\text { Diária } \\
\text { e alternada }\end{array}$ & $\begin{array}{l}\text { Parcialmente } \\
\text { manual }\end{array}$ \\
\hline Irecê/BA & Compactador & Varia de 2 a 12 & NI & Corretiva & $\begin{array}{l}\text { Distância a ser } \\
\text { percorrida }\end{array}$ & NI & 12 & Alternada & NI \\
\hline
\end{tabular}

NI - Nenhuma Informação 


\begin{tabular}{|c|c|c|c|c|c|c|c|c|c|}
\hline Município/Estado & $\begin{array}{c}\text { Tipo de veículo } \\
\text { utilizado }\end{array}$ & $\begin{array}{l}\text { Idade média } \\
\text { da frota (ano) }\end{array}$ & $\begin{array}{l}\text { Equipamento } \\
\text { de pesagem }\end{array}$ & $\begin{array}{l}\text { Manutenção } \\
\text { dos Veículos }\end{array}$ & $\begin{array}{l}\text { Parâmetros para dividir } \\
\text { os setores de coleta }\end{array}$ & $\begin{array}{l}\text { Velocidade } \\
\text { Média }(\mathrm{km} / \mathrm{h})\end{array}$ & $\begin{array}{l}\text { Distância média } \\
\text { setor de coleta/ } \\
\text { destino final }(\mathrm{km})\end{array}$ & $\begin{array}{c}\text { Frequência de } \\
\text { coleța }\end{array}$ & $\begin{array}{l}\text { Método para } \\
\text { definir a rota }\end{array}$ \\
\hline Penápolis/SP & Compactador e bas & 13 & Não existe & Preventiva & Produção de resíduos & 9,61 & 3,94 & $\begin{array}{l}\text { Diária } \\
\text { e alternada }\end{array}$ & NI \\
\hline Irati/PR & $\begin{array}{l}\text { Compactador } \\
\text { e basculante }\end{array}$ & 11 a 18 & NI & Corretiva & NI & NI & 30 & NI & Manual \\
\hline Araranguá/SC & $\begin{array}{l}\text { Compacatador } \\
\text { e basculante }\end{array}$ & $\mathrm{NI}$ & NI & Rotineira e corretiva & Capacidade do veículo & NI & 15 & $\begin{array}{l}\text { Diária } \\
\text { e alternada }\end{array}$ & NI \\
\hline Euclides da Cunha/BA & Basculantes & Varia de 9 a 18 & NI & Corretiva & NI & NI & 7 & $\begin{array}{l}\text { Diária } \\
\text { e alternada }\end{array}$ & NI \\
\hline Registro/SP & Compactador & 7 & Não existe & Corretiva & Densidade populacional & NI & 12 & $\begin{array}{l}\text { Diária } \\
\text { e alternada }\end{array}$ & Manual \\
\hline Ouricuri/PE & $\begin{array}{l}\text { Compactador, } \\
\text { basculante } \\
\text { e trator agrícola }\end{array}$ & 10 & NI & Corretiva & Nenhum & $\mathrm{NI}$ & 8 & Alternada & Manual \\
\hline São José do Rio Pardo/SP & NI & NI & NI & Corretiva & NI & NI & 14 & $\begin{array}{l}\text { Diária } \\
\text { e alternada }\end{array}$ & Manual \\
\hline
\end{tabular}

NI-Nenhuma Informação 


\begin{tabular}{|c|c|c|c|c|c|c|c|}
\hline \multirow[t]{2}{*}{ Município/Estado } & \multicolumn{2}{|c|}{ Guamição de Coleta } & \multirow{2}{*}{$\begin{array}{l}\text { Tipo de Treinamento } \\
\text { dado aos operários }\end{array}$} & \multirow{2}{*}{$\begin{array}{c}\text { Serviço social prestado } \\
\text { aos operários }\end{array}$} & \multirow{2}{*}{$\begin{array}{l}\text { Tipo de acidentes } \\
\text { durante a coleta }\end{array}$} & \multirow{2}{*}{$\begin{array}{l}\text { Equipamento de } \\
\text { Proteção Individual }\end{array}$} & \multirow{2}{*}{$\begin{array}{c}\text { Frequência de Limpeza } \\
\text { dos veículos }\end{array}$} \\
\hline & Motorista & Coletores & & & & & \\
\hline Salvador/BA & 1 & 4 & NI & $\begin{array}{l}\text { Recreativo, Alimentar e } \\
\text { ambulatorial }\end{array}$ & NI & NI & Alternada \\
\hline Belo Horizonte/MG & 1 & 4 & Cursos e Palestras & $\begin{array}{l}\text { Recreativa, alimentar e } \\
\text { ambulatorial }\end{array}$ & $\begin{array}{l}\text { Cortes, torções e } \\
\text { fraturas }\end{array}$ & $\begin{array}{l}\text { Uniformes, botas, } \\
\text { luvas e colete } \\
\text { refletivo }\end{array}$ & Alternada \\
\hline Brasilia/DF & 1 & 4 & Cursos e Palestras & NI & NI & $\begin{array}{l}\text { Uniformes de tecido } \\
\text { resistente, botas, } \\
\text { luvas e boné }\end{array}$ & Diária \\
\hline São Gonçalo/RJ & NI & NI & Nenhum & Alimentar e ambulatorial & Cortes & $\begin{array}{l}\text { Uniformes de tecido } \\
\text { resistente, botas e } \\
\text { luvas }\end{array}$ & Semanal \\
\hline São Bernado do Campo/SP & NI & NI & Palestras e Cursos & Alimentar e ambulatorial & Cortes & NI & Diária \\
\hline Uberlândia/MG & 1 & 4 & Palestras & ambulatorial & $\begin{array}{l}\text { Troções e } \\
\text { atropelamentos }\end{array}$ & $\begin{array}{l}\text { Luvas, Tênis e colete } \\
\text { refletor }\end{array}$ & Diária \\
\hline Sorocaba/SP & 1 & 3 & NI & Alimentar & Cortes & Luvas & Esporádica \\
\hline Santos/SP & 1 & 3 & Palestras e Cursos & Alimentar e ambulatorial & NI & NI & NI \\
\hline Joinville/SC & 1 & 3 & NI & NI & Cortes & $\begin{array}{l}\text { Botas, luvas e colete } \\
\text { refletor }\end{array}$ & Diária \\
\hline Mauá/SP & NI & NI & NI & NI & NI & NI & NI \\
\hline Piracicaba/SP & NI & NI & Palestras & Nenhum & Cortes & Tenis, luvas e bonés & Diária \\
\hline Jundiai/SP & NI & NI & NI & NI & NI & NI & Diária \\
\hline Bauru/SP & NI & NI & Nenhum & Alimentar e ambulatorial & Cortes & $\begin{array}{l}\text { Uniforme de tecido } \\
\text { resistente, tenis, } \\
\text { luvas e colete } \\
\text { refletor }\end{array}$ & Alternada \\
\hline Montes Claros/MG & NI & NI & Palestras e Cursos & NI & NI & NI & Quinzenal \\
\hline Florianópolis/SC & NI & NI & Palestras & $\begin{array}{l}\text { Recreativo, Alimentar e } \\
\text { ambulatorial }\end{array}$ & Cortes e torções & $\begin{array}{l}\text { Uniformes de tecido } \\
\text { resistente, botas e } \\
\text { luvas }\end{array}$ & Diária \\
\hline Novo Hamburgo/RS & 1 & 4 & Cursos e Palestras & Alimentar e ambulatorial & NI & NI & Diária \\
\hline Taboão da Serra/SP & 1 & 3 & Palestras & NI & Cortes & NI & Diária \\
\hline
\end{tabular}

NI - Nenhuma Informação 


\begin{tabular}{|c|c|c|c|c|c|c|c|}
\hline \multirow[t]{2}{*}{ Município/Estado } & \multicolumn{2}{|c|}{ Guarnição de Coleta } & \multirow{2}{*}{$\begin{array}{l}\text { Tipo de Treinamento } \\
\text { dado aos operários }\end{array}$} & \multirow{2}{*}{$\begin{array}{l}\text { Serviço social prestado } \\
\text { aos operários }\end{array}$} & \multirow{2}{*}{$\begin{array}{l}\text { Tipo de acidentes } \\
\text { durante a coleta }\end{array}$} & \multirow{2}{*}{$\begin{array}{l}\text { Equipamento de } \\
\text { Proteção Individual }\end{array}$} & \multirow{2}{*}{$\begin{array}{c}\text { Frequência de Limpeza } \\
\text { dos veículos }\end{array}$} \\
\hline & Motorista & Coletores & & & & & \\
\hline Suzano/SP & 1 & 3 & NI & Alimentar e ambulatorial & Torções e quedas & $\begin{array}{l}\text { Tenis, luvas, colete } \\
\text { refletivo e bonés }\end{array}$ & Diária \\
\hline Divinópolis/MG & 1 & 4 & Nenhum & NI & Corte & Botas, luvas e coletes refletores & Diária \\
\hline São José dos Pinhais/PR & 1 & 3 a 4 & Palestras & Alimentar e ambulatorial & Cortes & NI & NI \\
\hline Itaborai/RJ & 1 & 4 & Nenhum & Nenhum & $\begin{array}{l}\text { Acidentes } \\
\text { trânsito }\end{array}$ & Botas e luvas & Semanal \\
\hline Passo Fundo/RS & 1 & 4 & NI & NI & Torções & Luvas & Alternada \\
\hline Santa Luzia/MG & 1 & 4 & NI & NI & Cortes & Botas e luvas & Semanal \\
\hline Itajai/SC & 1 & 2 & Palestras e cursos & NI & $\begin{array}{l}\text { Corte e mordidas } \\
\text { de cães }\end{array}$ & $\begin{array}{l}\text { Uniforme, botas, luvas e } \\
\text { e colete refletor }\end{array}$ & Semanal \\
\hline Hortolândia/SP & NI & NI & Palestras & Alimentar e ambulatorial & $\begin{array}{l}\text { Corte, mordidas } \\
\text { de cães e torções }\end{array}$ & $\begin{array}{l}\text { Uniforme, tênis } \\
\text { e luvas }\end{array}$ & Diária \\
\hline Sapucaia do Sul/RS & 1 & 3 & Palestras e Cursos & Alimentar e ambulatorial & Cortes e mordidas de cães & Luvas & Diária \\
\hline Barreiras/BA & 1 & 4 & NI & Alimentar & Cortes & $\begin{array}{l}\text { Uniformes de tecido } \\
\text { resistente, botas, } \\
\text { luvas, faixas refletoras } \\
\text { e bonés }\end{array}$ & Semanal \\
\hline Itapetininga/SP & 1 & 3 & Palestras & Alimentar & NI & Botas e luvas & Alternada \\
\hline Francisco Morato/SP & 1 & 3 & NI & Alimentar e ambulatorial & Cortes e torções & Botas e luvas & Alternada \\
\hline Varginha/MG & 1 & 2 & Cursos e Palestras & Ambulatorial & Cortes & Botas e Luvas & Diária \\
\hline Lauro de Freitas/BA & 1 & em média 3 & Palestras & Alimentar & $\begin{array}{c}\text { Cortes e torções nas } \\
\text { pernas e pés }\end{array}$ & NI & Diária \\
\hline Itabira/MG & 1 & 3 & Cursos & Recreativo e alimentar & Corte e torções & Luvas & Diária \\
\hline Resende/RJ & 1 & 4 & Palestras e Cursos & NI & Cortes & $\begin{array}{l}\text { Uniforme de tecido } \\
\text { resistente, luvas e } \\
\text { botas }\end{array}$ & Diária \\
\hline Jaraguá do Sul/SC & 1 & 3 & Palestras e Cursos & Alimentar e recreativo & Cortes e torções & $\begin{array}{l}\text { Uniformes, botas } \\
\text { e luvas }\end{array}$ & 2 vezes por semana \\
\hline Passos/MG & 1 & 4 & Cursos e Palestras & Recreativa e alimentar & Cortes & Luvas & Diária \\
\hline Pinhais/PR & 1 & 4 & NI & NI & Cortes & NI & Alternada \\
\hline Ituiutaba/MG & 1 & 2 & Palestras & Ambulatorial & Cortes & Luvas & NI \\
\hline
\end{tabular}




\begin{tabular}{|c|c|c|c|c|c|c|c|}
\hline \multirow[t]{2}{*}{ Município/Estado } & \multicolumn{2}{|c|}{ Guamição de Coleta } & \multirow{2}{*}{$\begin{array}{l}\text { Tipo de Treinamento } \\
\text { dado aos operários }\end{array}$} & \multirow{2}{*}{$\begin{array}{c}\text { Serviço social prestado } \\
\text { aos operários }\end{array}$} & \multirow{2}{*}{$\begin{array}{l}\text { Tipo de acidentes } \\
\text { durante a coleta }\end{array}$} & \multirow{2}{*}{$\begin{array}{l}\text { Equipamento de } \\
\text { Proteção Individual }\end{array}$} & \multirow{2}{*}{$\begin{array}{c}\text { Frequência de Limpeza } \\
\text { dos veículos }\end{array}$} \\
\hline & Motorista & Coletores & & & & & \\
\hline Ourinhos/SP & 1 & 4 & Palestras & Alimentar e ambulatorial & Cortes e torções & $\begin{array}{l}\text { Luvas e avental de } \\
\text { de couro }\end{array}$ & Semanal \\
\hline Birigui/SP & 1 & 4 & NI & NI & Cortes & Botas e Luvas & Diária \\
\hline Poá/SP & 1 & 4 & NI & NI & Cortes e torções & Luvas & Diária \\
\hline Campo Mourão/PR & 1 & 4 & NI & NI & NI & Tênis e luvas & NI \\
\hline Ubá/MG & 1 & 3 & Palestras & Alimentar e ambulatorial & Cortes & $\begin{array}{l}\text { Botas, luvas e colete } \\
\text { refletor }\end{array}$ & Diária \\
\hline Três Lagoas/MS & 1 & 3 & Palestras & NI & Cortes & Luvas & Semanal \\
\hline Araxá/MG & 1 & 3 & NI & Alimentar & Cortes e atropelamentos & $\begin{array}{l}\text { Botas, Luvas e colete } \\
\text { refletor }\end{array}$ & Semanal \\
\hline Lavras/MG & 1 & 4 & NI & Alimentar & NI & $\begin{array}{l}\text { Uniformes, botas } \\
\text { e luvas }\end{array}$ & Semanal \\
\hline Bebedouro/SP & 1 & 4 & Cursos & Alimentar e ambulatorial & Cortes & NI & Diária \\
\hline Formosa/GO & NI & NI & Palestras & Alimentar e ambulatorial & Nenhum & Luvas & Esporádica \\
\hline Trindade/GO & 1 & 3 & Nenhum & NI & NI & Luvas & Diariamente \\
\hline Caraguatatuba/SP & 1 & 4 & Palestras & NI & NI & $\begin{array}{l}\text { Botas, Luvas e colete } \\
\text { refletor }\end{array}$ & Quinzenal \\
\hline Paragominas/PA & 1 & 3 & NI & Nenhum & Nenhum & $\begin{array}{l}\text { Uniformes de tecido resistente, } \\
\text { resistente, botas e } \\
\text { luvas }\end{array}$ & Diária \\
\hline Gurupi/TO & 1 & 4 & Palestras & NI & Cortes & $\begin{array}{l}\text { Uniformes de tecido } \\
\text { resistente, botas, } \\
\text { luvas e colete refletor }\end{array}$ & Diária \\
\hline Manacapuru/AM & 1 & 3 & Nenhum & Recreativa e Alimentar & NI & Luvas & Semanal \\
\hline Curvelo/MG & 1 & 4 & Nenhum & Alimentar e ambulatorial & Cortes e atropelamentos & Botas e Luvas & Semanal \\
\hline Pirassununga/SP & 1 & 4 & NI & NI & NI & Luvas & Esporádica \\
\hline Maricá/RJ & 1 & 3 & Nenhum & Ambulatorial & Nenhum & $\begin{array}{l}\text { Uniforme de tecido } \\
\text { resistente, botas e } \\
\text { luvas }\end{array}$ & Mensal \\
\hline Catalão/GO & NI & NI & NI & Nenhum & NI & NI & Diária \\
\hline Rio Largo/AL & NI & NI & Nenhum & Alimentar & Nenhum & Botas e Luvas & Diária \\
\hline
\end{tabular}

NI - Nenhuma Informação 


\begin{tabular}{|c|c|c|c|c|c|c|c|}
\hline \multirow[t]{2}{*}{ Município/Estado } & \multicolumn{2}{|c|}{ Guamição de Coleta } & \multirow{2}{*}{$\begin{array}{l}\text { Tipo de Treinamento } \\
\text { dado aos operários }\end{array}$} & \multirow{2}{*}{$\begin{array}{l}\text { Serviço social prestado } \\
\text { aos operários }\end{array}$} & \multirow{2}{*}{$\begin{array}{l}\text { Tipo de acidentes } \\
\text { durante a coleta }\end{array}$} & \multirow{2}{*}{$\begin{array}{l}\text { Equipamento de } \\
\text { Protę̧ão Individual }\end{array}$} & \multirow{2}{*}{$\begin{array}{c}\text { Frequência de Limpeza } \\
\text { dos veículos }\end{array}$} \\
\hline & Motorista & Coletores & & & & & \\
\hline Ceará Mirim/RN & NI & NI & Nenhum & Nenhum & NI & Botas e Luvas & Semanal \\
\hline Santo Amaro/BA & NI & NI & NI & Alimentar & Nenhum & Uniformes, botas e & Diária \\
\hline Concórdia/SC & 1 & 3 & Palestras e cursos & Alimentar e ambulatorial & Torções & $\begin{array}{l}\text { Uniformes de tecido } \\
\text { resistente, botas, } \\
\text { luvas, bonés e coletes } \\
\text { refletivos }\end{array}$ & Alternada \\
\hline Farroupilha/RS & 1 & 3 & Palestras & Alimentar & Corte & $\begin{array}{l}\text { Uniformes de tecido } \\
\text { resistente, botas, } \\
\text { luvas, bonés e colete } \\
\text { refletor }\end{array}$ & Diária \\
\hline Irecê/BA & NI & NI & NI & Alimentar & Cortes & Botas, Luvas e bonés & Semanal \\
\hline Penápolis/SP & 1 & 3 & Nenhum & NI & Corte e torções & NI & Diária \\
\hline Irati/PR & 3 & 2 & Palestras & Alimentar & NI & $\begin{array}{l}\text { Uniformes de tecido } \\
\text { resistente, botas e } \\
\text { luvas }\end{array}$ & Diária \\
\hline Araranguá/SC & NI & NI & Palestras & Alimentar e ambulatorial & Cortes & Botas e Luvas & Semanalmente \\
\hline Euclides da Cunha/BA & NI & NI & Palestras & $\begin{array}{l}\text { Alimentar, Recreativa e } \\
\text { Ambulatorial }\end{array}$ & NI & Botas e Luvas & Quinzenal \\
\hline Registro/SP & 1 & 3 & Nenhum & Ambulatorial & NI & Botas e Luvas & Semanal \\
\hline Ouricuri/PE & NI & NI & Nenhum & Nenhum & NI & NI & Não existe \\
\hline São José do Rio Pardo/SP & NI & NI & NI & NI & NI & NI & Diária \\
\hline
\end{tabular}




\section{ANEXO D \\ RELATÓRIO DE ENTRADA E SAÍDA DE DADOS E ITINERÁRIOS DE COLETA (TransCAD)}

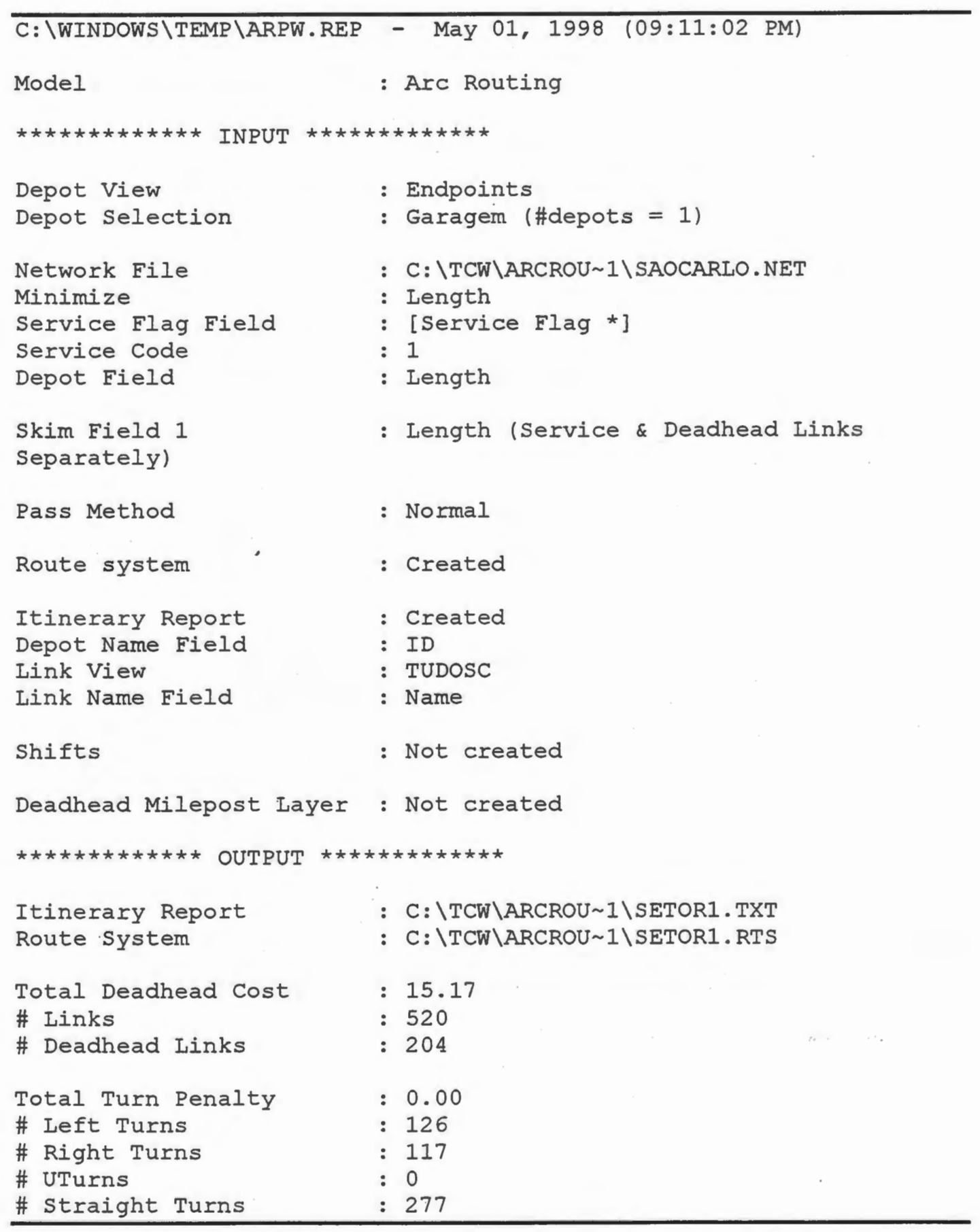




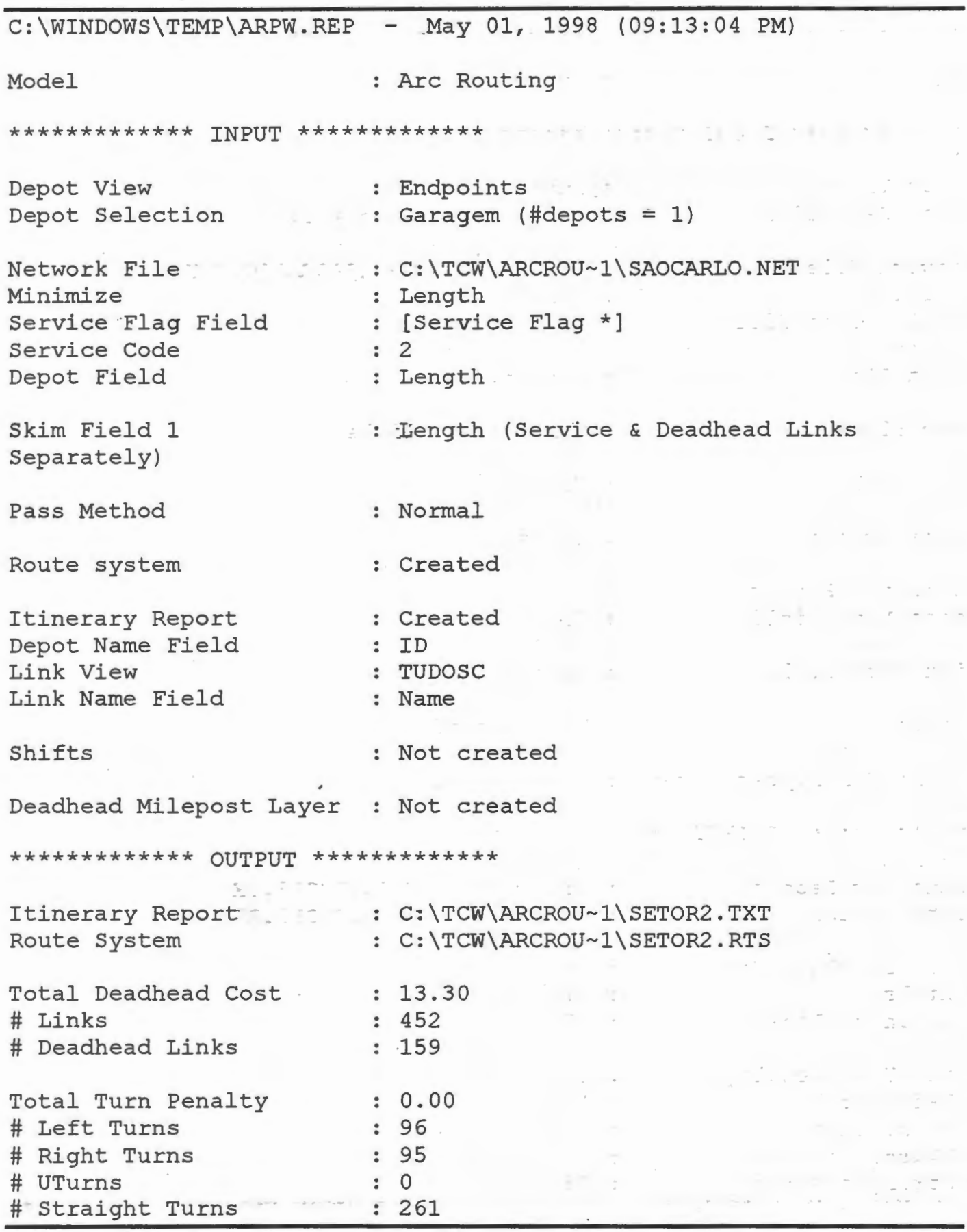




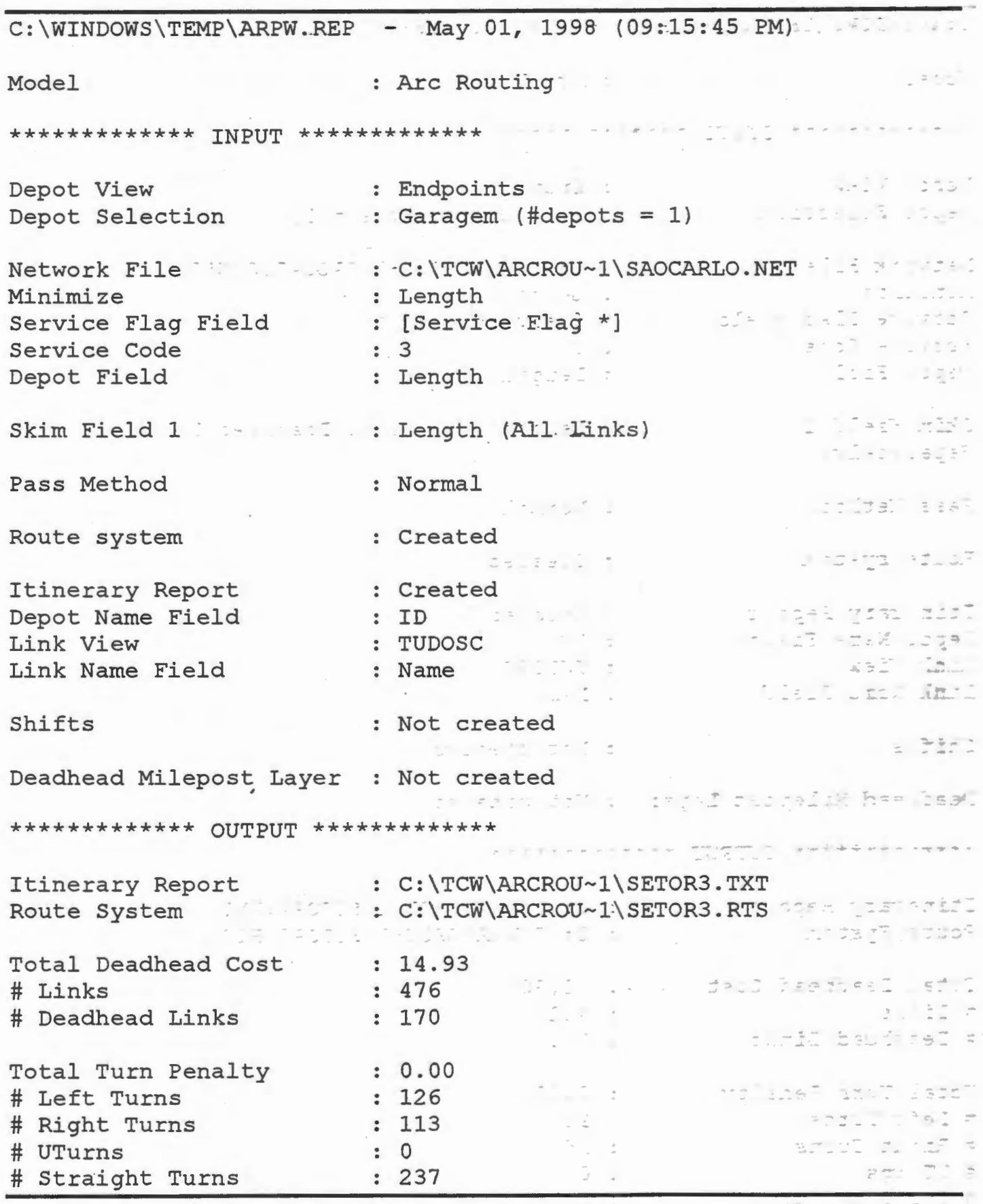




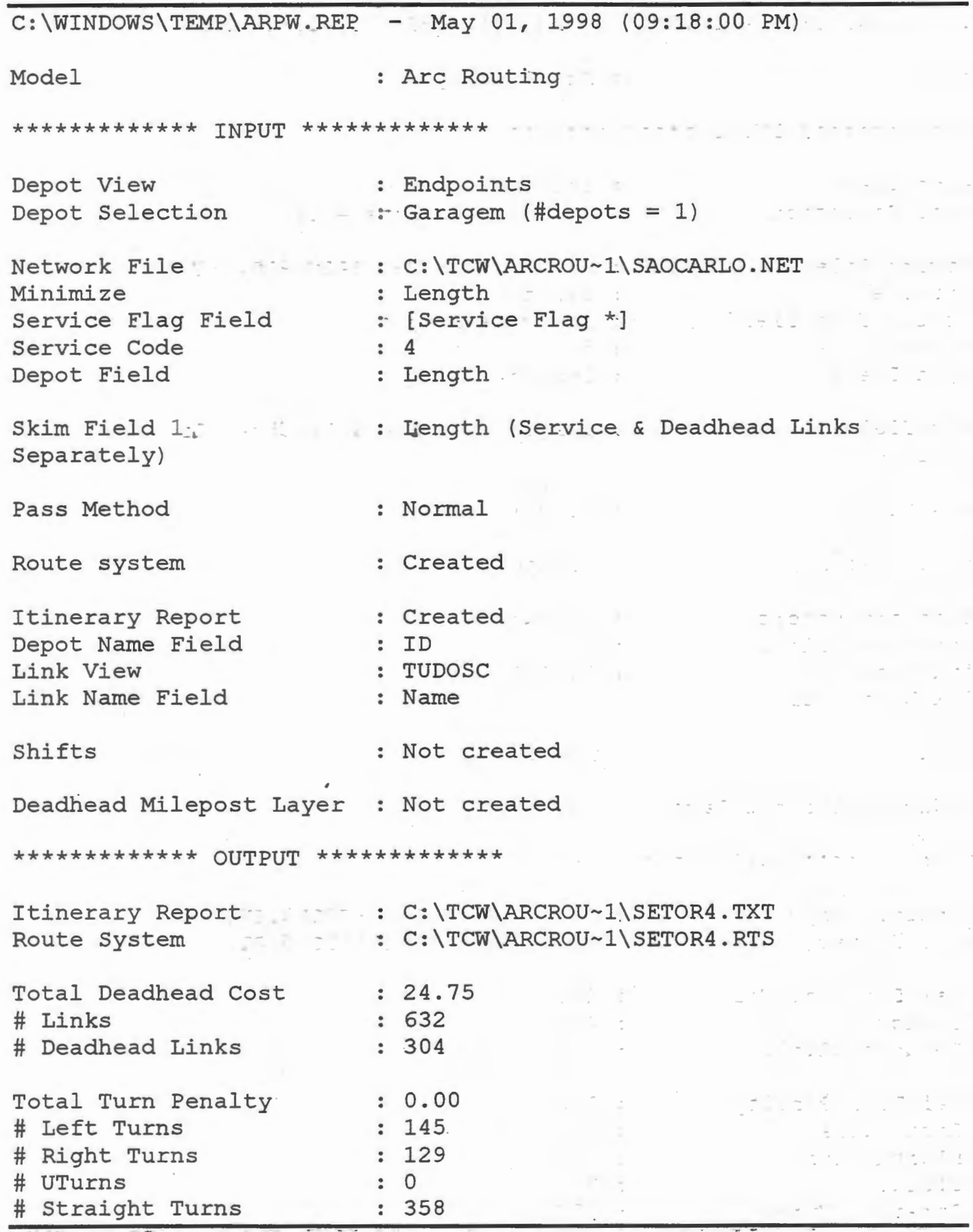




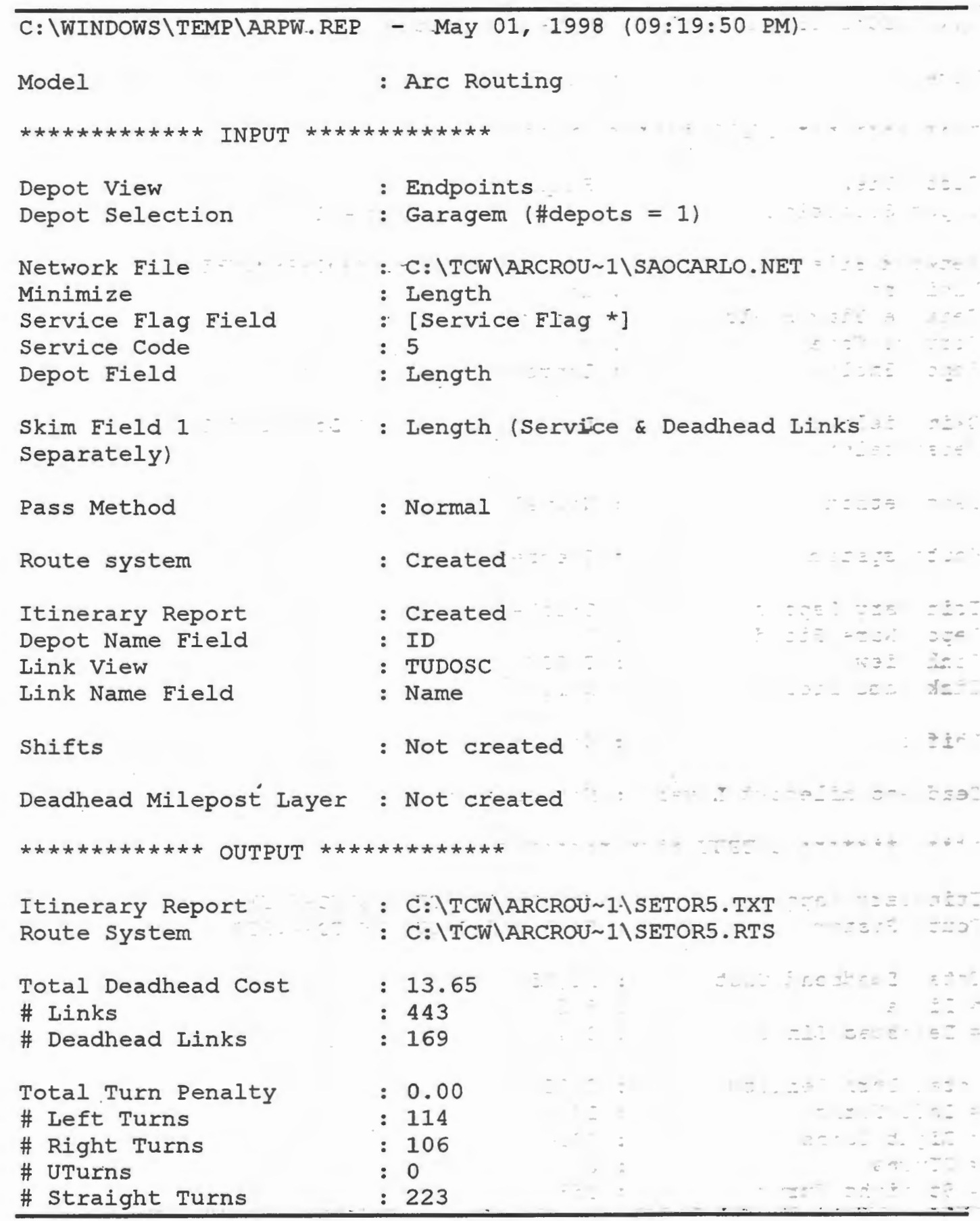




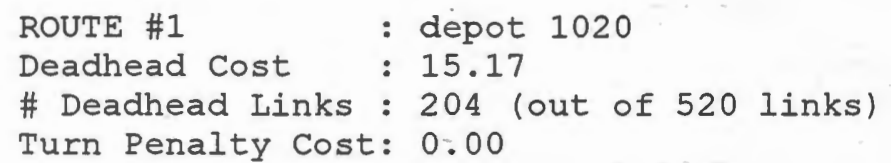

\begin{tabular}{|c|c|c|c|c|c|c|c|}
\hline 0. & Movement & Street_Name & Serv & & & & \\
\hline 1 & start on & St.ID 8668 & No & & & & \\
\hline 2 & Right on & AV GETULIO VARGAS & No & & & & \\
\hline 3 & straight & RUA RAIMUNDO CORREA & No & & & & \\
\hline 4 & straight & RUA RAIMUNDO CORREA & No & & & & \\
\hline 5 & Straight & RUA RAIMUNDO CORREA & No & & & & \\
\hline 6 & Straight & RUA RAIMUNDO CORREA & No & & & & \\
\hline 7 & straight & RUA RAIMUNDO CORREA & No & & & & \\
\hline 8 & Straight & RUA RAIMUNDO CORREA & No & & & & \\
\hline 9 & Straight & RUA RAIMUNDO CORREA & No & & & & \\
\hline 10 & straight & RUA RAIMUNDO CORREA & No & & & & \\
\hline 11 & straight & RUA RAIMUNDO CORREA & No & & & & \\
\hline 12 & Straight & RUA RAIMUNDO CORREA & No & & & & \\
\hline 13 & straight & RUA RAIMUNDO CORREA & No & & - & & \\
\hline 14 & Straight & RUA RAIMUNDO CORREA & No & & & & \\
\hline 15 & straight & RUA RAIMUNDO CORREA & No & & & & \\
\hline 16 & straight & RUA RAIMUNDO CORREA & No & & & & \\
\hline 17 & Straight & RUA RAIMUNDO CORREA & No - & & & & \\
\hline 18 & straight & RUA RAIMUNDO CORREA & No & & & & \\
\hline 19 & straight & RUA RAIMUNDO CORREA & No & & & & \\
\hline 20 & straight & RUA RAIMUNDO CORREA & No & & - & & \\
\hline 21 & straight & RUA RAIMUNDO CORREA & No & & & & \\
\hline 22 & Right on & RUA ṀAJ MANOEL ANTONIO D & Yes & & & & \\
\hline 23 & straight & RUA MAJ MANOEL ANTONIO D & Yes & & & & \\
\hline 24 & Left on & RUA PROF PAULO MONTE SER & No & & & & \\
\hline 25 & Right on & RUA MARCOLINO LOPES BARR & No & & & & \\
\hline 26 & Left on & RUA ENEAS CAMARGO & No. & & & & \\
\hline 27 & Left on & RUA RAFAEL DE ABREU SAMP & Yes & & & & 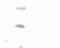 \\
\hline 28 & Right on & RUA RAIMUNDO CORREA & No & & & & - \\
\hline 29 & straight & RUA RAIMUNDO CORREA & No & & & & $=$ \\
\hline 30 & Straight & RUA RAIMUNDO CORREA & No & & & & \\
\hline 31 & Right on & RUA CAMPOS SALLES & Yes & & & & \\
\hline 32 & straight & RUA CAMPOS SALLES & Yes & & & & \\
\hline 33 & straight & RUA CAMPOS SALLES & Yes & & & & \\
\hline 34 & Right on & RUA JOSE RODRIGUES SAMPA & No & & & & \\
\hline 35 & straight & RUA JOSE RODRIGUES SAMPA & Yes & & & & \\
\hline 36 & Straight & RUA JOSE RODRIGUES SAMPA & Yes & & & & \\
\hline 37 & Right on & RUA MARCOLINO LOPES BARR & Yes & & & & \\
\hline 38 & straight & RUA MARCOLINO LOPES BARR & Yes & & & & \\
\hline 39 & Left on & RUA LUIZ ROHER & Yes & & & & \\
\hline 40 & Left on & RUA MAJ MANOEL ANTONIO D & No & & & & \\
\hline 41 & Straight & RUA MAJ MANOEL ANTONIO D & Yeśs & & & & \\
\hline 42 & straight & RUA MAJ MANOEL ANTONIO D & Yes & & & & \\
\hline 43 & Straight & RUA MAJ MANOEL ANTONIO D & Yes & & & & \\
\hline 44 & Left on & RUA BENTO CARLOS & Yes & & & & - \\
\hline 45 & Right on & RUA MARCOLINO LOPES BARR & No & & & & \\
\hline 46 & Right on & RUA GAL OSORIO & Yes & & & 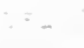 & \\
\hline 47 & Straight & RUA GAL OSORIO & Yes & & & & \\
\hline 48 & Right on & RUA TOTO LEITE & Yes & & & & \\
\hline 49 & Right on & RUA BENTO CARLOS & Yes & & & & \\
\hline
\end{tabular}


Right on RUÄ MAJ MANOEL ANTONIO D

Yes̆

Right on

straight

Right on

Right on

Left on

Right on

Left on

Right on

straight

Straight

Right on

Right on

Right on

Right on

Right on

Straight

Straight

Right on

Straight

Left on

straight

Straight

Left on

Straight

Left on

straight

Right on

Left on

Left on

straight

Left on

straight

Left on

straight

Left on

Left on

Left on

Left on

straight

Right on

straight

Left on

straight

straight

Left on

Left on

Left on

straight

Right on

Straight

Left on

Straight

straight

Right on

Straight

straight

straight

RUA GAL OSORIO

RUA GAL OSORIO

No

RUA DA MARIA IZABEL DE O

Yes

RUA BENTO CARLOS

RUA TOTO LEITE

RUA SANTA CRUZ

RUA MAJ MANOEL ANTONIO D

AV COM ALFREDO MAFFEI

AV COM ALFREDO MAFFEI

AV COM ALFREDO MAFFEI

St.ID. 8570

RUA GAI OSORIO

RUA MARCOLINO LOPES BARR

St.ID 8589

AV COM ALFREDO MAFFEI

AV COM ALFREDO MAFFEI

AV COM ALFREDO MAFFEI

RUA SAO PAULO

RUA SAO PAUIO

RUA JESUINO DE ARRUDA

RUA JESUINO DE ARRUDA

RUA JESUINO DE ARRUDA

RUA SAO JOAQUIM

RUA SAO JOAQUIM

RUA GEMINIANO COSTA

AV COM AIFREDO MAFFEI

RUA RUI BARBOSA

RUA GAL OSORIO

RUA SAO PAULO

RUA SAO PAULO

AV COM ALFREDO MAFFEI

AV COM ALFREDO MAFFEI

RUA RUI BARBOSA

RUA RUI BARBOSA

RUA GAI OSORIO

RUA SAO PAULO

AV COM ALFREDO MAFFEI

RUA RUI BARBOSA

RUA RUI BARBOSA

RUA BENTO CARLOS

RUA BENTO CARLOS

RUA SAO JOAQUIM

RUA SAO JOAQUIM

RUA SAO JOAQUIM

RUA JOSE RODRIGUES SAMPA

RUA DOM PEDRO II

RUA BELARMINO INDALECIO

RUA BELARMINO INDALECIO

RUA DA ALEXANDRINA

RUA DA ALEXANDRINA

RUA BENTO CARLOS

RUA BENTO CARLOS

RUA BENTO CARLOS

RUA 9. DE JULHO

RUA 9 DE JULHO

RUA 9 DE JULHO

RUA 9.DE JULHO

Left on

Yes

Yes

Yes

Yes

No

Yes

No

Yes

No-

Yes

Yes

No

No

No-

Yes

No

No

No

No-

No-

No

$\mathrm{No}=$

Yes

Yes

No

No.

No

Yes

Yes

Yes

Yes

No

Yes

Yes

Yes

Yes

Yes

No.

No-

Yes

Yes

-Yes

Yes

Yes

Yes

Yes

Yes

Yes

Yes

No

Yes

Yes

Yes

No.

No.

No: 


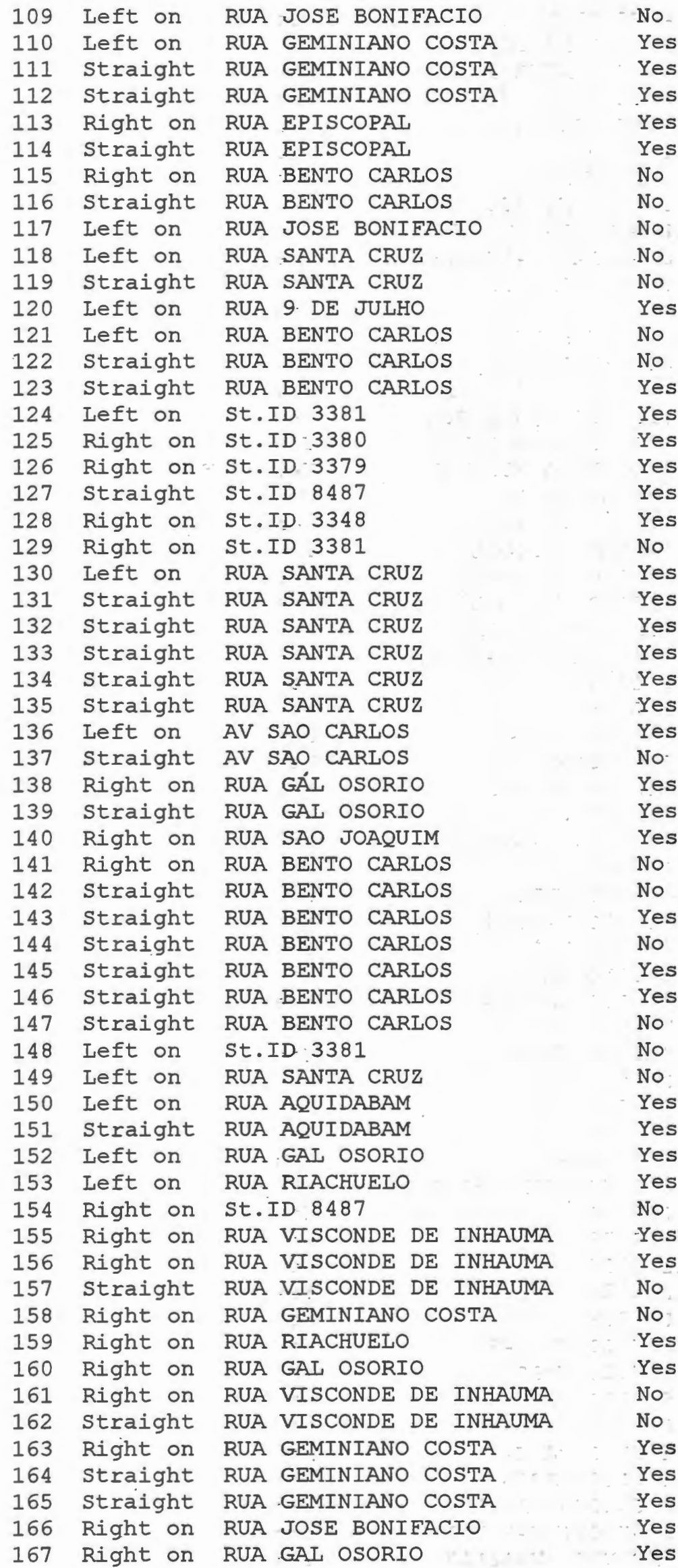


Right on Right on Right on straight straight Straight Left on Right on Right on Left on Left on straight straight Straight Right on straight straight Right on Left on

straight Straight straight Straight straight Straight Right on straight straight straight straight Straight straight Left on Left on Straight straight Straight Straight straight Straight straight Straight straight Left on Left on Right on straight Straight Left on Left on Right on Straight straight Left on Left on Straight Right on Straight Straight
RUA AQUIDABAM

RUA GEMINIANO COSTA

RUA JOSE BONIFACIO

RUA JOSE BONIFACIO

RUA JOSE BONIFACIO

St.ID 3389

RUA 1: DE MAIO

RUA FCO MARMORATO

RUA REGINA PASOUAIINI. 'E ' Yes RUA JOAQUIM EVANGELISTA ....... Yes RUA JULIEN FAUVEL RUA JULIEN FAUVEL

RUA JULIEN FAUVEL

RUA JULIEN FAUVEL

RUA DES ULISSES DORIA

RUA DES ULISSES DORIA

RUA DES ULISSES DORIA

RUA FCO SILVA RIBEIRO

RUA GASTAO VIDIGAI

RUA GASTAO VIDIGAI

RUA GASTAO VIDIGAI

RUA GASTAO VIDIGAI

RUA GASTAO VIDIGAI

RUA JOAQUIM EVANGELISTA

RUA JOAQUIM EVANGELISTA

St.ID 2384

St.ID- 2378

St.ID 8532

AV GETULIO VARGAS

AV GETULIO VARGAS

AV GETULIO VARGAS

AV GETULIO VARGAS

st.ID 8523

AV GETULIO VARGAS

AV GETULIO VARGAS

AV GETULIO VARGAS

AV GETULIO VARGAS

AV GETULIO VARGAS

AV GETULIO VARGAS

AV GETULIO VARGAS

St.ID 8526

St.ID 8527

St.ID 2387

PRACA ITALIA

RUA JOAQUIM EVANGELISTA

St.ID. 2384

St.ID 2378

St.ID 8536

St.ID" 8534

St.ID 2389

AV GETULIO VARGAS

AV GETULIO VARGAS

AV GETULIO VARGAS

St.ID-8523

AV GETULIO VARGAS

AV GETULIO VARGAS

RUA FAGUNDES VARELLA

RUA FAGUNDES VARELLA

RUA FAGUNDES VARELLA

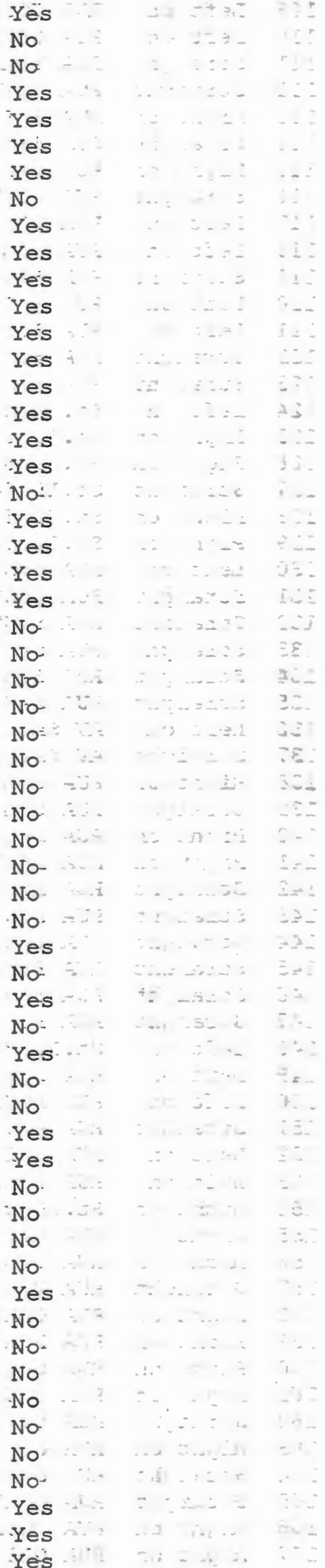




\begin{tabular}{|c|c|c|c|}
\hline 27 & Left on & RUA MACHADO DE ASSIS & es \\
\hline 28 & Left on & RUA VICENTE DE CARVALHO & Yes \\
\hline 29 & Left on & RUA HUMBERTO DE CAMPOS & Yes \\
\hline 30 & Left on & RUA FAGUNDES VARELLA & No \\
\hline & Straight & RUA FAGUNDES VARELLA & Yes \\
\hline 3 & Straight & RUA FAGUNDES VARELLA & \\
\hline 33 & Left on & RUA GONCALVES DIAS & \\
\hline & straight & RUA GONCALVES DIAS & isc \\
\hline & Straight & RUA GONCALVES DIAS & \\
\hline 36 & Left on & RUA ROCHA POMBO & \\
\hline 37 & Right on & RUA MACHADO DE ASSIS & es \\
\hline & Straight & RUA MACHADO DE ASSIS & \\
\hline 39 & Straight & RUA MACHADO DE ASSIS & \\
\hline 40 & Left on & RUA GASTAO VIDIGAL & No \\
\hline 41 & Right on & RUA EDILIO DE FREITAS & No. \\
\hline 2 & Left on & RUA JOAQUIM EVANGELISTA & \\
\hline 43 & straight & RUA JOAQUIM EVANGELISTA & Yes \\
\hline 44 & Straight & RUA JOAQUIM EVANGELISTA & \\
\hline & Right on & St.ID 2384 & \\
\hline 16 & Straight & St.ID-2378 & Jo' \\
\hline 17 & Straight & St.ID .8532 & No \\
\hline 48 & straight & St.ID: -2382 & No. \\
\hline 49 & straight & St.ID 8526 & To \\
\hline 50 & straight & St.ID 8527 & Yes \\
\hline 51 & Straight & St.ID 2387 & jo \\
\hline 22 & straight & AV SAO CARLOS & Yes \\
\hline 53 & Straight & AV SAO: CARLOS & Yes \\
\hline 54 & Straight & AV SAO CARLOS & No. \\
\hline 5 & straight & AV SAO CARLOS & Yes \\
\hline 56 & Right on & RUA OSWALDO CRUZ & Yes \\
\hline 57 & Left on & RUA DA ALEXANDRINA & No \\
\hline 58 & straight & RUA DA: ALEXANDRINA & Yes \\
\hline 59 & Left on & RUA BELARMINO INDALECIO & Yes \\
\hline 50 & Left on & AV SAO CARLOS & No \\
\hline 61 & straight & AV SAO CARLOS & No \\
\hline 62 & Left on & RUA RAIMUNDO CORREA & Yes \\
\hline 63 & straight & RUA RAIMUNDO CORREA & Yes \\
\hline 64 & straight & RUA RAIMUNDO CORREA & Yes \\
\hline 65 & Left on & RUA DOM PEDRO II & Yes \\
\hline 66 & Left on & RUA SILVERIO IGNARRA SOB & Yes \\
\hline 57 & Left on & RUA SAO JOAQUIM & Yes \\
\hline 268 & straight & RUA ROCHA POMBO & Yes \\
\hline 69 & Left on & RUA HUGO DORNFELD & No \\
\hline 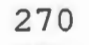 & straight & RUA HUGO DORNFELD & No \\
\hline 71 & straight & RUA HUGO DORNFELD & No \\
\hline & Left on & RUA FAGUNDES VARELLA & Yes \\
\hline 73 & Straight & RUA SAO PAULO & Yes \\
\hline 274 & Right on & RUA LUIZ ROHER & Yes \\
\hline 82 & Straight & RUA LUIZ ROHER & es \\
\hline 76 & straight & RUA LUIZ ROHER & Ys \\
\hline 277 & Straight & RUA LUTZ ROHER & Yes \\
\hline 70 & Right on & RUA MARCOLINO LOPES BARR & Ye \\
\hline & Left on & RUA ENEAS CAMARGO & \\
\hline 280 & Left on & RUA MAJ MANOEL ANTONIO D & Yes \\
\hline 81 & Straight & RUA MAJ MANOEL ANTONIO D & Ye \\
\hline & Left on & RUA SILVERIO IGNARRA SOB & \\
\hline & raight & RUA SILVERIO IGNARRA SOB & \\
\hline & Right on & RUA RAFAEL DE ABREU SAMP & ivo \\
\hline & Straight & RUA RAFAEL DE ABREU SAMP & In \\
\hline
\end{tabular}




\begin{tabular}{|c|c|c|c|c|c|c|c|}
\hline 36 & traight & UA -SOLEIL & & Yès & & $\therefore$ & \\
\hline 37 & eft on & RUA BENTO CARLOS & & Yes & & 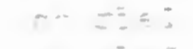 & \\
\hline & traight & RUA -BENTO CARLOS & & Yes & & & \\
\hline & ght & ZUA BENTO CARLOS & & & & $=$ & \\
\hline & ght & RUA BENTO CARLOS & & 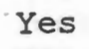 & & & \\
\hline & sht & IUA BENTO CARLOS & & & & & \\
\hline & ght & UUA BENTO CARLOS & & & & & \\
\hline & ght & RUA BENTO CARLOS & & & & & \\
\hline & on & RUA SAO PAULO & & 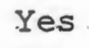 & & & \\
\hline & ght & RUA =SAO PAULO & & & & $\therefore \therefore$ & \\
\hline & $t$ on & AV COM ALFREDO MAFEEI & & 5 & & $\therefore=$ & \\
\hline & $t$ on & RUA CAMPOS SALLES & & & & $\therefore$ & \\
\hline & on & RUA BENTO CARLOS & & & & $\therefore:-$ & \\
\hline & $t$ on & RUA SORBONNE & & Yes & $5^{-1}$ & & \\
\hline & ight on & RUA SUL & & & & $\pi$ & \\
\hline & $=$ on & RUA CAMPOS SALLES & & ; & & $=\therefore$ & \\
\hline & ght & RUA CAMPOS SALLES'- & & 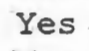 & 2 & $\cdots$ & \\
\hline & on & RUA BENTO CARLOS & & & & & \\
\hline & on & RUA CAMPOS SALLES & & & & \pm & \\
\hline & ght & RUA CAMPOS SAILES & & & & & \\
\hline & ght & RUA CAMPOS SALLES & & & & & \\
\hline & $=$ on & RUA BELARMINO INDALE & & & & & \\
\hline & on & RUA SAO PAULO & & 5 & & & \\
\hline & ght & RUA SAO PAULO & & & & $-1 \cdots$ & \\
\hline( & on & RUA BENTO CARLOS & & & & 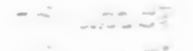 & \\
\hline & on & RUA RUI BARBOSA & & 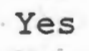 & $\cdots$ & $=\therefore$ & \\
\hline & Lght & RUA RUI BARBOSA & & & & & \\
\hline 3 & $=$ on & RUA BELARMINO INDALECIO & & Ye & & Ei & \\
\hline & on & RUA DOM PEDRO II & & 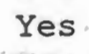 & & $=\vdots$ & \\
\hline & ght & RUA DOM PEDRO II & & 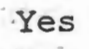 & $\therefore$ & $-8-$ & \\
\hline & on & RUA BENTO CARLOS & & $Y \epsilon$ & $\varepsilon$ & & \\
\hline & ght & RUA BENTO CARLOS & & $s$ & & & \\
\hline & on & RUA DA ALEXANDRINA & & $Y \epsilon$ & & $=\cdots$ & \\
\hline & ght & RUA DA ALEXANDRINA & & $Y \in$ & & $\therefore \quad=$ & \\
\hline$? 0$ & ght & RUA DA ALEXANDRINA & & 5 & & $\cdots$ & \\
\hline & ht & RUA DA AIEXANDRINA & & No & & $\ldots$ & \\
\hline 22 & ght & RUA DA ALEXANDRINA & & & & $\because \because \pi=3$ & \\
\hline 23 & on & RUA JESUINO DE ARRUDA. & & & & $x t^{2}=25$ & \\
\hline 24 & on & AV SAO CARLOS & & . & & $\ldots$ & \\
\hline 25 & ight & AV SAO CARLOS & & & & - & \\
\hline 26 & ght & AV SAO CARLOS & & & & $\therefore$ & \\
\hline & on & RUA GEMINIANO COSTA & & & & $\cdots=c$ & \\
\hline & ight & RUA GEMINIANO COSTA. & & & & $x^{2}=$ & \\
\hline 29 & $t$ on & RUA SAO JOAQUIM & & $s$ & & $\therefore \cdots=$ & \\
\hline & on & RUA GAI OSORIO & & s & & $=$ & \\
\hline & ight & RUA GAI OSORIO & & Yes & & & \\
\hline & $t$ on & RUA RUI BARBOSA & & $\mathrm{N}$ & & $=$ & \\
\hline & $t$ on & RUA BENTO CARLOS & & & & & \\
\hline & Right on & RUA DOM PEDRO II & & Yes & & & \\
\hline & ight & RUA DOM PEDRO II & & s & & & \\
\hline & ght & RUA DOM PEDRO II & & & & & \\
\hline & ght & RUA DOM PEDRO II & & No: & & $\therefore$ & \\
\hline & Let & RUA JESUINO DE ARRUDȦ & & No & & $\ddots$ & \\
\hline & ght & RUA JESUINO DE ARRUDA & & No & & $\therefore$ & \\
\hline & ght & RUA JESUINO DE ARRUDA & & No & & $\therefore 21++\cdots$ & \\
\hline & ght & RUA JESUINO DE ARRUDA & & No & & $i^{\cdots}-3$ & \\
\hline & on & RUA EPISCOPAI & & No & & & \\
\hline & 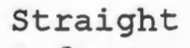 & RUA EPISCOPAI & & No & & & \\
\hline & on & RUA GEMINIANO COSTA & & Yes & & & \\
\hline
\end{tabular}




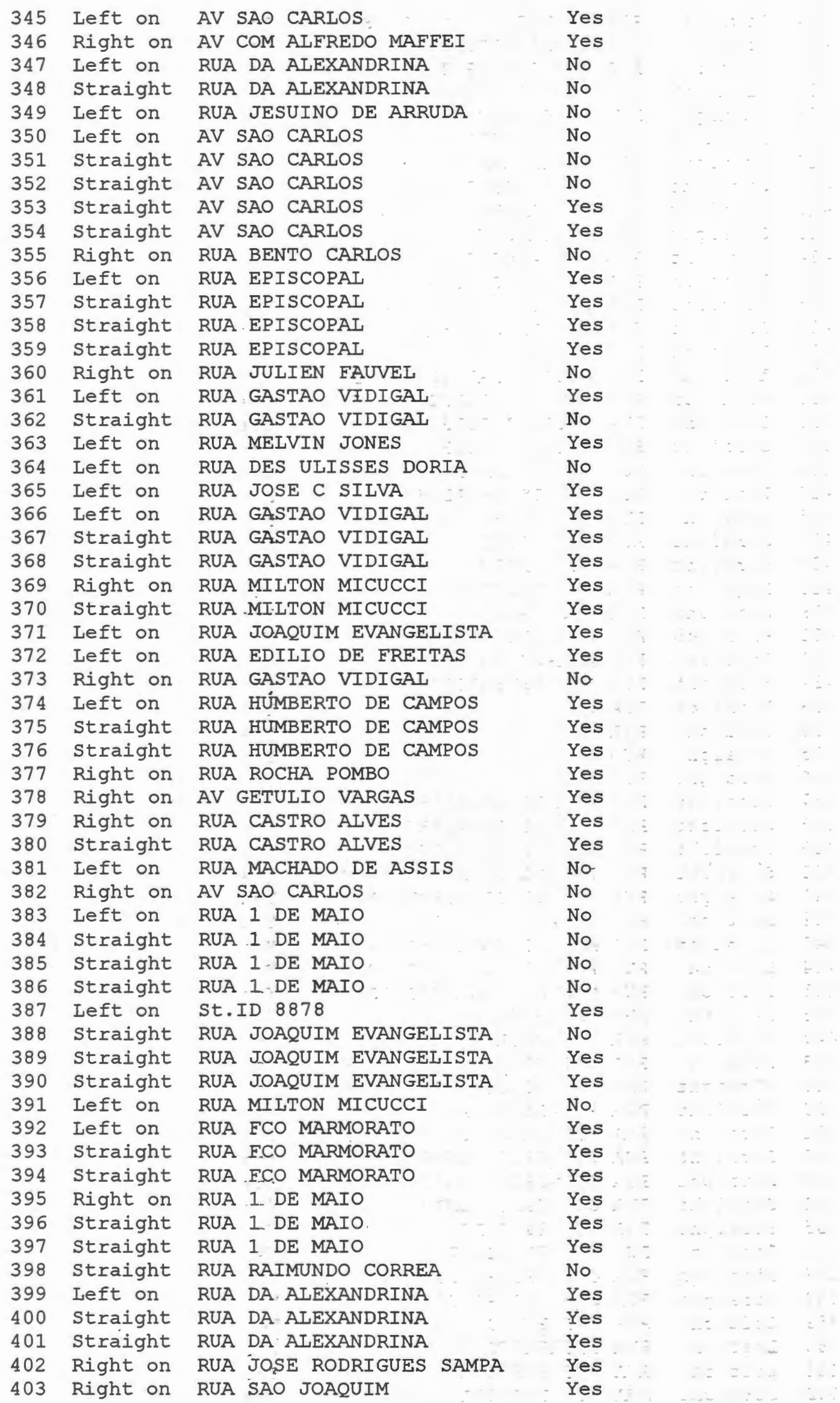




\begin{tabular}{|c|c|c|c|c|}
\hline 04 & ght on & RUA SILVERIO IGNARRA SOB & Yes & \\
\hline 05 & ight on & RUA DA ALEXANDRINA & No & $\because \quad \because=z$ \\
\hline 06 & eft on & RUA OSWALDO CRUZ & No & \\
\hline 07 & Right on & AV SAO CARLOS & Yes & \\
\hline 08 & traight & AV SAO CARLOS & Yes & 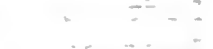 \\
\hline 09 & Right on & RUA SANTA CRUZ & & \\
\hline 10 & ght & RUA SANTA CRUZ & & \\
\hline 1 & straight & RUA SANTA CRUZ & & \\
\hline & sht & RUA SANTA CRUZ & & \\
\hline 13 & & RUA SANTA CRUZ & & \\
\hline 4 & ght & RUA SANTA CRUZ & & \\
\hline 5 & on & RUA CAMPOS SALLES & & 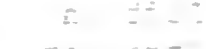 \\
\hline 16 & ght & RUA CAMPOS SALLES & & $\rightarrow$ \\
\hline 17 & fht & RUA CAMPOS SALLES & les & \\
\hline 18 & on & RUA CAMPOS SALLES & & $\therefore=$ \\
\hline 19 & on & RUA JOSE RODRIGUES SAMPA & & \\
\hline 20 & on & RUA ANTONIO RODRIGUES CA & & $=$ \\
\hline 21 & ght & RUA ANTONIO RODRIGUES $C$ & & \\
\hline 22 & ht & RUA ANTONIO RODRIGUES C & & \\
\hline 23 & Left on & RUA ENEAS CAMARGO & & \\
\hline 24 & Left on & RUA RAFAEL DE ABREU SAMI & & ? \\
\hline 25 & $\theta t$ & RUA LUIZ ROHER & & 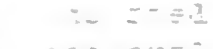 \\
\hline 26 & ight & RUA LUIZ ROHER & & \\
\hline 27 & ght & RUA LUIZ ROHER & & 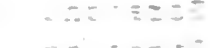 \\
\hline 28 & on & RUA SAO PAULO & & \\
\hline 29 & ght & RUA SAO PAULO & $Y$ & - \\
\hline 30 & on & RUA -JOSE RODRIGUES SAMPA & 0 & $\therefore$ \\
\hline$\$ 1$ & & RUA CAMPOS SALLES & $s$ & . \\
\hline 32 & & RUA CAMPOS SALLES & & \\
\hline 33 & & RUA SUL & $v$ & \\
\hline 34 & & RUA SU & & \\
\hline 35 & & RUA ST & & \\
\hline 36 & ht & RUA SUL & & \\
\hline 37 & & RUA RAFAEL DE ABREU SAMP & & \\
\hline 38 & & RUA RAFAEL DE ABREU SAMP & & \\
\hline 39 & & RUA RÄFAEL DE ABREU SAMP & & $\therefore$ \\
\hline 40 & & RUA RAFAEL DE ABREU SAMP & & 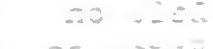 \\
\hline 4. & & RUA RAFAEL DE ABREU SAMP & & 3 \\
\hline 4 & & RUA ENEAS CAMARGO & & \\
\hline 43 & on & RUA MARCOLINO LOPES BARR & $Y$ & \\
\hline 4. & on & RUA PROF PAULO MONTE SER & & \\
\hline & $=$ & RUA MAJ MANOEL ANTONIO D & & \\
\hline 46 & on & RUA ENEAS CAMARGO & & \\
\hline & ight & RUA ENEAS CAMARGO & & \\
\hline & & RUA RAFAEL DE ABREU SAMP & & \\
\hline & & RUA RAFAEL DE ABREU SAMP & & \\
\hline & & RUA RAFAEL DE ABREU SAMP & & \\
\hline 5] & I & RUA SILVERIO IGNARRA SOB & $s$ & \\
\hline & $2 t$ & RUA SILVERIO IGNARRA SOB & & \\
\hline 53 & & RUA SILVERIO IGNARRA SOB & & \\
\hline 54 & Str & RUA SILVERIO IGNARRA SOB & & \\
\hline it & ght & RUA SIIVERIO IGNARRA SOB & & \\
\hline & on & RUA DOM P & & \\
\hline 57 & on & RUA JOSE RODRIGUES SAM & & \\
\hline & ight & RUA JOSE RODRIGUES 'SAMPA' & 5 & $=0$ \\
\hline & I & RUA SAO PAULO & & \\
\hline & Left on & RUA BELARMINO INDALECI & & \\
\hline & Left on & RUA RUI BARBOSA & $Y$ & \\
\hline & raic & UI BARBO & & \\
\hline
\end{tabular}


463

464

465

466

467

468

469

470

471

472

473

474

475

476

477

478

479

480

481

482

483

484

485

486

487

488

489

490

491

492

493

494

495

496

497

498

499

500

501

502

503

504

505

506

507

508

509

510

511

512

513

514

515

516

517

518

519

520
Straight Straight Straight straight Right on Straight Left on Left on Straight Right on Straight Right on Right on Right on Right on Right on Right on Straight Straight Straight Right on Straight Left on Left on Straight Straight Left on Left on Left on Straight Right on Straight straight Straight Straight straight straight Straight straight straight Straight straight Straight Straight Straight straight straight straight straight Straight Straight Straight Straight Straight straight Left on straight Straight
RUA RUI BARBOSA

RUA VICENTE DE CARVALHO

RUA VICENTE DE CARVALHO

RUA VICENTE DE CARVALHO

RUA MACHADO DE ASSIS

RUA MACHADO DE ASSIS

RUA ROCHA POMBO

RUA HUMBERTO DE CAMPOS

RUA HUMBERTO DE CAMPOS

RUA VICENTE DE CARVALHO

RUA VICENTE DE CARVALHO

AV GETULIO VARGAS

RUA AMADEU AMARAI

RUA CASEMIRO DE ABREU

RUA VICENTE DE CARVALHO

AV GETULIO VARGAS

RUA AMADEU AMARAL

RUA AMADEU AMARAL

RUA AMADEU AMARAL

RUA AMADEU AMARAI

RUA GONCALVES DIAS

RUA GONCALVES DIAS

RUA FAGUNDES VARELLA

RUA HUGO DORNEELD

RUA HUGO DORNFELD

RUA HUGO DORNFELD

RUA ROCHA POMBO

RUA GONCALVES DIAS

RUA AMADEU AMARAL

RUA AḾADEU AMARAI

RUA RAIMUNDO CORREA

RUA RAIMUNDO CORREA

RUA RAIMUNDO CORREA

RUA RAIMUNDO CORREA

RUA RAIMUNDO CORREA

RUA RAIMUNDO CORREA

RUA RAIMUNDO CORREA

RUA RAIMUNDO CORREA

RUA RAIMUNDO CORREA

RUA RAIMUNDO CORREA

RUA RAIMUNDO CORREA

RUA RAIMUNDO CORREA

RUA RAIMUNDO CORREA

RUA RAIMUNDO CORREA

RUA RAIMUNDO CORREA

RUA RAIMUNDO CORREA

RUA RAIMUNDO CORREA

RUA RAIMUNDO CORREA

RUA RAIMUNDO CORREA

RUA RAIMUNDO CORREA

RUA RAIMUNDO CORREA

RUA RAIMUNDO CORREA

RUA RAIMUNDO CORREA

RUA RAIMUNDO CORREA

RUA RAIMUNDO CORREA

RUA JOAO JORGE MARMORATO

RUA JOAO JORGE MARMORATO

RUA JOAO JORGE MARMORATO
Yes

Yes

Yes

Yes

Yes

Yes

Yes

Yes

Yes

Yes

No

Yes

No

Yes

Yes

No

Yes

Yes

Yes

Yes

No

No

Yes

Yes

Yes

Yes

Yes

No

Yes

Yes

Yes

Yes

Yes

Yes

Yes

Yes

Yes

Yes

No

No

No

No

No

No

No

No

No

No

No

No

No

No

No

No

No

No

No

No 


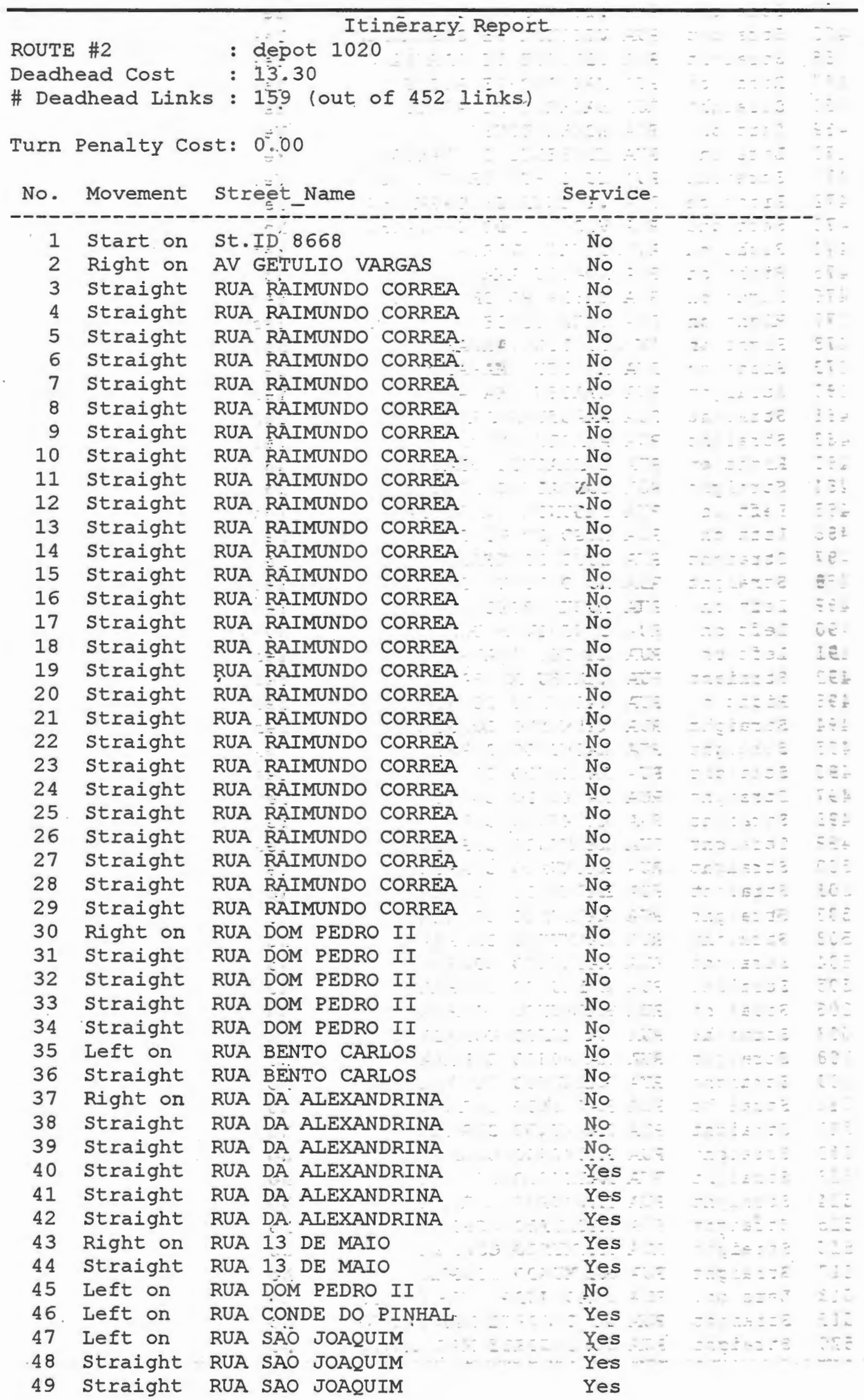


50 Left on

51 Left on

52 Left on

53 straight

54 Straight

55 straight

56 straight

57 Straight

58 Left on

59 Left on

60 Left on

61 Straight

62 straight

63 Right on

64 Right on

65 Right on

66 straight

67 Straight

68 Right on

69 straight

70 Right on

71 straight

72 Right on

73 straight

74 straight

75 straight

76 straight

77 Left on

78 Left on

79 Right on

80 Left on

81 straight

82 Left on

83 Left on

84 Straight

85 Right on

86 Left on

87 Straight

88 Right on

89 Straight

90 Right on

91 Left on

92 Left on

93 Right on

94 Right on

95 Right on

96 Left on

97 Right on

98 straight

99 Left on

100 straight

101 straight

102 straight

103 Straight

104 straight

105 straight

106 Right on

107 Straight

108 straight
AV COM ALFREDO MAFFEI

RUA DOM PEDRO II

RUA JESUINO DE ARRUDA

RUA JESUINO DE ARRUDA

RUA JESUINO DE ARRUDA

RUA JESUINO DE ARRUDA.

RUA JESUINO DE ARRUDA

RUA JESUINO DE ARRUDA

RUA JOSE BONIFACIO

RUA GEMINIANO COSTA.

RUA 9 DE JULHO

RUA 9.DE JULHO

RUA 9:DE JULHO

RUA 13 DE MAIO

RUA EPISCOPAI

RUA JESUINO DE ARRUDA

RUA JESUINO DE ARRUDA

RUA JESUINO DE ARRUDA

RUA AQUIDABAM

RUA AQUIDABAM

AV COM ALFREDO MAFFEI

AV COM ALFREDO MAFFEI

RUA JESUINO DE ARRUDA

RUA JESUINO DE ARRUDA

RUA JESUINO DE ARRUDA

RUA -JESUINO DE ARRUDA

RUA JESUINO DE ARRUDA

St.ID 8479

RUA 24 DE MAIO

RUA GÉMINIANO COSTA

RUA VISCONDE DE INHAUMA

RUA VISCONDE DE INHAUMA

RUA JESUINO DE ARRUDA

RUA 24 DE MAIO

RUA 24 DE MAIO

St.ID 8479

RUA JESUINO DE ARRUDA

RUA JESUINO DE ARRUDA

RUA -DELFINO M C PENTEADO

RUA DELFINO M C PENTEADO

RUA BENEDITO DA SILVA

RUA ALIPIO BENEDITO

RUA CONDE DO PINHAL

RUA DELFINO M C PENTEADO

AV COM ALFREDO MAFFEI

AV COM ALFREDO MAFFEI

RUA VISCONDE DE INHAUMA

RUA MAJ JOSE INACIO

RUA MAJ JOSE INACIO

RUA AQUIDABAM

RUA AQUIDABAM

RUA AQUIDABAM

RUA AQUIDABAM

RUA AQUIDABAM

RUA AQUIDABAM

RUA AQUIDABAM

RUA 28. DE SETEMBRO

RUA 28 DE SETEMBRO

RUA 28 DE SETEMBRO
No

No

Yes

Yes

Yes

Yes

Yes

Yes

Yes

No

Yes

Yes

Yes

Yes

Yes

No

No

Yes

Yes

Yes

Yes

Yes

No

No

No

Yes

Yes

Yes

Yes

Yes

Yes

Yes

No

Yes

No

No

Yes

Yes

Yes

Yes

Yes

Yes

Yes

Yes

Yes

No

No

Yes

Yes

Yes

Yes

Yes

Yes

Yes

Yes

Yes

No.

No

Yes 
Right on Straight Right on Straight straight Straight straight Straight Left on Straight straight Left on Left on Straight Right on Right on Right on Straight Straight Left on Left on Left on Left on Straight Straight Straight Left on Left on Left on Left on Right on Straight straight Straight straight Right on Straight Right on Left on Left on Left on Straight Left on Straight Left on Left on Left on Straight Straight straight Right on Right on Right on Right on Left on Left on straight Right on Right on
RUA EPISCOPAI

RUA EPISCOPAI

RUA 15 DE NOVEMBRÓ

RUA 15 DE NOVEMBRO

RUA 15 DE NOVEMBRO

RUA 15 DE NOVEMBRO

RUA $15^{\circ}$ DE NOVEMBRO

RUA 15 DE NOVEMBRO

RUA CAP ADAO PEREIRA DA

RUA CAP ADAO PEREIRA -DA

RUA CAP ADAO PEREIRA DA

RUA MAL DEODORO

RUA VISCONDE DE INHAUMA

RUA VISCONDE DE INHAUMA

RUA SAO SEBASTIAO

RUA RIACHUELO

RUA PE TEIXEIRA

RUA PE TEIXEIRA

RUA PE TEIXEIRA

RUA MAJ JULIO SALLES

RUA MAL DEODORO

RUA CAP ADAO PEREIRA DA

RUA PE TEIXEIRA

RUA PE TEIXEIRA

RUA PE TEIXEIRA

RUA PE TEIXEIRA

RUA ISIS FERNANDES

RUA ALDO POZZI

RUA VITOR MANOEL DE SOUZ

RUA PE TEIXEIRA

RUA PAULINO BOTELHO DE A RUA PAULINO BOTELHO DE A RUA PAULINO BOTELHO DE A RUA PAULINO BOTELHO DE A RUA PAULINO BOTELHO DE - A RUA SERAFIN VEIRA DE ALM RUA SERAFIN VEIRA DE ALM RUA CAP ADAO PEREIRA. DA RUA PRINCESA ISABEL RUA MIGUEL PETRONI RUA MIGUEL PETRONI RUA SERAFIN VEIRA DE ALM RUA CAP ADAO PEREIRA DA RUA CAP ADAO PEREIRA DA AV DR CARLOS BOTELHO RUA MIGUEL PETRONI RUA PRINCESA ISABEL RUA PRINCESA ISABEL RUA PRINCESA ISABEL RUA PRINCESA ISABEL RUA PAULINO BOTELHO DE A RUA SERAFIN VEIRA DE ALM RUA MÄJ JULIO SALLES RUA PRINCESA ISABEL RUA VITOR MANOEL DE SOUZ AV DR CARLOS BOTELHO AV DR ĆARLOS BOTELHO RUA CAP ADAO PEREIRA DA RUA 15. DE NOVEMBRO

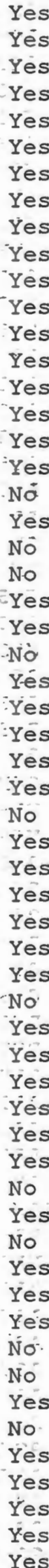

Yes

Yés

Yes

Yes

Yes

Yes

Yes

Yes

Yes

Yes

Yes

Yes

Yes

Yes

Yes

Yes

Yes

Yes

Nó

Yes

Nö

No

Yes

Yes

No

Yés

Yes

Yés

Yes

Yes

No

Yes

Yes

Yes

Yes

Yes

Yes

No

Yes

Yes

Yes

Yés

Yes

Yes

No

Ỳes

No

Yes

Yes

Yés

No.

No

Yes

No

Yes

Yes

Yes

Yes

Yes 
straight straight Right on Right on Right on Straight Straight Right on Right on Right on Straight Left on Straight Right on straight straight Right on Straight Left on straight Straight straight Right on straight Left on Right on Right on straight Right on Straight straight straight straight straight Left on straight straight Straight Left on straight straight Straight Right on straight straight straight straight Straight Straight straight straight Right on Left on straight Left on Left on straight straight straight
RUA 15 DE NOVEMBRO

RUA 15 DE NOVEMBRO

RUA PAULINO BOTELHO DE A AV DR CARLOS BOTELHO RUA VITOR MANOEL DE SOUZ RUA VITOR MANOEL DE SOUZ RUA VITOR MANOEL DE SOUZ RUA PE TEIXEIRA

RUA PAULINO BOTELHO DE A RUA SAO SEBASTIAO

RUA SAO SEBASTIAO

RUA MAJ JULIO SALLES

RUA MAJ JULIO SALLES

AV DR CARLOS BOTELHO

AV DR CARLOS BOTELHO

AV DR CARLOS BOTELHO RUA RIACHUELO

RUA RIACHUELO

RUA SAO SEBASTIAO

RUA SAO SEBASTIAO

RUA SAO SEBASTIAO

RUA SAO SEBASTIAO

RUA EP.ISCOPAL

RUA EPISCOPAL

RUA MAL DEODORO

AV SAO CARLOS

RUA 7: DE SETEMBRO

RUA 7: DE SETEMBRO

RUA 9. DE JULHO

RUA 9"DE JULHO

RUA 9 DE JULHO

St.ID 8879

RUA 9 .DE JULHO

RUA 9 DE JULHO

RUA 28 DE SETEMBRO

RUA 28. DE SETEMBRO

RUA 28. DE SETEMBRO

RUA JOSE BONIFACIO

AV DR-CARLOS BOTELHO

AV DR .CARLOS BOTELHO

AV DR -CARIOS BOTELHO

AV DR CARLOS BOTELHO

AV SAO CARLOS

AV SAO CARLOS

AV SAO CARLOS

AV SAO CARLOS

AV SAO CARLOS

AV SAO CARLOS

AV SAO CARLOS

AV SAO CARLOS

AV SAO CARLOS

RUA JESUINO DE ARRUDA

RUA EPISCOPAL

RUA EPISCOPAI

RUA GEMINIANO COSTA

AV SAO CARLOS

AV SAO" CARLOS

AV SAO CARLOS

AV SAO CARLOS
Yes

Yes

No

Yes

Yes

Yes

Yes

No

Yes

Yes

Yes

Yes

Yes

No

Yes

No

Yes

Yes

Yes

Yes

Yes

Yes

Yes

Yes

Yes

No

No

No

Yes

Yes

Yes

Yes

Yes

Yes

Yes

Yes

Yes

Yes

Yes

Yes

Yes

Yes

No

No

Yes

Yes

No

No

Yes

Yes

No.

No

Yes

Yes

No.

No.

Yes

Yes

Yes 
Right on Left on straight straight straight straight straight Straight straight Right on Right on straight Left on Left on Left on straight straight straight Left on Left on Left on straight Right on straight straight straight Right on Right on straight straight straight Left on Left on straight Right on Straight Left on Left on Left on straight straight straight straight straight Left on Left on straight Right on Straight straight straight Left on Left on Straight Right on straight straight Left on Left on
RUA 13 DE MAIO

RUA DA: ALEXANDRINA RUA DA ALEXANDRINA RUA DA ALEXANDRINA RUA DA - AIEXANDRINA RUA DA ALEXANDRINA. RUA DA ALEXANDRINA RUA DA ALEXANDRINA RUA DA ALEXANDRINA AV DR-CARLOS BOTELHO RUA SAO JOAOUIM RUA SAO JOAQUIM RUA SAO SEBASTIAO RUA DOM PEDRO II RUA 15 DE NOVEMBRO RUA 15 DE NOVEMBRO RUA 15: DE NOVEMBRO RUA 15 DE NOVEMBRO RUA EPISCOPAI RUA SAO SEBASTIAO AV SAO CARLOS AV SAO CARLOS AV DR CARLOS BOTELHO AV DR. CARLOS BOTELHO AV DR-CARIOS BOTELHO AV DR- CARLOS BOTELHO RUA RUI BARBOSA RUA 15 DE NOVEMBRO RUA 15. DE NOVEMBRO RUA 15. DE NOVEMBRO RUA 15, DE NOVEMBRO AV SAO CARLOS RUA SAO SEBASTIAO RUA SAO SEBASTIAO RUA SAO JOAQUIM RUA SAO JOAQUIM RUA MAI DEODORO RUA DOM PEDRO II RUA PE TEIXEIRA RUA PE TEIXEIRA RUA PE TEIXEIRA RUA PE TEIXEIRA RUA PE TEIXEIRA RUA PE TEIXEIRA RUA JOSE BONIFACIO RUA MAI DEODORO RUA MAL DEODORO RUA EPISCOPAI RUA EPISCOPAI RUA EPISCOPAI RUA EPISCOPAL RUA 13. DE MAIO AV SAO CARLOS AV SAO CARLOS RUA MAJ JOSE INACIO RUA MAJ JOSE INACIO RUA MAJ JOSE INACIO RUA DOM PEDRO II RUA 7 DE SETEMBRO

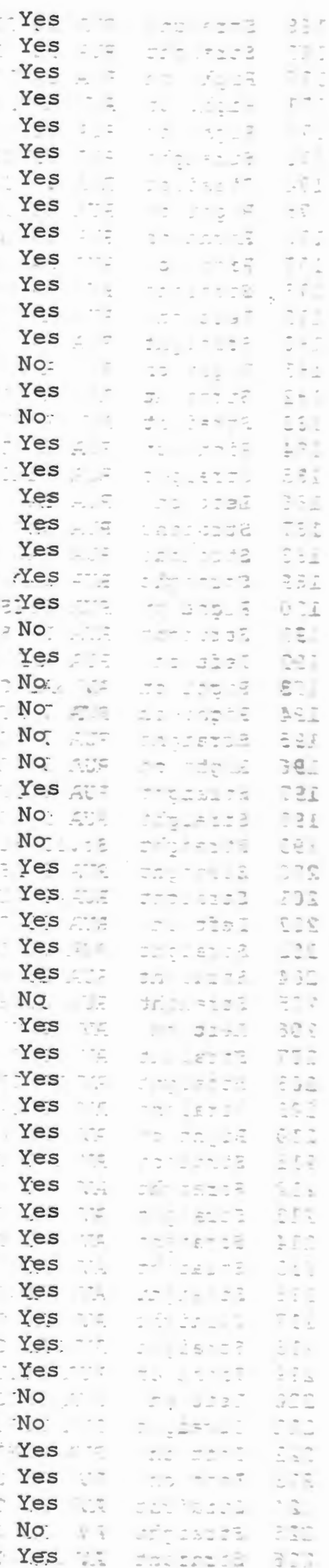




\begin{tabular}{|c|c|c|c|c|}
\hline 86 & eft & RUA SAO JOAQUIM & & \\
\hline 87 & straight & RUA SAO JOAQUIM & & Yes \\
\hline & Right on & RUA CONDE DO PINHAL & - & \\
\hline & straight & RUA CONDE DO PINHAL & & \\
\hline & straight & RUA CONDE DO PINHAI & & \\
\hline & Straight & RUA CONDE DO PINHAL & & \\
\hline & Right on & RUA 9 DE JULHO & & \\
\hline & Right on & RUA MAJ JOSE INACIO & & \\
\hline & Straight & RUA MAJ JOSE INACIO & & \\
\hline & Left on & AV SAO CARLOS & & \\
\hline & straight & AV SAO CARLOS & & \\
\hline & $=$ on & RUA MAI DEODORO & & es \\
\hline & ight & RUA MAI DEODORO & & \\
\hline & Right on & RUA SAO JOAQUIM & & \\
\hline & Right on & RUA 7. DE SETEMBRO & & \\
\hline & ight & RUA 7. DE SETEMBRO & & \\
\hline & ght & RUA 7 DE SETEMBRO & & \\
\hline & ght & RUA 7.DE SETEMBRO & & \\
\hline & straight & RUA 7. DE SETEMBRO & & \\
\hline & Left on & RUA JOSE BONIFACIO & & \\
\hline & Left on & RUA MAJ JOSE INACIO & & \\
\hline & Left on & RUA 9 DE JULHO & & \\
\hline 8 & straight & RUA 9. DE JULHO & & \\
\hline & Left on & RUA 7 DE SETEMBRO & & \\
\hline & ight & RUA 7.DE SETEMBRO & & \\
\hline & ght & RUA 7.DE SETEMBRO & & \\
\hline & ght & RUA 7.DE SETEMBRO & & \\
\hline & ton & RUA VISCONDE DE II & & \\
\hline & $=$ on & RUA MAL DEODORO & & \\
\hline & ght & RUA MÁI DEODORO & & \\
\hline & ght & RUA MAL DEODORO & & \\
\hline & $t$ on & RUA JOSE BONIFACIO & & \\
\hline & $t$ on & RUA 7 DE SETEMBRO & & \\
\hline & ght & RUA 7 DE SETEMBRO & & \\
\hline & Let & RUA RIACHUELO & & \\
\hline & ght & RUA RIACHUELO & & \\
\hline & $=$ on & St.ID 8901 & & \\
\hline & Lef & St.ID 8900 & & \\
\hline & ton & RUA CONDE DO PINHAI & & \\
\hline & ght & RUA CONDE DO PINHAI & & \\
\hline & Lef & RUA ALIPIO BENEDITO & & \\
\hline 7 & $t$ on & RUA BENEDITO DA SILVA & & \\
\hline & Right on & RUA DELFINO M C PENTEAI & & $Y \in$ \\
\hline 0 & Right on & RUA CONDE DO PINHAI & & $\mathrm{NC}$ \\
\hline 30 & $t$ on & RUA AIIPIO BENEDITO & & NO \\
\hline & ght & RUA AIIPIO BENEDITO & & Ye \\
\hline & ght & RUA AIIPIO BENEDITO & & 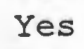 \\
\hline & on & RUA JESUINO DE ARRUDA & & 0 \\
\hline & ght & RUA JESUINO DE ARRUDA & & Yes \\
\hline & on & RUA I3 DE MAIO & & 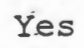 \\
\hline & ght & RUA 13. DE MAIO & & Yes \\
\hline & ght & RUA 13 DE MAIO & & Yes \\
\hline & Lef & RUA VISCONDE DE INHAUMA & & \\
\hline & ight & RUA VISCONDE DE INHAUMA- & & Yes \\
\hline & ght & RUA VISCONDE DE INHAUMA & & \\
\hline & ght & RUA VISCONDE DE INHAUMA & & \\
\hline & Lef & RUA 7 .DE SETEMBRO & & Ye: \\
\hline & ight & RUA $T$ DE SETEMBRO & & Ye \\
\hline & Rigl & St.ID 7993 & & \\
\hline
\end{tabular}




\begin{tabular}{|c|c|c|c|c|}
\hline 45 & straight & St.ID 8476 & & \\
\hline 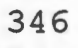 & Right on & RUA 7 DE SETEMBRO & & \\
\hline 7 & Left on & RUA JOAO DE OLIVEIRA JR & & \\
\hline 8 & straight & RUA MAI DEODORO & & \\
\hline & Left on & RUA CAP ADAO PEREIRA DA & & \\
\hline & Left on & RUA PE TEIXEIRA & & \\
\hline & Right on & RUA MAJ JULIO SALLES & & \\
\hline 2 & Right on & RUA SAO SEBASTIAO & & \\
\hline 3 & straight & RUA SAO SEBASTIAO & & \\
\hline 54 & Left on & RUA VISCONDE DE INHAUMA & & \\
\hline 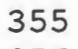 & straight & RUA VISCONDE DE INHAUMA & & \\
\hline 56 & Right on & AV DR CARLOS BOTELHO & & \\
\hline 57 & straight & AV DR CARLOS BOTELHO & & \\
\hline 8 & ight & AV DR CARLOS BOTELHO & & \\
\hline 59 & Right on & RUA JOSE BONIFACIO & & \\
\hline 50 & straight & RUA JOSE BONIFACIO & & \\
\hline 61 & straight & RUA JOSE BONIFACIO & & \\
\hline 52 & Right on & RUA PE TEIXEIRA & & \\
\hline 63 & straight & RUA PE TEIXEIRA & & \\
\hline 64 & Left on & RUA RIACHUELO & & \\
\hline 55 & straight & RUA RIACHUELO & & \\
\hline 56 & ight & RUA RIACHUELO & & \\
\hline 57 & ight & RUA RIACHUELO & & \\
\hline 68 & Right on & St.ID 8901 & & \\
\hline 69 & Left on & St.ID 8900 & & \\
\hline 70 & Left on & St.ID 8899 & & \\
\hline 11 & straight & St.ID 8898 & & \\
\hline 12 & Right on & AV COM ALFREDO MAFFEI & & \\
\hline 3 & Left on & RUA AQUIDABAM & & \\
\hline 74 & Straight & ŔUA AQUIDABAM & & \\
\hline 15 & Right on & RUA MAJ JOSE INACIO & & \\
\hline 76 & Right on & RUA JOSE BONIFACIO & & \\
\hline 377 & Right on & RUA CONDE DO PINHAI & & \\
\hline 78 & straight & RUA CONDE DO PINHAI & & \\
\hline 79 & Straight & St.ID 8896 & & \\
\hline 380 & Left on & St.ID 8901 & & \\
\hline 81 & Right on & AV COM ALFREDO MAFFEI & & \\
\hline 382 & ight & AV COM ALFREDO MAFFEI. & & \\
\hline 383 & Straight & AV COM AIFREDO MAFFEI. & & \\
\hline 384 & Right on & AV COM ALFREDO MAFEEI & & \\
\hline 385 & Left on & RUA DELFINO M C PENTEAD & & \\
\hline 386 & Left on & AV COM ALFREDO MAFFEI & & \\
\hline 387 & Right on & AV COM ALFREDO MAFFEI & & \\
\hline 388 & straight & AV COM ALFREDO MAFFEI & & \\
\hline 389 & straight & AV COM ALFREDO MAFFEI & & \\
\hline 390 & Right on & St.ID 8900 & & \\
\hline 391 & Left on & St.ID 8899 & & \\
\hline 392 & Right on & RUA RIACHUELO & & \\
\hline 393 & straight & RUA RIACHUELO & & \\
\hline 394 & straight & RUA RIACHUELO & & \\
\hline 395 & Left on & RUA GEMINIANO COSTA & & \\
\hline 396 & Left on & RUA AQUIDABAM & & \\
\hline 397 & Left on & RUA JESUINO DE ARRUDA & & \\
\hline 398 & Straight & RUA JESUINO DE ARRUDA & & \\
\hline 399 & Right on & RUA VISCONDE DE INHAUMA & & \\
\hline 400 & Right on & RUA 13 DE MAIO & & \\
\hline 101 & straight & RUA 13.DE MAIO & & \\
\hline 402 & Straight & RUA 13, DE MAIO & & \\
\hline 403 & Straight & RUA 13 DE MAIO & & \\
\hline
\end{tabular}

Yes

No

Yés

Yes

Yes

Yës

yes

Yes

Yes

Yes

Yes

Yes

Yes

Yes

yes

yes

No

Yes

No

No

No

No

Yes

Yes

Yes

Yes

Yes

Yes

Yes

No

No

Yes

Yès

yès

Yes

Yes

No

No

No.

No

No

No

Yes

Yes

Ýes

No

Yes

Yes

Yes

Yes

Yes

Yes

Yes.

Yes

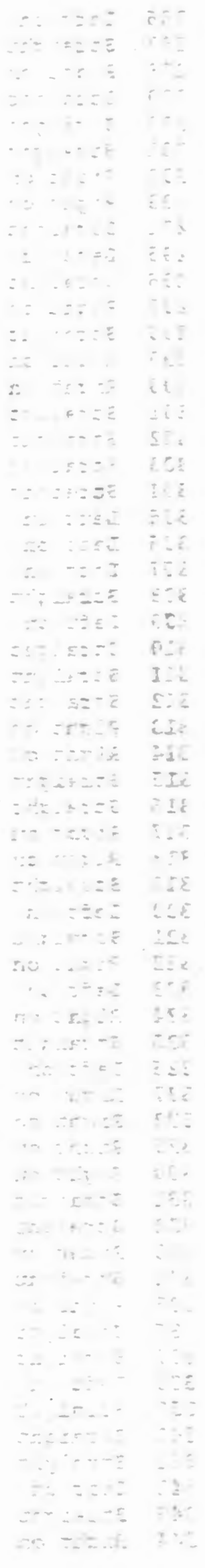




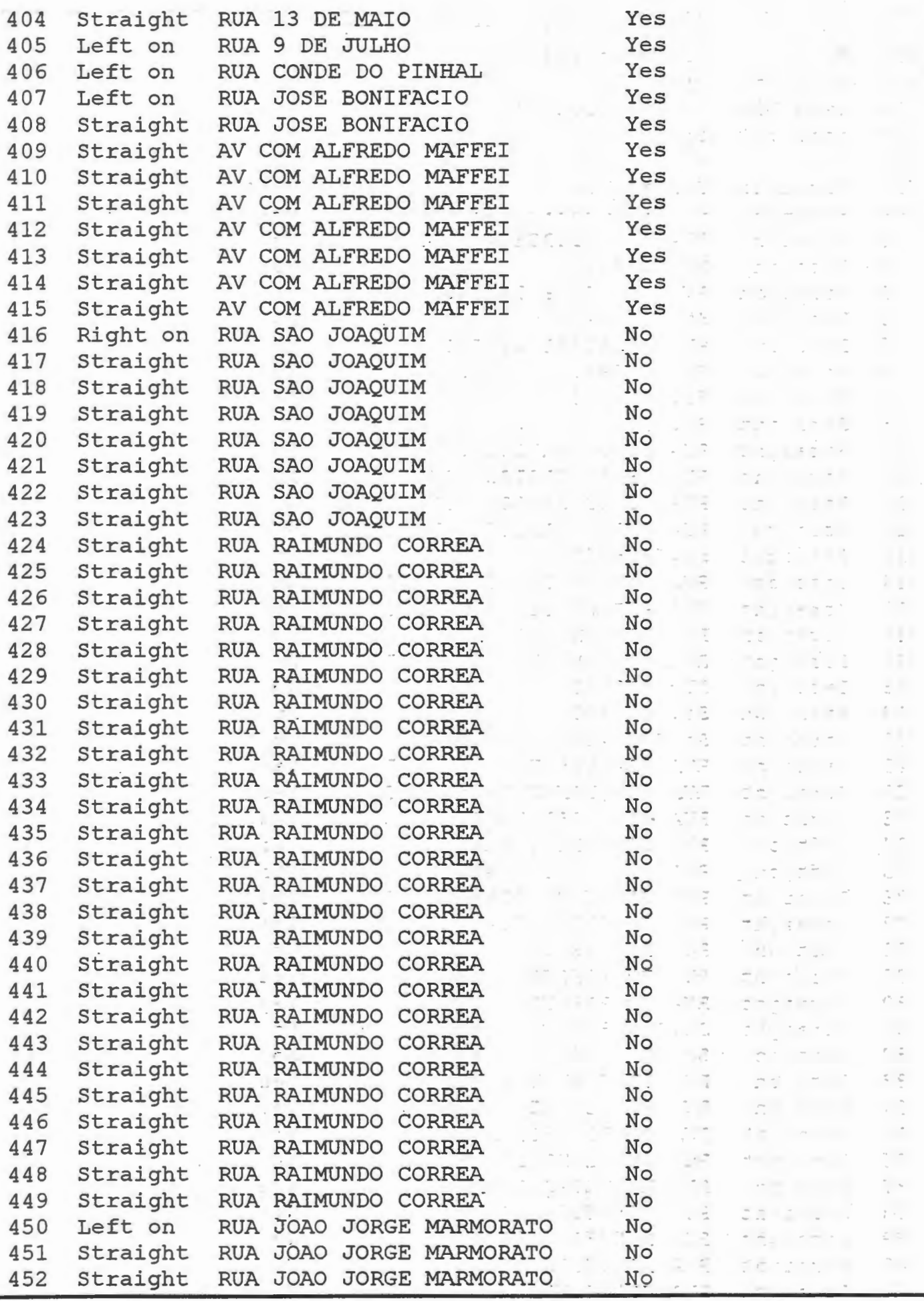




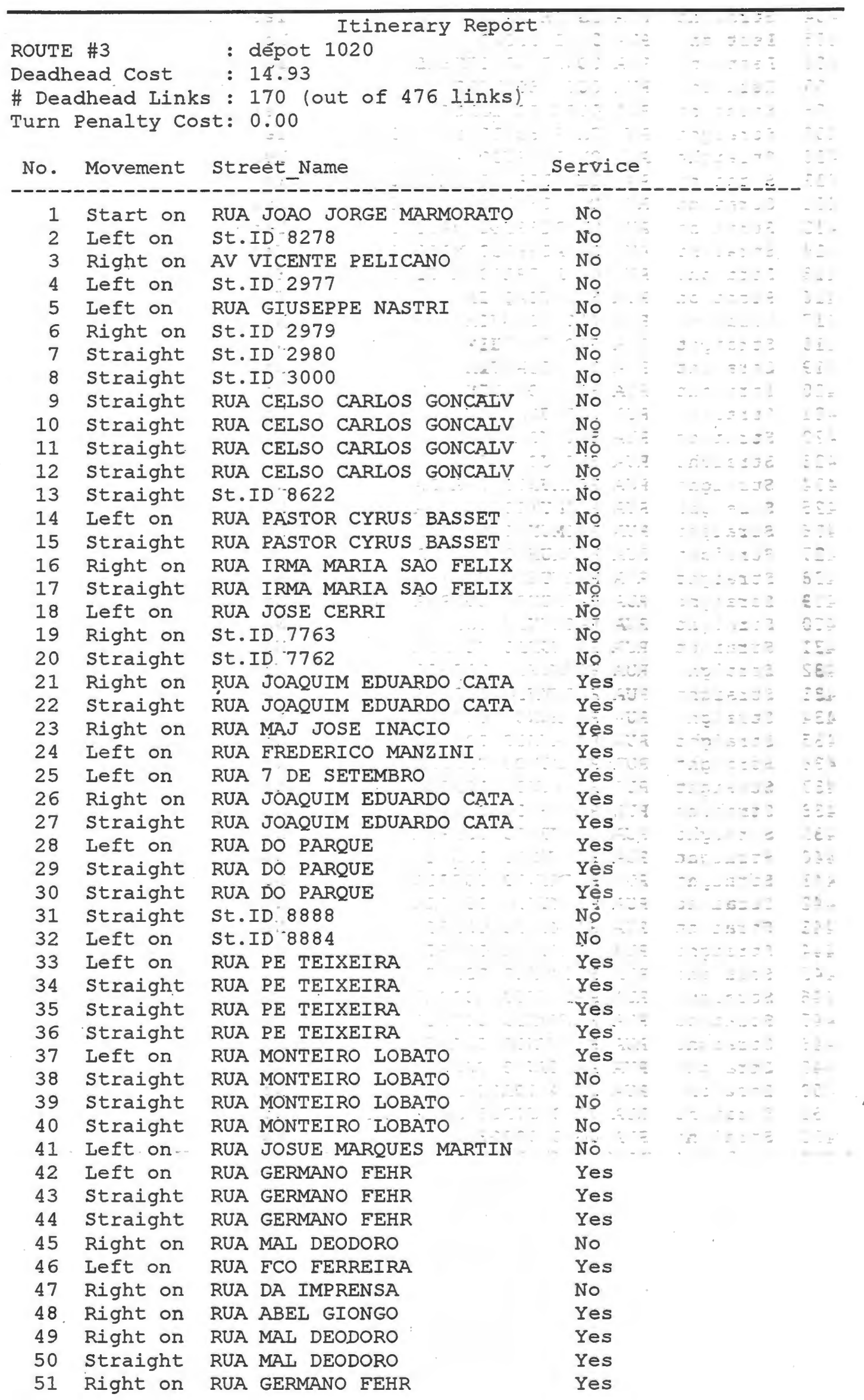


52 Right on

53 Straight

54 Right on

55 straight

56 Right on

57 straight

58 Straight

59 Right on

60 Right on

61 Right on

62 straight

63 Left on

64 Straight

65 Right on

66 straight

67 Left on

68 Left on

69 Left on

70 Right on

71 straight

72 Straight

73 Right on

74 straight

75 Straight

76 straight

77 Left on

78 Right on

79 Right on

80 Left on

81 Straight

82 Left on

83 Straight

84 straight

85 Straight

86 Right on

87 Straight

88 Right on

89 Right on

90 Right on

91 Right on

92 straight

93 Left on

94 Left on

95 Right on

96 straight

97 Ieft on

98 Straight

99 straight

100 straight

101 Straight

102 straight

103 straight

104 Right on

105 Right on

106 Left on

107 Right on

108 Left on

109 Left on

110 Left on
RUA DA IMPRENSA

RUA DA IMPRENSA

RUA FCO FERREIRA

RUA FCO FERREIRA

RUA 7 DE SETEMBRO

RUA 7. DE SETEMBRO

RUA 7 -DE SETEMBRO

RUA EUGENIO FRANCO DE CA

RUA MAL DEODORO

RUA MONTEIRO LOBATO

RUA MONTEIRO IOBATO

RUA MAJ JOSE INACIO

RUA MAJ JOSE INACIO

RUA FCO FERREIRA

RUA F̈CO FERREIRA

RUA 13 DE MAIO

RUA ABEL GIONGO

RUA JOSUE MARQUES MARTIN

RUA FCO FERREIRA

RUA FCO FERREIRA

RUA FCO FERREIRA

RUA MAL DEODORO

RUA MAL DEODORO

RUA MAL DEODORO

RUA MAL DEODORO

RUA THEREZA CORNACHIONI

St.ID̃..8058

RUA DO PARQUE

RUA JOAQUIM EDUARDO CATA

RUA J̈GAQUIM EDUARDO CATA

AV CAP LUIZ BRANDAO

AV CAP IUIZ BRANDAO

AV CAP LUIZ BRANDAO

AV CAP LUIZ BRANDAO

RUA 1.5 DE NOVEMBRO

RUA 15 DE NOVEMBRO

RUA GIOVANNI ROSSI

AV DR: CARLOS BOTELHO

RUA MONTEIRO IOBATO

RUA 15 DE NOVEMBRO

RUA 15 DE NOVEMBRO

RUA EUGENIO FRANCO DE CA

RUA SAO SEBASTIAO

RUA MONTEIRO LOBATO

RUA MONTEIRO LOBATO

RUA DA IMPRENSA

RUA DA IMPRENSA

RUA DA IMPRENSA

RUA DA IMPRENSA

RUA DA IMPRENSA

RUA DA IMPRENSA

RUA DA IMPRENSA

RUA DQ PARQUE

RUA THEREZA CORNACHIONI

St.ID 8058

RUA DO PARQUE

RUA JOAQUIM EDUARDO CATA

RUA JULIO CONSTANTINO

AV CAP LUIZ BRANDAO
No

No

No

No

Yes

Yes

Yes

Yes

Yes

Yes

Yes

Yes

Yes

No

No

Yes

No

No

Yes

Yes

Yes

No

No

Yes

Yes

Yes

No

No

Yes

Yes

Yes

Yes

Yes

Yes

No

Yes

Yes

No

Yes

No

Yes

No

Yes

Yes

No

Yes

Yes

Yes

Nó

Yes

Yes

Yes

No

Yès

Yes

No

No

Yes

No 
111

112

113

114

115

116

117

118

119

120

121

122

123

124

125

126

127

128

129

130

131

132

133

134

135

136

137

138

139

140

141

142

143

144

145

146

147

148

149

150

151

152

153

154

155

156

157

158

159

160

161

162

163

164

165

166

167

168

169
Right on Left on straight Right on Straight Straight Right on Left on Right on Right on Straight Right on Right on Left on straight Straight Straight straight Right on Straight Straight straight straight Straight Left on straight Right on Straight straight Right on Straight Left on straight Right on Right on Right on Straight Straight Right on Right on Straight Straight Straight Left on Left on Straight Straight Straight Straight Left on Left on straight Right on straight straight Straight Left on Left on Left on
RUA 15 DE NOVEMBRO

RUA MONTEIRO LOBATO

RUA MONTEIRO LOBATO

RUA PE TEIXEIRA

RUA PE TEIXEIRA

RUA PE TEIXEIRA

RUA TOTO LEITE

RUA 15 DE NOVEMBRO

RUA TOTO LEITE

AV DR CARLOS BOTELHO

AV DR CARLOS BOTELHO

RUA EUGENIO FRANCO DE CA

RUA 15 DE NOVEMBRO

RUA DA MARIA IZABEL DE O

RUA DA MARIA IZABEL DE-O

RUA DA MARIA IZABEL DE O

RUA DA MARIA IZABEL DE 0

RUA DA MARIA IZABEL DE 0

RUA CONDE DO PINHAL

RUA CONDE DO PINHAL

RUA CONDE DO PINHAL

RUA CONDE DO PINHAL

RUA CONDE DO PINHAL

RUA CONDE DO PINHAL

RUA RAFAEL DE ABREU SAMP

RUA RAFAEL DE ABREU SAMP

RUA JESUINO DE ARRUDA

RUA JESUINO DE ARRUDA

RUA JESUINO DE ARRUDA

RUA SAO PAULO

RUA SAO PAULO

RUA CONDE DO PINHAL

RUA CONDE DO PINHAL

RUA DOM PEDRO II

RUA MAJ JOSE INACIO

RUA RUI BARBOSA

RUA RUI BARBOSA

RUA RUI BARBOSA

RUA JESUINO DE ARRUDA

RUA DOM PEDRO II

RUA DOM PEDRO II

RUA DOM PEDRO II

RUA DOM PEDRO II

RUA 7 DE SETEMBRO

RUA SAO JOAQUIM

RUA SAO JOAQUIM

RUA SAO JOAQUIM

RUA SAO JOAQUIM

RUA SAO JOAQUIM

AV COM ALFREDO MAFFEI

RUA DOM PEDRO II

RUA DOM PEDRO II

RUA 13 DE MAIO

RUA 13 DE MAIO

RUA 13 DE MAIO

RUA 13 DE MAIO

RUA ANTONIO RODRIGUES CA

RUA CONDE DO PINHAL

RUA CAMPOS SALLES

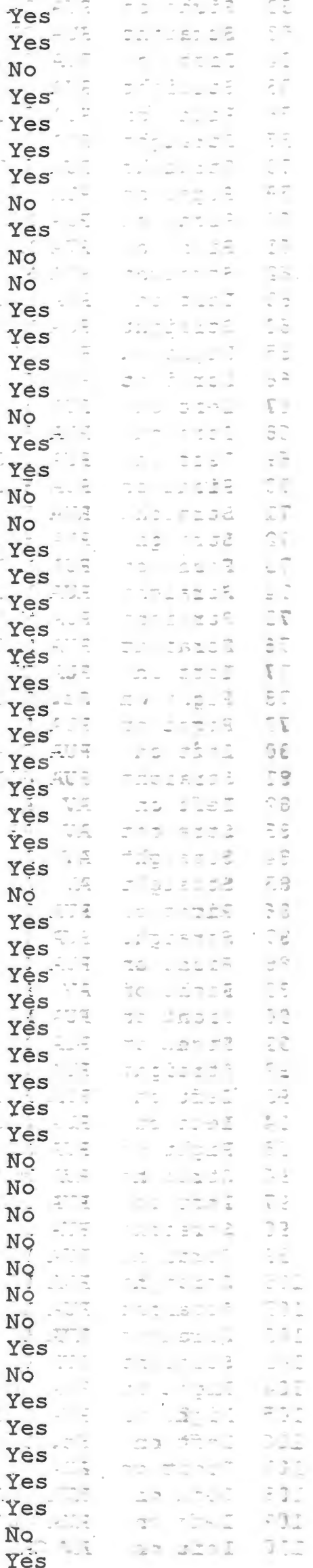


Straight straight Left on Straight Left on straight Right on straight Left on Straight Right on straight straight straight Left on Left on Straight Right on Straight Left on Left on straight Right on Right on Right on straight Straight Straight Left on straight Straight Left on straight straight Straight straight straight straight straight straight straight Left on straight Right on Right on straight straight Right on Right on Straight Left on straight Right on straight Left on Left on Straight Right on straight
RUA CAMPOS SALLES

RUA CAMPOS SALLES

RUA GEMINIANO COSTA

RUA GEMINIANO COSTA

RUA ANTONIO RODRIGUES CA RUA ANTONIO RODRIGUES CA RUA 13 DE MAIO RUA 13 DE MAIO RUA MARCOLINO LOPES BARR RUA MARCOLINO LOPES BARR RUA MAJ JOSE INACIO RUA MAJ JOSE INACIO RUA MAJ JOSE INACIO RUA MAJ JOSE INACIO RUA EUGENIO FRANCO DE CA RUA 7 DE SETEMBRO RUA 7 .DE SETEMBRO RUA TOTO LEITE RUA TOTO LEITE RUA PE TEIXEIRA RUA MAJ MANOEL ANTONIO D RUA MAJ MANOEL ANTONIO D RUA 7. DE SETEMBRO RUA MARCOLINO LOPES BARR RUA MAL DEODORO RUA MAL DEODORO RUA MAL DEODORO RUA MAL DEODORO RUA EUGENIO FRANCO DE CA RUA EUGENIO FRANCO DE CA RUA EUGENIO FRANCO DE CA RUA 15 DE NOVEMBRO RUA 15. DE NOVEMBRO RUA 15 DE NOVEMBRO RUA 15. DE NOVEMBRO RUA 15 DE NOVEMBRO RUA 15 DE NOVEMBRO RUA 15 DE NOVEMBRO RUA 15 DE NOVEMBRO RUA 15 DE NOVEMBRO RUA 15 DE NOVEMBRO RUA RUUI BARBOSA RUA RUI BARBOSA RUA PE TEIXEIRA RUA DOM PEDRO II RUA DOM PEDRO II RUA DOM PEDRO II AV DR CARLOS BOTELHO RUA RUI BARBOSA RUA RUII BARBOSA RUA SAAO SEBASTIAO RUA SAO SEBASTIAO RUA CAMPOS SALLES RUA CAMPOS SALLES RUA MAL DEODORO RUA ANTONIO RODRIGUES CA RUA ANTONIO RODRIGUES CA RUA SAO SEBASTIAO RUA SAO SEBASTIAO
Yes

Yes

Yes

Yes

Yes

Yes

Yes

Yes

Yes

Yes

Yes

Yes

No

No

Yes

Yes

No

Yes

Yes

Yes

Yes

Yes

Yes

Yes No

Yes

Yes

Yes

Yes

Yes

Yes No

Yes

No

No

Yes

Yes

Yes

Yes

Yes

Yes

Yes

Yes

Yes

Yes

Yes

Yes

No

Yes

No

Yes

Yes

Yes

Yes

Yes

Yes

Yes

Yes

Yes 
Right on Right on straight straight Straight Right on straight straight Right on Right on straight Straight Straight Left on Left on straight Straight Left on Left on Right on straight straight Straight Left on straight straight Left on Straight Right on Right on Right on Straight Straight Right on Right on straight Left on straight Left on straight Right on Left on Right on Left on Straight Straight Right on Straight Right on Straight Left on Right on Right on Left on Straight straight Straight Right on straight
RUA MARCOLINO LOPES BARR RUA PE TEIXEIRA

RUA PE TEIXEIRA.

RUA PE TEIXEIRA

RUA PE TEIXEIRA

RUA SAO PAULO

RUA SAO PAULO

RUA SAO PAULO

AV DR CARLOS BOTELHO

RUA CAMPOS SALLES

RUA CAMPOS SALIES

RUA CAMPOS SALLES

RUA CAMPOS SALLES

RUA SAO SEBASTIAO

RUA ANTONIO RODRIGUES CA RUA ANTONIO RODRIGUES CA RUA ANTONIO RODRIGUES CA RUA MACHADO ROLEMBERG RUA CAMPOS SALIES

RUA I5 DE NOVEMBRO

RUA 15 DE NOVEMBRO

RUA 15 DE NOVEMBRO

RUA 15 DE NOVEMBRO

RUA SAO JOAQUIM

RUA SAO JOAQUIM

RUA SAO JOAQUIM

RUA MAL DEODORO

RUA MAL DEODORO

RUA RUI BARBOSA

RUA 7 DE SETEMBRO

RUA DOM PEDRO II

RUA DOM PEDRO II

RUA DOM PEDRO II

RUA SAO SEBASTIAO

RUA RUI BARBOSA

RUA RUI BARBOSA

RUA MAL DEODORO

RUA MAL DEODORO

RUA CAMPOS SALLES

RUA CAMPOS SALLES

RUA SAO SEBASTIAO

RUA CAMPOS SALLES

RUA ROLANDO ROLEMBERG

RUA ANTONIO RODRIGUES CA

RUA ANTONIO RODRIGUES CA

RUA ANTONIO RODRIGUES CA

AV DR CARLOS BOTELHO

AV DR CARLOS BOTELHO

RUA RAFAEL DE ABREU SAMP

RUA RAFAEL DE ABREU SAMP

RUA SAO SEBASTIAO

RUA MARCOLINO LOPES BARR RUA PE TEIXEIRA

RUA RAFAEL DE ABREU SAMA RUA RAFAEL DE ABREU SAMP RUA RAFAEL DE ABREU SAMP RUA RAFAEL DE ABREU SAMP RUA CONDE DO PINHAL RUA CONDE DO PINHAL

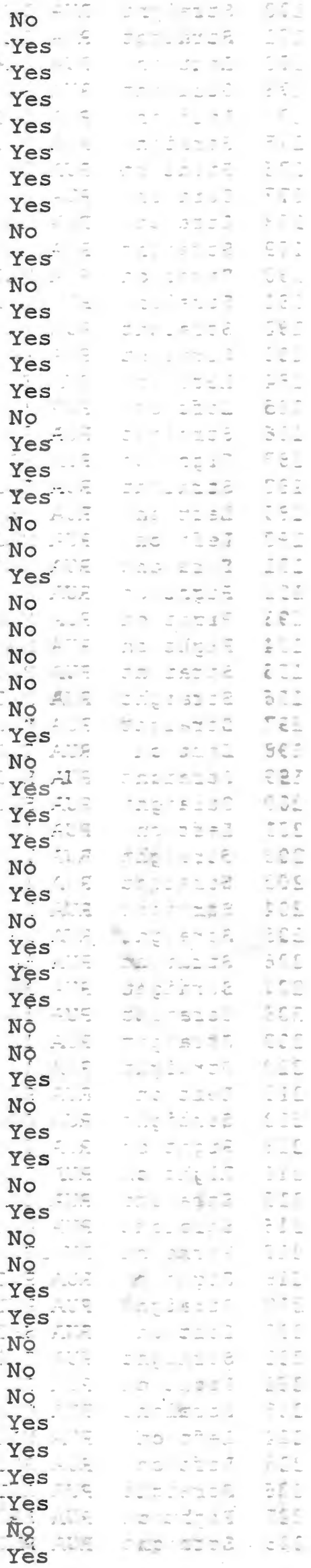

No

Yes

Yes

Yes

Yes

Yes

No

Yes

Yes

Yes

Yes

Yes

No

No

Yes

No

No

No

Yes

Yês

Yẹs

Yes

Nó

Yès

No

Yes

Yes

Yès

Nộ

No

Yes

No

Yes

Yes

No

No

Yes

No

No

Yes

Yes

Yes

Yés 


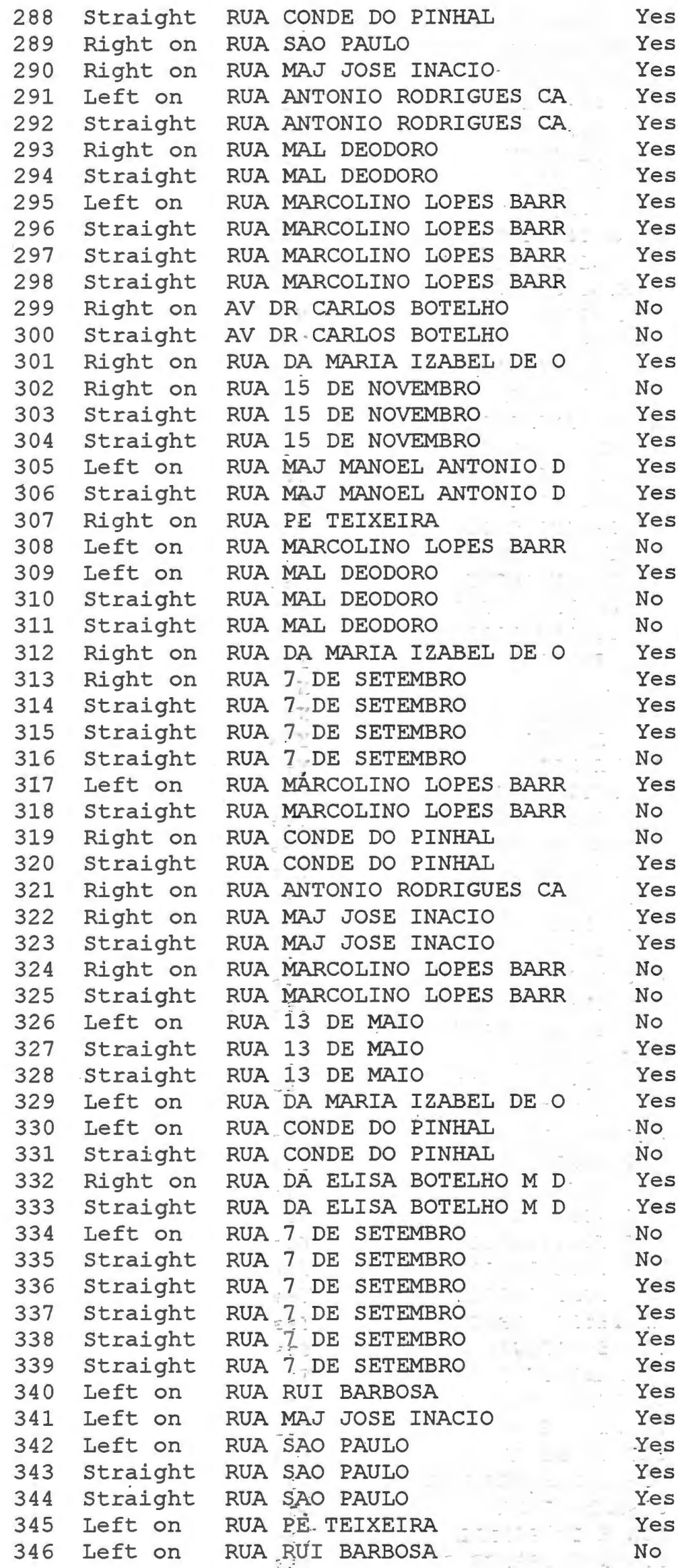




\begin{tabular}{|c|c|c|c|}
\hline 47 & ght & UA RUI BARBOSA & \\
\hline 48 & Right on & RUA 7-DE SETEMBRO & \\
\hline 19 & Straight & RUA 7 - DE SETEMBRO & \\
\hline 0 & Left on & RUA SAO JOAQUIM & \\
\hline 1 & straight & RUA SAO JOAQUIM & \\
\hline & Straight & RUA SAO JOAQUIM & \\
\hline 3 & straight & RUA SAO JOAQUIM & \\
\hline 4 & straight & RUA SAO JOAQUIM & \\
\hline 55 & Left on & AV COM ALFREDO MAFEEI & \\
\hline 6 & straight & RUA GEMINIANO COSTA - & \\
\hline 57 & ight & RUA GEMINIANO COSTA & \\
\hline 8 & Straight & RUA GEMINIANO COSTA & \\
\hline 9 & Left on & RUA SAO PAULO & \\
\hline 0 & Left on & RUA JESUINO DE ARRUDA & \\
\hline I & Left on & RUA RUI BARBOSA & \\
\hline 2 & Left on & RUA GEMINIANO COSTA & \\
\hline 63 & straight & RUA GEMINIANO COSTA & \\
\hline 24 & ight & RUA GEMINIANO COSTA & \\
\hline 55 & straight & RUA GEMINIANO COSTA & \\
\hline 56 & ight & RUA GEMINIANO COSTA & \\
\hline 67 & ght & RUA GEMINIANO COSTA & \\
\hline 58 & Straight & RUA GEMINIANO COSTA & \\
\hline 69 & Left on & RUA MARCOLINO LOPES BARR & \\
\hline 70 & Straight & RUA MARCOLINO LOPES BARR & \\
\hline 71 & Right on & RUA 13 DE MATIO & \\
\hline 72 & ight & RUA 13 DE MAIO & \\
\hline 73 & ght & RUA 13 DE MAIO & \\
\hline 4 & ight & RUA 13 DE MAIO & \\
\hline 15 & Lght & RUA 13 DE MAIO & \\
\hline 76 & Left on & RUAA EUGENIO FRANCO DE & \\
\hline 77 & Left on & RUA CONDE DO PINHAL & \\
\hline 78 & straight & RUA CONDE DO PINHAI & \\
\hline 79 & ight & RUA CONDE DO PINHAI & \\
\hline 80 & Left on & RUA TOTO LEITE & \\
\hline 31 & ight & RUA TOTO LEITE & \\
\hline 82 & $t$ on & RUA JESUINO DE ARRUDA & \\
\hline 83 & ight & RUA JESUINO DE ARRUDA & \\
\hline 84 & ight & RUA JESUINO DE ARRUDA & \\
\hline 85 & Left on & RUA RAFAEL DE ABREU SAMP & \\
\hline 86 & Left on & RUA GEMINIANO COSTA & \\
\hline 8 & straight & RUA GEMINIANO COSTA & \\
\hline 88 & Lef & RUA MAJ MANOEL ANTONIO D & \\
\hline 38 & ight & RUA MAJ MANOEL ANTONIO D & \\
\hline 390 & ght & RUA MAJ MANOEL ANTONIO D & \\
\hline 391 & ight & RUA MAJ MANOEL ANTONIO D & \\
\hline 392 & Right on & RUA MAJ JOSE INACIO & \\
\hline 393 & ght & RUA MAJ JOSE INACIO & \\
\hline 94 & ght & RUA MAJ JOSE INACIO & \\
\hline 395 & Straight & RUA MAJ JOSE INACIO & \\
\hline 396 & Right on & RUA MONTEIRO LOBATO & \\
\hline 397 & Left on & RUA JOSUE MARQUES MARTIN & \\
\hline 398 & Right on & RUA GERMANO FEHR & \\
\hline 99 & Left on & RUA CONDE DO PINHAL & \\
\hline 400 & Left on & RUA 13 DE MAIO & \\
\hline 401 & Left on & RUA FCO FERREIRA & \\
\hline 402 . & Left on & RUA JOSUE MARQUES MARTIN & \\
\hline 403 & Left on & RUA GERMANO FEHR & No \\
\hline 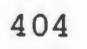 & Rigl & RUA CONDE DO PINHAI & \\
\hline & e & RUA EUGENIO FRANCO & \\
\hline
\end{tabular}

Yes

No

No

No

No

Yes

Yes

Yes

Yes

Yes

Yes

Yes

Yes

No

No

Yes

Yes

No

No

Yes

Yes

Yes

Yes

Yes

Yes

No

No

Yes

Yés

Yés

No

Yes

Yes

Yes

Yes

No

Yès

Yes

Yes

Yes

Yes

No

Yes

Yes

Yes

No

No

Ye's

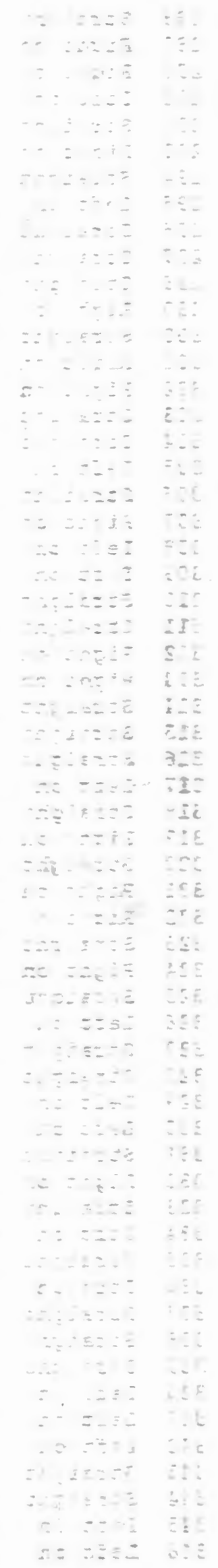


406

407

408

409

410

411

412

413

414

415

416

417

418

419

420

421

422

423

424

425

426

427

428

429

430

431

432

433

434

435

436

437

438

439

440

441

442

443

444

445

446

447

448

449

450

451

452

453

454

455

456

457

458

459

460

461

462

463

464
Left on Straight Left on Right on Right on Straight straight Left on Straight Left on Left on Left on Straight Right on Right on Left on Left on Left on Right on Straight Left on Straight Straight Straight Left on Straight Straight Left on straight Left on Left on Left on Straight Right on Left on Left on Right on Left on Left on Right on Straight Left on Left on Right on Right on Left on Straight Straight Left on Right on Straight Left on Right on Straight Straight Straight straight Right on Left on
RUA 13 DE MAIO

RUA 13 DE MAIO

RUA CONDE DO PINHAL

RUA GERMANO FEHR

RUA JOSUE MARQUES MARTIN

RUA JOSUE MARQUES MARTIN

RUA JOSUE MARQUES MARTIN

RUA ASTOR DIAS DE ANDRAD

RUA ASTOR DIAS DE ANDRAD

RUA 7 DE SETEMBRO

RUA ABEL GIONGO

RUA MAJ JOSE -INACIO

RUA MAJ JOSE -INACIO

RUA WAMBERTO DIAS DA COS

RUA JOSUE MARQUES MARTIN

RUA ASTOR DIAS DE ANDRAD

RUA 13 DE MAIO-

RUA WAMBERTO DIAS DA COS

RUA JOSUE MARQUES MARTIN

RUA JOSUE MARQUES MARTIN

RUA FREDERICO MANZINI

RUA FREDERICO MANZINI

RUA FREDERICO MANZINI

RUA FREDERICO MANZINI

RUA MAI DEODORO

RUA MAI DEODORO

RUA MAI DEODORO

RUA WAMBERTO DIAS DA COS

RUA WAMBERTO DIAS DA COS

RUA MÁJ JOSE INACIO-

RUA JOAQUIM EDUARDO CATA

RUA 7 DE SETEMBRO

RUA 7.DE SETEMBRO

RUA ASTOR DIAS DE ANDRAD

RUA MAL DEODORO

RUA ABEL GIONGO

RUA 7 DE SETEMBRO

RUA FCO FERREIRA

RUA MAJ JOSE INACIO

RUA ABEL GIONGO

RUA ABEL GIONGO

RUA 13 DE MAIO

RUA ASTOR DIAS DE ANDRAD

RUA JOSUE MARQUES MARTIN

RUA WAMBERTO DIAS DA COS

RUA 13 DE MAIO

St.ID 7762

St.ID 7763

RUA JOSE CERRI

RUA IRMA MARIA SAO FELIX

RUA IRMA MARIA SAO FELIX

RUA PASTOR CYRUS BASSET

St.ID 8624

St.ID 8625

St.ID 8608

St.ID .8615

St.ID 8607

RUA ELIAS MIGUEL MIRDAUI

RUA ELISA RODRIGUES
Yes

Yes

No

Yes

Yes

Yes

Yes

Yes

Yes

Yes

Yes

Yes

Yes

Yes

No

No

Yes

No

Yes

Yes

Yes

Yes

No

Yes

Yes

Yes

No

Yes

Yes

Yes

Yes

Yes

Yes

Yes

Yes

Yes

Yes

No

Yes

Yes

Yes

Yes

Yes

Yes

Yes

Yes

No

No

No

No

No

No

No

No

No

No

No

No

No 


$\begin{array}{ll}465 & \text { Right on } \\ 466 & \text { Straight } \\ 467 & \text { Straight } \\ 468 & \text { Straight } \\ 469 & \text { Straight } \\ 470 & \text { Straight } \\ 471 & \text { Straight } \\ 472 & \text { Straight } \\ 473 & \text { Straight } \\ 474 & \text { Straight } \\ 475 & \text { Straight } \\ 476 & \text { Left on }\end{array}$

RUA GERMANO FEHR JR

RUA GERMANO FEHR JR

RUA GERMANO FEHR 'JR

RUA GERMANO FEHR JR

RUA GERMANo FEHR JR

RUA GERMANO FEHR JR

RUA GERMANO FEHR JR

RUA GERMANO FEHR JR

RUA GERMANO"FEHR JR

RUA GERMANO FEHR JR

RUA GERMANO FEHR - JR

RUA JOAO JORGE MARMORATO
No

No

No

No

No

No

No

No

No

No

No

No

Itinerary Report

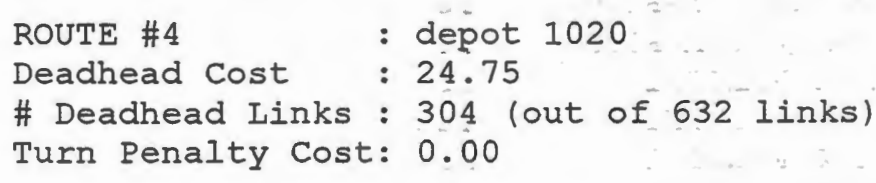

No. Movement Street_Name Service

1 Start on RUA EDUARDO DE CAMPOS MAIA

Left on AV VICENTE PELICANO

Straight AV VICENTE PELICANO

Right on

Straight

Straight

Straight

Right on

Left on

Straight

RUA ANTONIO ROSSETTI

RUA ANTONIO ROSSETTI

RUA ANTONIO ROSSETTI

RUA ANTONIO ROSSETTI

RUA FRANCISCO MONARETTI

RUA PROF PAULO MONTE SER

Straight

RUA PROF PAULO MONTE SER

Straight

RUA PROF PAULO MONTE SER

RUA PROF PAULO MONTE SER

Straight

RUA PROF PAULO MONTE SER

Straight

RUA PROF PAULO MONTE SER

Straight

RUA PROF PAULO MONTE SER

Straight

Straight

RUA PROF PAULO MONTE SER

RUA PROF . PAULO MONTE SER

Straight

RUA PROF PAULO MONTE SER

straight

RUA PROF PAULO MONTE SER

straight

RUA PROF PAULO MONTE SER

straight

RUA PROF PAULO MONTE SER

Straight

RUA PROF PAULO MONTE SER

Right on

Straight

RUA TOTO LEITE

RUA TOTO LEITE

Straight

RUA TOTO LEITE

Left on

RUA SILVERIO IGNARRA SOB

Right on

Left on

RUA MAJ MANOEL ANTONIO D

Straight

AV COM ALFREDO MAFFEI

Straight

St.ID 8590

straight

RUA MARCOLINO LOPES BARR

Straight

RUA MARCOLINO LOPES BARR

RUA MARCOLINO LOPES BARR

Straight

RUA MARCOLINO LOPES BARR NO

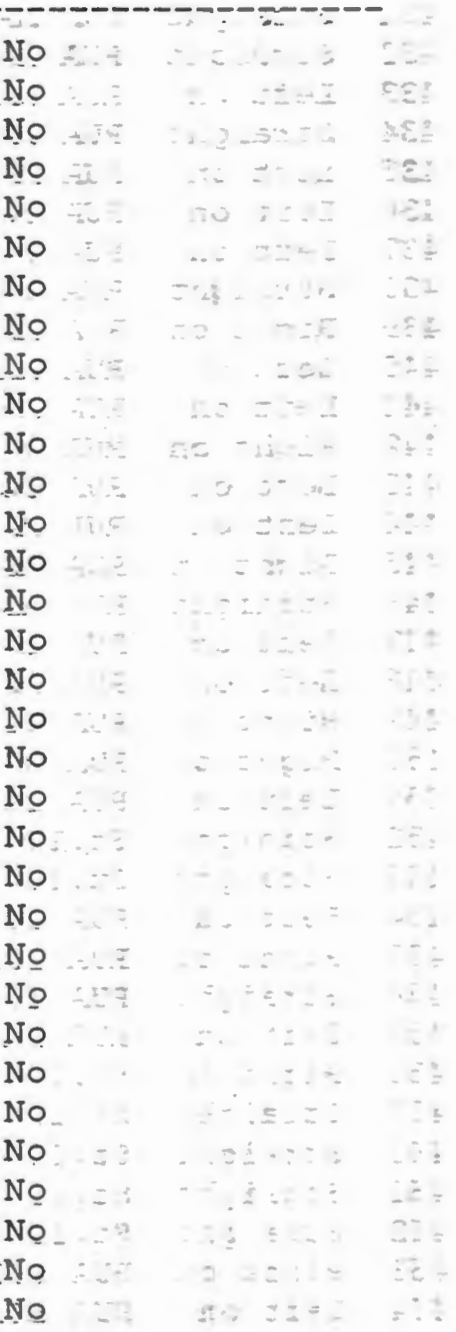


Straight straight straight straight straight straight straight Left on Right on Right on straight Left on straight Straight straight straight Right on Left on Left on Right on Left on straight straight Right on Right on straight Right on Right on Straight Right on Straight Right on Straight Left on Left on straight Straight Left on Left on Left on straight Right on straight straight straight Straight straight straight Straight straight Left on Left on Left on Straight Left on Left on Right on Straight straight
RUA. MARCOLINO LOPES BARR RUA MARCOLINO LOPES BARR RUA MARCOLINO LOPES BARR RUA MARCOLINO LOPES BARR RUA MARCOLINO LOPES BARR RUA MARCOLINO LOPES BARR RUA MARCOLINO LOPES BARR RUA 15 DE NOVEMBRO RUA RAFAEL DE ABREU SAMP AV DR CARLOS BOTELHO AV DR CARLOS BOTELHO RUA MIGUEL GIOMETTI RUA MIGUEL GIOMETTI RUA MARCOLINO- LOPES BARR RUA MARCOIINO LOPES BARR RUA MARCOLINO LOPES BARR RUA ALFREDO LOPES RUA MIGUEL GIOMETTI RUA ADOLPHO CATTANI RUA MARCOLINO LOPES BARR RUA FRITZ JOHASEN RUA FRITZ JOHASEN RUA FRITZ JOHASEN RUA WANDERLEI CAJUCY ACI RUA ANTONIO RODRIGUES CA RUA ANTONIO RODRIGUES CA RUA ADOLPHO CATTANI RUA WANDERLEI CAJUCY ACI RUA WANDERLEI CAJUCY ACI RUA ANTONIO RODRIGUES CA RUA ANTONIO-RODRIGUES CA RUA ADOLPHO CATTANI RUA ADOLPHO CATTANI RUA CAMPOS SALLES RUA ALFREDO LOPES RUA ALFREDO LOPES RUA ALFREDO LOPES RUA MARCOLINO LOPES BARR RUA ADOLPHO CATTANI RUA RAFAEL DE ABREU SAMP RUA RAFAEL DE ABREU SAMP RUA DR ORLANDO DAMIANO RUA DR ORIAANDO DAMIANO RUA DR ORLANDO DAMIANO RUA DR ORLANDO DAMIANO RUA DR -ORLANDO DAMIANO RUA DR: ORLANDO DAMIANO RUA DR ORLANDO DAMIANO RUA DR-ORLANDO DAMIANO RUA DR ORLANDO DAMIANO RUA EPISCOPAL RUA TIRADENTES AV SAO CARLOS AV SAO -CARLOS RUA ADOLPHO CATTANI RUA EPISCOPAI RUA DR CARLOS DE CAMARGO RUA DR CARLOS DE CAMARGO RUA DR CARLOS DE CAMARGO

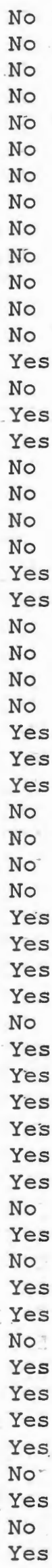


straight straight Straight Right on straight straight Right on straight straight straight Left on Left on Left on straight straight straight straight Right on Right on Right on Straight straight Right on Left on Right on Right on straight Straight straight Left on Right on Right on Straight Right on Straight straight Right on Straight Straight straight Straight Right on straight straight Right on Right on Left on straight Right on Right on Left on Right on straight Right on straight Right on Right on Left on Left on
RUa dR carlos de camargo

RUA DR CARLOS DE CAMARGO RUA DR CARLOS DE CAMARGo RUA DOS INCONFIDENTES

RUA DR CARLOS DE CAMARGO RUA DR CARLOS DE CAMARGO AV TRABALHADOR SAOCARLEN AV TRABALHADOR SAOCARLEN AV TRABALHADOR SAOCARLEN AV TRABALHADOR SAOCARLEN AV DAS AZALEIAS AV TRABALHADOR SAOCARLEN RUA LUIZ VAL TOLEDO PIZZ RUA LUIZ VAL TOLEDO PIZZ RUA LUIZ VAL TOLEDO PIZZ RUA LUIZ VAZ TOLEDO PIZZ St.ID 8632

RUA DR CARLOS DE CAMARGO RUA DOS INCONFIDENTES

RUA CEZAR RICOME

RUA CEZAR RICOME RUA CEZAR RICOME St.ID : 6230

RUA CEZAR RICOME

RUA EPISCOPAL

RUA JACINTO FAVORETTO

RUA JACINTO FAVORETTO

RUA JACINTHO FAVORETO

St.ID 8631

Śt.ID 8632

RUA DR CARLOS DE CAMARGO

RUA DOS INCONFIDENTES

RUA DR CARLOS DE CAMARGO

RUa salomao dibBo

RUA SALOMAO DIBBo

AV TRABALHADOR SAOCARLEN

RUA NOVE DE JULHO

St.ID 6230

RUA NOVE DE JULHO

RUA NOVE DE JULHO

RUA NOVE DE JULHO

RUA DR CARLOS DE CAMARGO

RUA ACHILE BASSI

RUA ACHILE BASSI"

RUA CEZAR RICOME

St.ID 6230

RUA CEZAR RICOME

RUA CEZAR RICOME

AV SAO CARLOS

RUA JACINTO FAVORETTO

RUA EPISCOPAI

RUA ADOLPHO CATTANI

RUA ADOLFO CATANI

RUA ACHILE BASSI

RUA ACHILE BASSI

RUA CEZAR RICOME

St. ID $=6230$

RUA CEZAR RICOME

RUA EPISCOPAL
Yes

Yes

No

No

Yes

Yes

Yes

Yes

No

Yes

No

Yes

Yes

Yes

Yes

Yes

No

Yés

Yes

Yes

Yes

No

No

No

No

Yes

Yes

Yes

No

No

No

No

No

Yes

Yes

Yes

Yes

No

Yes

Yes

Yés

Yés

No

Yes

Yes

No

Yes

Yes

Yés

Yes

Nö.-

Yes

Yes

Yes

No

No

No

No

Yes

s




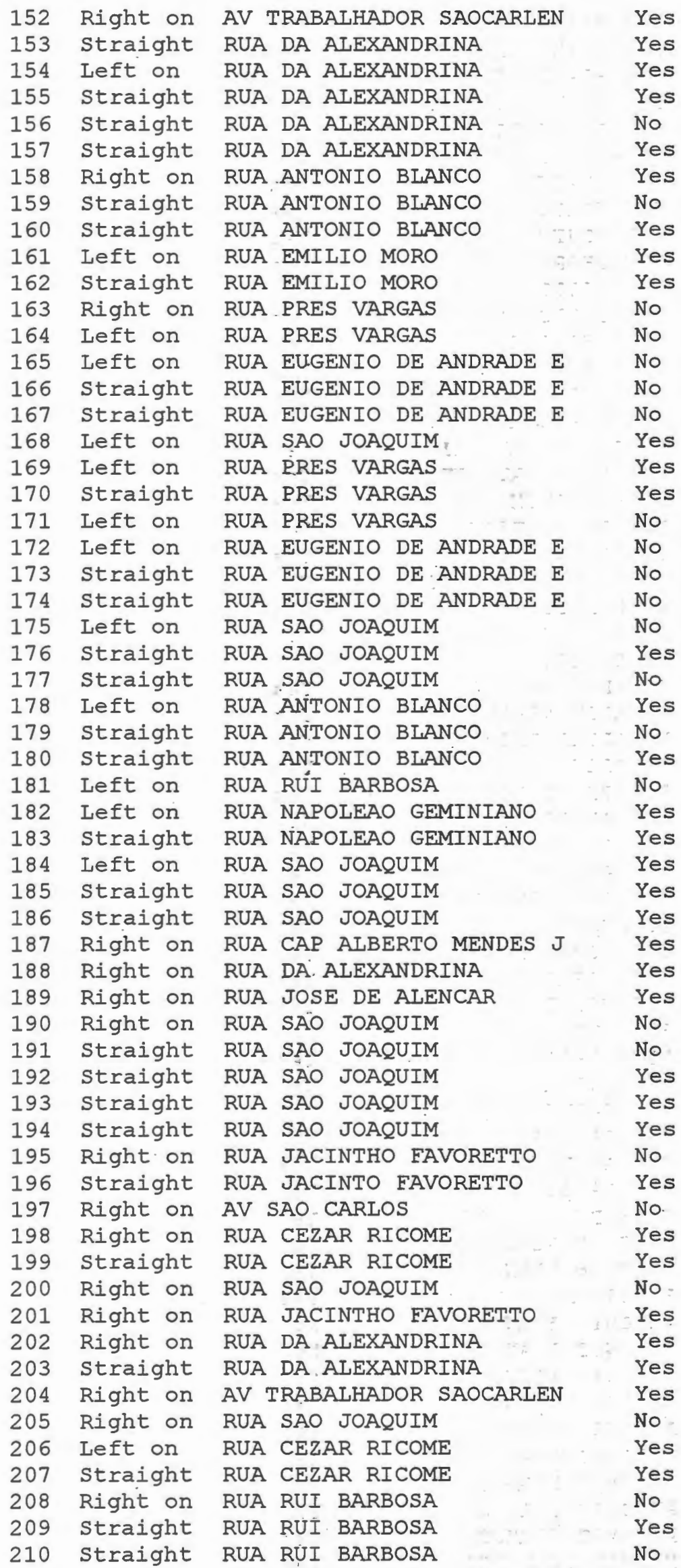


211 Straight

212 Right on

213 straight

214 Straight.

215 Right on

216 Right on

217 Right on

218 straight

219 Left on

220 Left on

221 Straight

222 straight

223 Straight

224 straight

225 Right on

226 Right on

227 Right on

228 straight

229 Left on

230 Right on

231 Right on

232 Left on

233 Left on

234 straight

235 straight

236 Left on

237 Left on

straight

straight

Left on

241 Left on

straight

straight

244 Right on

245 Right on

246 Straight

247 Straight

248 Straight

249 straight

250 straight

251 Straight

252 straight

253 straight

254 Right on

255 Left on

256 Right on

257 straight

258 straight

259 Left on

260 Right on

261 straight

262 straight

263 straight

264 straight

265 straight

266 straight

267 straight

268 straight

269 Left on

RUA RUI BARBOSA

RUA DR ORLANDO DAMIANO

RUA DR ORLANDO DAMIANO

RUA DR ORIANDO DAMIANO

RUA DA ALEXANDRINA

RUA ALFREDO LOPES

RUA SAO JOAQUIM

RUA SAO JOAQUIM

RUA FCO COUTO

RUA DOM PEDRO II

RUA DOM PEDRO II

RUA DOM PEDRO II

RUA DOM PEDRO II

RUA DOM PEDRO II

RUA CEZAR RICOME

RUA RUI BARBOSA:

RUA JACINTHO FAVORETTO

RUA JACINTHO FAVORETTO

RUA SAO JOAOUIM

RUA ADOLPHO CATTANI

RUA DA ALEXANDRINA

RUA JACINTO FAVORETTO

AV SAO CARLOS

AV SAO CARLOS

AV SAO CARLOS

RUA TIRADENTES

RUA DA ALEXANDRINA

RUA DA ALEXANDRINA

RUA DA ALEXANDRINA

ŔUA ADOLPHO CATTANI

AV SAO CARLOS

AV SAO CARLOS

AV SAO CARLOS

RUA 28 DE SETEMBRO

RUA EPISCOPAI

RUA EPISCOPAI

RUA EPISCOPAI

RUA EPISCOPAI

RUA EPISCOPAI

RUA EPISCOPAL

RUA EPISCOPAL

AV DAS AZALEIAS

AV DAS AZALEIAS

RUA CAP ALBERTO MENDES J

AV SAO CARLOS

RUA JOSE DE ALENCAR

RUA JOSE DE ALENCAR

RUA JOSE DE ALENCAR

RUA EMILIO MORO

RUA ANTONIO BLANCO

RUA ANTONIO BLANCO

RUA ANTTONIO BLANCO

RUA ANTONIO BLANCO

RUA ANTONIO BLANCO

RUA ANTONIO BLANCO

RUA ANTONIO BLANCO

RUA ANTONIO BLANCO

RUA ANTONIO BLANCO

RUA MIGUEL GIOMETTI

Nó

Yes

No

Yes

No

Yes

Yes

Yes

Yes

Yes

Yes

Yes

Yes

Yes

No

No

Yes

Yes

Yes

Yes

Yes

No.

Yes

Nó

No

Yes

Yes

Yes

Yes

Yes

No

No

Yes

Yes

Yes

Yes

Yes

Yes

Yes

Yes

No

No

No

Yes

Yes

Yes

No:

Yes

Yès

Nö.

Nŏ

No

Yes

Yes

Yes

Ye's

Yëș

Yes

Yès 
270 straight

271 Straight

27.2 Left on

273 straight

274 straight

275 Straight

276 straight

277 Right on

278 Right on

279 Straight

280 Straight

281 Right on

282 Right on

283 Straight

284 Straight

285 straight

286 Straight

287 Right on

288 Right on

289 Left on

290 Right on

291 Right on

292 Left on

293 Right on

294 Right on

295 straight

296 Straight

297 Left on

298 Left on

299 Straight

300 straight

301 Left on

302 Left on

303 straight

304 straight

305 straight

306 straight

307 Right on

308 straight

309 Left on

310 Left on

311 Straight

312

313
RUA MIGUEL GIOMETTI

RUA MIGUEL GIOMETTI

RUA COSTA DO SOL

RUA COSTA DO SOL

RUA COSTA DO SOL

RUA COSTA DO SOL

RUA COSTA DO SOL

RUA CAMPOS SALLES

RUA PROF MOZART SANTOS M

RUA PROF MOZART SANTOS $M$.

RUA PROF MOZART SANTOS $M$

RUA MIGUEL GIOMETTI

RUA COSTA DO SOL

RUA COSTA DO SOL

RUA COSTA DO SOL

RUA COSTA DO SÖL

RUA COSTA DO SOL

RUA CAMPOS SALLES

RUA PROE MOZART SANTÓS M

RUA JOAO B DE ARRUDA

RUA LUIZ M RODRIGUES

RUA ANTONIO NARVAES

RUA PROF MOZART SANTOS M

RUA MIGUEL GIOMETTI

RUA COSTA DO SOL

RUA COSTA DO SOL

RUA "COSTA DO SOL

RUA ANTONIO RODRIGUES CA

RUA PRES VARGAS

RUA PRES VARGAS

RUA PRES VARGAS

RUA MIGUEL GIOMETTI

RUA COSTA DO SOL

RUA COSTA DO SOL

RUA COSTA DO SOL

RUA COSTA DO SOL

RUA COSTA DO SOL

RUA CAMPOS SALLES

RUA CAMPOS SALLES

RUA LUIZ M RODRIGUES

RUA SAOO PAULO

RUA SAO PAULO

RUA COSTA DO SOL

RUA LUIZ M RODRIGUES

RUA PRES VARGAS

RUA PRES VARGAS

RUA PRES VARGAS

RUA CAMPOS SALLES

RUA PRES VARGAS

RUA ANTONIO RODRIGUES CA

RUA ESTADOS UNIDOS

RUA ESTADOS UNIDOS

RUA ESTADOS UNIDOS

RUA ESTADOS UNIDOS

RUA RUI BARBOSA

RUA ANTONIO BLANCO

RUA RUI BARBOSA

RUA JOSE DE ALENCAR

RUA JOSE DE ALENCAR
Yes

No

No

Yes

Yes

No

Yes

No

Yes

Yes

Yes

Yes

No

No

No

No

No

Yes

No

Yes

No

No

No

No

No

No.

No.

Yes

Yes

Yes

Yes

Yes

Yes

No

No.

No.

No.

No.

Yes

No

No

No

Yes

No

Yes

Yes

Yes

Yes

Yes

Yes

Yes

Yes

Yes

Yes

Yes

Yes

Yes

No

No

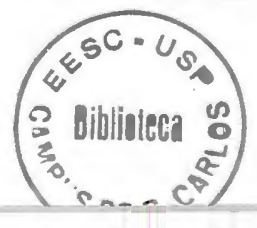


Straight Right on Left on Left on straight Left on Left on straight straight Left on straight Left on straight Left on Right on straight Left on straight Left on straight straight straight straight Left on Right on straight straight straight Right on Straight Left on straight straight Straight Right on straight straight straight Right on Right on Right on Straight Left on straight straight straight Left on Left on straight straight Straight Right on Right on straight straight straight Left on Left on Left on
RUA JOSE DE ALENCAR RUA ANTONIO RODRIGUES CA RUA JOSE DE ALENCAR RUA RAFAEL DE ABREU SAMP RUA RAFAEI DE ABREU SAMP RUA ESTADOS UNIDOS RUA ANTONIO RODRIGUES CA RUA ANTONIO RODRIGUES CA RUA ANTONIO RODRIGUES CA RUA JOSE DE ALENCAR RUA JOSE DE ALENCAR RUA MARCOLINO LOPES BARR RUA MARCOLINO LOPES BARR RUA ESTADOS UNIDOS RUA RAFAEL DE ABREU SAMP RUA RAFAEL DE ABREU SAMP RUA COSTA DO SOL RUA COSTA DO SOL RUA CAMPOS SALLES RUA CAMPOS SALLES RUA CAMPOS SALLES RUA CAMPOS SALLES RUA CAMPOS SALLES RUA JOSE DE ALENCAR RUA ANTONIO RODRIGUES CA RUA ANTONIO RODRIGUES CA RUA ANTONIO RODRIGUES CA RUA ANTONIO RODRIGUES CCA RUA ADOLPHO CATTANI RUA ADOLPHO CATTANI RUA CAMPOS SALLES RUA CAMPOS SALLES RUA CAMPOS SALLES RUA CAMPOS SALLES RUA 28 DE SETEMBRO RUA 28 DE SETEMBRO RUA 28 DE SETEMBRO RUA 28 DE SETEMBRO RUA DOM PEDRO II RUA TIRADENTES RUA RUI BARBOSA RUA RUI BARBOSA AV DR CARLOS BOTELHO AV DR CARLOS BOTELHO AV DR CARLOS BOTELHO AV DR CARLOS BOTELHO RUA MARIA ESTELA GIANNOT RUA 28 DE SETEMBRO RUA 28 DE SETEMBRO RUA 28-DE SETEMBRO RUA 28 DE SETEMBRO RUA FLAVIO WELLICHAN RUA TIRADENTES RUA TIRADENTES RUA TIRADENTES RUA TIRADENTES RUA MARCOLINO LOPES BARR RUA DR ORLANDO DAMIANO RUA RAFAEL DE ABREU SAMP
No

No

No

Yes

Yes

Yes

Yes

Yes

Yés

Yes

Yes

Yes

Yes

Yes

Yes

Yes

No

No

Yes No

Yes

Yes

Yes

Yes

No

Yes

No

Yes

Yes

Yes

Yes

Yes

Yes

Yes

No

No

No

Yes

Yes

Yes

No

No

No

No

No

No

Yes

No-

No

Yés

Nó:

Yes

Yes

No

No

No

No

Yes

Yes

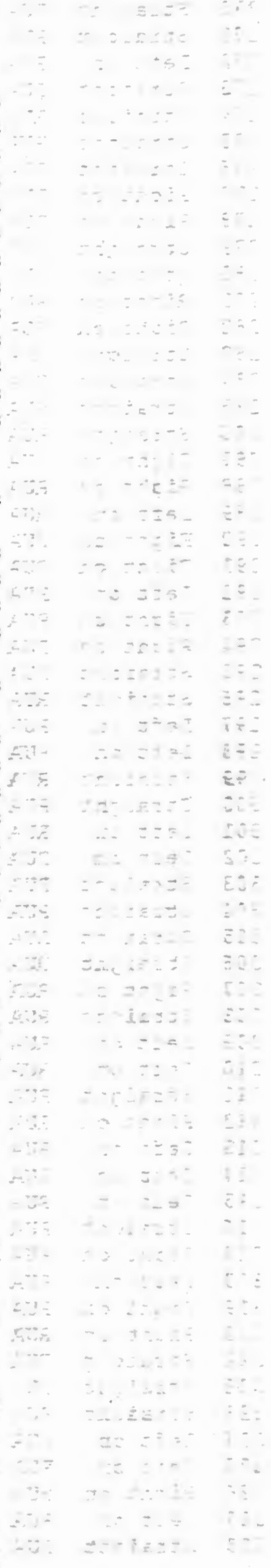




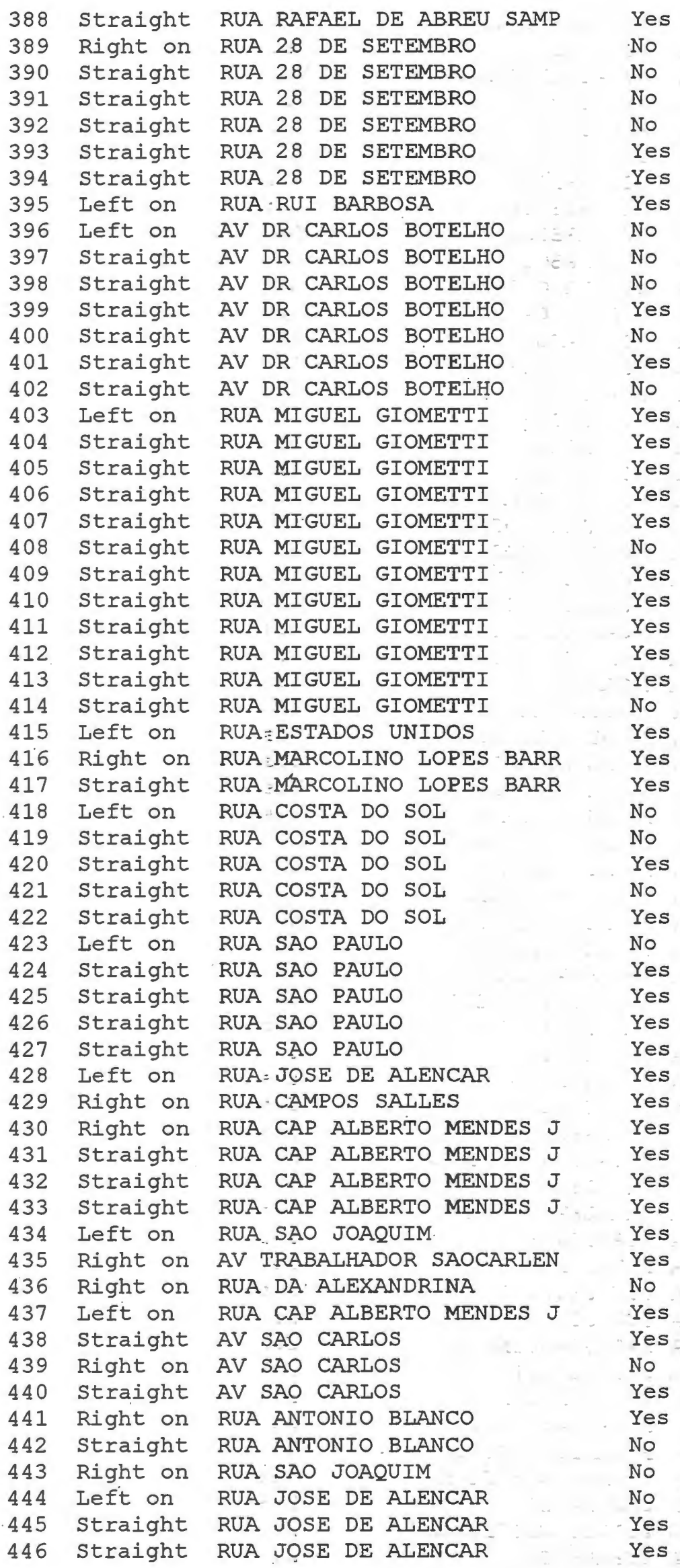


Straight

Right on Right on straight Right on Right on Right on Straight Straight straight Right on straight Left on Left on Straight Right on Straight straight Straight Left on Straight straight Straight Straight straight straight Left on Left on straight Straight straight Straight Straight straight Straight straight Left on Left on Left on Left on Straight Straight Left on Left on Left on Straight Right on Straight Left on Left on Left on Straight Straight Left on Straight Straight Left on Straight Right on
RUA JOSE DE ALENCAR

RUA SAO PAULO

RUA CAP ALBERTO MENDES J

RUA CAP ALBERTO MENDES J

RUA EMILIO MORO

RUA JOSE DE ALENCAR

RUA RUI BARBOSA

RUA RUI BARBOSA

RUA RUI BARBOSA

RUA RUंI BARBOSA

RUA ADOLPHO CATTANI

RUA ADOLPHO CATTANI

RUA SAO JOAQUIM

RUA ALFREDO LOPES

RUA ALFREDO LOPES

RUA RUI BARBOSA

RUA RUI BARBOSA

RUA RUI BARBOSA

RUA RUI BARBOSA

AV DR CARLOS BOTELHO

AV DR CARLOS BOTELHO

AV DR-CARLOS BOTELHO

AV DR CARLOS BOTELHO

AV DR CARLOS BOTELHO

AV DR CARLOS BOTELHO

AV DR-CARLOS BOTELHO

RUA MIGUEL GIOMETTI

RUA 28 DE SETEMBRO

RUA 28 DE SETEMBRO

RUA 28 DE SETEMBRO

RUA 28 DE SETEMBRO

RUA 28 DE SETEMBRO

RUA 28 DE SETEMBRO

RUA 28 DE SETEMBRO

RUA 28 DE SETEMBRO

RUA 28 DE SETEMBRO

RUA SAO JOAQUIM

AV DR CARLOS BOTELHO

RUA DOM PEDRO II

RUA 28 DE SETEMBRO

RUA 28 DE SETEMBRO

RUA 28 DE SETEMBRO

AV SAO CARLOS

AV DR CARLOS BOTELHO

RUA DA ALEXANDRINA

RUA DA ALEXANDRINA

RUA TIRADENTES

RUA TIRADENTES

RUA DOM PEDRO II

RUA FCO COUTO

RUA SAO JOAQUIM

RUA SAO JOAQUIM

RUA SAO JOAQUIM

AV DR CARLOS BOTELHO

AV DR-CARLOS BOTELHO

AV DR CARLOS BOTELHO

RUA SAO PAULO

RUA FLAVIO WELIICHAN

RUA TIRADENTES
Yes

Yes

$\mathrm{NO}$

No

Yes

No.

Yes

Yes

Yes

No.

Yes

Yes.

Yes.

Yes

Yes

Yes

No

$\mathrm{Na}$

$\mathrm{Na}$

No

No.

No

No

Yes.

No

Yès.

No

Yes

Yés.

Yes

Yes

No

No

No

No

No

No

No

Y̌es

Yes

Yes

Yes

Yes

No

Yes

Yes

Yes

Yes

Y̌es

No

Yes

Yês

Yes

No

Yes

Yes

Yes

No

No 


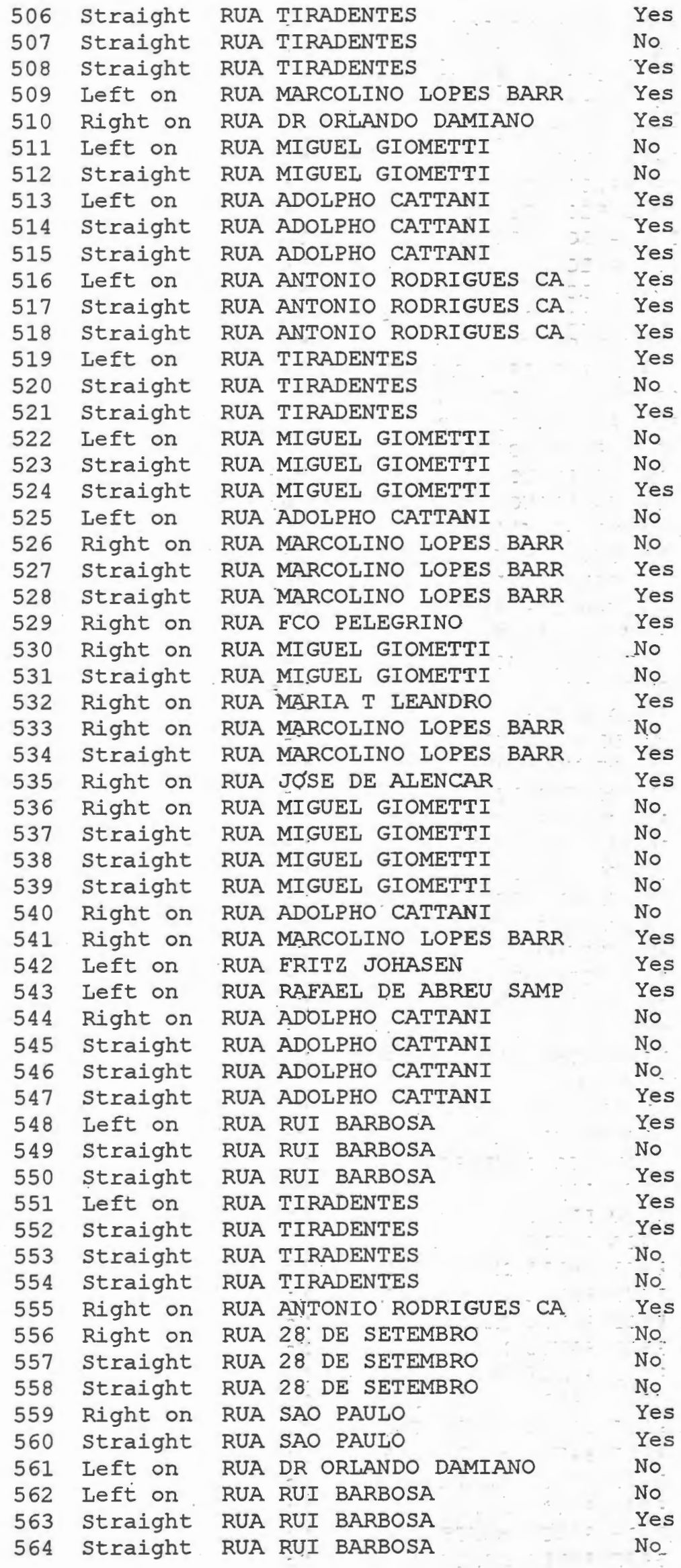




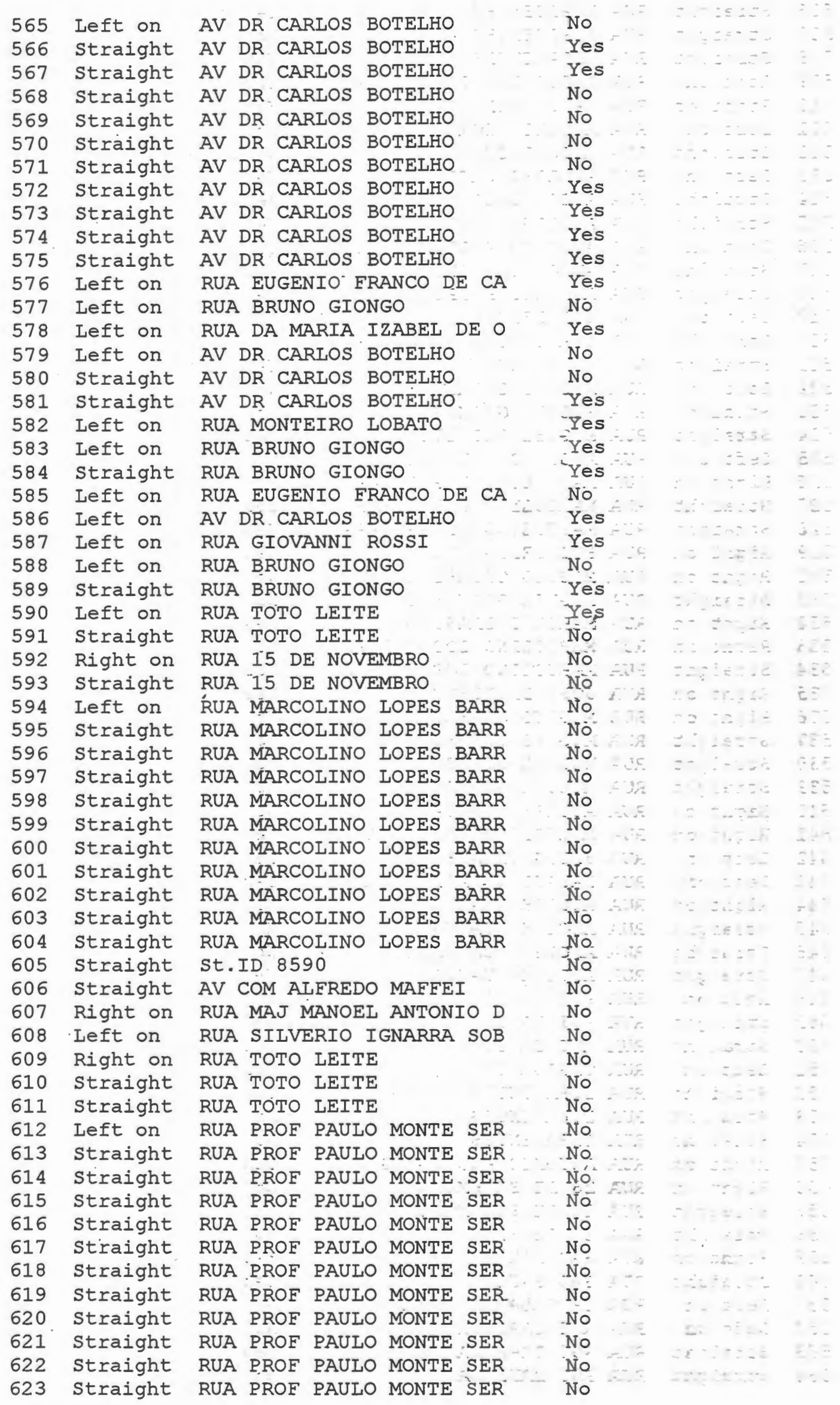




$\begin{array}{llll}624 & \text { Straight } & \text { RUA ANTONIO ROSSETTI } & \text { No } \\ 625 & \text { Straight } & \text { RUA ANTONIO ROSSETTI } & \text { No } \\ 626 & \text { Straight } & \text { RUA ANTONIO ROSSETTI } & \text { No } \\ 627 & \text { Straight } & \text { RUA ANTONIO ROSSETTI } & \text { No } \\ 628 & \text { Straight } & \text { RUA ANTONIO ROSSETTI } & \text { No } \\ 629 & \text { Straight } & \text { RUA ANTONIO ROSSETTI } & \text { NO } \\ 630 & \text { Left on } & \text { AV VICENTE PELICANO } & \text { No } \\ 631 & \text { Right on RUA GERMANO FEHR JR } & \text { NO } \\ 632 & \text { Left on } & \text { RUA JOAO JORGE MARMORATO }\end{array}$

Itinerary Report

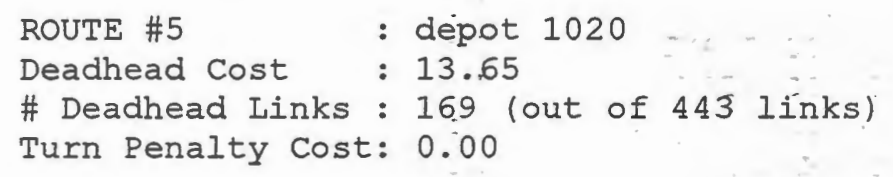

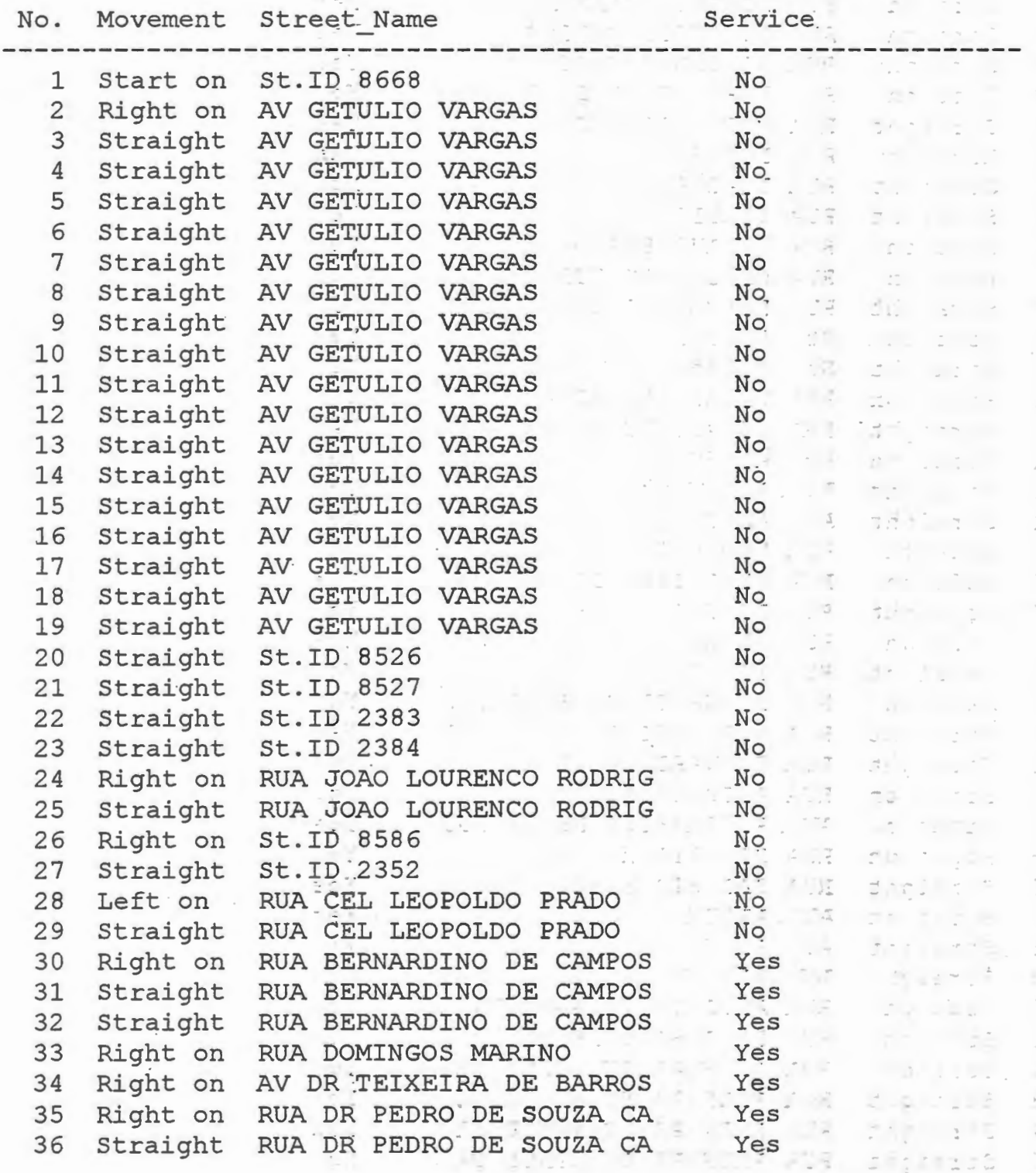


Right on straight Left on straight straight straight straight straight Right on straight Left on Left on Left on Straight Right on Left on Right on straight straight Left on straight straight straight Left on straight Right on Straight straight Left on Left on straight Left on straight Right on straight Right on straight straight Left on Left on straight Left on Straight Left on straight straight Right on Right on Right on straight Right on straight straight Left on Left on Left on straight straight straight
AV SALLUM

AV SALLUM

RUA CIDADE DE MILAO

RUA CIDADE DE MILAO

RUA CIDADE DE MILAO

RUA CIDADE DE MILAO

RUA CIDADE DE MILAO

RUA THEODURETO DE CAMARG

RUA FRANCISCO FIORENTINO

RUA FRANCISCO FIORENTINO

RUA JERONOMO TERRA

RUA LUIZ CARLOS DE ARRUD

RUA DESEMBARGADOR JULIO

RUA DESEMBARGADOR JULIO

RUA PEDRO JOSE NETTO

RUA ITALIA

RUA BENJAMIN CONSTANT

RUA BENJAMIN CONSTANT

RUA BENJAMIN CONSTANT

RUA DOMINGOS MARINO

RUA DOMINGOS MARINO

RUA DOMINGOS MARINO

RUA DOMINGOS MARINO

RUA BERNARDINO DE CAMPOS

RUA BERNARDINO DE CAMPOS

RUA ITALIA

RUA ITALIA

RUA ITALIA

RUA DA ANA PRADO

RUA DESEMBARGADOR JULIO

RUA DESEMBARGADOR JULIO

St.ID 8852

St.ID 8856

RUA CIDADE DE MILAO

RUA CIDADE DE MILAO

AV SALLUM

AV SALLUM

AV SALLUM

RUA SAO PIO X

RUA DR GASTAO DE SA

RUA DR GASTAO DE SA

RUA ITALIA

RUA ITALIA

RUA BERNARDINO DE CAMPOS

RUA BERNARDINO DE CAMPOS

RUA BERNARDINO DE CAMPOS

RUA ANTONIO BOTELHO

AV DR TEIXEIRA DE BARROS

RUA SAO PIO $X$

RUA SȦO PIO $X$

AV SALLUM

AV SALLUM

AV SALLUM

RUA ANTONIO DE ALMEIDÁ I

RUA DR GASTAO DE SA

RUA ANANIAS EVANGELISTA

RUA ANANIAS EVANGELISTA

RUA ANANIAS EVANGELISTA

RUA ANANIAS EVANGELISTA
Yes

Yes

Yes

Yes

Yes

Yes

Yes

No.

Yes

Yes

Yes

Yes

No

No

Yes

Yes

No

Yes

No

No

Yes

Yes

Yés

Yes

Yes

Yess

Nọ

Yès

No

Yés

Nô.

Yes

Yes

Yes

Yes

Yes

Yes

Yes

Yes

Yes

Yes

Yés

Yes

Yes

Yes

Yés

Yès

Yés

Yès

Yés

Yěs

Yes

Yes

Yés

Yes

Yes

Yes

Yes

No 


\begin{tabular}{|c|c|c|c|}
\hline 36 & Left & AV DR TEIXEIRA DE & \\
\hline 97 & Right on & RUA-ANTONIIO DE ALMEIDA & No \\
\hline 98 & Right on & RUA DA ANA PRADO & \\
\hline 99 & Straight & RUA DA ANA PRADO & \\
\hline 100 & straight & RUA DA ANA PRADO & \\
\hline 01 & Right on & RUA SAO PIO $\mathrm{X}$ & \\
\hline 02 & Right on & AV DR TEIXEIRA DE BARROS & \\
\hline & straight & AV DR TEIXEIRA DE BARROS & \\
\hline 04 & Right on & RUA ANANIAS EVANGELISTA & $=$ \\
\hline 05 & straight & RUA ANANIAS EVANGELISTA & \\
\hline 06 & Left on & RUA CINCINATO BRAGA & $\because$ \\
\hline 07 & Left on & RUA ANTONIO DE ALMEIDA I & 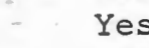 \\
\hline 8 & Right on & RUA ROBERTO SIMONSEN & \\
\hline 9 & Right on & St.ID 3399 & \\
\hline 10 & Right on & RUA MARCOLINO PELICANO & \\
\hline 11 & Right on & RUA ANTONIO DE AIMEIDA I & \\
\hline 12 & straight & RUA ANTONIO DE ALMEIDA I & \\
\hline 13 & straight & RUA ANTONIO DE ALMEIDA I & \\
\hline 14 & Right on & RUA DA ANA PRADO & \\
\hline 15 & Left on & RUA JOSE BENETTI & \\
\hline 116 & Right on & AV DR TEIXEIRA DE BARROS & \\
\hline 1 & Right on & RUA CANDIDO PADIM & \\
\hline & straight & RUA CANDIDO PADIM & \\
\hline 19 & straight & RUA CANDIDO PADIM & \\
\hline 20 & Right on & RUA MARCOLINO PELICÁNO & \\
\hline 21 & Right on & st.ID.3399 & \\
\hline 22 & Right on & RUA ROBERTO SIMONSEN & \\
\hline 123 & straight & St.ID 8301 & \\
\hline 124 & Left on & RUA 24 DE MAIO & \\
\hline 125 & Left on & RUA GAL OSORIO & \\
\hline 26 & straight & RUA GAI OSORIO & \\
\hline 127 & straight & AV DR JOSE PEREIRA LOPES & $\mathrm{N}$ \\
\hline 28 & Left on & RUA DR DUARTE NUNES & \\
\hline 129 & Left on & RUA DA ANA PRADO & \\
\hline 130 & Left on & RUA CANDIDO PADIM & $\mathrm{N}$ \\
\hline 131 & Left on & St.ID 8301 & \\
\hline 132 & Left on & RUA 24 DE MAIO & \\
\hline 133 & Left on & RUA GAI OSORIO & \\
\hline 134 & Straight & RUA GAI OSORIO & \\
\hline 135 & Straight & AV DR JOSE PEREIRA LOPES & \\
\hline 136 & Lef & RUA DR DUARTE NUNES & $\mathrm{N}$ \\
\hline 137 & straight & RUA DR DUARTE NUNES & \\
\hline 138 & ight & RUA DR DUARTE NUNES & \\
\hline 139 & straight & RUA DR DUARTE NUNES & Y \\
\hline 140 & Right on & RUA ALFA & $\mathrm{N}$ \\
\hline 141 & Right on & St.ID 3733 & No \\
\hline 142 & Left on & RUA ALFA & No \\
\hline 143 & Right on & AV DR JOSE PEREIRA LOPES & . \\
\hline 144 & Lef & RUA THOMAZ EDSON & No \\
\hline 145 & Right on & RUA. FIORIANO PEIXOTO & NC \\
\hline 146 & Right on & RUA JOAO RIBEIRO DE BARR & $\mathrm{N}$ \\
\hline 147 & Right on & AV DR JOSE PEREIRA LOPES & \\
\hline 14 & straight & St.ID 4095 & . \\
\hline 149 & Straight & AV DR JOSE PEREIRA LOPES & \\
\hline 150 & straight & AV DR JOSE PEREIRA LOPES & \\
\hline 151 & straight & AV DR JOSE PEREIRA LOPES & $Y \in$ \\
\hline 5 & Left on & RUA DR GASTAO DE SA & $Y$ \\
\hline 15 & Left on & RUA DR CASTRO NERI & $\dot{Y}$ \\
\hline 154 & Left on & AV SALLUM & \\
\hline
\end{tabular}

Yes

No

Yes

Yes

Yes

Yes

Yes

Yes

Yes

Yes

Yes

Yes

Yes

No

Yes

Yes

Yes

Yes

Yes

Yes

es

Yes

Yes.

No

Yes

No

No

No

Yes

Yes

Yes

No

Yes

Yes

No

No

No

Yes

No

No

No

No

No

No

Yes

Yes

Yes

Yes

Yes.

Yes

Yes

Yes 
155
Right on Right on Right on Left on Right on Left on straight Straight Left on Right on straight Left on straight Left on Straight Left on Right on Right on Left on Left on Right on Left on Left on Straight Straight Right on Right on Straight straight Left on Right on straight Left on Left on Right on Straight Left on Left on Left on Left on Straight straight Straight Left on Straight Straight Straight Left on Left on Straight Straight Right on straight Right on Right on Straight Straight Right on Right on
AV DR JOSE PEREIRA LOPES RUA ALFA

St.ID 3733

RUA ALFA

RUA DR DUARTE NUNES

St.ID 3829

RUA BERNARDINO DE CAMPOS RUA BERNARDINO DE CAMPOS RUA ANTONIIO DE ALMEIDA. AV DR TEIXEIRA DE B BARROS AV DR TEIXEIRA DE BARROS RUA ANTONIO BOTELHO RUA ANTONIO BOTELHO RUA DA ANA PRADO

RUA DA ANA PRADO RUA ANTONIIO DE ALMEIDA AV DR TEIXEIRA DE BARROS RUA JOSE BENETTI RUA DA ANA PRADO RUA CANDIDO PADIM AV DR TEIXEIRA DE BARROS RUA DR DUARTE NUNES AV DR TEIXEIRA DE BARROS AV DR TEIXEIRA DE BARROS AV DR TEIXEIRA DE BARROS RUA ANTONIIO DE ALMEIDA RUA BERNARDINO DE CAMPOS RUA BERNARDINO DE CAMPOS St.ID 3829

RUA DR DUARTE NUNES AV SALIUM AV SALLUM RUA DR CASTRO NERI RUA DR GASTAO DE SA RUA LUIZ GAMA RUA LUIZ GAMA RUA BENJAMIN CONSTANT RUA CRISOSTOMO DOS REIS RUA QUINTINO BOCAIUVA RUA LUIZ GAMA RUA LUIZ GAMA RUA LUIZ GAMa RUA IUIZ GAMA RUA LUIZ CARLOS DE ARRUD RUA LUIZ CARLOS DE ARRUD RUA lUIZ CARLOS DE ARRUd RUA IUIZ CARLOS DE ARRUD RUA ANANIAS EVANGELISTA RUA FRANCISCO FIORENTINO RUA FRANCISCO FIORENTINO RUA FRANCISCO FIORENTINO RUA DR DUARTE NUNES RUA DR DUARTE NUNES RUA BENJAMIN CONSTANT RUA JOSE BENETTI RUA JOSE BENETTI RUA JOSE BENETTI RUA LUIZ CARLOS DE ARRUD RUA DR DUARTE NUNES
No

Yes

Yes

Yes

Yes

No

No

No

No

Yes

Yes

No

Yes

Yes

No

Yes

Ýes

No

Yes

No

Yes

No

Yes

No

Yes

Yes

Yes

Yes

Yes

Yes ${ }^{k}$

No

Yés

No

Yes

Yes

Yes

Yes

Yes

Yes

No

Yes

Yes

Yes

Yes

Yes

Yes

No

Yes

Yes

Yès

Yes

Yes

Yes

Yes

Yès

Yes

Yes

No

Yes 


\begin{tabular}{|c|c|c|c|}
\hline 14 & ft on & RUA FRANCISCO FIORENTINO & Y \\
\hline 15 & ight on & RUA LUIZ GAMA & No \\
\hline 16 & Right on & RUA FRANCISCO DE OLIVEIR & Yes \\
\hline & Left on & RUA CRISOSTOMO DOS REIS & Yes \\
\hline & Right on & RUA BENJAMIN CONSTANT & Yes \\
\hline 19 & Left on & RUA DR DUARTE NUNES & Y \\
\hline 20 & Straight & RUA DR DUARTE NUNES & Yes \\
\hline & straight & RUA DR DUARTE NUNES & Yes \\
\hline 22 & Left on & AV SALLUM & $Y \in$ \\
\hline 23 & Left on & RUA LUIZ GAMA & \\
\hline & Left on & RUA DR GASTAO DE SA & Yese \\
\hline 25 & Right on & RUA DR DUARTE NUNES & No \\
\hline 26 & Left on & RUA QUINTINO BOCAIUVA & No \\
\hline 27 & Left on & RUA CANDIDO PADIM & $Y_{f}$ \\
\hline 28 & straight & RUA CANDIDO PADIM & \\
\hline 29 & Left on & AV SALLUM & Yes \\
\hline 30 & Left on & RUA DR DUARTE NUNEES & No \\
\hline & Left on & RUA DR GASTAO DE SA & \\
\hline 32 & Straight & RUA DR GASTAO DE SA & Yes \\
\hline 33 & Right on & RUA JOSE BENETTI & Yes \\
\hline 4 & Right on & RUA QUINTINO BOCAIUVA & \\
\hline 35 & straight & RUA QUINTINO BOCAIUVA & Yes \\
\hline 36 & straight & RUA QUINTINO BOCAIUVA & Yes \\
\hline 37 & Left on & RUA CRISOSTOMO DOS REIS & \\
\hline 38 & Straight & RUA CRISOSTOMO DOS REIS & 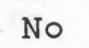 \\
\hline 39 & Left on & RUA FRANCISCO DE OLIVEIR & Yes \\
\hline 40 & Straight & RUA FRANCISCO DE OLIVEIR & Yes \\
\hline 41 & straight & RUA FRANCISCO DE OLIVEIR & Yes \\
\hline 42 & straight & RUA FRANCISCO DE OLIVEIR & Yes \\
\hline 43 & straight & RUA FRANCISCO DE OLIVEIR & Yes \\
\hline 44 & Right on & RUA ANTONIO BOTELHO & \\
\hline 45 & Straight & RUA ANTONIO BOTELHO & 0 \\
\hline 46 & Left on & RUA IUIZ CARLOS DE ARRUD & Yes \\
\hline 247 & Left on & RUA JERONOMO TERRA & No \\
\hline 48 & Left on & RUA FRANCISCO FIORENTINO & Yes \\
\hline 49 & Straight & RUA FRANCISCO FIORENTINO & Yes \\
\hline 50 & Right on & RUA ANANIAS EVANGELISTA & Yes \\
\hline 51 & straight & RUA ANANIAS EVANGELISTA & Yes \\
\hline 52 & straight & RUA ANANIAS EVANGELISTA & Yes \\
\hline 253 & Left on & RUA QUINTINO BOCAIUVA & Yes \\
\hline 254 & straight & RUA QUINTINO BOCAIUVA & Yes \\
\hline$=c$ & Left on & RUA JOSE BENETTI & Yes \\
\hline 56 & Left on & RUA BENJAMIN CONSTANT & Yes \\
\hline 257 & Right on & RUA ANTONIO DE ALMEIDA I & Yes \\
\hline 58 & ight & RUA ANTONIO DE ALMEIDA I & Y \\
\hline 259 & straight & RUA ANTONIO DE ALMEIDA I & Yes \\
\hline 260 & Left on & RUA IUIZ CARLOS DE ARRUD & Yes \\
\hline 6 & Straight & RUA LUIZ CARLOS DE ARRUD & \\
\hline 62 & Left & RUA ANTONIO :BOTELHO & Yes \\
\hline 263 & Straight & RUA ANTONIO BOTELHO & Yes \\
\hline 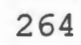 & straight & RUA ANTONIO BOTELHO & Yes \\
\hline 65 & Right on & RUA BENJAMIN CONSTANT & Yës \\
\hline 66 & Left on & RUA SAO PIO $\mathrm{X}$ & No \\
\hline 67 & Straight & RUA SAO PIO $\mathrm{X}$ & \\
\hline 0 & Stra & RUA SAO PIO $\mathrm{X}$ & \\
\hline 269 & Straight & RUA SAO PIO $X$ & No \\
\hline 70 & Straight & RUA SAO PIO $X$ & No \\
\hline & ligh & AV DR TEIXEIRA DE & Yes \\
\hline & $h t$ & ILIO & $Y \in$ \\
\hline
\end{tabular}


Straight

Straight

Straight

Right on

Straight

Right on

Straight

straight

Left on

Straight

Left on

Right on

Straight

Right on

Straight

Right on

Right on

straight

Straight

Left on

Right on

Straight

Left on

Straight

Left on

Left on

RUA DESEMBARGADOR JULIO

RUA DESEMBARGADOR JULIO

RUA DESEMBARGADOR JULIO

RUA QUINTINO BOCAIUVA

RUA QUINTINO BOCAIUVA

RUA ANTONIO BOTELHO

RUA ANTONIO BOTELHO

RUA ANTONIO BOTELHO

RUA BERNARDINO DE CAMPOS

RUA BERNARDINO DE CAMPOS

RUA ANTONIO DE ALMEIDA I

AV SALLUM

AV SALIUM

RUA CANDIDO PADIM

RUA CANDIDO PADIM

AV DR TEIXEIRA DE BARROS

RUA JOSE BENETTI

RUA JOSE BENETTI

RUA JOSE BENETTI

RUA DR GASTAO DE SA

RUA ANTONIO DE ALMEIDA L

RUA ANTONIO DE ALMEIDA I

RUA BENJAMIN CONSTANT

RUA BENJAMIN CONSTANT

RUA ANTONIO BOTELHO

RUA, QUINTINO BOCAIUVA

Right on

Right on

Straight

RUA ANANIAS EVANGELISTA

RUA DR GASTAO DE :SA

Right on

RUA DR GASTAO DE SA

Straight

Left on

Straight

Straight

RUA SAO PIO $X$

RUA SAO PIO $X$

RUA BENJAMIN CONSTANT

RUA BENJAMIN CONSTANT

RUA BENJAMIN CONSTANT

Left on

Left on

RUA ITALIA

RUA QUINTINO BOCAIUVA

Left on

Straight

RUA DESEMBARGADOR JULIO

310

Straight

straight

Left on

Straight

Left on

RUA DESEMBARGADOR JULIO

RUA DESEMBARGADOR - JULIO

RUA DESEMBARGADOR JULIO

RUA LUIZ CARLOS DE ARRUD

RUA IUIZ CARLOS DE ARRUD

AV GRECIA

straight

AV GRECIA

Left on

RUA PEDRO JOSE NETTO

RUA THEODURETO DE CAMARG

319 Straight

320 Straight

321 Right on

322 Right on

323 Straight

324 Right on

325 Straight

326 Left on

327 Right on

Left on

329 Straight

330 Right on

RUA THEODURETO :DE CAMARG

RUA THEODURETO DE CAMARG

RUA LUIZ CARLOS DE ARRUD

RUA DESEMBARGADOR JULIO

RUA DESEMBARGADOR JULIO

RUA PEDRO JOSE NETTO

RUA PEDRO JOSE NETTO

RUA CIDADE DE MILAO

RUA BENJAMIN CONSTANT

RUA DOMINGOS MARINO

RUA DOMINGOS MARINO

RUA DR GASTAO DE SA

331 Left on

RUA DR PEDRO DE SOUZA CA

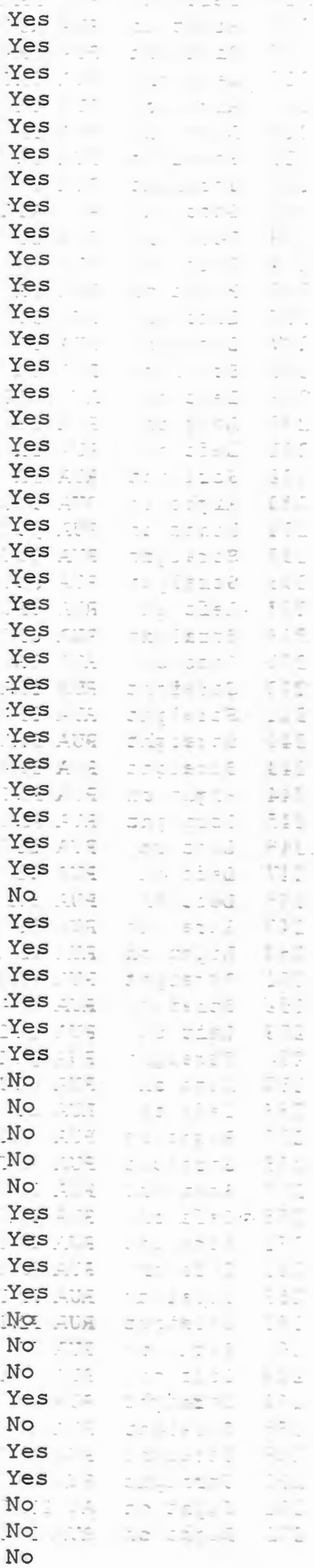


Right on Right on straight Straight straight Right on Straight Straight Right on Right on Straight straight straight straight Left on straight straight Left on Right on Right on Right on straight Right on Left on Left on straight Straight straight straight Straight Right on Right on Right on straight straight Left on Straight straight Straight straight Straight straight Straight Straight Straight Left on straight Left on Straight Right on Right on Left on Left on Straight Left on Left on Left on straight straight
AV SAILUM

RUA MIGUEL DAHMA

RUA THEODURETO DE CAMARG RUA THEODURETO DE CAMARG RUA. THEODURETO DE CAMARG RUA QUINTINO BOCAIUVA RUA QUINTINO BOCAIUVA RUA QUINTINO BOCAIUVA RUA ITALIA

RUA DR GASTAO DE SA RUA DR GASTAO DE SA RUA DR GASTAO DE SA RUA DR GASTAO DE SA RUA DR GASTAO DE SA AV GRECIA

RUA CEL LEOPOLDO PRADO RUA CEL LEOPOLDO PRADO AV SALLUM

RUA MIGUEL DAFMA

RUA BERNARDINO DE CAMPOS RUA CEL LEOPOLDO PRADO RUA THEODURETO DE CAMARG RUA MIGUEL DAHMA AV SALLUM RUA DR PEDRO DE SOUZA CA RUA -DR PEDRO - DE SOUZA CA RUA THEODURETO DE CAMARG RUA THEODURETO DE CAMARG RUA THEODURETO DE CAMARG RUA THEODURETO DE CAMARG RUA PEDRO JOSE NETTO RUA CIDADE DE MILAO RUA BENJAMIN CONSTANT RUA BEIJAMIN CONSTANT RUA BENJAMIN CONSTANT AV GRECIA AV GRECIA AV GRECIA RUA. CEL LEOPOLDO PRADO RUA CEL LEOPOLDO PRADO RUA CEL LEOPOLDO PRADO RUA CEL LEOPOLDO PRADO RUA CEL LEOPOLDO PRADO RUA CEI LEOPOLDO PRADO RUA CEL LEOPOLDO PRADO RUA MARCILIO DIAS RUA MARCILIO DIAS RUA DR PEDRO DE SOUZA CA RUA DR PEDRO DE SOUZA CA AV DR TEIXEIRA DE BARROS RUA DOMINGOS MARINO RUA DA ANA PRADO RUA CIDADE DE MILAO RUA CIDADE DE MILAO AV DR TEIXEIRA DE BARROS RUA DOMINGOS MARINO AV DR TEIXEIRA DE BARROS AV DR TEIXEIRA DE BARROS AV DR TEIXEIRA DE BARROS
No

No

Yes

Yes

No

Yes

Yes

Yes

Yes

Yes

Yes

Yes

Yes

No

No

No

No

Yes

Yes

No

Yes

Yes

Yes

Yes

Yes

Yes

Yes

Yes

Yes

Yes

Yes

No

No

No

No

No

No

No

No

No

No

Yes

No

Yes

Yes

Yes

Yes

No

Yes

Yes

Yes

No

Yes

No

Yes

No

Yes

Yes

Yes 


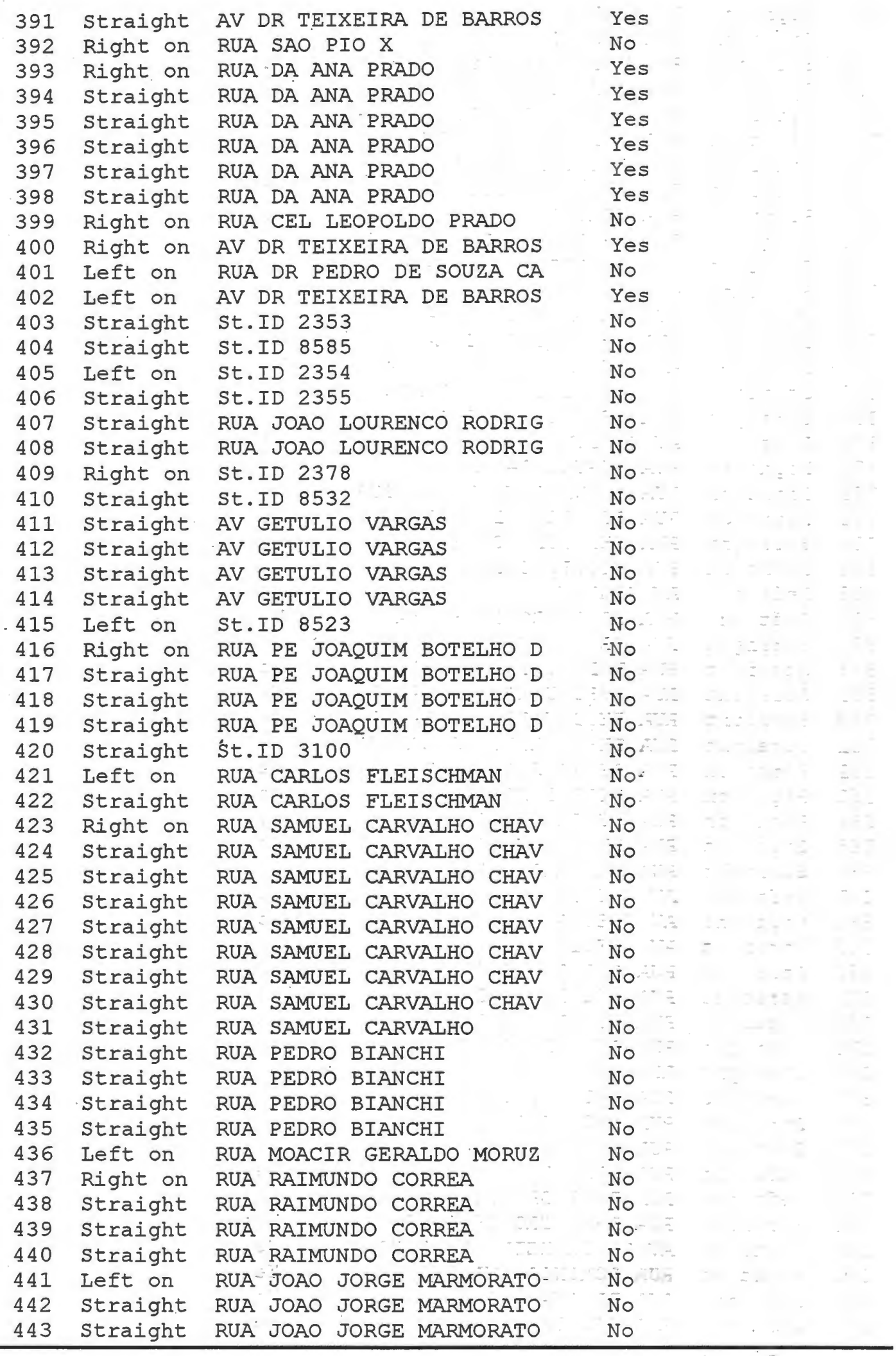




\section{REFERÊNCIA BIBLIOGRÁFICA}

AGUIAR, E.M. de (1993). Um modelo para avaliação de sistemas de coleta e transporte de resíduos sólidos domiciliares para cidades de pequeno e médio porte In: VII ANPET Congresso Brasileiro e Ensino em Transportes. Planejamento dos Transportes e Modelos, São Paulo, v.2, p.593-604.

AMORIM, V.P.; AGUIAR, M.I.O. (1979). As Características físicas e químicas do lixo do Distrito Federal. Limpeza Pública, n.15, p.10-7, jul-ago.

ANDRADE, J. B. L. (1997). Análise do Fluxo e das Características Físicas, Químicas e Microbiológicas dos Resíduos de Serviço de Saúde: Proposta de Metodalogia para o Gerenciamento em Unidades Hospitalares. São Carlos. 222p. Tese (Doutorado) - Escola de Engenharia de São Carlos, Universidade de São Paulo.

ASSOCIAÇÃO BRASILEIRA DE NORMAS TÉCiNICAS (1985). NBR 8419. Apresentação de projetos de aterros sanitários de resíduos sólidos urbanos. São Paulo, ABNT.

ASSOCIAÇÃO BRASILEIRA DE NORMAS TÉCNICAS (1987). NBR 10.004. Resíduos Sólidos - Sólidos - Classificação. São Paulo, ABNT.

ASSOCIAÇÃO BRASILEIRO DE NORMAS TÉCNICA (1992). NBR 9191 - Sacos Plásticos para acondicionamento de lixo - Especificação. Rio de Janeiro, ABNT.

ASSOCIAÇÃO BRASILEIRO DE NORMAS TÉCNICAS (1985). NBR 9190 - Sacos Plásticos para acondicionamento de lixo - Classificação. Rio de Janeiro, ABNT.

BRAVO, F.; CERDA, T; J. (1995). Tecnologia SIG Aplicada a Sistemas de Transportes. Actas VII Congresso Chileno de Ingenieria de Transporte, Santiago, Chile. 
- CALIJURI, M.L; ROHM, S.A. (1993). Sistemas de Informação Geográficas. Universidade Federal de Viçosa - Imprensa Universitária, Minas Gerais.

CALIPER (1996). TransCAD - Transportation GIS Software. Routing and Logistics with TransCAD. Caliper Corporation, Version 3.0 for use with Microsoft Windows.

CÂMARA, G. (1994). Anatomia de um SIG. Revista Fator GIS, Sagres Editora, nº 04, p.11-5.

CANASSA, E.M. (1992). Planejamento de Roteiros dos Veículos Coletores de Resíduos Sólidos Urbanos. Florianópolis. 135p. Dissertação (Mestrado) Universidade Federal de Santa Catarina.

CHANG, B.N.; LU, H.Y.; WEI, Y.L. (1997). GIS Technology for Vehicle Routing and Sheduling in Solid Waste Collection Systems. Journal of Environmental Enginneering, p.902-10, Sept.

CHINPLUNKAR, A.V.; MEHNDIRATTA, S.L.; KHANNA, P. (1981). Optimization of Refuse Collection Systems. Journal of the Environmental Engineerinh Division, p.1203-10, dez.

CONSONI, A.J.; PERES, C.S. (1995). Origem e Composição do Lixo In: Lixo Municipal: manual de gerenciamento integrado. Niza Silva Jardim (coordenador). $1^{a}$ ed. São Paulo: Instituto de Pesquisas Tecnológica - IPT, Compromisso Empresarial para Reciclagem - CEMPRE, (Publicação IPT 2163), 279p. (capítulo II).

COSTA, H.C.B. da (1982). Rotas para distribuição de bens e serviços - Proposta de um sistema de informação. Campina Grande. Dissertação (Mestrado) Universidade Federal da Paraíba.

CUNHA, C.B. (1997). Uma Contribuição para o Problema de Roteirização de Veículos com Restrições Operacionais. São Paulo. p. Tese (Doutorado) - Escola Politécnica. Universidade de São Paulo.

CUNHA, C.B. et al. (1995). Serviços de Limpeza In Lixo Municipal In: manual de gerenciamento integrado. Niza Silva Jardim (coordenador). $1^{\text {a }}$ ed. São Paulo: Instituto de Pesquisas Tecnológica - IPT, Compromisso Empresarial para Reciclagem - CEMPRE, (Publicação IPT 2163), 279p. (capítulo III). 
- DANTAS, A.S; TACO, P.W.G.; YAMASHITA, Y. (1996). Sistemas de Informação Geográfica em Transportes - $O$ Estudo do Estado da Arte. In: X ANPET Congresso de Pesquisa e Ensino em Transportes, Brasília,. v.1, p.211-22.

DHINGRA, S.L.; GEORGE, R. (1998). Network and Vehicle Routing for Municipal Waste Collection and Transportation. Computers in Urban Planning and Urban Management, v.1, p.351-62.

EISELT, H. A.; GENDREAU, M.; LAPORTE G. (1995). Arc Routing Problems, Part I: The Chinese Postman Problem.. Operation Research 43, n 2, p.231-42.

FERNANDES et al. (1995). Método para Avaliação do Serviço de Coleta de Resíduos Sólidos Domiciliares em Belo Horizonte In: 18 CONGRESSO BRASILEIRO DE ENGENHARIA SANITÁRIA E AMBIENTAL, Salvador, 1995. Disco 5/9.

FERRARI, R. (1997). Viagem ao SIG, Sagres Editora, Curitiba-PR.

FERREIRA, A.B.H. (1988). Dicionário Aurélio Básico da Língua Portuguesa. Editora Nova Fronteira, $1^{\mathrm{a}}$ edição. $687 \mathrm{p}$.

FUNDAÇÃO INSTITUTO BRASILEIRO DE GEOGRAFIA E ESTATÍSTICA. IBGE (1989). Pesquisa Nacional de Saneamento Básico - PNSB, São Paulo. 70p.

FUNDAÇÃO PARA O DESENVOLVIMENTO DA UNESP - FUNDUNESP (1995). A questão dos resíduos sólidos: um projeto institucional da UNESP. São Paulo.

GALVEZ, F. (1979). Programação de Coleta. Revista Limpeza Pública. Março-Abril. 1979. $\mathrm{N}^{\circ} 14$.

GODOI, M.O. (1997). Origem e Destino dos Resíduos Sólidos Domiciliares em São Paulo. São Carlos. 223p. Dissertação (Mestrado) - Escola de Engenharia de São Carlos, Universidade de São Paulo.

GOMES, L.P. (1989). Estudo da Caracterização Física e da Biodegradabilidade dos Resíduos Sólidos Urbanos em Aterros Sanitórios. São Carlos. 166p. Dissertação (Mestrado) - Escola de Engenharia de São Carlos, Universidade de São Paulo.

GRACIOLLI, O.D. (1994). Otimização de Roteiros de Veículos Coletores de Resíduos Sólidos de Serviço de Saúde. Florianópolis. 126p. Dissertação (Mestrado) Universidade Federal de Santa Catarina. 
HEMENWAY, C.G. ; GLDERSLEEVE, J.P. (1995). ISO 14000 O Que é?. Tradução Sônia de Sá B. Mello. São Paulo. Instituto IMAM.

HICKMAN, H.L. (1981). Collection of Residential Solid Waste. In: ROBINSON, W., ed. The Solid Waste Handbook - A pratical guide. Washington D.C., Wiley Interscience. Cap. 8, p.177-90.

HUXHOLD, W.E. (1991). An Introduction to Urban Geographic Information System, Oxford Univertsity Press, Inglaterra.

JARDIM, N.S., coord. (1995). Lixo Municipal - Manual de Gerenciamento Integrado. $1^{a}$ ed. São Paulo: Instituto de Pesquisas Tecnológica - IPT, Compromisso Empresarial para Reciclagem - CEMPRE, (Publicação IPT 2163).

LARSON, C.; ODONI, A.R. (1981). Urban Operation Research. Prentice Hall, Englewood Cliffs, N.J.

LEÃO, A.L. (1997). Geração de resíduos sólidos urbanos e seu impacto ambiental. In: MARTOS, H.L., coord. Indicadores Ambientais. Cap. p.213 -222.

LEITE, W.C. de A. (1997). Estudo da Gestão de Resíduos Sólidos: Uma Proposta de Modelo Tomando a Unidade de Gerenciamento de Recursos Hídricos (UGRHI-5) como Referência. São Carlos. 270p. Tese (Doutorado) - Escola de Engenharia de São Carlos, Universidade de São Paulo.

LIMA. L.M.Q. (1991). Tratamento de Lixo. $2^{\mathrm{a}}$ ed. São Paulo, Hemus.

- LOUREIRO, C.F.G.; RALSTON, B.A. (1996). SIG como Plataforma para Modelos de Análise de Rede de Transporte In: X ANPET Congresso de Pesquisa e Ensino em Transportes, Brasília, v.1, p.235-44.

MANDL, C. (1979). Apllied Network Optmization. Academic Press Inc. New YorK.

MANSUR, G.L. (1987). O Lixo Urbano no Brasil. Alternativas para evitar o Caos. Engenharia Sanitária, v 26, n.1, p 13-26, jan-mar.

MARKS, D. H.; STRICKER, R. (1971). Routing for Public Service Vehicles, Journal of the Urban Planning and developing Division, ASCE, Vol. 27, UP2, p.165-178. 
MARQUES, H.N. (1998). Um Sistema de Informações para Usuórios de Transporte Coletivo em Cidades de Médio Porte. São Carlos. 96p. Dissertação (Mestrado) Escola de Engenharia de São Carlos, Universidade de São Paulo.

MATION, H. (1984). Análise da alocação do transporte de resíduos entre as regiões de coleta e pontos de destino final, PRODESP - Cia. Processamento de Dados do Estado de São Paulo.

MEIRA, A.D.; CALIJURI, M.L. (1995). A utilização de Sistema de Informação Geográfica-SIG no planejamento da disposição de Rejeitos Estéreis In: III SIMPÓSIO DE BARRAGENS DE REJEITOS E DISPOSIÇÃO DE RESÍDUOS - Anais Vol. 1. Ouro Preto-MG, p.299-310.

MENDONÇA, R. (1997). O Brasil e os Resíduos Sólidos: a situação atual da disposição de lixo no país - problemas - desafios - perspectivas. São Paulo. JCA.

MERCEDES, S.S.P.; PEREIRA NETO, J.T. (1993). O Efeito da Temperatura na Eliminação de Patógenos Durante a Fase Ativa da Compostagem do Lixo Urbano. In: 17 CONGRESSO DE ENGENHARIA SANITÁRIA E AMBIENTAL, Natal, Trabalhos Técnicos. Vol 2.

MOISÉS et al. (1995). Legislação. In: JARDIM, N. S. coord. Lixo Municipal Manual de Gerenciamento Integrado. $1^{a}$ ed. São Paulo: Instituto de Pesquisas Tecnológica - IPT, Compromisso Empresarial para Reciclagem - CEMPRE, (Publicação IPT 2163), Anexo A, p.243-55.

OLIVEIRA, W. E. (1992). Resíduos Sólidos e Limpeza Pública In: PHILIPI JUNIOR, A. org. Saneamento do Meio, FUNDACENTRO, São Paulo, Cap.3, p.81-114.

ORTH, M.H.A; ROCHA, A.A.; RUOCCO Jr. (1976). Lixo e Demais Resíduos Sólidos, CETESB/ABES/ABLP.

PAIVA JUNIOR, I.C.O \& GUIMARÃES, J.R.L. (1995). Sistema de Gerenciamento Integrado de Limpeza Urbana do Município do Natal. In: 18 CONGRESSO DE BRASILEIRO DE ENGENHARIA SANITÁRIA E AMBIENTAL, Salvador, Trabalhos Técnicos Disco 3.

PARAFINA, S. (1995). GIS based automated routing for solid waste collection. Proceedings of GIS/LIS'95 Annual Conference \& amp; Exposition Bethesda, p. 799-803. 
PARAGUASSÚ DE SÁ, A.F.; VERAS, O. D. F. (1986). Algumas regras práticas para a elaboração e implantação de roteiros de coleta. Rio de Janeiro: COMLURB COMPANHIA MUNICIPAL DE LIMPEZA URBANA, 36p.

PAREDES, E.A. (1994). Sistema de Informação Geográfica (SIG) - Princípios e Aplicações (Geoprocessamento), Editora Érica, São Paulo.

PEIXOTO, R.S.S.L. (1997). Utilização de Sistemas de Informações Geográficas para Gerenciamento de Cidades de Pequeno Porte. São Carlos. 173p. Dissertação (Mestrado) - Escola de Engenharia de São Carlos, Universidade de São Paulo.

PENIDO, J.H. ; MANSUR, G.L. (1997). Gestão dos Serviços de Limpeza Urbana no Brasil: Uma primeira abordagem. http://www.bem.com.br/limpubr.htm

PEREIRA NETO, J.T.; MESQUITA, (1994). Compostagem de Resíduos Sólidos Urbanos - Aspectos Teóricos, Operacionais e Epidemiológicos. In: Curso: Resíduos Sólidos Urbanos: Métodos e Equacionamento (Reciclagem/Compostagem). Lisboa, Laboratório de Engenharia Civil - LNEC. p. 123-91.

PHILIPI JUNIOR, A. (1986). Sistemas de Resíduos Sólidos: Coleta e Transporte no Meio Urbano. São Paulo: CETESB - Companhia de Tecnologia de Saneamento Ambiental.182p.

PIEDADE, M.; NEO, M.F. (1988). Campanha de Caracterização dos Resíduos Sólidos de Lisboa - Incidência Sobre os Aspectos de Remoção e Tratamento. In: Encontro Nacional de Saneamento Básico. Lisboa. Comunicações. Laboratório Nacional de Engenharia Civil (LNEC) / Associação Portuguesa para Estudos de Saneamento Básico - APESB. p.III 45-43.

PINTO COELHO, P.E.F. (1989). Lixo ou Luxo. Revista de Engenharia Sanitária, v. 28, n. 1, p. $42-48$, jan/mar.

PRANDINI, F.L. et al. (1995). O Gerenciamento Integrado do Lixo Municipal. In: JARDIM, N. S. Lixo Municipal - Manual de Gerenciamento Integrado. $1^{2}$ ed. São Paulo: Instituto de Pesquisas Tecnológica - IPT, Compromisso Empresarial para Reciclagem - CEMPRE, (Publicação IPT 2163), Cap. 1, p. 3-19.

QUERZOLI, A. (1988). Há Sempre Uma Boa Opção para o Lixo Urbano. Dirigente Municipal,v.19, n 7, jul. 
REVISTA BIO (1997). Associação Brasileira de Engenharia Sanitária e Ambiental. Rio de Janeiro, $n^{\circ} 3$, jul/ago.

REVISTA LIMPEZA PÚBLICA (1977). Associação Brasileira de Limpeza Pública. São Paulo, n 8 , jul/ago.

REVISTA LIMPEZA PÚBLICA (1997). Associação Brasileira de Limpeza Pública. São Paulo, $n^{\circ} 44$, abr.

ROCHA, A.A. (1993). A história do lixo. In: Resíduos Sólidos e Meio Ambiente, Série seminários. São Paulo: Secretaria do Meio Ambiente, Coordenadoria de Educação Ambiental, p.15-22.

ROSSETTO, C.F; CUNHA, C.B. (1994). A Aplicação do Geoprocessamento na Roteirização de Veículos. In: Congresso de Geoprocessamento-GIS BRASIL 94, Curitiba, v.1, p.35-44.

RUBBO, J. (1978). A problemática do lixo domiciliar. Revista Limpeza Pública. n. 10. p.20-6. mar./abr.

SANCHES, S.P. (1988). Contribuição à análise operacional de redes de transporte coletivo em cidades de porte médio. São Carlos. 2v. Tese (Doutorado) - Escola de Engenharia de São Carlos, Universidade de São Paulo.

SARTORI, H.J.F. (1995). Discussão sobre a Caracterização Física de Resíduos Sólidos. Belo Horizonte. 102p. Dissertação (Mestrado) - Universidade Federal de Minas Gerais.

SCHALCH, V. (1996). Curso Gerenciamento de Resíduos Sólidos - Notas de Aula. Escola de Engenharia de São Carlos, Universidade de São Paulo.

SCHALCH, V.; LEITE, W.C.A. (1995). Curso Sobre Gerenciamento Integrado de Resíduos Sólidos, Universidade Federal do Ceará, Fortaleza.

SEWELL, G.H. (1978). Administração e controle da qualidade ambiental. Trad. por Gildo Magalhães dos Santos Filho. São Paulo. CETESB.

SILVA, A.N.R. da; WAERDEN, P.V.W. (1997). Firts Steps With a Geographic Information System for Transportation, São Francisco, Ribeirão Preto. 
SILVA, A.N.R.; LOTTI, C.P. MARGARIDO, S.A.; PAMPOLHA, V.M.P. (1996). Quem não tem Tiger...Revista Fator GIS, Curitiba-PR, 4(14), 18-19.

SILVESTRE JUNIOR, A.A. (1978). Coleta Domiciliar. Revista Limpeza Pública. $n^{0}$ 12. p. $22-23$.

STOKES, R. W.; MARUCCI, G. (1995). Gis For Transportation: Current Practices, Problems and Prospects. ITE JOURNAL. Mar.

TCHOBANOGLOUS, G. et al. (1993). Integrated Solid Waste Management: Engineering Principles and Managment Isssues. EUA, McGraw-Hill.

TEIXEIRA, A.L.; MORETTI, E.; CHRISTOFOLETI, A. (1992). Introdução aos Sistemas de Informação Geográfica, Edição do Autor, Rio Claro-SP.

THOMAZ, A. C. F. et al (1984). Optmal scenario for waste collection in Fortaleza city: an application of the chinese postman problem. COPPE/Sistemas. Universidade Federal do Rio de Janeiro, Rio de Janeiro.

TRUCH, P.; ANDERSON, R. (1996). Solid Waste Collection Route Design in a Gis Environment - Phase One, Proceedings of the Annual Conference System Association - URISA'1996, Washington, D.C., p.141-152.

VALLE, C.E. (1995). Qualidade ambiental: como ser competitivo protegendo o meio ambiente. São Paulo. Pioneira, Biblioteca Pioneira de Administração e Negócios.

WILSON, D.C. (1981). Waste Management Planning, Evaluation, Technologies. New York, Oxford University, Harwell Laboratory.

WOLMER, F.A. (1982). Coleta Regular de Lixo. CETESB - Companhia de Tecnologia de Saneamento Ambiental. São Paulo. p.5.1 - 5.16.

YOSHIMURA, T. (1990). As ofertas para a coleta de lixo. Saneamento e Saúde Pública. p.28-31. 